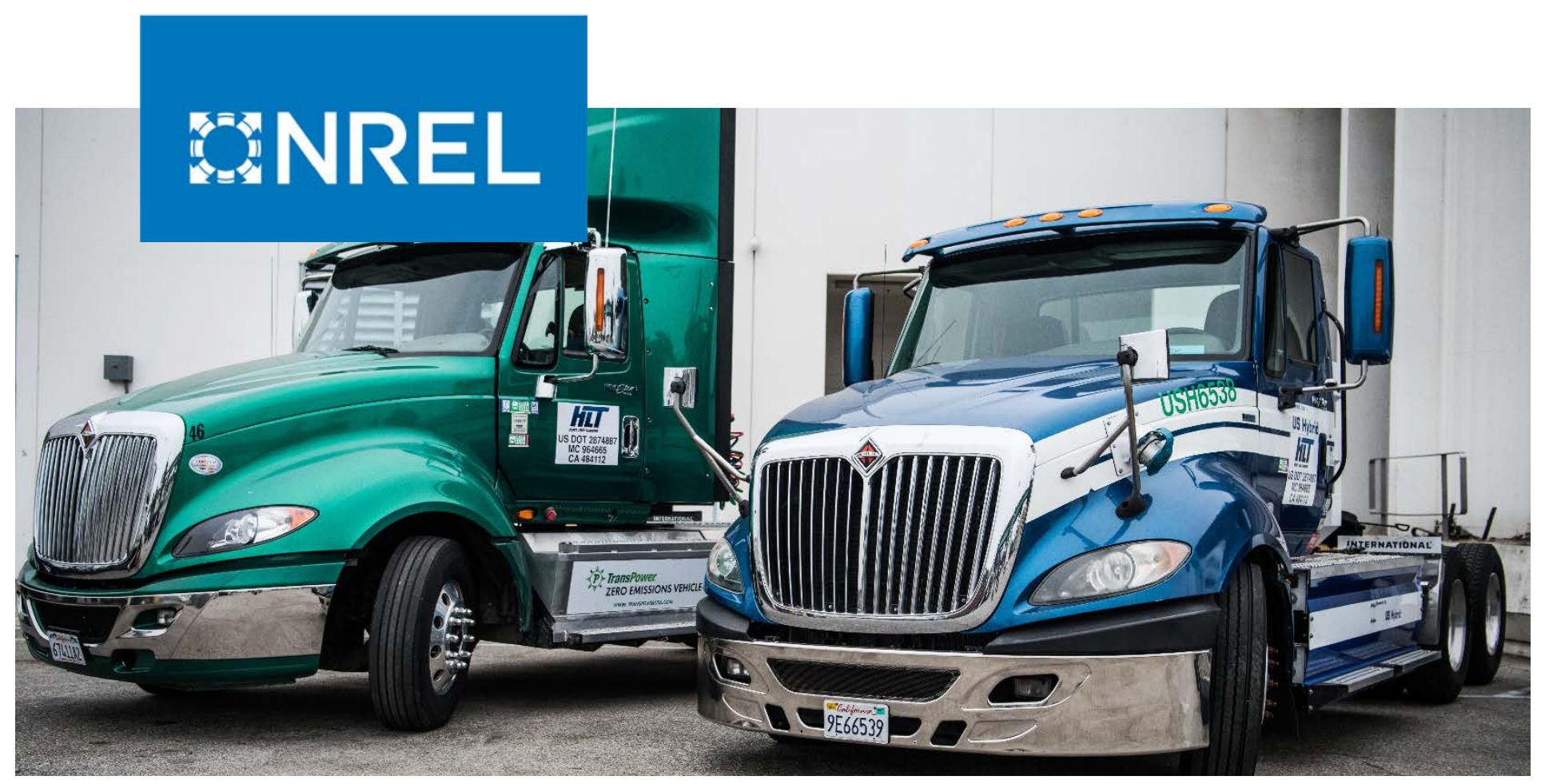

\title{
Spatial and Temporal Analysis of the Total Cost of Ownership for Class 8 Tractors and Class 4 Parcel Delivery Trucks
}

Chad Hunter, Michael Penev, Evan Reznicek, Jason Lustbader, Alicia Birky, and Chen Zhang

National Renewable Energy Laboratory

NREL is a national laboratory of the U.S. Department of Energy Office of Energy Efficiency \& Renewable Energy

Operated by the Alliance for Sustainable Energy, LLC

This report is available at no cost from the National Renewable Energy Laboratory (NREL) at www.nrel.gov/publications.
Technical Report

NREL/TP-5400-71796

September 2021 


\title{
GNREL
}

\section{Spatial and Temporal Analysis of the Total Cost of Ownership for Class 8 Tractors and Class 4 Parcel Delivery Trucks}

\author{
Chad Hunter, Michael Penev, Evan Reznicek, \\ Jason Lustbader, Alicia Birky, and Chen Zhang \\ National Renewable Energy Laboratory
}

\section{Suggested Citation}

Hunter, Chad, Michael Penev, Evan Reznicek, Jason Lustbader, Alicia Birky, and Chen Zhang. 2021. Spatial and Temporal Analysis of the Total Cost of Ownership for Class 8 Tractors and Class 4 Parcel Delivery Trucks. Golden, CO: National Renewable Energy Laboratory. NREL/TP-5400-71796. https://www.nrel.gov/docs/fy21osti/71796.pdf.

NREL is a national laboratory of the U.S. Department of Energy Office of Energy Efficiency \& Renewable Energy Operated by the Alliance for Sustainable Energy, LLC

This report is available at no cost from the National Renewable Energy Laboratory (NREL) at www.nrel.gov/publications.

Contract No. DE-AC36-08G028308
Technical Report NREL/TP-5400-71796

September 2021

National Renewable Energy Laboratory 15013 Denver West Parkway Golden, CO 80401 303-275-3000 • www.nrel.gov 


\section{NOTICE}

This work was authored by the National Renewable Energy Laboratory, operated by Alliance for Sustainable Energy, LLC, for the U.S. Department of Energy (DOE) under Contract No. DE-AC36-08GO28308. Funding provided by the U.S. Department of Energy Office of Energy Efficiency and Renewable Energy Hydrogen and Fuel Cell Technologies Office. The views expressed herein do not necessarily represent the views of the DOE or the U.S. Government.

This report is available at no cost from the National Renewable Energy Laboratory (NREL) at www.nrel.gov/publications.

U.S. Department of Energy (DOE) reports produced after 1991 and a growing number of pre-1991 documents are available free via www.OSTI.gov.

Cover Photo by Dennis Schroeder: NREL 46494.

NREL prints on paper that contains recycled content. 


\section{Acknowledgments}

The authors wish to thank the U.S. Department of Energy (DOE) Hydrogen and Fuel Cell Technologies Office, and Neha Rustagi, Sunita Satyapal, and Fred Joseck in particular, for their continued support in developing the Scenario Evaluation and Regionalization Analysis (SERA) model over the years. The authors would also like to acknowledge Brian Bush at the National Renewable Energy Laboratory for his development of the SERA model over the years, Yuche Chen at Vanderbilt University for his support of the operating and maintenance cost literature review, and Aaron Brooker at the National Renewable Energy Laboratory for his guidance and support with vehicle powertrain modeling. The authors would also like to give a special thanks to Neha Rustagi at the Hydrogen and Fuel Cell Technologies Office and Jake Ward at the Vehicle Technologies Office for their significant effort helping coordinate and catalyze collaboration across multiple parallel analysis projects related to commercial vehicle electrification.

The authors would also like to give a special thanks to all the other contributors and reviewers of this analysis that provided useful feedback through interim presentations and reports. In particular, the authors would like to thank Dimitrios Papegeorgopoulos, Ned Stetson, Jesse Adams, Jason Marcinkoski, and Greg Kleen at the Hydrogen and Fuel Cell Technologies Office. At the Vehicle Technologies Office, the authors would like to thank Samm Gillard, Brian Cunningham, Kevin Stork, Susan Rogers, Madhur Boloor, Dennis Smith, Mark Smith, and Linda Bluestein. From the DOE Office of the Deputy Assistant Secretary of Transportation, we would like to thank Michael Berube and Rachael Nealer. From Strategic Analysis, Inc., we would like to thank Brian James and Jennie Huya-Kouadio. Additionally, the authors would like to thank Ram Vijayagopal, Amgad Elgowainy, and Aymeric Rousseau from Argonne National Laboratory, and Burak Ozpineci, Scott Curran, and Ron Graves from Oak Ridge National Laboratory. We would also like to thank Matteo Muratori, Michael Lammert, John Farrell, and Keith Wipke from the National Renewable Energy Laboratory. Finally, we would like to thank the peer reviewers from industry and organizations external to DOE, including Giovanna Bucci at Bosch; Marc Melaina at Boston Governmental Services; Fang Yan, Leslie Goodbody, and Andrew Martinez at the California Air Resources Board; Jason Hanlin at the Center for Transportation and the Environment; Vivek Sujan at Cummins; Mihai Dorobantu at Eaton Corporation PLC; Brian Goldstein and Justo Robles at Energy Independence Now; Boris Kort-Packard and Phil Galbach at Federal Express; and James Kast at Toyota Motor Corporation. 


\section{Abstract}

The medium- and heavy-duty transportation sector is experiencing rapid changes in powertrain technology innovation, with recent announcements of battery electric and fuel cell electric trucks being offered. The economics of these alternative powertrain vehicles are uncertain and difficult to compare directly. This analysis seeks to provide a rigorous, techno-economic analysis of all of these alternative powertrain vehicles within the same analytic framework. Specifically, this report evaluates the total cost of ownership (TCO) of six different truck powertrain technologies (diesel, diesel hybrid electric, plug-in hybrid electric, compressed natural gas, battery electric, and fuel cell electric) for three different truck vocations (Class 8 long haul [750-mile range and 500-mile range], Class 8 short haul [300-mile range], and Class 4 parcel delivery [120-mile range]), for three different time frames (2018, 2025, and Ultimate). The TCO framework includes direct costs (purchase price, fuel, operating and maintenance, driver wages and benefits, insurance, tire replacements, permits, and tolls) and indirect costs (dwell time costs due to refueling/recharging and lost payload capacity costs from heavier advanced vehicle powertrains), and uses the best practices developed across the U.S. Department of Energy TCO studies. The TCO was evaluated for four scenarios that reflect typical business operating conditions (incurring or not incurring dwell-time and payload capacity costs).

This analysis finds that each powertrain technology may have an economic advantage on a TCO basis in certain business operating conditions, depending on fuel price realized. In general, battery electric powertrains may be best for shorter-range applications or when dwell time is not a concern, and are complemented by fuel cell powertrains that may be better for longer ranges or operating scenarios that require higher uptime. Specifically, the Class 8 long-haul (750-mile-range) fuel cell electric vehicle (FCEV) is the lowest-cost zero-emissions vehicle (ZEV) if technology targets are met (regardless of dwell and payload costs). For the Class 8 long-haul (500-mile-range) vocation, FCEVs and battery electric vehicles (BEVs) are very competitive with diesel if Ultimate targets are met (regardless of dwell and payload costs). If dwell time costs are incurred, FCEVs are the lowest-cost ZEV for Class 4 parcel delivery, Class 8 short haul (300 miles), and Class 8 long haul (500 miles). For the Class 8 short-haul (300-mile-range) and Class 4 parcel delivery (120-mile-range) vocations, BEVs are the lowest-cost ZEV if dwell time costs are not incurred and Ultimate targets are achieved. Additionally, lost payload capacity cost for Class 8 long-haul (500+ mile) FCEVs or Class 8 short-haul (300-mile) BEVs is small due to the 2,000-lb exemption for alternative powertrain trucks. This analysis also shows that electricity price and hydrogen fuel price are the most influential parameters to the TCO of all trucks, and medium- and heavy-duty refueling/recharging cost reduction/management should be a key focus area for R\&D. In summary, this analysis shows that medium- and heavy-duty trucks with battery and fuel cell electric powertrains could be economically competitive with diesel powertrains under several operating scenarios as early as 2025 for shorter-range applications (<500-mile Class 8 tractors, 120-mile Class 4 delivery) if high diesel prices $(>\$ 3 / \mathrm{gal})$ and low hydrogen/electricity prices are realized. 


\section{Acronym List}

AEO
BEV
CNG
DCFC
DOE
FASTSim
FCEV
gge
GVWR
HEV
HFTO
LTL
M/HDT
MSRP
NREL
O\&M
PHEV
SERA
T3CO
TCO
VIUS
VMT
ZEV

\author{
Annual Energy Outlook \\ battery electric vehicle \\ compressed natural gas \\ direct current fast charger \\ U.S. Department of Energy \\ Future Automotive Systems Technology Simulator \\ fuel cell electric vehicle \\ gasoline gallon equivalent \\ gross vehicle weight rating \\ hybrid electric diesel vehicle \\ Hydrogen and Fuel Cell Technologies Office \\ less-than-truck load \\ medium- and heavy-duty truck \\ manufacturer's suggested retail price \\ National Renewable Energy Laboratory \\ operating and maintenance \\ plug-in hybrid electric vehicle \\ Scenario Evaluation and Regionalization Analysis \\ Transportation Technology Total Cost of Ownership \\ total cost of ownership \\ Vehicle Inventory and Use Survey \\ vehicle miles traveled \\ zero-emissions vehicle
}




\section{Executive Summary}

The medium- and heavy-duty transportation sector is experiencing rapid changes in technology innovation. Alternative powertrains, including fuel cell electric and battery electric, have been announced within the last few years for truck applications across the medium- and heavy-duty spectrum. Because trucks are used primarily for business applications, the value proposition associated with a truck is a key metric that helps determine whether the truck technology will be adopted. The total cost of ownership (TCO) is a useful metric that owners and operators use to assess the value proposition of a truck purchase. Although not the only metric a business will consider, the TCO provides a benchmark that allows for direct comparison across different truck options.

This report aims to analyze multiple powertrain technologies using a consistent and extensive analytic framework applied to each technology and commercial vehicle application. The report evaluates the TCO for three truck applications and six powertrains. The truck applications include Class 8 long-haul (sleeper, 750-mile range and 500-mile range), Class 8 short-haul (day cab, 300-mile range), and Class 4 parcel delivery (120-mile range) trucks. The powertrains analyzed are conventional (diesel), diesel hybrid-electric vehicle (HEV), plug-in hybrid electric vehicle (PHEV), compressed natural gas (CNG), fuel cell electric vehicle (FCEV), and battery electric vehicle (BEV). The TCO includes direct and indirect costs incurred by owning and using the truck that are specific to each powertrain. Direct costs included in this analysis are the upfront purchase cost (segmented by powertrain component), purchase price, fuel, operating and maintenance (O\&M), driver wages and benefits, insurance, tire replacements, permits, and tolls. The indirect costs included in this analysis are dwell time costs due to refueling/recharging and lost payload capacity costs from potentially heavier advanced vehicle powertrains.

The TCO modeling framework involves two National Renewable Energy Laboratory (NREL) models, which were integrated to create a full, end-to-end TCO model. First, the vehicle performance and cost modeling was completed using NREL's Future Automotive Systems Technology Simulator (FASTSim) model. Second, the spatially resolved TCO was modeled using NREL's Scenario Evaluation and Regionalization Analysis (SERA) model. These models were integrated together to form the Transportation Technology Total Cost of Ownership (T3CO) model to rapidly and flexibly evaluate the TCO of commercial vehicles.

T3CO first estimates the upfront vehicle cost. Vehicle models for each truck application (Class 8 long haul [750-mile and 500-mile ranges], Class 8 short haul, and Class 4 parcel delivery) were built in FASTSim to match observed conventional vehicle performance and cost data including fuel economy, acceleration, and manufacturer's suggested retail price. Real-world, representative drive cycles from NREL's Fleet DNA database were used in the vehicle model. FASTSim takes the diesel truck, removes the diesel-specific powertrain components (e.g., engine, aftertreatment), and builds the new powertrain to meet the acceleration requirements of the truck. Input powertrain component cost and performance data were based on current status (2018 used as a baseline for current technology due to data availability), future projections from literature, the U.S. Department of Energy (DOE) Office of Energy Efficiency and Renewable Energy technology performance and cost targets, and additional scenario assumptions. Vehicles were assessed for three technology time frames: 2018, DOE 2025 scenario assumptions, and DOE Ultimate scenario assumptions.

T3CO then estimates the TCO analysis, including all direct and indirect costs. Low, mid, and high costs for each cost component were analyzed. Regional fuel costs (diesel, CNG, electricity) were based on the 2021 Annual Energy Outlook, whereas hydrogen costs were taken from demonstration data and future DOE targets. O\&M costs were based on an extensive literature survey. Lost payload capacity costs were based on the costs to purchase an additional truck to move the lost cargo capacity. The dwell time cost was based on the refueling/recharging time and the cost per hour that carriers charge for dwell fees.

The TCO was estimated for four scenarios representing different commercial vehicle applications: (1) Single-Shift, Volume-Limited; (2) Single-Shift, Weight-Limited; (3) Multi-Shift, Volume-Limited; and (4) Multi-Shift, WeightLimited. Single-shift operation implies no dwell time costs, whereas volume-limited correlates with no lost payload capacity costs.

Class 8 long-haul (750-mile-range) truck TCO in the Single-Shift, Volume-Limited scenario and the Multi-Shift, 
Weight-Limited scenario in the Middle Atlantic U.S. Census Division region is shown in Figure ES-1. These two scenarios (without incurring either dwell-time and payload capacity costs, or incurring both dwell-time and payload capacity costs) are shown as they reflect the edge cases in this analysis. Error bars represent uncertainty in fuel prices and $\mathrm{O} \& \mathrm{M}$ costs.

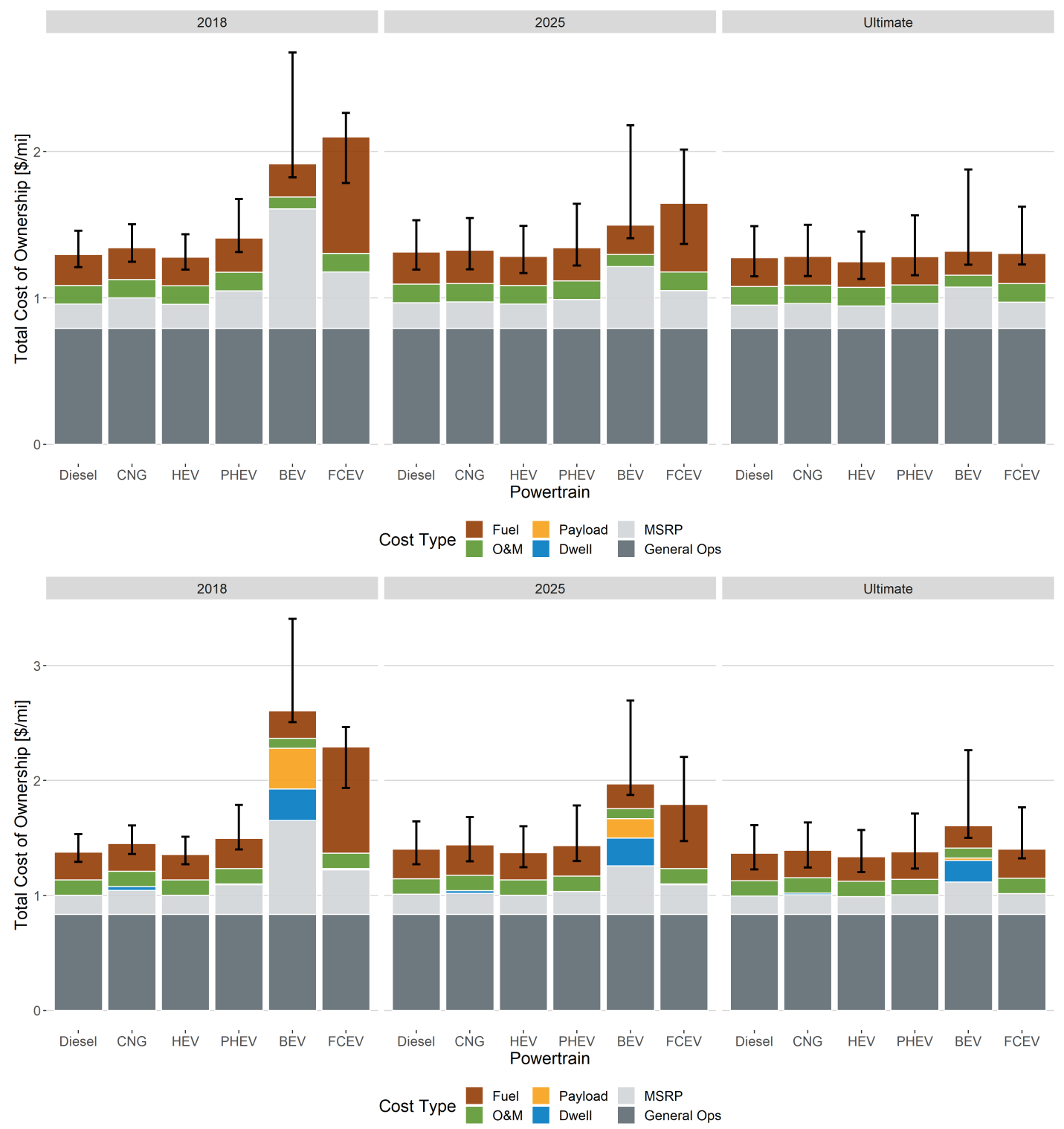

Figure ES-1. TCO ( $\$ / \mathrm{mile})$ for Class 8 long-haul tractors $(750-\mathrm{mile}$ range) in the Middle Atlantic region in (top) Single-Shift, Volume-Limited scenario and (bottom) Multi-Shift, Weight-Limited scenario.

As seen in Figure ES-1, the advanced powertrain TCO is significantly higher than the diesel truck TCO in the 2018 time frame, but rapidly decreases as technology cost and performance improves to the 2025 and Ultimate scenario assumptions. If no dwell or payload costs are incurred, the BEV and FCEV can be within the range of TCO uncertainty as soon as 2025 and very competitive if the Ultimate scenario assumptions are achieved. Payload costs primarily impact only the BEV powertrain and reduce to effectively zero as the Ultimate scenario assumptions are achieved. If dwell time costs are incurred, the FCEV powertrain is the lowest-cost zero-emission vehicle powertrain. 
Figure ES-2 shows the 500-mile-range Class 8 long-haul truck TCO in the Middle Atlantic U.S. Census Division region. Although mostly similar to the 750-mile range summarized in Figure ES-1, the shorter range results in lower onboard battery and hydrogen fuel storage requirements. The smaller battery pack reduces the potential BEV payload cost in the 2018 and 2025 time frames, as seen in Figure ES-2. Additionally, the BEV TCO is within the range of uncertainty of the diesel truck TCO as soon as 2025 if no dwell time costs are incurred, whereas the FCEV TCO is within the range of uncertainty (error bar ranges overlap) by 2025 regardless of dwell or payload costs.

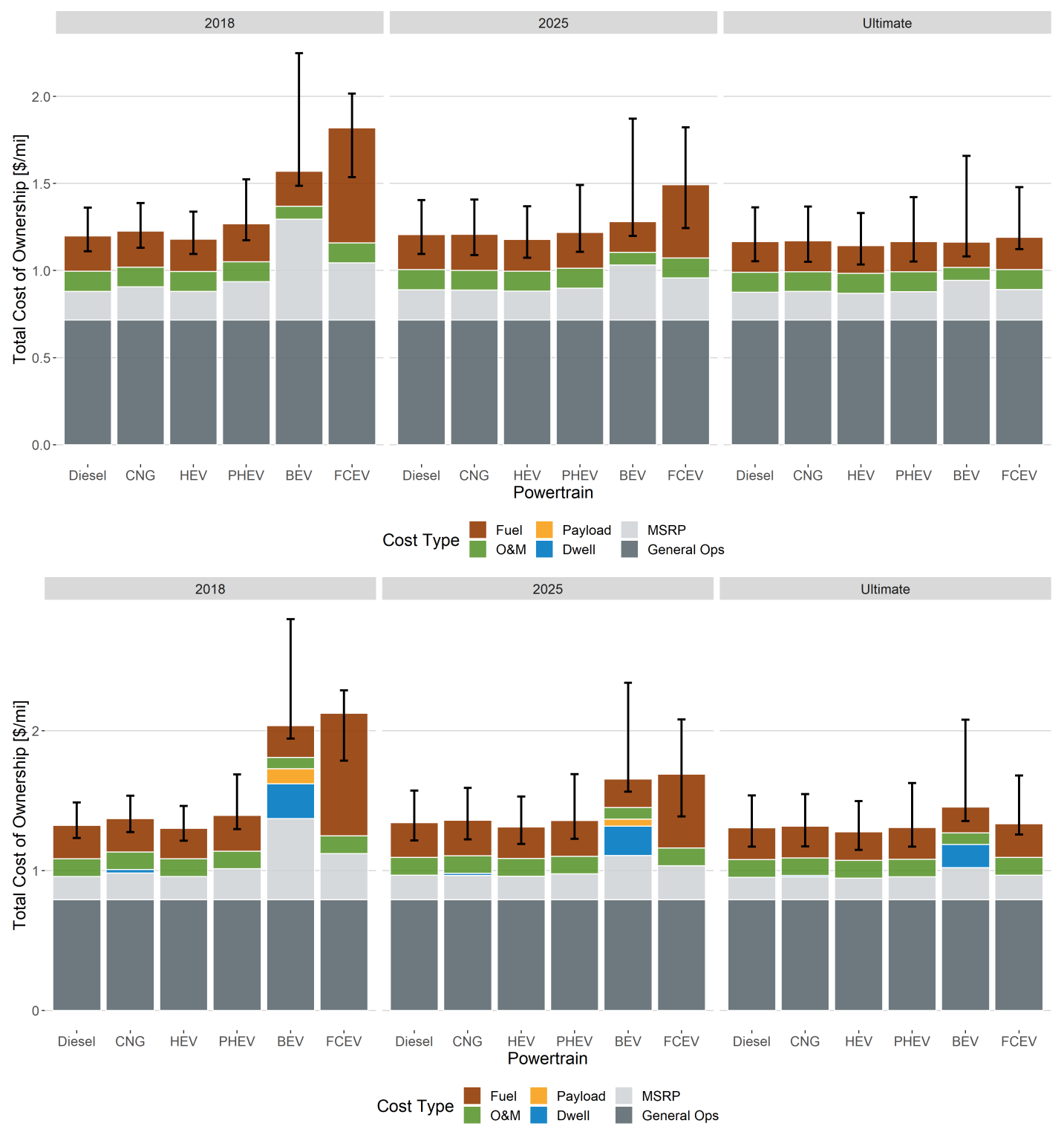

Figure ES-2. TCO (\$/mile) for Class 8 long-haul tractors (500-mile range) in the Middle Atlantic region in (top) Single-Shift, Volume-Limited scenario and (bottom) Multi-Shift, Weight-Limited scenario.

For Class 8 short-haul (300-mile-range) trucks, the TCO in the Single-Shift, Volume-Limited scenario and the Multi-Shift, Weight-Limited scenario in the Middle Atlantic U.S. Census Division region are shown in Figure ES-3. Because the onboard energy storage requirements are lower than the Class 8 long haul and the 2,000-lb weight-limit exemption for advanced powertrain trucks is accounted for, the impact of payload costs is minimal for all power- 
trains. If dwell time costs are not incurred, the BEV could potentially achieve TCO parity with the diesel incumbent if low electricity prices are realized. By 2025, both the BEV and FCEV are within the range of uncertainty and both could be economically attractive if low fuel prices could be achieved. If dwell time costs are incurred, the FCEV is the lowest-TCO zero-emission vehicle (ZEV).
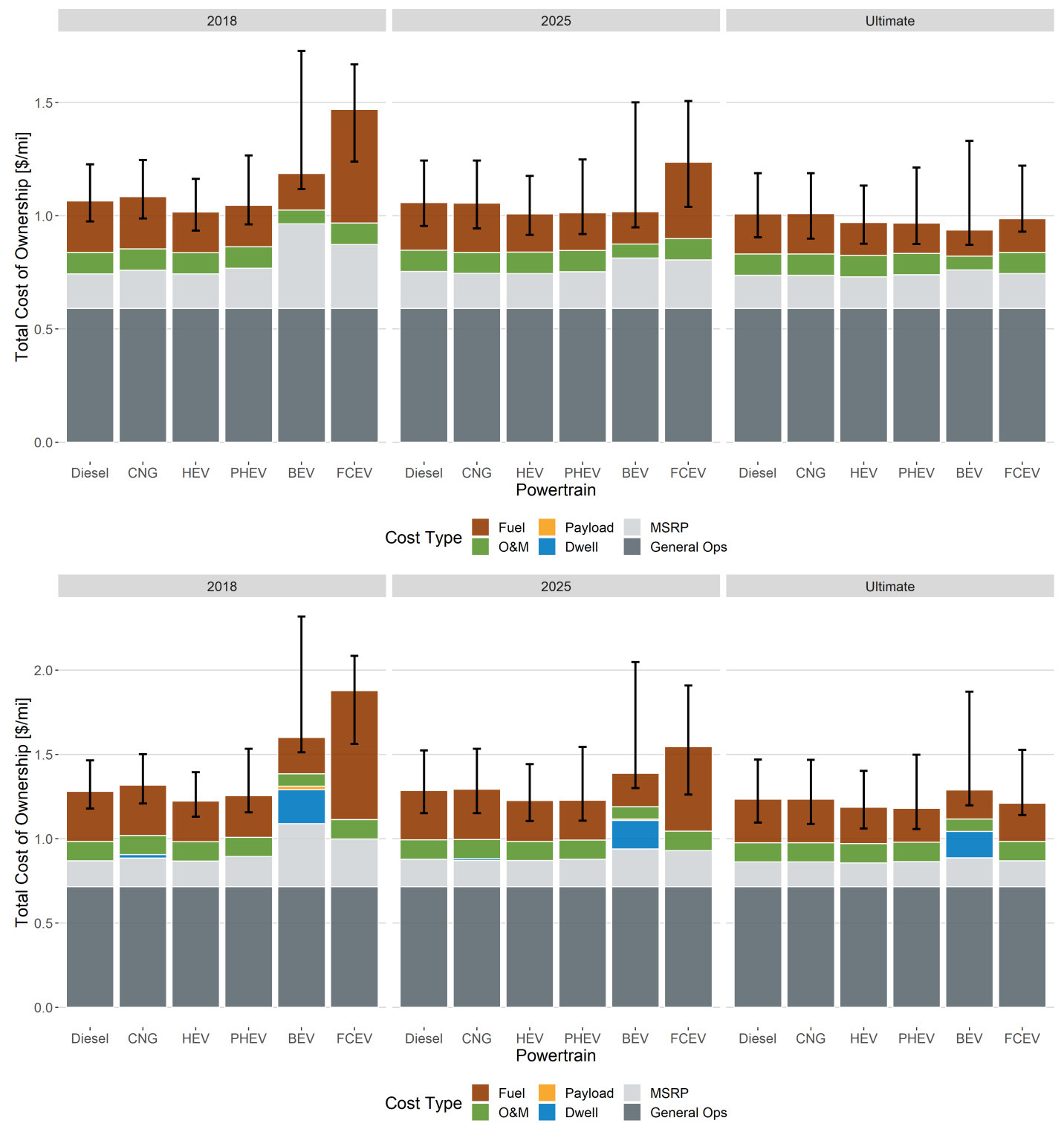

Figure ES-3. TCO (\$/mile) for Class 8 short-haul tractors (300-mile range) in the Middle Atlantic region in (top) Single-Shift, Volume-Limited scenario and (bottom) Multi-Shift, Weight-Limited scenario.

Figure ES-4 summarizes the TCO results for the Class 4 parcel delivery trucks in the Single-Shift, Volume-Limited scenario and the Multi-Shift, Weight-Limited scenario in the Middle Atlantic U.S. Census Division region. For the Single-Shift, Volume-Limited scenario, all powertrains have TCOs within the range of fuel and O\&M cost uncertainty with current (2018) technology status except the FCEV due to the high upfront purchase price and hydrogen price $(\$ 7-\$ 10 / \mathrm{kg})$. The BEV and FCEV costs significantly decline in the 2025 time frame and, in the absence of dwell time costs, the BEV becomes the lowest-cost powertrain. In the Multi-Shift, Weight-Limited 
operation, dwell time is a significant cost driver of TCO for the BEV due to frequent recharging events but it is complemented by the FCEV, which has faster refueling times and may be able to help decarbonize this market segment.
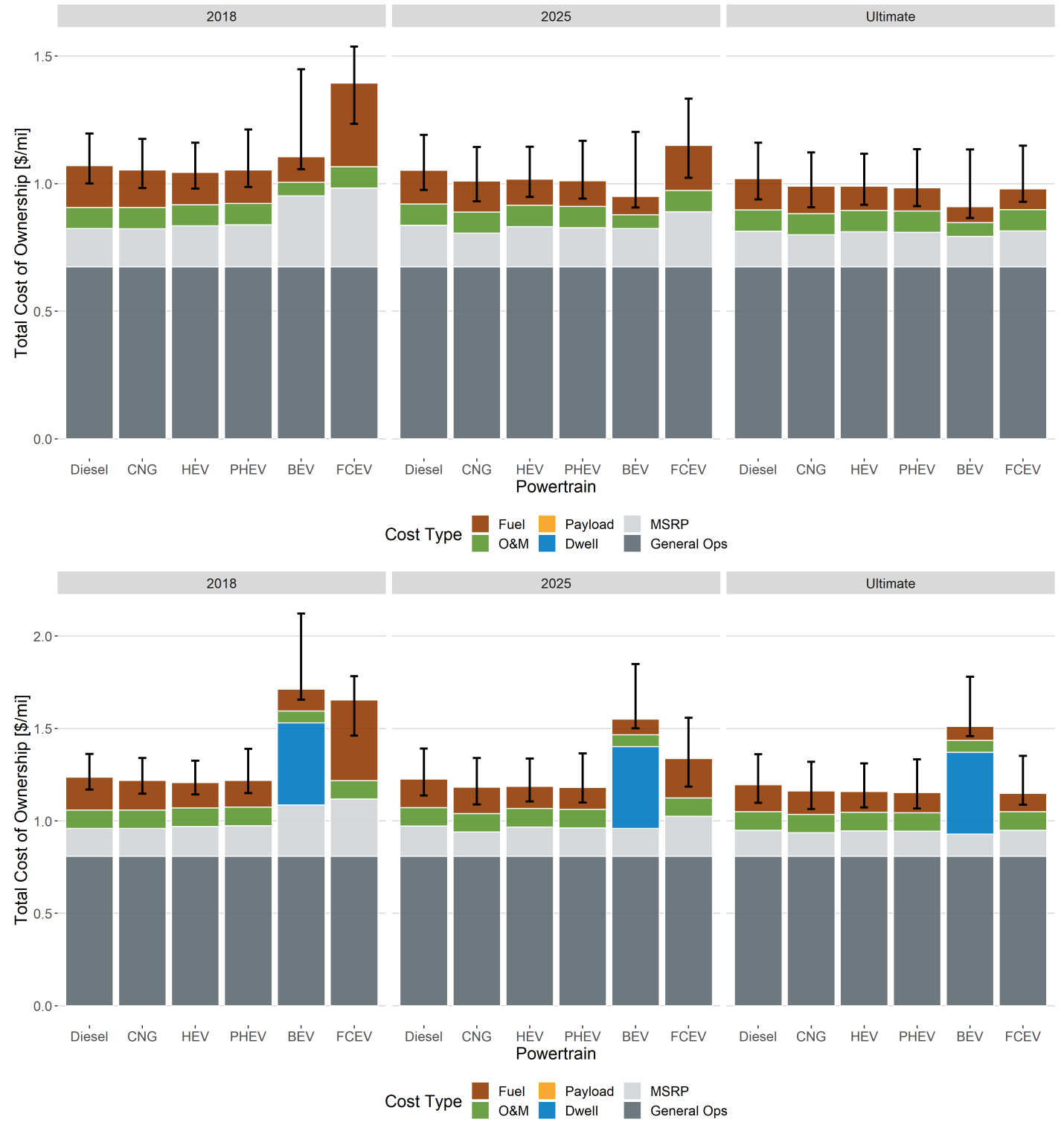

Figure ES-4. TCO (\$/mile) for Class 4 parcel delivery truck (120-mile range) in the Middle Atlantic region in (top) Single-Shift, Volume-Limited scenario and (bottom) Multi-Shift, Weight-Limited scenario. 


\section{Context, Constraints, and Limitations}

Medium- and heavy-duty vehicle decarbonization is critical for the transition to a net-zero economy. During the time this analysis was ongoing, there were multiple coordinated and collaborative efforts across the U.S. Department of Energy and U.S. national laboratory system focused on analyzing commercial vehicle decarbonization pathways. In particular, two closely related and collaborative parallel efforts included the Comprehensive Total Cost of Ownership Quantification for Vehicles with Different Size Classes and Powertrains (Burnham et al. 2021) and the Vehicle Technologies and Hydrogen and Fuel Cells Technologies Research and Development Programs Benefits Assessment Report for 2020 (Brooker et al. 2021). Specifically, Burnham et al. (2021) focuses on outlining a data framework for total cost of ownership evaluations across light-, medium-, and heavy-duty vehicles, identifying data gaps, and filling those where possible. Related, Brooker et al. (2021) focuses on technology evolution pathways and commercial vehicle adoption modeling across the light-, medium-, and heavy-duty vehicle sectors. This current project focuses most deeply on applying a scenario analysis to evaluate the total cost of ownership challenges and opportunities for medium- and heavy-duty vehicles with advanced powertrains. Among other aspects, this work provided the basis for dwell time and payload-cost evaluations included in Burnham et al. (2021) and coordinated vehicle modeling assumptions and approach with Brooker et al. (2021). Although each report is distinct, they are all coordinated where possible but differ in their analysis objective. 


\section{Table of Contents}

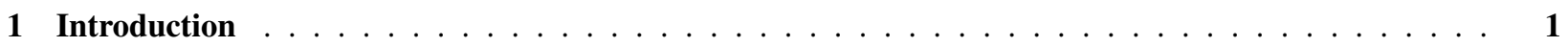

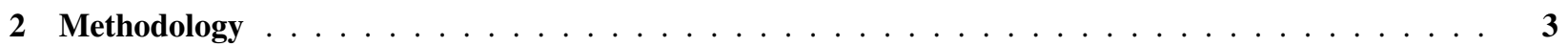

2.1 Selection of Vocations and Vehicle Ranges Modeled in This Study . . . . . . . . . . . . . 3

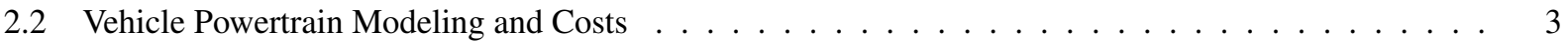

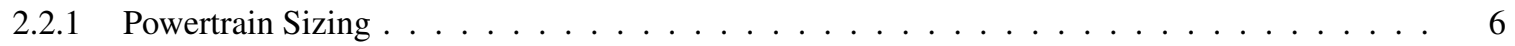

2.2.2 Onboard Energy Storage and Fuel Economy Estimation $\ldots \ldots \ldots \ldots \ldots$

2.2.3 Powertrain Technology Cost and Performance Data . . . . . . . . . . . . . . . . . 9

2.3 Other Vehicle Costs . . . . . . . . . . . . . . . . . . . . . . . . . . . . . 12

$2.3 .1 \quad$ Fuel Costs . . . . . . . . . . . . . . . . . . . . . . . . . . . 12

2.3.2 Operating and Maintenance Costs . . . . . . . . . . . . . . . . . . 13

2.3.3 Payload: Capacity Costs . . . . . . . . . . . . . . . . . . . . . . . . 16

2.3.4 Dwell Time: Refueling/Recharging . . . . . . . . . . . . . . . . . . . . . . . . . . . . 18

2.3.5 Resale and Salvage Value . . . . . . . . . . . . . . . . . . . . . . . 20

2.3.6 Other Costs: Taxes, Incentives, and Environmental Impacts . . . . . . . . . . . . . . . . . 21

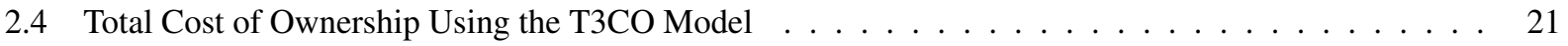

2.4.1 General Total Cost of Ownership Modeling Assumptions . . . . . . . . . . . . . . . . . . . 21

2.4.2 Total Cost of Ownership Scenario Analysis . . . . . . . . . . . . . . . . . . . . . 21

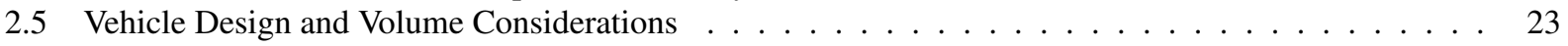

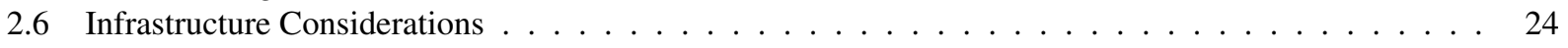

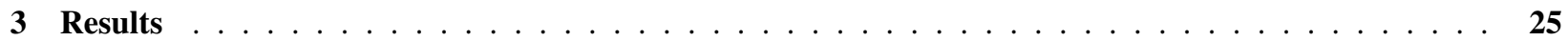

3.1 Vehicle Modeling . . . . . . . . . . . . . . . . . . . . . . 25

3.1.1 Vehicle Weight Breakdown: Class 8 Long-Haul and Short-Haul Trucks . . . . . . . . . . . 25

3.1.2 Vehicle Weight Breakdown: Class 4 Parcel Delivery Trucks . . . . . . . . . . . . . . . . . 29

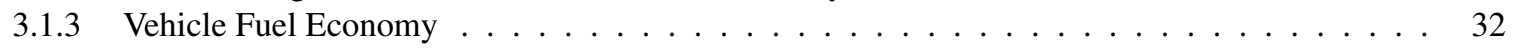

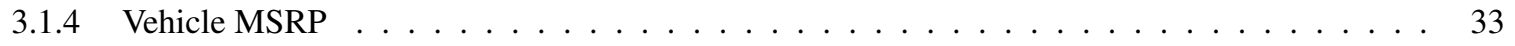

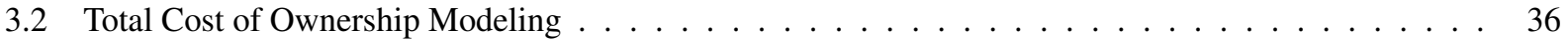

3.2.1 Class 8 Long-Haul Tractor $(750-$ Mile Range) $\ldots \ldots \ldots \ldots \ldots$. . . . . . . . . . . . 37

3.2.2 Class 8 Long-Haul Tractor $(500-$ Mile Range $) \ldots \ldots \ldots \ldots \ldots$. . . . . . . . . . 41

3.2.3 Class 8 Short-Haul Tractor (300-Mile Range) . . . . . . . . . . . . . . . . . . . . . 45

3.2.4 Class 4 Parcel Delivery (120-Mile Range) . . . . . . . . . . . . . . . . . . . . . . . . . . . . 49

3.3 Sensitivity Analysis . . . . . . . . . . . . . . . . . . . . . . . . . 53

3.3.1 Class 8 Long-Haul Tractor $(750-$ Mile Range) $\ldots \ldots \ldots \ldots$. . . . . . . . . . . . . . . . 54

3.3.2 Class 8 Long-Haul Tractor $(500-$ Mile Range $) \ldots \ldots \ldots \ldots \ldots \ldots$. . . . . . . . 58

3.3.3 Class 8 Short-Haul Tractor (300-Mile Range) . . . . . . . . . . . . . . . . . . . . 61

3.3.4 Class 4 Parcel Delivery $(120-$ Mile Range $) \ldots \ldots \ldots \ldots \ldots$

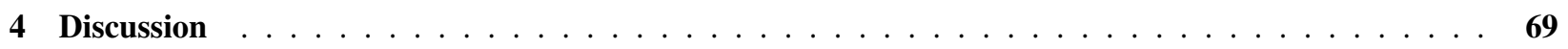

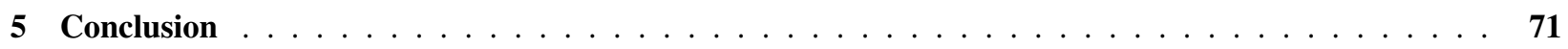

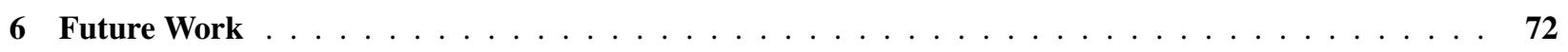

References $\ldots \ldots \ldots \ldots \ldots \ldots \ldots \ldots \ldots \ldots \ldots \ldots \ldots \ldots \ldots \ldots$

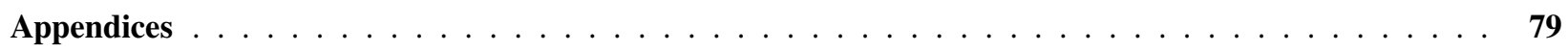




\section{List of Figures}

Figure 1. Generic data flow in the FASTSim model. Note: these graphics are general and do not reflect a specific vehicle from this study. . . . . . . . . . . . . . . . . . .

Figure 2. Visual example of how the FASTSim model estimates alternative powertrain trucks. A conventional truck is modeled as the sum of the masses, performance, and cost of its components (top). The conventional vehicle is stripped down to the glider by removing powertrain components (middle). FASTSim builds the alternative powertrains (fuel cell, shown at the bottom) to match the performance required and outputs vehicle mass and cost. Power electronics and cost use FASTSim default validated values, and transmission is assumed to be used on all powertrain configurations. . . . . . . . . . . . . . .

Figure 3. Representative drive cycles used for Class 8 long-haul (sleeper cab), Class 8 short-haul (day cab), and Class 4 parcel delivery vocations. One representative drive cycle from NREL's Fleet DNA database is used for each vocation. . . . . . . . . . . . . . . . . . . . . . . . .

Figure 4. State average DCFC electricity rates reported by EPRI (Dunckley and Valluri 2017) . . . . . . . . 13

Figure 5. Low, mid, and high U.S. average electricity and hydrogen prices . . . . . . . . . . . . . . . . 14

Figure 6. Summary of literature sources of O\&M costs by vehicle class, vocation, and powertrain . . . . . 15

Figure 7. Summary of ways to quantify the cost of lost payload capacity in Class 8 tractors due to heavier powertrains $(\mathrm{TL}=$ truckload, $\mathrm{LTL}=$ less-than-truckload $) \ldots \ldots$

Figure 8. Cargo density versus allowable cargo weight and the threshold density at which the truck load becomes weight-limited (above the line) rather than volume-limited (below the line). Example cargo types that typically fall into each freight class are provided (Logistics 2021) . . . . . . . . . . .

Figure 9. VIUS data on average weight of a truck/trailer by (top) count and (bottom) VMT fraction when they are operated with a typical payload over the year . . . . . . . . . . . . . . . . . 20

Figure 10. Summary of the T3CO M/HDT stock model data flow and output . . . . . . . . . . . . . . 22

Figure 11. Summary of TCO scenarios evaluated . . . . . . . . . . . . . . . . . . . 23

Figure 12. Estimation of percentage of Class 8 and Class 4 trucks associated with each scenario considered in this study based on VIUS data updated with Department of Motor Vehicle registration data (Lustbader et al. 2021; U.S. Census Bureau 2002; R.L. Polk and Co. 2013) . . . . . . . . . . . . . . . . . . . . . .

Figure 13. Class 8 FCEV long-haul truck (750-mile range) mass distribution relative to vehicle range using (left) 2025 scenario assumptions and (right) Ultimate scenario assumptions . . . . . . . . . . . . .

Figure 14. Class $8 \mathrm{BEV}$ long-haul truck (750-mile range) mass distribution relative to vehicle range using (left) 2025 scenario assumptions and (right) Ultimate scenario assumptions . . . . . . . . . . . . .

Figure 15. Class 8 long-haul 750-mile-range (top) and 500-mile-range (bottom) relative powertrain weight compared to a diesel powertrain that can achieve equivalent range and 0-60-mph acceleration time . . . .

Figure 16. Class 8 long-haul maximum cargo capacity, limited by 80,000-lb limit, for (left) 2025 and (right) Ultimate (2050) scenario assumptions . . . . . . . . . . . . . . . . . . . . . 28

Figure 17. Class 8 FCEV short-haul truck (300-mile range) mass distribution relative to vehicle range for (left) 2025 and (right) Ultimate (2050) scenario assumptions . . . . . . . . . . . . . . . . . .

Figure 18. Class $8 \mathrm{BEV}$ short-haul truck (300-mile range) mass distribution relative to vehicle range for (left) 2025 and (right) Ultimate (2050) scenario assumptions . . . . . . . . . . . . . . . . . . . .

Figure 19. Class 8 short-haul relative powertrain weight compared to a diesel powertrain that can achieve equivalent range and $0-60-\mathrm{mph}$ acceleration time . . . . . . . . . . . . . . .

Figure 20. Class 8 short-haul truck maximum cargo capacity, limited by 80,000-lb limit, for (left) 2025 and (right) Ultimate (2050) scenario assumptions 
Figure 21. FCEV Class 4 parcel delivery truck mass distribution relative to vehicle range for (left) 2025 and (right) Ultimate (2050) scenario assumptions . . . . . . . . . . . . . . . . . . . . . . 30

Figure 22. BEV Class 4 parcel delivery mass distribution relative to vehicle range for (left) 2025 and (right) Ultimate $(2050)$ scenario assumptions . . . . . . . . . . . . . . . . . . . . 3

Figure 23. Class 4 parcel delivery truck relative powertrain weight compared to a diesel powertrain that can achieve equivalent range and $0-60-m p h$ acceleration time . . . . . . . . . . . . . . . . . . 31

Figure 24. Vehicle maximum cargo capacity, limited to 16,000 lb, for (left) 2025 and (right) Ultimate (2050) scenario assumptions . . . . . . . . . . . . . . . . . . . . . . . . . . .

Figure 25. FASTSim-predicted fuel economy for a (top) Class 8 long-haul 750-mile-range truck, (top middle) Class 8 long-haul 500-mile-range truck, (bottom middle) Class 8 short-haul truck (300-mile range), and (bottom) Class 4 parcel delivery truck $(120$-mile range) . . . . . . . . . . . . . . . . 33

Figure 26. Class 8 long-haul (750-mile-range) FASTSim-estimated MSRP . . . . . . . . . . . . . . . . . . 34

Figure 27. Class 8 long-haul (500-mile-range) FASTSim-estimated MSRP . . . . . . . . . . . . . . . 35

Figure 28. Class 8 short-haul (300-mile-range) FASTSim-estimated MSRP . . . . . . . . . . . . . . . . 36

Figure 29. Class 4 parcel delivery (120-mile-range) FASTSim-estimated MSRP . . . . . . . . . . . . . . . . 36

Figure 30. Single-Shift, Volume-Limited scenario TCO for Class 8 long-haul tractors (750-mile range) in the Middle Atlantic region . . . . . . . . . . . . . . . . . . . . . . . . . . . . 37

Figure 31. Multi-Shift, Weight-Limited scenario TCO for Class 8 long-haul tractors (750-mile range) in the Middle Atlantic region . . . . . . . . . . . . . . . . . . . . . . . . . . 38

Figure 32. Regional TCO distribution for the Single-Shift, Volume-Limited scenario of a Class 8 long-haul

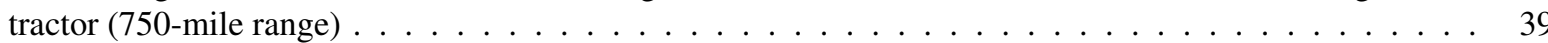

Figure 33. Regional TCO distribution for the Multi-Shift, Weight-Limited scenario of a Class 8 long-haul tractor $(750$-mile range $) \ldots \ldots \ldots \ldots$

Figure 34. Single-Shift, Volume-Limited break-even fuel price analysis for Class 8 long-haul trucks (750mile range) in the Middle Atlantic Region . . . . . . . . . . . . . . . . . . . . .

Figure 35. Multi-Shift, Weight-Limited break-even fuel price analysis for Class 8 long-haul trucks (750mile range) in the Middle Atlantic Region . . . . . . . . . . . . . . . . . . . . . . .

Figure 36. Single-Shift, Volume-Limited scenario TCO for Class 8 long-haul tractors (500-mile range) in the Middle Atlantic region . . . . . . . . . . . . . . . . . . .

Figure 37. Multi-Shift, Weight-Limited scenario TCO for Class 8 long-haul tractors (500-mile range) in the Middle Atlantic region . . . . . . . . . . . . . . . . . . . . . . . . . .

Figure 38. Regional TCO distribution for the Single-Shift, Volume-Limited scenario of a Class 8 long-haul

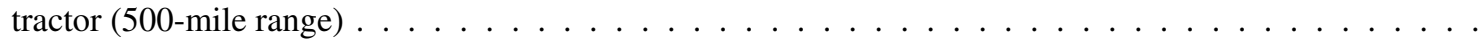

Figure 39. Regional TCO distribution for the Multi-Shift, Weight-Limited scenario of a Class 8 long-haul tractor $(500$-mile range $) \ldots \ldots \ldots \ldots \ldots \ldots$

Figure 40. Single-Shift, Volume-Limited break-even fuel price analysis for Class 8 long-haul trucks (500mile range) in the Middle Atlantic Region . . . . . . . . . . . . . . . . . . . . . . . . . .

Figure 41. Multi-Shift, Weight-Limited break-even fuel price analysis for Class 8 long-haul trucks (500mile range) in the Middle Atlantic Region . . . . . . . . . . . . . . . . . . . .

Figure 42. Single-Shift, Volume-Limited scenario TCO for Class 8 short-haul tractors (300-mile range) in the Middle Atlantic region . . . . . . . . . . . . . . . . . . .

Figure 43. Multi-Shift, Weight-Limited scenario TCO for Class 8 short-haul tractors (300-mile range) in the Middle Atlantic region . . . . . . . . . . . . . . . . . . . . . . 
Figure 44. Regional TCO distribution for the Single-Shift, Volume-Limited scenario of a Class 8 short-haul tractor $(300-$ mile range $) \ldots \ldots \ldots \ldots$

Figure 45. Regional TCO distribution for the Multi-Shift, Weight-Limited scenario of a Class 8 short-haul tractor $(300-$ mile range $) \ldots \ldots \ldots \ldots \ldots \ldots$

Figure 46. Single-Shift, Volume-Limited break-even fuel price analysis for Class 8 short-haul trucks (300mile range) in the Middle Atlantic region . . . . . . . . . . . . . . . . . . . . . . .

Figure 47. Multi-Shift, Weight-Limited break-even fuel price analysis for Class 8 short-haul trucks (300mile range) in the Middle Atlantic region . . . . . . . . . . . . . . . . . . . . . . . .

Figure 48. Single-Shift scenario TCO for Class 4 parcel delivery truck (120-mile range) in the Middle Atlantic region . . . . . . . . . . . . . . . . . . . . . . . . . . . . 50

Figure 49. Multi-Shift scenario TCO for Class 4 parcel delivery truck (120-mile range) in the Middle At-

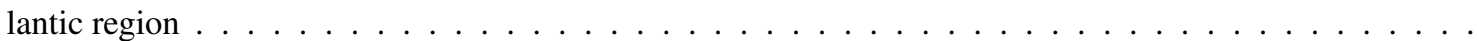

Figure 50. Regional TCO distribution for the Single-Shift, Volume-Limited scenario of a Class 4 parcel delivery truck $(120$-mile range $) \ldots \ldots \ldots \ldots \ldots$

Figure 51. Regional TCO distribution for the Multi-Shift, Volume-Limited scenario of a Class 4 parcel delivery truck $(120$-mile range $) \ldots \ldots \ldots \ldots$. . . . . . . . . . . . . . . . . 52

Figure 52. Single-Shift, Volume-Limited break-even fuel price analysis for Class 4 parcel delivery trucks (120-mile range) in the Middle Atlantic region . . . . . . . . . . . . . . . . . . .

Figure 53. Multi-Shift, Volume-Limited break-even fuel price analysis for Class 4 parcel delivery trucks (120-mile range) in the Middle Atlantic region . . . . . . . . . . . . . . . . .

Figure 54. Sensitivity analysis on a fuel cell Class 8 long-haul truck (750-mi range, 150,000 mi/yr) showing impact of low/high estimates $(\$ / \mathrm{mi})$ relative to the mid estimate . . . . . . . . . . . . . . . . 55

Figure 55. Double waterfall chart for a fuel cell electric Class 8 long-haul (750-mile) truck . . . . . . . . . . 56

Figure 56. Sensitivity analysis on a battery electric Class 8 long-haul truck (750-mi range, 150,000 mi/yr) showing impact of low/high estimates $(\$ / \mathrm{mi})$ relative to the mid estimate . . . . . . . . . . . . 57

Figure 57. Double waterfall chart for a battery electric Class 8 long-haul (750-mile) truck . . . . . . . . . . 57

Figure 58. Sensitivity analysis on a fuel cell Class 8 long-haul truck (500-mi range, 100,000 mi/yr) showing impact of low/high estimates $(\$ / \mathrm{mi})$ relative to the mid estimate . . . . . . . . . . . . . . . . 58

Figure 59. Double waterfall chart for a fuel cell electric Class 8 long-haul (500-mile) truck . . . . . . . . . . 59

Figure 60. Sensitivity analysis on a battery electric Class 8 long-haul truck (500-mi range, 100,000 mi/yr) showing impact of low/high estimates $(\$ / \mathrm{mi})$ relative to the mid estimate . . . . . . . . . . . . . . 60

Figure 61. Double waterfall chart for a battery electric Class 8 long-haul (500-mile) truck . . . . . . . . . . 61

Figure 62. Sensitivity analysis on a fuel cell Class 8 short-haul truck (300-mi range, 60,000 mi/yr) showing impact of low/high estimates $(\$ / \mathrm{mi})$ relative to the mid estimate . . . . . . . . . . . . . 62

Figure 63. Double waterfall chart for a fuel cell electric Class 8 short-haul truck . . . . . . . . . . . . . . 63

Figure 64. Sensitivity analysis on a battery electric Class 8 short-haul truck (300-mi range, 60,000 mi/yr) showing impact of low/high estimates $(\$ / \mathrm{mi})$ relative to the mid estimate . . . . . . . . . . 64

Figure 65. Double waterfall chart for a battery electric Class 8 short-haul (300-mile) truck . . . . . . . . 64

Figure 66. Sensitivity analysis on a fuel cell Class 4 parcel delivery truck (120-mi range, 25,000 mi/yr) showing impact of low/high estimates $(\$ / \mathrm{mi})$ relative to the mid estimate . . . . . . . . . . . . 65

Figure 67. Double waterfall chart for a fuel cell electric Class 4 parcel delivery truck . . . . . . . . . . 66 
Figure 68. Sensitivity analysis on a battery electric Class 4 parcel delivery truck (120-mi range, 25,000 $\mathrm{mi} / \mathrm{yr})$ showing impact of low/high estimates $(\$ / \mathrm{mi})$ relative to the mid estimate . . . . . . . . . 67

Figure 69. Double waterfall chart for a battery electric Class 4 parcel delivery (120-mile) truck . . . . . . . . 68

Figure C1. Impact of the cost of power electronics and electric motor (PEEM) on MSRP . . . . . . . . . 83

Figure D1. Impact of battery cost on BEV MSRP in current time frame . . . . . . . . . . . . . . . . . 84

Figure D2. Impact of battery cost on BEV MSRP in 2025 time frame . . . . . . . . . . . . . . . . . 85

Figure D3. Impact of battery cost on BEV MSRP in Ultimate time frame . . . . . . . . . . . . . . . . . . 85

Figure E1. Regional fuel pricing . . . . . . . . . . . . . . . . . . . . . 86

Figure H1. U.S. Environmental Protection Agency (EPA) 65-mph regulatory cycle fuel economy . . . . . . . 90

Figure H2. EPA $55-m p h$ regulatory cycle fuel economy . . . . . . . . . . . . . . . . . 91

Figure H3. EPA city regulatory cycle fuel economy . . . . . . . . . . . . . . . . . . . . . . . 92

Figure I1. Single-Shift, Weight-Limited scenario TCO for Class 8 long-haul tractors (750-mile range) in the Middle Atlantic region . . . . . . . . . . . . . . . . . . . . . . . . . . 93

Figure I2. Multi-Shift, Volume-Limited scenario TCO for Class 8 long-haul tractors (750-mile range) in the Middle Atlantic region . . . . . . . . . . . . . . . . . . . . . . 93

Figure I3. Regional TCO distribution for the Single-Shift, Weight-Limited scenario of a Class 8 long-haul tractor $(750$-mile range $) \ldots \ldots \ldots \ldots$

Figure I4. Regional TCO distribution for the Multi-Shift, Volume-Limited scenario of a Class 8 long-haul

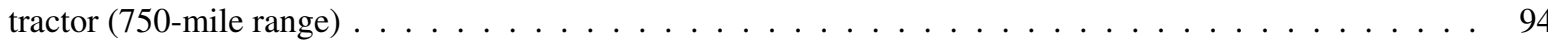

Figure I5. Single-Shift, Weight-Limited break-even fuel price analysis for Class 8 long-haul trucks (750mile range) in the Middle Atlantic region . . . . . . . . . . . . . . . . . . . . . . . . . . . 95

Figure I6. Multi-Shift, Volume-Limited break-even fuel price analysis for Class 8 long haul trucks (750mile range) in the Middle Atlantic region . . . . . . . . . . . . . . . . . . . . . . . .

Figure I7. Single-Shift, Weight-Limited scenario TCO for Class 8 long-haul tractors (500-mile range) in the Middle Atlantic region . . . . . . . . . . . . . . . . . . . . . . 96

Figure I8. Multi-Shift, Volume-Limited scenario TCO for Class 8 long-haul tractors (500-mile range) in the Middle Atlantic region . . . . . . . . . . . . . . . . . . . . . . . . . . 96

Figure I9. Regional TCO distribution for the Single-Shift, Weight-Limited scenario of a Class 8 long-haul

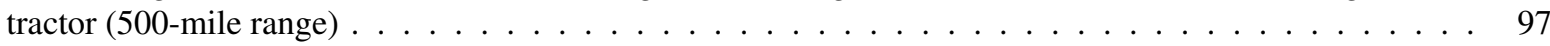

Figure I10. Regional TCO distribution for the Multi-Shift, Volume-Limited scenario of a Class 8 long-haul

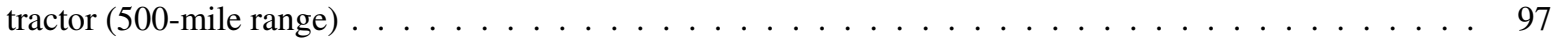

Figure I11. Single-Shift, Weight-Limited break-even fuel price analysis for Class 8 long-haul trucks (500mile range) in the Middle Atlantic region . . . . . . . . . . . . . . . . . . . . . . . . 98

Figure I12. Multi-Shift, Volume-Limited break-even fuel price analysis for Class 8 sleeper trucks (500-mile range) in the Middle Atlantic region . . . . . . . . . . . . . . . . . . . . . . . . . . . . . . . . .

Figure I13. Single-Shift, Weight-Limited scenario TCO for Class 8 short-haul tractors (300-mile range) in

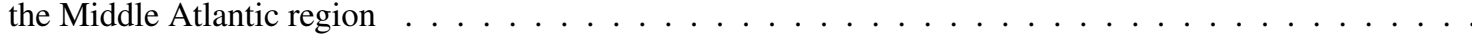

Figure I14. Multi-Shift, Volume-Limited Scenario TCO for Class 8 short-haul tractors (300-mile range) in the Middle Atlantic region . . . . . . . . . . . . . . . . . . . . . .

Figure I15. Regional TCO distribution for the Single-Shift, Weight-Limited scenario of a Class 8 short-haul tractor $(300$-mile range $) \ldots \ldots \ldots \ldots$ 
Figure I16. Regional TCO distribution for the Multi-Shift, Volume-Limited scenario of a Class 8 short-haul

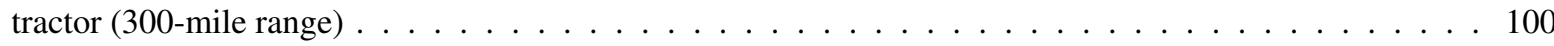

Figure I17. Single-Shift, Weight-Limited break-even fuel price analysis for Class 8 short-haul trucks (300mile range) in the Middle Atlantic region . . . . . . . . . . . . . . . . . . . . . . 101

Figure I18. Multi-Shift, Volume-Limited break-even fuel price analysis for Class 8 short-haul trucks (300mile range) in the Middle Atlantic region . . . . . . . . . . . . . . . . . . . . . . . . . . . 101

\section{List of Tables}

Table 1. Power Required To Achieve Target Acceleration for 2018, 2025, 2050 . . . . . . . . . . . . 8

Table 2. Technology Metrics and Assumptions Used in FASTSim Powertrain Modeling . . . . . . . . . . 10

Table 3. Assumptions of Battery Useable State of Charge in Each Technology Year . . . . . . . . . . . . 12

Table 4. Ranges for Fuel Costs Considered . . . . . . . . . . . . . . . . . . . . . . . . . . 12

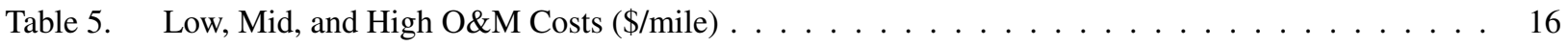

Table 6. Payload Cost Range for Class 8 Long-Haul (500-Mile-Range) Truck . . . . . . . . . . . . . . . . 18

Table 7. Low, Mid, and High Refueling Rates by Powertrain . . . . . . . . . . . . . . . . . . . . . . 19

Table 8. Lower Limit on Refueling/Recharging Times . . . . . . . . . . . . . . . . . . . . . . 20

Table 9. Annual and Daily VMT for Each Vehicle Analyzed . . . . . . . . . . . . . . . . . 23

Table 10. Sensitivity Parameter Summary for a Class 8 Long-Haul (750-mi) Fuel Cell Truck . . . . . . . . . 54

Table 11. Sensitivity Parameter Summary for a Class 8 Long-Haul (750-mi) Battery Electric Truck . . . . 55

Table 12. Sensitivity Parameter Summary for a Class 8 Long-Haul (500-mi) Fuel Cell Truck . . . . . . . . . 58

Table 13. Sensitivity Parameter Summary for a Class 8 Long-Haul (500-mi) Battery Electric Truck . . . . . 59

Table 14. Sensitivity Parameter Summary for a Class 8 Short-Haul Fuel Cell Truck . . . . . . . . . . . . . . 61

Table 15. Sensitivity Parameter Summary for a Class 8 Short-Haul Battery Electric Truck . . . . . . . . . 62

Table 16. Sensitivity Parameter Summary for a Class 4 Parcel Delivery Fuel Cell Truck . . . . . . . . . . . . 65

Table 17. Sensitivity Parameter Summary for a Class 4 Parcel Delivery Battery Electric Truck . . . . . . . . 66

Table A1. Powertrain Sizing . . . . . . . . . . . . . . . . . . . . . . . . . 79

Table A2. Powertrain Sizing . . . . . . . . . . . . . . . . . . . . . 80

Table B1. Benchmark Against Autonomie . . . . . . . . . . . . . . . . . . . . . . 81

Table B2. Benchmark Against Industry . . . . . . . . . . . . . . . . . . . . . . 82

Table F1. Payload Cost Range for Class 8 Long-Haul (750-Mile-Range) Truck . . . . . . . . . . . . . . 87

Table F2. Payload Cost Range for Class 8 Short-Haul (300-Mile-Range) Truck . . . . . . . . . . . . . . 87

Table G1. Operating and Maintenance Cost Literature Review ． . . . . . . . . . . . . . . . . . . . . 88

Table G2. Operating and Maintenance Cost Literature Review (continued) . . . . . . . . . . . . . . . . 89 


\section{Introduction}

The medium- and heavy-duty truck (M/HDT) segment is experiencing rapid changes toward the adoption of alternative powertrains (Heid et al. 2017; Hyundai 2018; Tesla 2021; Nikola 2020; O’'Dell 2018; Rondini et al. 2020). As trucks are used primarily for revenue-generating activities for firms or individual owners and operators, the adoption of these vehicles is strongly tied to the fundamental economics associated with each truck. One of the most relevant metrics by which to evaluate various trucks against each other is the total cost of ownership (TCO) metric.

TCO aims to identify all costs and aggregate into a single metric that allows for consistent comparison across different truck options. Although TCO does not directly account for the riskiness of certain technologies or the payback time a purchase may have, it does provide a strong indicator of the economics associated with each truck. Overall, TCO is a primary metric for an economic evaluation of various truck powertrains, while the adoption of a particular truck technology may be related to specific operational and financial requirements by each individual firm.

Several recent studies have analyzed TCO of heavy duty vehicles. Phadke et al. (2021) estimated that battery electric Class 8 trucks with 375 miles of range can achieve a TCO 13\% lower than diesel trucks with current technology and a $3 \%$ payload capacity reduction, and could see up to $40 \%$ lower TCO in the future. However, they do not use a dynamic vehicle model to estimate the powertrain efficiency (fuel economy) over time or for different drive cycles, adjust for cost to price markups required due to non-vertical truck integration, benchmark against a diesel truck with a fuel economy much lower than the industry standard for new trucks, nor account for diesel truck improvements over time (e.g., diesel engine efficiency).

Other reports have also focused on a subset of all possible powertrain technologies (Transport \& Environment 2020; Mihelic et al. 2020) or provided broad characterizations of the challenges facing commercial transportation in general (Shell and Deloitte 2020). The literature lacks any comprehensive studies that compare all viable powertrain options with a consistent, rigorous analytical framework and considering uncertainty in fueling and maintenance costs. Additionally, no studies have attempted to quantify the value of potential lost payload capacity due to heavier advanced powertrain designs or potential dwell time costs due to slower refueling or recharging. These facets are critical to understand to help prioritize $\mathrm{R} \& \mathrm{D}$ and accelerate the transition to a decarbonized commercial vehicle sector.

For this analysis, the TCO for Class 8 tractors (long-haul or "sleeper cab" [750- and 500-mile range] and shorthaul or "day cab" [300-mile range]) and Class 4 parcel delivery (120-mile-range) trucks is assessed. These truck applications serve to evaluate a wide array of the M/HDT space and serve as typical trucks for which a TCO analysis framework can be developed.

The powertrains considered in this analysis are conventional (diesel), diesel hybrid electric (HEV), plug-in hybrid electric (PHEV), compressed natural gas (CNG), fuel cell electric (FCEV), and battery electric (BEV).

The TCO for each truck is based on all direct and indirect costs. For this analysis, the key economic costs, including opportunity costs, were quantified and evaluated. These costs include the upfront purchase price of the vehicle, fuel costs, and operating and maintenance costs, as well as lost payload capacity costs and dwell time costs associated with recharging/refueling. Finally, these costs are combined to determine the net present value cost associated with owning and operating the truck under various conditions. This analysis assumes the costs associated with general operations (driver wages and benefits, insurance, permits, tolls) are the same across powertrains.

Four scenarios are defined and evaluated to understand TCO under different commercial vehicle operating regimes: (1) Single-Shift, Volume-Limited, (2) Single-Shift, Weight-Limited, (3) Multi-Shift, Volume-Limited, and (4) MultiShift, Weight-Limited. Single-shift operation assumes there are no dwell time costs incurred for charging/refueling because there is sufficient time for that to occur off-shift (e.g., charging/refueling can be done overnight). In the Multi-Shift scenarios, however, dwell time costs associated with the driver and truck being idle are incurred because the firm may be able to realize more revenue or reduce costs if the truck did not need to be idle. Volume-limited scenarios assume the payload is volumetrically limited (i.e., cubes out) before weighing out, so there are no lost payload capacity (weight) costs incurred. The Weight-Limited scenarios, however, account for weight-related lost payload capacity costs if the alternative powertrain is heavier than the conventional (diesel) powertrain. 
Sensitivity analysis is completed to understand the largest drivers of TCO for BEV and FCEV powertrains. Additionally, a waterfall analysis is completed to understand the pathways to reducing BEV and FCEV TCO and the most important cost parameters.

Lastly, as this study is primarily focused on understanding the TCO of various M/HDT market segments with advanced powertrains, detailed design and volumetric considerations for building these trucks are outside the scope of this report but are important to consider. Section 2.5 briefly discusses this aspect in greater detail. 


\section{Methodology}

The total cost of ownership for M/HDTs is subject not only to the typical, direct costs of a vehicle but also to opportunity costs associated with value streams that the truck provides. The direct costs evaluated in this paper include vehicle purchase cost, fuel costs, and operating and maintenance (O\&M) costs. ${ }^{1}$ The opportunity costs quantified include potential lost payload capacity and dwell time. Subsequent sections describe approaches to modeling each of these cost components. Other costs such as salvage costs, powertrain technology-specific taxes, incentives, differences in insurance costs, and environmental benefits were excluded from this analysis but could readily be included in future work.

\subsection{Selection of Vocations and Vehicle Ranges Modeled in This Study}

The medium- and heavy-duty transportation sector covers a wide variety of vehicle classes and types. Although many of these will be explored in depth in future studies, the present analysis focuses on Class 8 tractors and Class 4 parcel delivery vehicles. We consider Class 8 short- and long-haul tractors because they represent nearly $70 \%$ of total medium- and heavy-duty fuel consumption (U.S. Census Bureau 2002; R.L. Polk and Co. 2013). Class 4 parcel delivery trucks are also a fairly common vehicle type (approximately $6 \%$ of Class $4-8$ trucks are in Class 4 U.S. Census Bureau 2002), but are much lighter and may represent a near-term opportunity for electrification. Together, the Class 8 tractors and Class 4 parcel delivery trucks bookend the commercial vehicle sector and will help provide insights into particular vehicle attributes and operational characteristics that may present both opportunities and challenges for deep decarbonization in this sector.

For Class 8 tractors, three definitions were analyzed in this report: a 300-mile short-haul (day cab) tractor, a 500mile long-haul (i.e., sleeper cab) tractor, and a 750-mile long-haul tractor. Battery electric truck manufacturers have announced Class 8 tractor models with ranges of 150-500 miles (Tesla 2021; Nikola 2020; Kenworth 2020; Volvo 2021), while fuel cell electric truck manufacturers have announced ranges of 300-900 miles (Nikola 2020; Hirsch 2021). Thus, both 300- and 500-mile-range Class 8 tractors were selected for analysis. Based on 2002 Vehicle Inventory and Use Survey (VIUS) truck operating data (U.S. Census Bureau 2002), a 750-mile Class 8 tractor is likely sufficient to meet $99 \%$ of the truck's daily requirements (Marcinkoski et al. 2019) and is currently in the range of powertrains announced by manufacturers, so this analysis also evaluates a Class 8 tractor with a 750-mile range. For Class 4 parcel delivery trucks, 120 miles of range was selected as it meets $>90 \%$ of the truck's daily requirements based on VIUS data (U.S. Census Bureau 2002).

\subsection{Vehicle Powertrain Modeling and Costs}

The National Renewable Energy Laboratory's (NREL's) Future Automotive Systems Technology Simulator (FASTSim) model was used for vehicle evaluations in this report (National Renewable Energy Laboratory, 2018a). The model was developed under funding from the U.S. Department of Energy's (DOE's) Vehicle Technologies Office to enable rigorous estimation of light-, medium-, and heavy-duty vehicle fuel consumption and performance. The following powertrains are assessed in this analysis:

- Conventional diesel and gasoline vehicles

- Hybrid electric vehicles (HEVs)

- Battery electric vehicles (BEVs)

- Compressed natural gas (CNG) vehicles

- Fuel cell electric vehicles (FCEVs)

- Plug-in hybrid electric vehicles (PHEVs).

\footnotetext{
${ }^{1}$ This analysis assumes that the truck is purchased upfront rather than financed. This assumption removes costs associated with the riskiness of resale and buyer credit ratings, and thus is internally consistent within this report and allows for simpler, more direct comparison of powertrain technologies. Additionally, this analysis ignores any fleet discounts, which are assumed to be equal across all powertrain technologies, if available.
} 
The FASTSim model is a comprehensive physical driving model for vehicles. It uses 53 parameter vehicle specifications covering items such as:

- Vehicle and cargo mass and weight distribution

- Frontal area and drag coefficient

- Glider weight and cost

- Fuel storage system weight, volume, and cost

- Engine power, efficiency curve, mass, ramp-up rate, and cost

- Electric motor power, efficiency, ramp rate, and cost

- Battery energy, power, degradation, and cost

- Wheel inertia, rolling resistance, radius, and friction

- Energy management specifications

- Specifications for power electronics, battery charger, auxiliary loads, and transmission.

The model simulates the above vehicle characteristics over drive cycles in which vehicle speed set point and associated road grade are updated every second. Specific performance measurements such as vehicle acceleration, fuel consumption, and battery state of charge are calculated each second to arrive at a net vehicle performance of fuel efficiency and road performance. Figure 1 shows an information flow for the FASTSim model. 


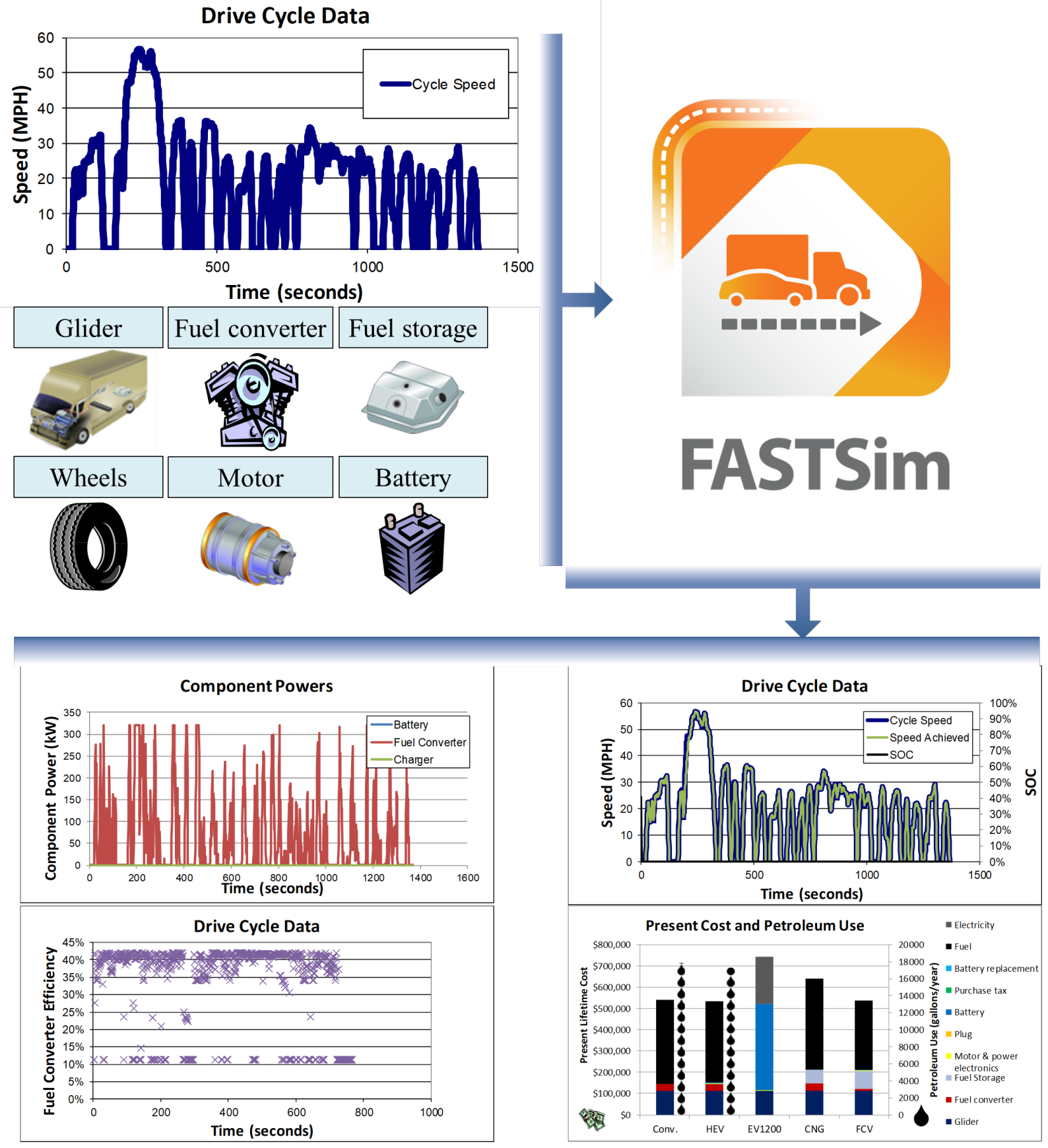

Figure 1. Generic data flow in the FASTSim model. Note: these graphics are general and do not reflect a specific vehicle from this study.

The FASTSim model uses a subsystem level of performance characterization suitable to quickly evaluate hypothetical scenarios where a certain driving vocation is served by alternative powertrains. This analysis focuses on the powertrain differences and maintains every other aspect of the vehicle the same-such as aerodynamics, rolling resistance, transmission, and light-weighting. For example, a diesel long-haul truck can be converted into a fuel cell truck by removing the diesel engine, emissions equipment, and fuel storage system and replacing them with a fuel cell, hydrogen storage system, hybrid batteries, and an electric motor. Each powertrain uses a vehicle's transmission to deliver mechanical power and drive the vehicle. Thus, to estimate the mass of each vehicle, the glider mass 
(stripped diesel truck) is augmented with the additional mass of the fuel cell, hydrogen storage system, batteries, and motor. Similarly, the vehicle cost is stripped of the upfront cost of the diesel components and augmented with the cost of the added fuel cell components.

In addition to vehicle mass and cost estimation, FASTSim simulates the vehicle operation based on the vehicle characteristics and selected duty cycle. Based on this operational analysis, FASTSim can size powertrains to meet specific performance constraints (e.g., acceleration, gradeability, range) and estimate the average fuel economy for any drive cycle over which the truck operation is simulated. Figure 2 summarizes this process.

The FASTSim model outputs vehicle designs with their total upfront costs, performance, and weight. Powertrain costs reflect purchase cost of components (e.g., engine) and are then multiplied by 1.5 to account for original equipment manufacturer markup.
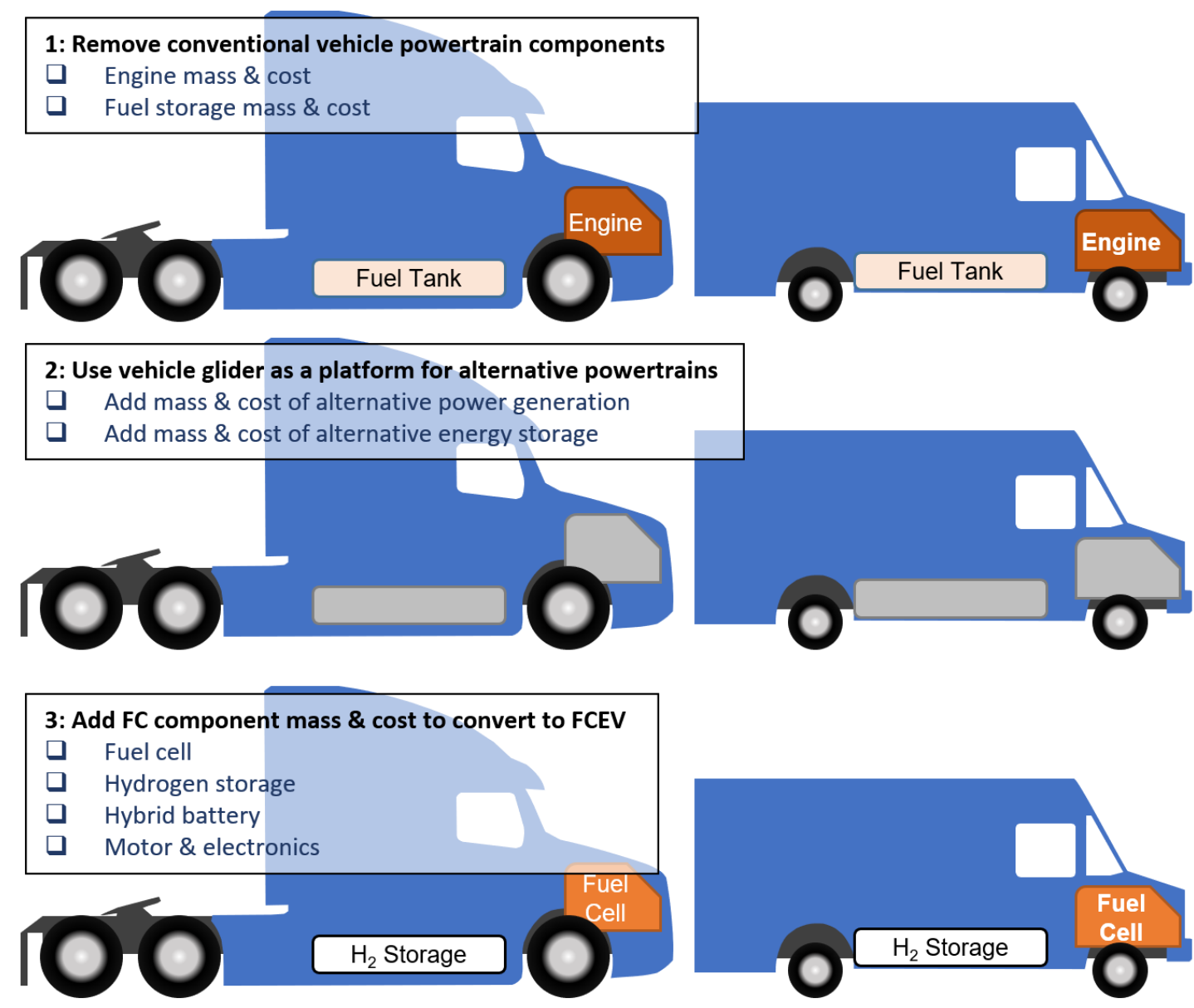

Figure 2. Visual example of how the FASTSim model estimates alternative powertrain trucks. A conventional truck is modeled as the sum of the masses, performance, and cost of its components (top). The conventional vehicle is stripped down to the glider by removing powertrain components (middle). FASTSim builds the alternative powertrains (fuel cell, shown at the bottom) to match the performance required and outputs vehicle mass and cost. Power electronics and cost use FASTSim default validated values, and transmission is assumed to be used on all powertrain configurations.

\subsubsection{Powertrain Sizing}

The FASTSim model was programmed to automatically perform powertrain comparisons by stripping a given vehicle of its conventional powertrain components and building it back up with various alternative propulsion systems. As seen in Figure 2, all components were removed down to the vehicle's glider, and then alternative system com- 
ponents were added for each powertrain. The replaced power generation components (engines and motors) were sized to achieve acceleration consistent with that of a conventional powertrain. This was done by testing vehicle acceleration from 0-60 mph while being loaded to the full extent of the vehicle class. For Class 8 long-haul trucks (80,000-lb gross vehicle weight rating [GVWR]), targeted acceleration from 0-60 mph on flat terrain was 59 seconds (determined by FASTSim assessment of the acceleration of a conventional powertrain with a benchmarked engine power of $317 \mathrm{~kW})$. Similarly, acceleration of 55 seconds (0-60-mph time) was used as a target for Class 8 short-haul vehicles based on their computed acceleration with a 340-kW diesel engine. For Class 4 parcel delivery vehicles (16,000-lb GVWR), targeted acceleration from $0-60 \mathrm{mph}$ on flat terrain was estimated at 30 seconds based on a conventional engine power of $155 \mathrm{~kW}$. Table 1 shows the powertrain sizing required to achieve consistent acceleration performance for different powertrain types and different vehicles. In future technology years, improvements in rolling resistance and aerodynamics result in lower power requirement to achieve the target accelerations in Table 1. Detailed FASTSim results for powertrain sizes are provided in Appendix A. Results have been benchmarked against commercial and demonstration vehicles of their type (see Appendix B).

HEVs used a design point of $75 \%$ power being supplied by the fuel converter and the remaining power supplied via the electric motor. PHEV systems were designed to have 55\% of power coming from the fuel converter with the remaining power supplied by the electric motor, based on the design of the 2018 PHEV Toyota Prius (ultimateSPECS 2021). PHEV target acceleration is achievable in either charge-depleting or charge-sustaining modes of operation by leveraging both the fuel converter and electric motor. PHEV ranges for Class 4 were simulated in two modes of operation: charge-depleting mode and charge-sustaining mode. Sixty percent of the vehicle range was modeled as being in charge-depleting mode and $40 \%$ of the subsequent range was simulated in charge-sustaining mode. Battery storage and fuel storage were sized to achieve the energy requirements of both modes of operation. It should be noted that PHEV powertrain sizing was not optimized to minimize the TCO of the truck, and engine downsizing needs to be considered as it may reduce the capabilities of the truck if the battery is depleted.

\subsubsection{Onboard Energy Storage and Fuel Economy Estimation}

Fuel economy of each powertrain was estimated by evaluating the vehicle performance relative to a drive cycle. A drive cycle consists of a recorded or simulated 1-second incremented schedule of speeds and road grade, which reflects the representative vehicle driving characteristics. For example, a package delivery truck drive cycle typically has relatively low average driving speed, has many stops along its route, and experiences limited highway driving. A Class 8 long-haul truck, on the other hand, has relatively high driving speed and few stops. FASTSim evaluates each vehicle on its design drive cycle and adjusts onboard energy storage to achieve the desired range of the truck.

Although there is no drive cycle that perfectly represents the operation of all commercial vehicles within particular vocations, representative drive cycles were selected to reflect the key characteristics of the Class 8 short-haul, Class 8 long-haul, and Class 4 parcel delivery vocations. This work uses the same Class 8 long-haul and Class 8 short-haul tractor representative drive cycles determined in Lustbader et al. (2021), which used a rigorous, machine-learning approach to identify representative drive cycles. These drive cycles come from NREL's Fleet DNA database (National Renewable Energy Laboratory, 2018b), which stores drive cycle data from GPS-instrumented trucks. The truck velocity and GPS location is logged each second to evaluate truck operations and road grade. The Class 4 parcel delivery truck drive cycle data were also selected from NREL's Fleet DNA database based on typical operating data for a delivery truck. Using representative, real-world drive cycles is critical to reflect real-world fuel consumption for the TCO analysis. Figure 3 summarizes the representative drive cycles used to estimate the truck onboard energy storage and fuel economy in this analysis.

The fuel economy estimated with these representative Fleet DNA drive cycles is also used to size the onboard fuel or energy storage capacity to meet the desired vehicle range. We performed this calculation for Class 8 trucks assuming cargo weight is fixed at an average 36,000 pounds for both long- and short-haul trucks, while capping total vehicle weight at 82,000 pounds (which includes the 2,000-lb weight exemption for alternative powertrain vehicles) at the expense of cargo, where necessary. For the 2025 and Ultimate time periods, improvements in rolling resistance and aerodynamics over time were incorporated into the analysis and result in smaller powertrain requirements for future years (see Appendix A).

These representative cycles do not cover the full breadth of driving demands a vehicle could experience, but never- 
Table 1. Power Required To Achieve Target Acceleration for 2018, 2025, 2050

\begin{tabular}{lccccc}
\hline Vehicle & Powertrain & $\begin{array}{c}\text { Motor }^{\mathrm{b}} \\
(\mathrm{kW})\end{array}$ & $\begin{array}{c}\text { Engine }^{\mathrm{b}} \\
(\mathrm{kW})\end{array}$ & $\begin{array}{c}\text { Fuel Cell }^{\mathrm{b}} \\
(\mathrm{kW})\end{array}$ & $\begin{array}{c}\text { Battery } \\
(\mathrm{kWh})\end{array}$ \\
\hline C8 long-haul (750) & Diesel & & $317,309,300$ & & \\
C8 long-haul (750) & CNG & & $317,309,300$ & & $25,20,16$ \\
C8 long-haul (750) & HEV & $78,76,74$ & $235,229,223$ & & $2,200,1,800,1,200$ \\
C8 long-haul (750) & BEV & $309,302,294$ & & $303,295,288$ & $20,20,20$ \\
C8 long-haul (750) & FCEV & $303,295,288$ & & & $336,265,182$ \\
C8 long-haul (750) & PHEV & $140,136,133$ & $170,166,161$ & & \\
\hline C8 long-haul (500) & Diesel & & $317,309,300$ & & $25,20,16$ \\
C8 long-haul (500) & CNG & & $317,309,300$ & & $1,436,1,173,789$ \\
C8 long-haul (500) & HEV & $78,76,74$ & $235,229,223$ & & $20,20,20$ \\
C8 long-haul (500) & BEV & $309,302,294$ & & $303,295,288$ & \\
C8 long-haul (500) & FCEV & $303,295,288$ & & & $27,22,17$ \\
C8 long-haul (500) & PHEV & $140,136,133$ & $170,166,161$ & & $823,682,452$ \\
\hline C8 short-haul & Diesel & & $340,331,320$ & & $20,20,20$ \\
C8 short-haul & CNG & & $340,331,320$ & & $128,124,128$ \\
C8 short-haul & HEV & $84,82,79$ & $253,245,238$ & & \\
C8 short-haul & BEV & $332,323,314$ & & $325,316,307$ & \\
C8 short-haul & FCEV & $325,316,307$ & & & $17,12,10$ \\
C8 short-haul & PHEV & $150,146,142$ & $182,177,171$ & & $4,4,4$ \\
\hline C4 parcel delivery & Diesel & & $155,143,140$ & & $33,24,17$ \\
C4 parcel delivery & CNG & & $155,143,140$ & & \\
C4 parcel delivery & HEV & $38,35,34$ & $115,106,103$ & & \\
C4 parcel delivery & BEV & $146,135,132$ & & & \\
C4 parcel delivery & FCEV & $146,135,132$ & & & \\
C4 parcel delivery & PHEV & $68,62,61$ & $82,76,74$ & & \\
\hline
\end{tabular}

a: Vehicle masses: Class 8: 80,000 lb, Class 4: 16,000lb

b: Acceleration (0-60 mph): Long-haul: $59 \mathrm{sec}$, Short-haul: $55 \mathrm{sec}$, Parcel Delivery: $30 \mathrm{sec}$

theless yield reasonably sized energy storage components for the average vehicle range demand. Unlikely light-duty vehicles, where customer purchase decisions are influenced greatly by a vehicle's performance (e.g. acceleration capability highly influences vehicle sales), in the medium- and heavy-duty space purchase decisions are based primarily on capital and operating costs. For example, a long-haul (sleeper cab) truck will find little economic benefit from having a larger engine than needed for flat roads and to yield 0-60 mph acceleration in less than approximately 60 seconds. As acceleration represents a relatively low fraction of a long-haul truck's driving behavior, a larger engine and sportier tractor would only yield a heavier and more fuel-intensive cargo transport with diminished cargo capacity. Similarly, the ability to climb steep road grades is seldom needed in most of the United States, and commercial trucking settles for an economic optimum of slower speeds or lighter loads for extensive road climbs in return for more efficient operation on flat terrain. However, the powertrain power yielded with the above analysis matches favorably to the power ratings found in today's commercial applications. For example, the conventional diesel powertrain with $400-\mathrm{kW}$ power $(536 \mathrm{hp}$ ) is well within surveyed commercial engine capacities found on the Commercial Truck Trader website (Trader 2021). Class 8 long-haul trucks found on the site ranged in power from $246 \mathrm{~kW}(330 \mathrm{hp})$ to $420 \mathrm{~kW}(560 \mathrm{hp})$ with an average of $330 \mathrm{~kW}(448 \mathrm{hp})$. All powertrains in the results of this analysis fall within the engine capacities of the survey. 


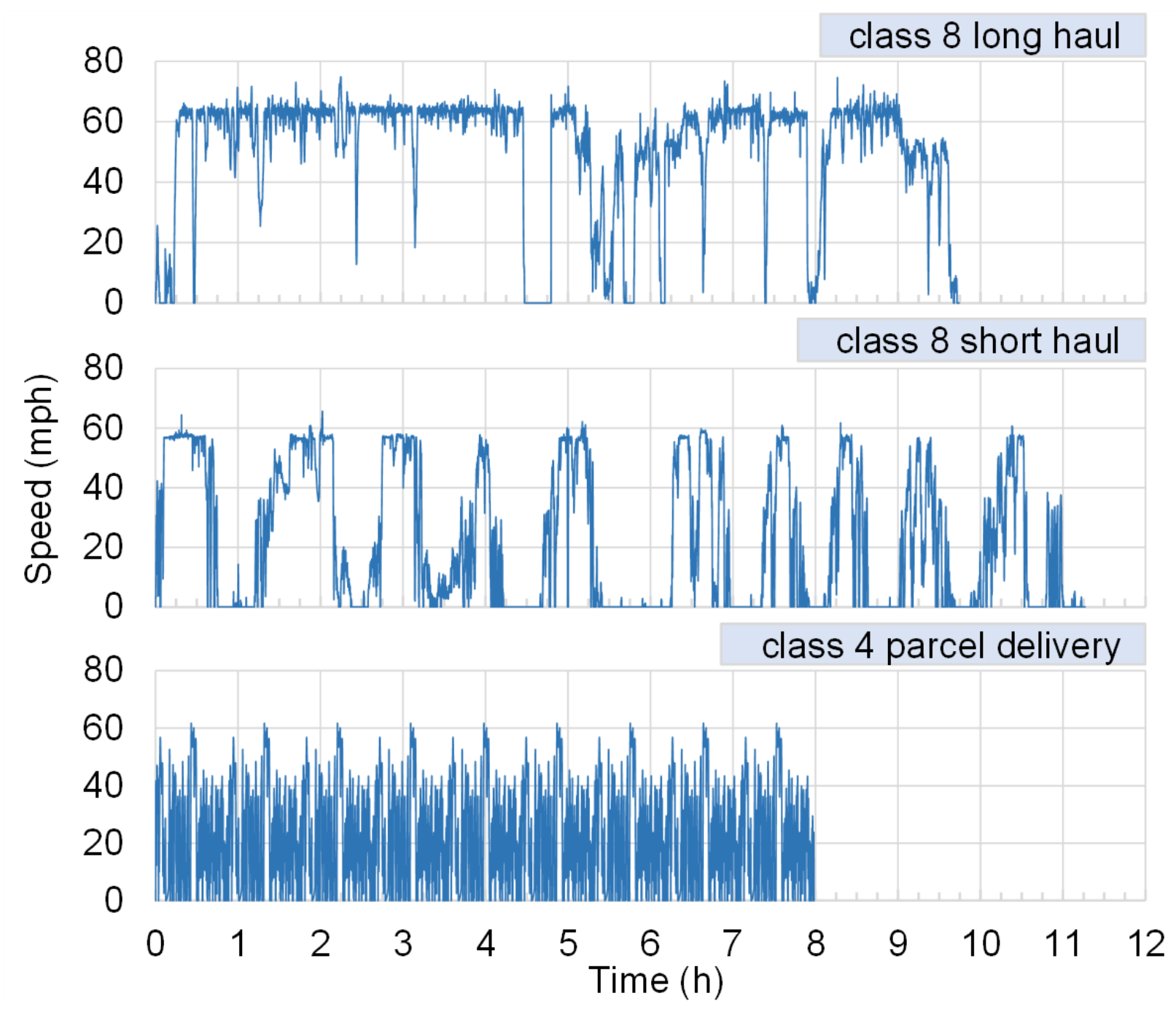

Figure 3. Representative drive cycles used for Class 8 long-haul (sleeper cab), Class 8 short-haul (day cab), and Class 4 parcel delivery vocations. One representative drive cycle from NREL's Fleet DNA database is used for each vocation.

\subsubsection{Powertrain Technology Cost and Performance Data}

The powertrain technology cost and performance data used in TCO analyses can be critical to the TCO results. Although many of these data are hard to determine for the nascent commercial electric vehicle sector and can be highly uncertain when projecting into the future, the data in this analysis come from multiple existing data sets, studies, and conversations with experts across DOE and the national laboratories. The component cost and performance data for each powertrain technology and model year used in this analysis are summarized in Table 2.

For electric trucks, the battery pack energy density and costs are based on the DOE Vehicle Technologies Office's review of current technology status and future light-duty cost targets (U.S. Department of Energy 2021; Boyd 2018). Battery costs for M/HDV applications are uncertain: BloombergNEF recently reported that prices for battery packs for electric buses in China have been cited at less than $\$ 100 / \mathrm{kWh}$ (Bloomberg NEF 2020), while conversations with U.S. original equipment manufacturers suggest that it is currently difficult to purchase batteries for mediumand heavy-duty vehicles in the United States for less than $\$ 300 / \mathrm{kWh}$ (Lustbader et al. 2021). Additionally, higher prices may be observed for medium- and heavy-duty applications due to higher power ratings needed and lower purchasing volume in the near term, but, prices are expected to decline rapidly in the next few years. The value for 
Table 2. Technology Metrics and Assumptions Used in FASTSim Powertrain Modeling

\begin{tabular}{|c|c|c|c|}
\hline Technology year & 2018 & 2025 & Ultimate (2050) \\
\hline \multicolumn{4}{|l|}{ Batteries } \\
\hline Battery pack mass $[\mathrm{kg} / \mathrm{kWh}]$ & 4.70 & 4.03 & 2.50 \\
\hline Battery pack price HEV $[\$ / \mathrm{kW}]$ & 0 & 0 & 0 \\
\hline HEV battery pack cost $[\$ / k W h]$ & 197 & 100 & $80^{\mathrm{a}}$ \\
\hline PHEV battery pack cost [ $\$ / \mathrm{kWh}]$ & 197 & 100 & $80^{\mathrm{a}}$ \\
\hline PHEV battery pack cost [ $\$ / \mathrm{kWh}]$ & 197 & 100 & $80^{\mathrm{a}}$ \\
\hline \multicolumn{4}{|l|}{ Power electronics } \\
\hline Power electronics w/ boost and motor [ $\$ 2016 / \mathrm{kW}]$ & $8-49.2$ & $6-41.7$ & $4-20.9$ \\
\hline \multicolumn{4}{|l|}{ FCEV } \\
\hline Fuel cell specific power $[\mathrm{kW} / \mathrm{kg}]$ & 0.96 & 1.02 & 1.08 \\
\hline Fuel cell cost $[\$ / \mathrm{kW}]$ & 196 & 140 & 60 \\
\hline Fuel cell system peak efficiency [\% LHV] & $64 \%$ & $66 \%$ & $72 \%$ \\
\hline Storage specific mass [kWh-LHV/kg] & 1.48 & $1.80^{\mathrm{a}}$ & 2.20 \\
\hline Storage cost [\$/kWh-LHV] & 36 & 16 & 8.0 \\
\hline Hydrogen price $[\$ / \mathrm{kg}]$ & 10 & 7 & 4 \\
\hline \multicolumn{4}{|l|}{ CNG } \\
\hline Engine peak efficiency [\%] & $38 \%$ & $41 \%$ & $46 \%$ \\
\hline Engine cost $[\$ / \mathrm{kW}]$ & 55 & 55 & 55 \\
\hline Fuel storage cost [\$/usable $\mathrm{kWh} N G]$ & 7.47 & 4.70 & 3.82 \\
\hline Fuel storage mass $[\mathrm{kWh} / \mathrm{kg}]$ & 4.21 & 4.47 & 5.10 \\
\hline \multicolumn{4}{|l|}{ Conventional } \\
\hline Engine specific power $[\mathrm{kW} / \mathrm{kg}]$ & 0.275 & 0.275 & 0.275 \\
\hline Engine cost $a_{0}$ coefficient [ $\left.\$\right]^{\mathrm{b}}$ & 7,617 & 7,617 & 7,617 \\
\hline Engine cost $a_{1}$ coefficient [ $\left.\$ / \mathrm{kW}\right]^{\mathrm{b}}$ & 15.1 & 15.1 & 15.1 \\
\hline Engine cost $a_{2}$ coefficient [\$] $]^{\mathrm{b}}$ & 0.1 & 0.1 & 0.1 \\
\hline Waste heat recovery cost increase $[\$]^{\mathrm{c}}$ & 0 & 10,000 & 5,000 \\
\hline Transmission cost reduction $[\$]^{c}$ & 0 & 1,100 & 1,800 \\
\hline Engine advancement cost increase $[\$]^{c}$ & 0 & 1,500 & $-6,000$ \\
\hline Class 8 engine peak efficiency [\%] & $47.3 \%$ & $51.8 \%$ & $57.0 \%$ \\
\hline Class 4 engine peak efficiency [\%] & $42.1 \%$ & $45.7 \%$ & $49.6 \%$ \\
\hline Fuel storage specific mass $[\mathrm{kWh} / \mathrm{kg}]$ & 9.88 & 9.88 & 9.88 \\
\hline
\end{tabular}

a: Based on 2025 light-duty vehicle targets

b: Lower heating value

c: Conventional engine cost curve fit $=a_{0}+a_{1} P+a_{2} P^{2}$

d: Costs based on Class 8 long-haul and applied proportionally to powertrain power

2018 of $\$ 197 / \mathrm{kWh}$ is within the range of values reported and represents a reasonable estimate for current technology, and a sensitivity analysis of BEV manufacturer's suggested retail price (MSRP) to battery pack price is included in Appendix D. This analysis assumes that these battery pack costs are reported at the system level and no additional costs are assumed for cooling/structural components needed for vehicle glider integration. Also, note that these battery costs are on a total energy basis and the usable energy available in the battery depends on the usable stateof-charge window. Battery minimum and maximum states of charge should be respected for optimal performance and durability, and Table 3 gives the battery state-of-charge window used in this study, which are consistent with Brooker et al. (2021). The power electronics costs provide a range of values. The low end of the range was used for most of the scenarios in this report and are based on the US DRIVE Electrical and Electronics Technical Team 2017 Roadmap (U.S. DRIVE 2017). The upper range is based on the power electronics costs for M/HDTs in Brooker 
et al. (2021) and was used to evaluate the sensitivity of MSRP to power electronic costs, which can be found in Appendix C.

For fuel cell trucks, the 2018 and projected 2025 fuel cell specific power values are based on a 2018 S.A. Inc. analysis (James et al. 2018). The Ultimate (2050) value is based on achieving a similar improvement from 2025 to 2050 as the improvement from 2018 to 2025, and was reviewed with experts at the DOE Hydrogen and Fuel Cell Technologies Office (HFTO). The fuel cell system cost for 2018 is based on an S.A. Inc. bottom-up manufacturing analysis for M/HDT fuel cells (James, Huya-Kouadio, and Houchins 2021). The Ultimate fuel cell system cost is based on HFTO's Class 8 truck targets (Marcinkoski et al. 2019). The 2025 fuel cell system cost is based on HFTO guidance based on preliminary technology target-setting. The fuel cell system peak efficiency is based on HFTO's Class 8 truck targets (Marcinkoski et al. 2019). The onboard hydrogen storage specific mass and storage costs are based on HFTO's onboard storage cost and performance status record (Adams, Houchins, and Ahluwalia 2019). Note that hydrogen tanks for FCEVs are assumed to be installed in 10-kg increments based on tank sizes that are currently available, and costs given in Table 2 reflect this assumption ${ }^{2}$. Hydrogen prices are discussed in detail in Section 2.3.1, but the 2018 dispensed hydrogen price is based on average costs demonstrated in fuel cell bus evaluations (Eudy 2019) for those fleets with dedicated hydrogen refueling infrastructure (e.g., SunLine). The 2025 and Ultimate (2050) hydrogen costs were based on efforts by HFTO for M/HDTs and similar to those for light-duty vehicles (Ramsden and Joseck 2018).

For CNG trucks, the CNG engine peak efficiency is based on a 2020 Vehicle Technologies Office natural gas report sent to Congress and reviewed with an industry original equipment manufacturer (Stork, Kevin and Curran, Scott and Graves, Ronald and Pihl, Josh 2021). CNG engines are expected to continue to improve over time via the stoichiometric, exhaust gas recirculation engine with three-way catalysts. Additionally, further advancements in natural gas engine, aftertreatment, and controls will facilitate more stoichiometric and lean-burn switching (currently demonstrated in conventional gasoline passenger car applications) to achieve the Ultimate engine efficiency. CNG engine costs, storage costs, and storage-specific mass were also reviewed by the Vehicle Technologies Office and found to be in line with their expert expectations (Stork, Kevin 2021).

For conventional diesel trucks, the engine specific power is based on NREL's FASTSim model default (National Renewable Energy Laboratory, 2018a). The engine cost coefficients are based on recent analysis in Brooker et al. (2021). The waste heat recovery, transmission, and engine advancement costs are aligned with HFTO's Class 8 truck target report (Marcinkoski et al. 2019). The Class 8 tractor and Class 4 parcel delivery truck engine efficiencies are aligned with those in the recent Brooker et al. (2021). Lastly, the fuel storage specific mass is based on NREL's FASTSim model default (National Renewable Energy Laboratory, 2018a).

All component costs in Table 2 reflect costs and not prices to the truck purchaser. To convert to an MSRP, costs are multiplied by 1.5 to account for price markup and integration into the vehicle powertrain system (National Renewable Energy Laboratory, 2018a). Although markups are hard to assess and depend on multiple factors including the riskiness of the technologies, maturity of the market, and level of vertical integration among technology supplies and truck manufacturers, a value of $50 \%$ was assumed in this analysis and is based primarily on light-duty vehicles (National Renewable Energy Laboratory, 2018a). Early battery electric and fuel cell electric bus demonstration data may indicate a higher markup closer to 90\%-100\% (Deloitte 2020). However, because these data are very early stage and reflect a nascent market, a 50\% markup was assumed. A detailed study of component cost multipliers (U.S. Environmental Protection Agency 2016) finds that component cost multipliers for vocational Class 4 through Class 8 tractor trailers are similar. Thus, we assume the same markup for the Class 4 and Class 8 trucks evaluated in this study. Finally, it should be noted that all component masses are multiplied by 1.2 to account for supplemental integration hardware (U.S. Environmental Protection Agency and National Highway Traffic Safety Administration 2011).

Benchmarking of the FASTSim results against reported industry claims is included in Appendix B. Additional modeling parameters are included in Appendix A.

\footnotetext{
${ }^{2}$ For example, in the 2018 scenario, each incremental 10-kg tank installed would result in nearly $\$ 18,000$ increase in the MSRP (\$36/kWh $\mathrm{x}$ $33 \mathrm{~kg} / \mathrm{kWh}-\mathrm{LHV} \times 10 \mathrm{~kg}$ x 1.5 (markup)).
} 
Table 3. Assumptions of Battery Useable State of Charge in Each Technology Year

\begin{tabular}{lccc}
\hline Powertrain & 2018 & 2025 & Ultimate \\
\hline HEV \& FCEV & $40 \%$ & $40 \%$ & $40 \%$ \\
BEV \& PHEV & $75 \%$ & $78 \%$ & $95 \%$ \\
\hline
\end{tabular}

\subsection{Other Vehicle Costs}

The purchase price of the M/HDT is the initial upfront cost of the vehicle. However, there are several other vehicle costs that must be accounted for in the TCO analysis for an M/HDT. These include both direct costs (fuel, O\&M) and indirect costs (lost payload capacity cost and dwell time). Due to the high uncertainty with many of these costs, each cost component was evaluated at three cost tiers (low, mid, high) with the costs associated at each tier dependent on the data currently available.

\subsubsection{Fuel Costs}

To quantify fuel costs for M/HDTs, two things must be known: the vehicle's fuel consumption and the fuel price. Section 2.2.2 discusses how vehicle fuel efficiency was estimated for the M/HDTs considered in this analysis. Fuel prices were based on the U.S. Energy Information Administration's 2021 Annual Energy Outlook (AEO) (U.S. Energy Information Administration 2021), the Electric Power Research Institute's national charging costs analysis (Dunckley and Valluri 2017), Muratori, Kontou, and Eichman (2019) and Borlaug et al. (2020), today's observed fuel cell bus fleet hydrogen prices with dedicated refueling stations (Eudy 2019), and HFTO cost targets (Ramsden and Joseck 2018). Table 4 summarizes the sources uses in this analysis. The Ultimate time frame was associated with the commercial year 2050, and because vehicles may require fuel prices beyond 2050 (the last year in the AEO forecast), the AEO price trends were extrapolated linearly based on the previous 5 years of data. Plots of the prices used in this analysis are provided in Appendix E for convenience.

Table 4. Ranges for Fuel Costs Considered

\begin{tabular}{lccc}
\hline Fuel & Low & Mid & High \\
\hline Diesel & AEO Low Oil & AEO Reference & AEO High Oil \\
Electricity & Muratori & AEO Reference & EPRI reported \\
& $2019(\$ 0.07 / \mathrm{kWh})$ & - Transportation & DCFC prices \\
Hydrogen & HFTO Target & HFTO Interim & Fuel Cell Electric Bus \\
& Cost $(\$ 4 / \mathrm{kg})$ & Target $(\$ 7 / \mathrm{kg})$ & evaluations $(\$ 10 / \mathrm{kg})$ \\
\hline
\end{tabular}

Natural gas costs are anchored to diesel prices and adjusted by the reported CNG/diesel price spread based on Alternative Fuels Data Center data from 2016-2020 (Smith 2021). Electricity prices for M/HDTs are highly uncertain given the local rate structure and high power requirements that may be needed for direct current fast chargers (DCFCs) or extreme fast chargers. In the light-duty vehicle sector, electric charging infrastructure shows a high variability in rate structures where customers may be charged per kilowatt-hour, per hour, per session, or not at all (Alternative Fuels Data Center 2018). Additionally, depending on the charger type (e.g., Level 1, Level 2, DCFC), the costs can vary substantially. Muratori, Kontou, and Eichman (2019) show that DCFC costs for depot-like scenarios $(400 \mathrm{~kW})$ could be $\$ 0.078-\$ 2 / \mathrm{kWh}$, and Borlaug et al. (2020) show that the levelized cost of charging could be between $\$ 0.08 / \mathrm{kWh}$ and $\$ 0.27 / \mathrm{kWh}$, though they only evaluate light-duty vehicle stations up to $150 \mathrm{~kW}$. For this analysis, the low electricity price is based on these analyses, along with the stated Tesla price $(\$ 0.07 / \mathrm{kWh})$ for its Class 8 short-haul truck (Tesla 2021). The mid electricity prices by U.S. Census division are based on the 2021 AEO Reference scenario for transportation, and the high electricity prices are based on DCFC rates currently observed for light-duty vehicles in each U.S. state (Dunckley and Valluri 2017), which are shown in Figure 4. As seen in Figure 4, nearly all the observed state average DCFC rates are greater than $\$ 0.30 / \mathrm{kWh}$.

To obtain electricity costs over time in the high scenario, the current DCFC prices were then extrapolated into the 


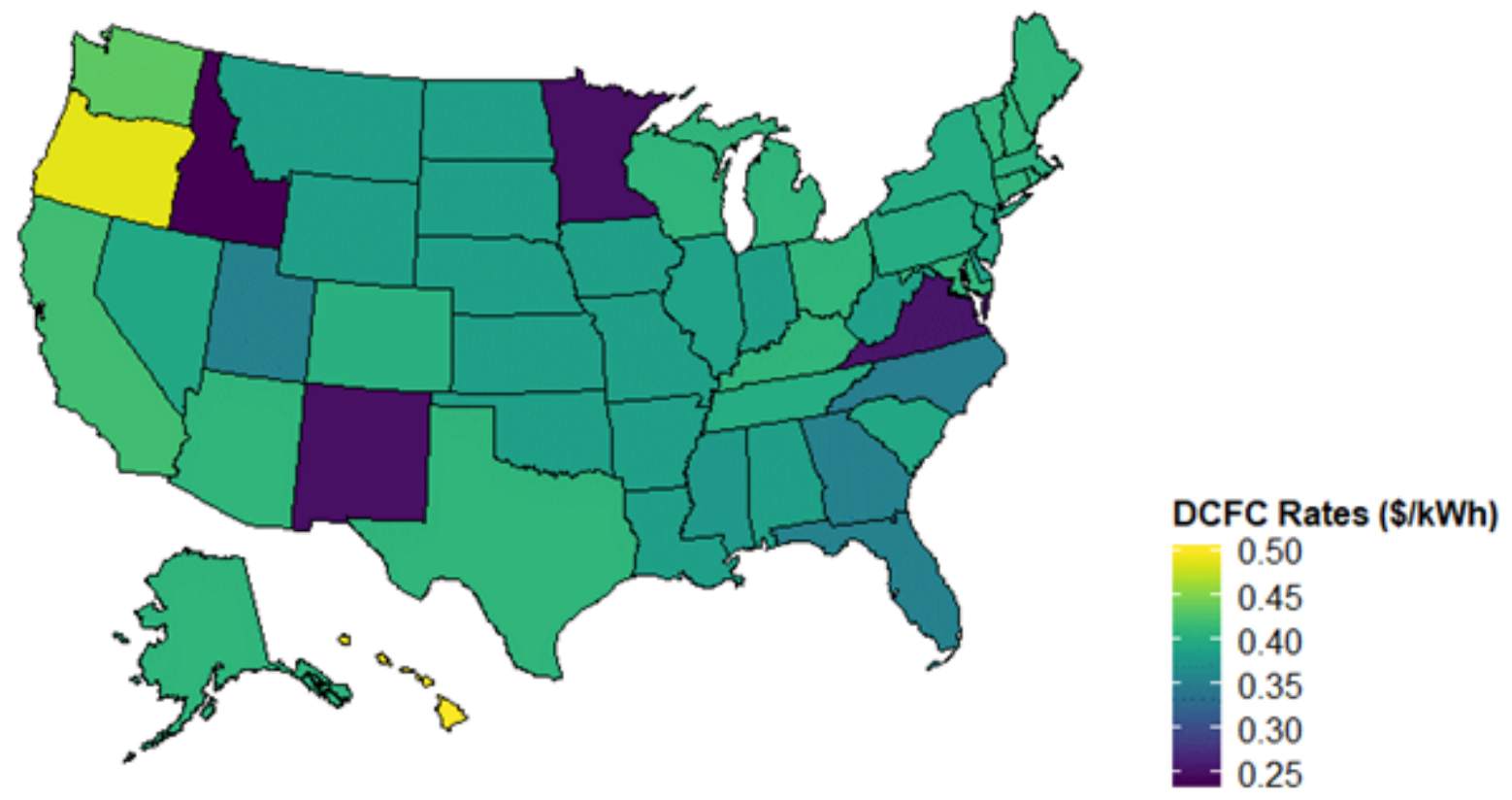

Figure 4. State average DCFC electricity rates reported by EPRI (Dunckley and Valluri 2017)

future based on the AEO Reference scenario trends over time. Because these DCFC prices may be based on low utilization and limited economies of scale, these values likely ${ }^{3}$ set an upper bound on the cost of electricity for this analysis. It should be noted that the high power requirements needed to charge large batteries in certain trucks (e.g., Class 8 tractors) may result in high demand charges (e.g., a 2-MWh battery charging in 1 hour requires 2-MW charging), but the DCFC prices used in this study may capture these charges and provide an approximate upper bound on the cost of electricity.

Because hydrogen prices are not forecasted in the AEO, hydrogen prices used in this analysis are based on both hydrogen prices observed in fuel cell bus evaluations in California and HFTO cost targets. The low and mid hydrogen prices are set as \$4 per gasoline gallon equivalent (gge) and \$7/gge, respectively, based on DOE's dispensed hydrogen cost targets. The high hydrogen price is set to $\$ 10 /$ gge based on hydrogen prices observed in Eudy (2019), which show a range of $\$ 5-\$ 14 / \mathrm{kg}$. Current hydrogen prices observed in light-duty vehicle markets were not selected to be used as the upper bound because those stations are often served by costly gaseous tube trailers with low utilization, whereas refueling stations supporting M/HDTs will require more cost-effective liquid tankers or on-site generation of hydrogen and may be designed to meet the specific needs of a fleet (private refueling) (CARB 2020).

Figure 5 summarizes the U.S. electricity prices (simple average across regions) and hydrogen prices assumed in this analysis. Other costs are taken directly from the 2021 AEO (U.S. Energy Information Administration 2021). For regional prices across all fuels, please refer to Appendix E. These fuel prices are all assumed to reflect the costs of the infrastructure needed to generate, transmit, and transfer the fuel or energy to the vehicle. Detailed infrastructure analysis around the placement, sizing, rollout strategy, cost, and renewable energy and grid integration optimization of widespread electric charging or hydrogen refueling stations is beyond the scope of this work but should be considered in future work.

\subsubsection{Operating and Maintenance Costs}

O\&M costs in this report refer to those operational, maintenance, and repair costs not accounted for in the other categories in this analysis. O\&M costs occur throughout the life of the vehicle and can be significant. These include fluid

\footnotetext{
${ }^{3}$ Incentives or subsidies for DCFCs may be reflected in these rates so the true levelized cost of charging may be higher if that is the case.
} 

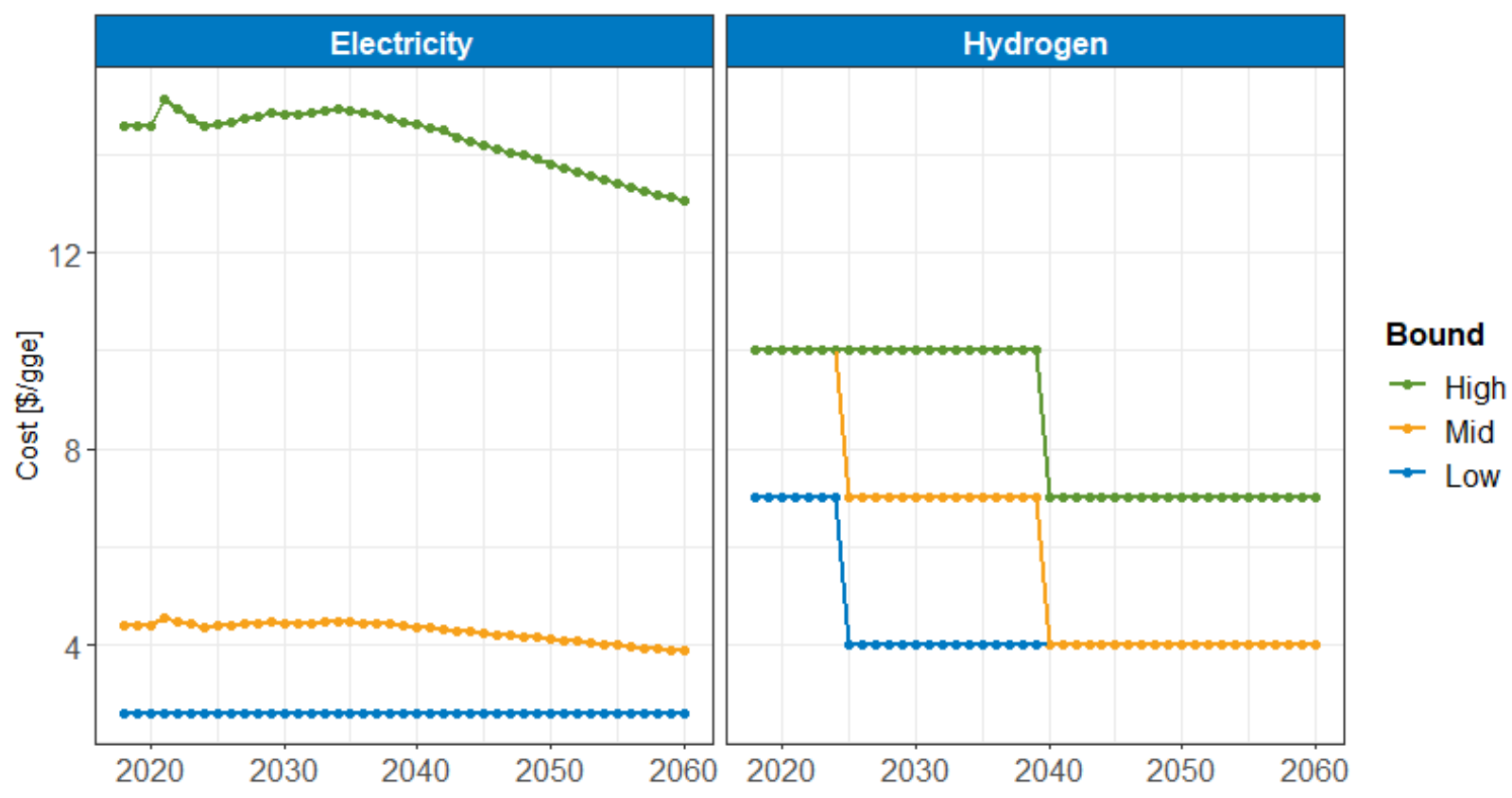

Figure 5. Low, mid, and high U.S. average electricity and hydrogen prices

replacements, engine maintenance, aftertreatment system maintenance, and other general maintenance items. An extensive literature survey was completed to assess the available O\&M data across different vehicle types, vocations, and powertrains. Figure 6 summarizes the data found for each vehicle class, vocation, and powertrain type. As seen in Figure 6, there are limited data for fuel cell and battery electric powertrains. The specific O\&M costs compiled from each reference are included in Appendix $G$ for easy reference.

Data on Class 8 diesel tractors show a small spread, typically in the $\$ 0.12-\$ 0.19 /$ mile range (Hooper and Dan 2017; Stella 2015; Financial 2014; Josephs 2015; Barradas 2012a; OOIDA 2015; MNDOT 2003; Ernst and Young 2003; ATRI 2020). Although there are limited data, Class 8 CNG tractors have demonstrated O\&M costs around $\$ 0.10 /$ mile (Josephs 2015). Currently, there are no available data on Class 8 tractors with fuel cell or electric powertrains.

Costs for Class 4-6 delivery trucks are based on the California Air Resources Board technology assessment (CARB 2015); a survey by Automotive Fleet, which compiled the O\&M costs for 35,000 medium-duty trucks in 2004 (Automotive Fleet 2006); data on gasoline hybrid electric delivery trucks (Barnitt 2011; Lee, Thomas, and Brown 2013; Lammert 2009); and one study on battery and fuel cell electric trucks (Kleiner et al. 2015). As with Class 8 tractors, there is a very limited set of data for fuel cell and electric Class 4-6 delivery trucks due to limited demonstration of these vehicles in the market.

Class 6 bus powertrain types—including diesel, diesel hybrid, CNG, electric, and hydrogen fuel cell—are in operation and have been studied more extensively than the other classes and vocations. The Class 6 bus O\&M cost data are based on numerous studies (CARB 2016; HART 2017; ACPS 2015; Eudy and Post 2020; National Center for Transit Research 2011; Lajunen and Lipman 2016; Hua et al. 2014; Transportation Research Board 2018) and demonstrate costs in the approximate ranges of $\$ 0.10-\$ 1.30 / \mathrm{mile}$ for diesel, $\$ 0.30-\$ 0.80 / \mathrm{mile}$ for compressed natural gas, $\$ 0.75-\$ 1.45 / \mathrm{mile}$ for hybrid electric, $\$ 0.25-\$ 0.40 / \mathrm{mile}$ for electric, and $\$ 0.55-\$ 1.00 / \mathrm{mile}$ for fuel cell powertrains.

It was assumed that each powertrain would be guaranteed by the manufacturer to last the required total vehicle miles traveled (VMT) and that no battery or fuel cell stack replacement costs would be incurred by the owner/operator beyond the assumed O\&M cost (Tesla 2021). 


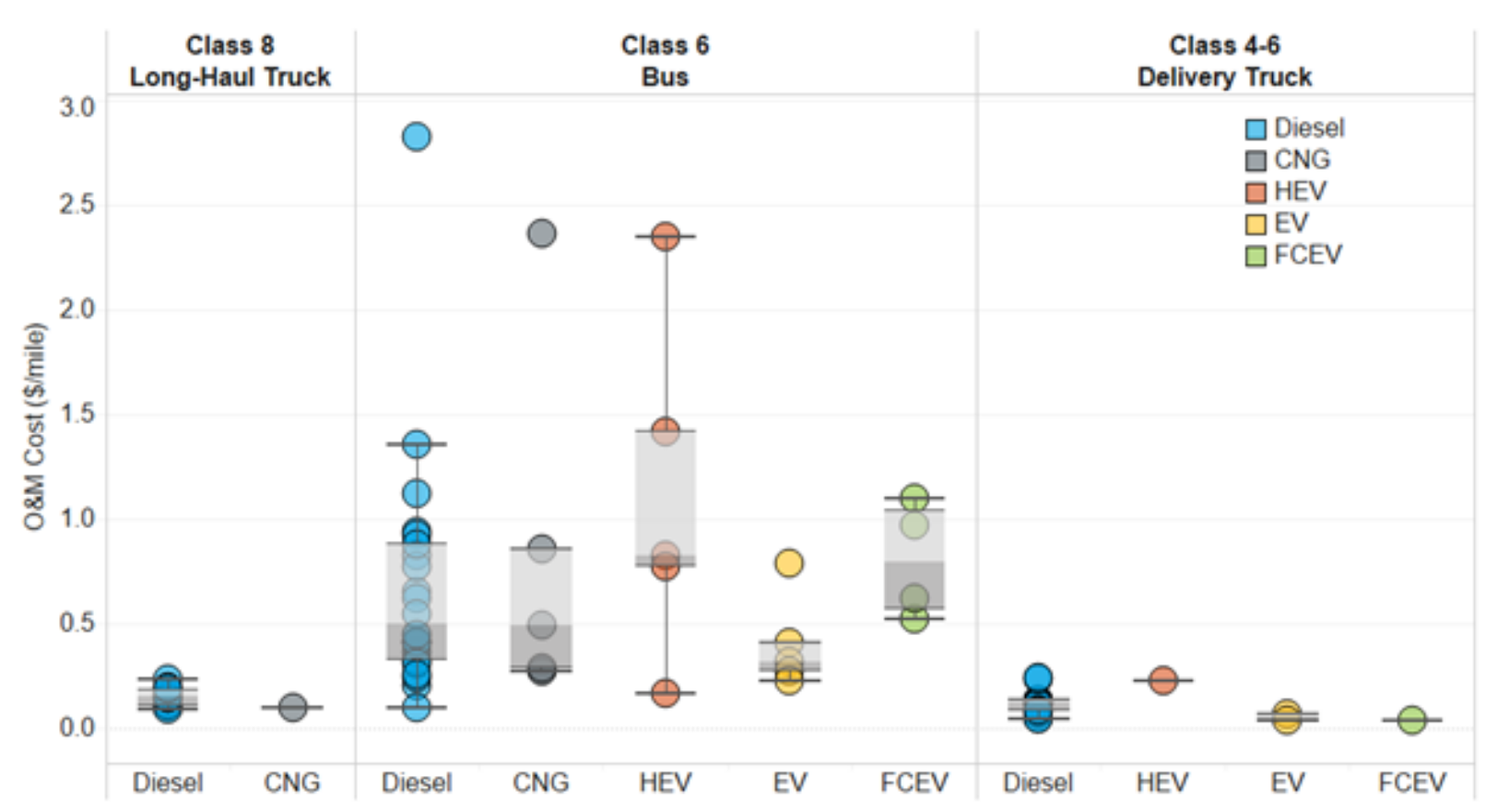

Figure 6. Summary of literature sources of O\&M costs by vehicle class, vocation, and powertrain

Because Class 6 buses provide the largest amount of data for powertrains that are not the conventional diesel type, these values were used as a reference by which to scale the Class 8 diesel tractor and Class 4 diesel delivery trucks. Ranges of O\&M costs were based on each powertrain's first quartile, median, and third quartile value compared to the median diesel bus value. This factor was then applied to the Class 8 diesel tractor O\&M costs and Class 4 delivery truck costs to obtain a full set of $O \& M$ costs by powertrain.

Class 6 bus cost data on fuel cell powertrain maintenance indicate that most of the current O\&M cost is based on labor and over half of the current cost is unplanned (Eudy and Post 2019; Eudy and Jeffers 2019), indicating that the O\&M costs are likely to come down over time as labor skills and techniques improve and as technology matures. Because fuel cell vehicle electric powertrains are mechanically simpler than diesel powertrains, lower O\&M costs are expected relative to conventional vehicles (Total Transportation Services, Inc 2018). Thus, the mid estimate for fuel cell powertrains is set to that of diesel, whereas the low estimate is set lower than diesel and equivalent to that of battery electric vehicles. Although the fuel cell electric powertrain is more complex than a battery electric powertrain, the fuel cell bus evaluations demonstrate this is a feasible lower bound (Eudy and Post 2020).

There are limited data for hybrid-electric diesel powertrains and no data for plug-in hybrid diesel powertrains, as shown in Figure 6. Based solely on the limited data shown in Figure 6, the HEV powertrain may appear to have higher O\&M costs. However, the one study that evaluated both together showed very similar O\&M costs between diesel and HEVs (Barnitt 2011). Because the HEV powertrain is mechanically equivalent in complexity and design to the conventional diesel, the O\&M costs of diesel are used for HEVs. PHEV powertrains are also assumed to have O\&M costs equal to those of diesel, and further research should be done to demonstrate and quantify the O\&M costs of these powertrains in various M/HDT applications.

The O\&M costs used in this analysis are summarized in Table 5 and are aligned with and bracket those in other works (Lustbader et al. 2021; ATRI 2020; Phadke et al. 2021). It should be noted that O\&M costs are not assumed to decline over time; rather, the lower bound for each vocation captures potential cost reductions with improvements in technology and labor practices. 
Table 5. Low, Mid, and High O\&M Costs (\$/mile)

\begin{tabular}{lccccc}
\hline \multirow{3}{*}{ Vehicle } & Bound & Diesel, & & & \\
Class 4 parcel delivery & Low & 0.057 & 0.049 & 0.046 & 0.046 \\
& Mid & 0.118 & 0.117 & 0.076 & 0.118 \\
& High & 0.233 & 0.231 & 0.111 & 0.270 \\
\hline \multirow{3}{*}{ Class 8 tractor } & Low & 0.075 & 0.064 & 0.060 & 0.060 \\
& Mid & 0.152 & 0.151 & 0.098 & 0.153 \\
& High & 0.301 & 0.298 & 0.143 & 0.349 \\
\hline
\end{tabular}

\subsubsection{Payload: Capacity Costs}

Truck classes are based on the maximum loaded GVWR, which encompasses the truck weight plus any cargo (payload) on it. M/HDTs provide value to the owner/operators and carrier fleets by being capable of transporting products from an origin to a destination. Thus, if the truck weight increases, the allowable payload for that truck decreases, representing a potential loss to the owner/operator/carrier that should be factored into the TCO analysis if the truck operates in a weight-limited regime (i.e., it does cube-out before weighing-out). However, the Fixing America's Surface Transportation Act signed in 2015 allows CNG powertrains to have a gross vehicle weight up to 82,000 lbs (U.S. Department of Transportation 2015), and California's Assembly Bill No. 2061 extends that to zero-emissions vehicles (ZEVs) (California Legislative Information 2018). Thus, for this analysis, alternative powertrain trucks are assumed to have no lost payload capacity cost associated with a heavier powertrain up to the 2,000-lb difference between diesel powertrains and the alternative powertrain. If the alternative powertrain is more than 2,000 lbs heavier than the diesel counterpart, then a payload capacity loss cost could be incurred (depending on the operating scenario evaluated).

Lost payload capacity costs from heavier alternative powertrains can be quantified in four ways_-"Buy," "Rent," "Outsource," and "Nothing"- as summarized in Figure 7. First, the fleet owner could buy additional alternative powertrain trucks to move the cargo that is displaced by the heavier powertrain. This could be the lowest-cost option, but would depend on the utilization of the additional truck the fleet purchases (e.g., low utilization of the truck would make the levelized cost of moving that displaced cargo very expensive). Second, the "Rent" option would be to quantify the cost of lost payload capacity as if the fleet would rent a similar tuck to move the displaced cargo. In principle, this would be a slightly more costly route on a marginal basis but would be useful if the fleet does not want to invest the capital in a new truck. The third option would be to "Outsource" the movement of the cargo by buying contracts in the less-than-truckload (LTL) or truckload markets. This option will likely be more expensive than the first two options, as LTL rates for part loads are much higher than if full loads can be achieved. Finally, the fourth option would be for the fleet to do "Nothing" and potentially not meet the needs of their customers or forgo business opportunities, which we assume is not a feasible option.

The "Buy" option is used in this analysis to quantify the potential impact of cannibalizing cargo capacity with a heavier powertrain. We assume that additional payload capacity cost is equivalent to the levelized cost of a fully loaded truck with the same advanced powertrain (e.g., any cargo weight lost from a battery electric powertrain would be carried by another truck with a battery electric powertrain). For an actual fleet, adding a new truck may be more expensive than this as we assume the truck cargo weight is fully utilized.

The "Rent" option was not used in this analysis as rates for renting trucks are based on prices in the market today and do not reflect advanced powertrains. A brief survey of rent prices (Penske 2021) was completed to obtain the order of magnitude cost shown in Figure 7. These costs would likely be similar to but marginally more expensive than those of the "Buy" option, as the rent price would include overhead and profit of the renting agency.

The "Outsource" option can be thought of as the carrier rate that the fleet owner would have had to pay an LTL truck to move the cargo. The LTL carrier rate is primarily based on three components: the freight class, origin/destination pair, and weight break used for the LTL pricing. First, the National Motor Freight Classification system classifies products into 18 different freight classes based on a combination of density, value, handling, and other transporta- 


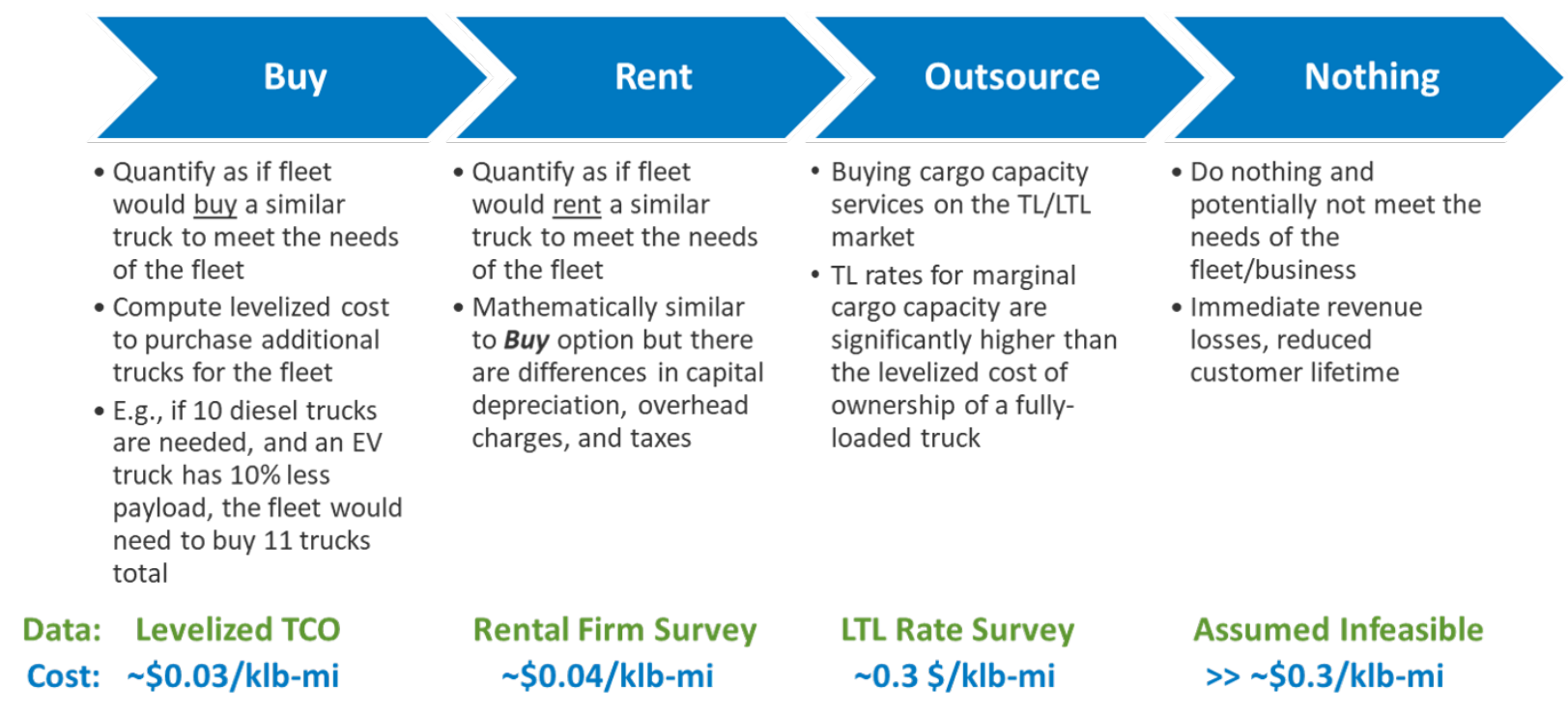

Figure 7. Summary of ways to quantify the cost of lost payload capacity in Class 8 tractors due to heavier powertrains (TL = truckload, LTL = less-than-truckload)

bility metrics. After the freight class has been defined for the product, the origin/destination pair must be known as different rates exist for different origins/destinations. Once the freight class and origin/destination pair are known, the last component is to determine the appropriate weight break for the LTL shipment. Typically, nine weight breaks are used based on the weight of the LTL shipment. As the size of the shipment increases, the cost per $100 \mathrm{lb}$ (century weight) decreases. Because the carrier rate is dependent on product types, origin/destination pairs, and LTL weight breaks, no single number will represent all shipment opportunity costs. A brief survey of LTL rates (Robinson, C.H. 2021) was completed to obtain an order of magnitude estimated cost for the "Outsource" option and the results are summarized in Figure 7, indicating this option is an order of magnitude more expensive than the "Buy" or "Rent" options as the incremental shipments would be relatively small on the LTL market (a few thousand pounds).

In summary, we approximate carrier cost by estimating a levelized cost of "buying" an additional, equivalent truck to transport the cargo that could have been transported if the alternative powertrain had not reduced the cargo capacity. We assume a 2,000-lb allowance for advanced powertrain trucks per National Motor Freight Traffic Association (2018). In the present study, this levelized cost is calculated for each powertrain option, model year, and region (because fuel prices will vary across regions). Payload costs can be expected to decrease over time as advanced powertrain weight decreases. Table 6 gives the payload cost ranges for Class 8 long-haul (500-mile-range) tractor for each powertrain technology. Class 8 short-haul (300-mile range) and a Class 8 long-haul with 750-mile-range payload capacity costs can be found in Appendix F. Negative values in Table 6 indicate the alternative powertrain can be lighter than the diesel powertrain, potentially allowing it to haul more cargo. However, for this analysis, no credit was given to lighter powertrains.

Because not all trucks may weigh-out, we evaluate a low/mid/high potential lost payload capacity cost. The low cost is set to zero, which reflects trucks that cube-out before weighing-out. The mid and high payload capacity costs are based on the mid and high levelized costs of truck operation (e.g., high payload capacity costs would be based on the upper bound in levelized TCO based on high fuel prices). These bounds are summarized in Table 6 and were applied to Class 8 tractors, as Class 4 delivery trucks were assumed to simply move into the Class 5 categorization if the truck's weight exceeded 16,000 lbs.

There are limited recent data available on the frequency of a truck being volume-limited or weight-limited (USCB2004; U.S. Census Bureau 2002; Shoettle, Sivak, and Tunnell 2016), and it is dependent on the mix of goods shipped. An informative visualization is to plot the density at which the truck load will become weight-limited against allowable 
Table 6. Payload Cost Range for Class 8 Long-Haul (500-Mile-Range) Truck

\begin{tabular}{llcccc}
\hline $\begin{array}{l}\text { Model } \\
\text { Year }\end{array}$ & Bound & $\begin{array}{c}\text { HEV } \\
(\$ / \mathrm{mi})\end{array}$ & $\begin{array}{c}\mathrm{CNG} \\
(\$ / \mathrm{mi})\end{array}$ & $\begin{array}{c}\text { BEV } \\
(\$ / \mathrm{mi})\end{array}$ & $\begin{array}{c}\text { FCEV } \\
(\$ / \mathrm{mi})\end{array}$ \\
\hline \multirow{3}{*}{2018} & Low & 0 & 0 & 0 & 0 \\
& Mid & $-0.002^{\mathrm{a}}$ & 0 & 0.247 to $-0.255^{\mathrm{a}}$ & 0 \\
& High & $-0.001^{\mathrm{a}}$ & 0 & 0.081 to $-0.09^{\mathrm{a}}$ & 0 \\
\hline \multirow{3}{*}{2025} & Low & 0 & 0 & 0 & 0 \\
& Mid & $-0.002^{\mathrm{a}}$ & 0 & 0.079 to $-0.081^{\mathrm{a}}$ & 0 \\
& High & $-0.001^{\mathrm{a}}$ & 0 & 0.037 to $-0.031^{\mathrm{a}}$ & 0 \\
\hline \multirow{3}{*}{ Ultimate } & Low & 0 & 0 & 0 & 0 \\
& Mid & $-0.002^{\mathrm{a}}$ & 0 & 0.001 to $-0.002^{\mathrm{a}}$ & -0.003 to $-0.002^{\mathrm{a}}$ \\
& High & $-0.001^{\mathrm{a}}$ & 0 & 0.001 & $-0.002^{\mathrm{a}}$ \\
\hline
\end{tabular}

a: Negative values indicate lighter powertrains but no credit was applied in the TCO analysis

cargo weight. This was completed and shown in Figure 8 for a standard $53-\mathrm{ft}$ trailer $\left(3,816 \mathrm{ft}^{3}\right.$ of space) representing a typical Class 8 truck trailer. Additionally, the standard freight class data were mapped onto this plot to indicate which types of materials may be weight-limited. As seen in Figure 8, a significant number of product types may be shipped in weight-limited trucks, indicating that the payload capacity cost could be substantial.

The VIUS data set (U.S. Census Bureau 2002) contains data on the average weight at which a truck/trailer combination typically operated during the year. Although old, this is one of the most comprehensive, nationally representative data sets that exists. The total truck count and fraction of total VMT for all M/HDTs are plotted against the typical truck/trailer average weight data in Figure 9. These data show that a significant number of truck/trailer and VMT combinations are pushing the limits of the Class 8 GVWR, and that payload could be either a significant cost if a powertrain is heavier than conventional technology or a significant value stream if it the powertrain is lighter than conventional technology.

\subsubsection{Dwell Time: Refueling/Recharging}

Dwell time refers to any on-duty time that the M/HDT and driver are not in transit moving the products. This includes time loading and unloading equipment, as well as time spent refueling, which is currently considered on-duty time (Federal Motor Carrier Safety Administration 2015). M/HDTs that have fast refueling times have the advantage of reducing both forced downtime that uses up hours of service (Federal Motor Carrier Safety Administration 2017 ) and overall shipment time. Carriers (trucking service firms) typically have detention rates of $\$ 50-\$ 100 / \mathrm{h}$ for dwell time costs imposed on them, which accounts for unproductive driver labor hours (approximately $\$ 30-\$ 40 / \mathrm{h}$ ) (ATRI 2020) and other indirect logistics costs associated with waiting (Federal Motor Carrier Safety Administration 2018; Load Delivered 2017; OOIDA 2011; Truck Drivers Salary 2017; Transport Topics 2021). For this analysis, a $\$ 75 / \mathrm{h}$ cost was assumed for dwell time associated with refueling/recharging of vehicles. The cost of vehicle dwelling during loading/unloading was not included, as this cost is assumed to be the same across powertrains.

To model dwell time for each vehicle, three typical industry scenarios were constructed: a "Low" bound for which refueling/recharging occurs overnight and has no impact on cost of ownership, a "Mid" scenario with ideal refueling/recharging rates or times, and a "High" bound with unideal refueling/recharging rates or times. These scenarios attempt to encompass the bounds of typical M/HDT operation and are summarized in Table 7 along with the refueling/recharging rate assumed for each powertrain.

The CNG refueling rates are based on estimates from DOE's Alternative Fuels Data Center (Alternative Fuels Data Center 2021). The FCEV hydrogen fill rates are based on the DOE target of filling a 60-kg hydrogen tank in 6 minutes (Marcinkoski et al. 2019). The BEV charge rate of $1 \mathrm{MW}$ is based on technology currently being explored by DOE and the national labs (Meintz 2020).

Because CNG and hydrogen tank filling rates are nonlinear due to the compressibility of the gas, smaller tanks cannot be filled with the same average rate as larger tanks. Thus, a lower dwell time bound of 5-10 minutes is es- 


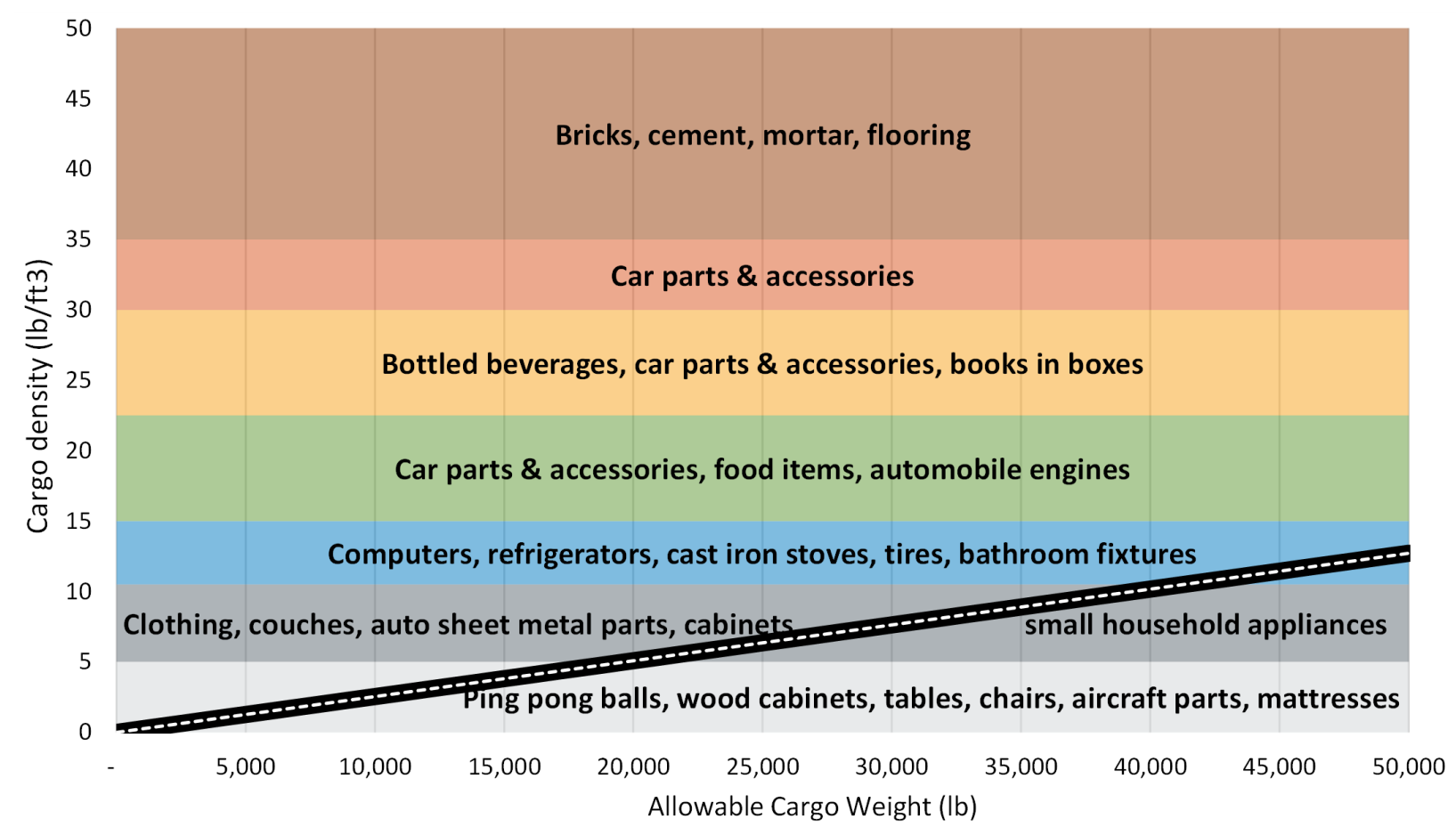

Figure 8. Cargo density versus allowable cargo weight and the threshold density at which the truck load becomes weight-limited (above the line) rather than volume-limited (below the line). Example cargo types that typically fall into each freight class are provided (Logistics 2021).

Table 7. Low, Mid, and High Refueling Rates by Powertrain

\begin{tabular}{|c|c|c|c|c|}
\hline Bound & $\begin{array}{c}\mathrm{CNG} \\
\text { (gge/min) }\end{array}$ & $\begin{array}{c}\text { FCEV } \\
(\mathrm{kg} / \mathrm{min})\end{array}$ & $\begin{array}{l}\mathrm{BEV} \\
(\mathrm{kW})\end{array}$ & Industry Scenario \\
\hline Low & - & - & - & Day trip with refueling/recharging overnight \\
\hline Mid & 8 & 10 & 1,000 & $\begin{array}{l}\text { Continuous (team) driving, refueling/recharging } \\
\text { as needed. Ideal refueling/recharging time }\end{array}$ \\
\hline High & 4 & 5 & 500 & $\begin{array}{l}\text { Continuous (team) driving, refueling/recharging } \\
\text { as needed. Unideal refueling/recharging time. }\end{array}$ \\
\hline
\end{tabular}

tablished for all nonelectric powertrains. For BEV architectures, an upper bound on C-rate of 2 is applied, corresponding to an ideal minimum charge time of 30 minutes. PHEVs are not subjected to this limit because they have a diesel powertrain and fuel tank that can be filled quickly. However, the PHEV sizing in this analysis may not accommodate all potential duty cycle requirements (e.g., hilly terrain) after the battery is depleted, as the diesel engine is downsized relative to the full diesel powertrain (see Section 2.2 for more details). PHEV powertrain optimization for duty cycle requirements or TCO is outside the scope of this work but should be investigated in further work. Table 8 summarizes the lower limits on refueling/recharging times for each bound and powertrain.

These dwell times were converted to costs based on the number of refueling/recharging events the M/HDT would undergo each year based on the VMT and the range of the truck. Mathematically, this is expressed as:

$$
\text { Dwell Time Cost }[\$ / \mathrm{yr}]=\left(\frac{\mathrm{VMT}[\mathrm{mi} / \mathrm{yr}]}{\text { Range }[\mathrm{mi}]}\right)\left(\frac{\text { Fuel Tank Size }[\mathrm{kWh}]}{\text { Fill Rate }[\mathrm{kWh} / \mathrm{h}]}\right) \text { Dwell Rate }[\$ / \mathrm{h}]
$$

where VMT is the miles driven per year, Range is the vehicle range (miles/refueling), and Dwell Rate is set at $\$ 75 / \mathrm{h}$. 

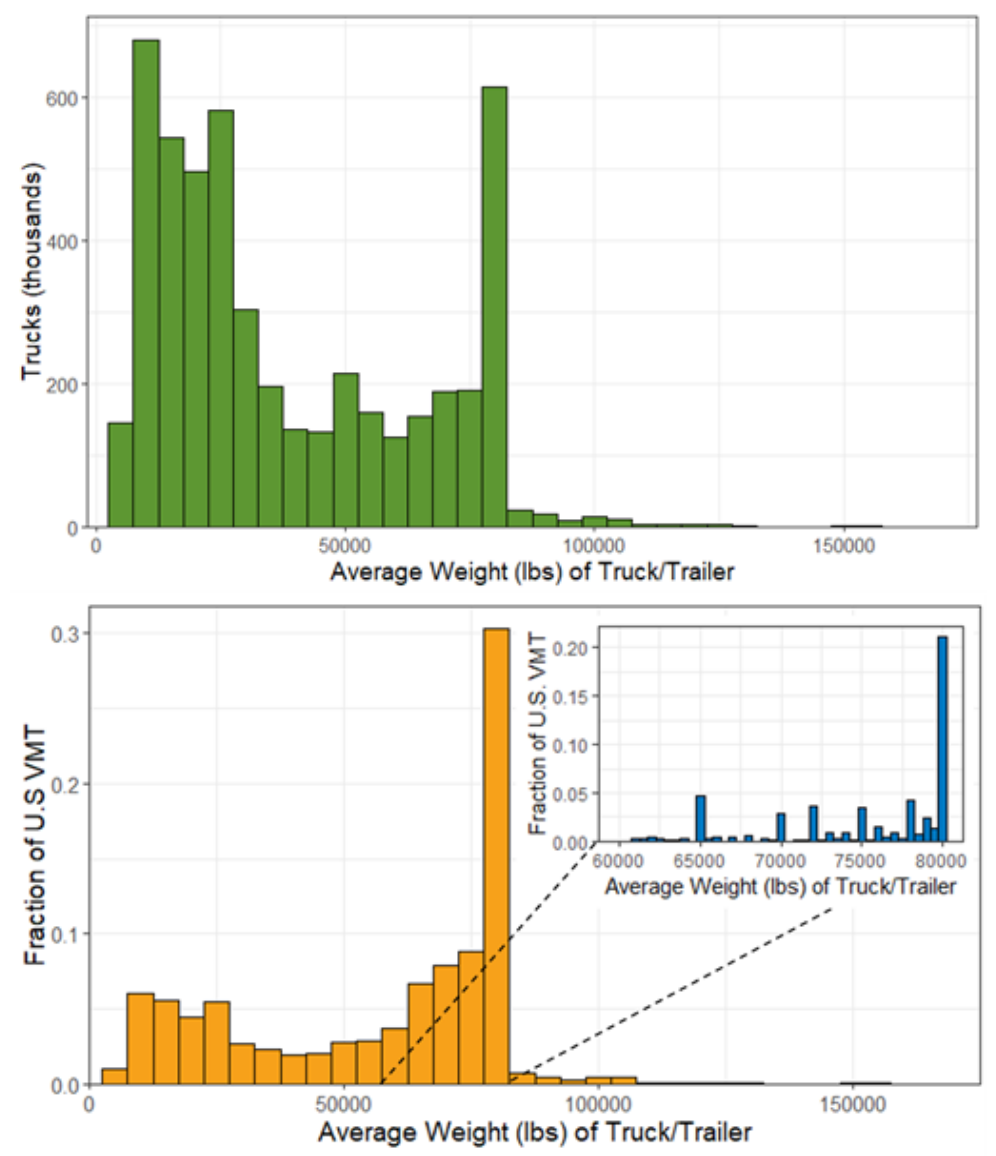

Figure 9. VIUS data on average weight of a truck/trailer by (top) count and (bottom) VMT fraction when they are operated with a typical payload over the year

Table 8. Lower Limit on Refueling/Recharging Times

\begin{tabular}{lcc}
\hline Bound & $\begin{array}{c}\text { Diesel, HEV, PHEV, CNG, FCEV } \\
(\mathrm{min})\end{array}$ & $\begin{array}{c}\text { BEV } \\
(\mathrm{min})\end{array}$ \\
\hline Low & - & - \\
Mid & 5 & 30 \\
High & 10 & 60 \\
\hline
\end{tabular}

These costs occur over the life of the vehicle and must be discounted back to determine their present value. All dwell times are computed relative to diesel dwell times because the $\$ 75 /$ hour value incorporates drive wages. Diesel dwell times assume diesel fuel rates of 15 gallons per minute through a diesel nozzle, resulting in fuel times of 5-10 minutes.

\subsubsection{Resale and Salvage Value}

At the end of the vehicle lifetime, the truck must either be sold or disposed of. Due to the unknown resale values or disposal costs for $\mathrm{CNG}$, battery electric, and fuel cell electric truck types, the salvage cost was not included in this analysis. This could readily be added to the TCO framework in future work if data became available. For this analysis, the TCO assumes the vehicle will be held by the owner through the entire lifetime and that the same value/cost will be incurred at the end of the lifetime for all powertrains. This allows each powertrain to be compared against others in a more straightforward manner. It should be noted that this does not reflect how Class 8 tractors 
are owned today: A typical first life is approximately $2-5$ years before being sold in a secondary market. However, because the price cost to purchase the truck by the second owner equals the cash flow to the first owner, this should not impact the truck TCO.

\subsubsection{Other Costs: Taxes, Incentives, and Environmental Impacts}

The present analysis assumes costs associated with general operation costs (driver wages and benefits, insurance, permits, tolls) are the same across powertrains and are approximately $\$ 0.75-\$ 0.95 /$ mile (ATRI 2020). The assumption used in this analysis was $\$ 0.95 /$ mile, consistent with the 2018 values reported in ATRI (2020). Federal, state, and local tax impacts specific to each powertrain technology were not included because they are highly speculative at this time, so a flat tax of $5 \%$ was assumed for all vehicle purchases. Similarly, financial incentives for adopting advanced powertrain and ZEV technology were not included in this analysis but could be added in future studies or when evaluating specific markets (e.g., Low Carbon Fuel Standard in California). Lastly, environmental costs/benefits such as air quality or the social cost of carbon were not included in this analysis, but they could be readily quantified in future work.

\subsection{Total Cost of Ownership Using the T3CO Model}

NREL's Transportation Technology Total Cost of Ownership (T3CO) model integrates NREL's FASTSim and Scenario Evaluation and Regionalization Analysis (SERA) model into an end-to-end vehicle TCO modeling framework as described in Lustbader et al. (2021). T3CO leverages the SERA model's detailed vehicle stock module that tracks vehicle populations, travel mileage, energy consumption, and vehicle-associated expenses both spatially and temporally (Bush et al. 2021; Bush et al. 2019; Melaina et al. 2017). The SERA model has been applied to light-duty vehicles (Melaina et al. 2017) and was updated and integrated into T3CO for this M/HDT analysis. T3CO can model regionally explicit TCO analysis for individual vehicles and track ownership costs across entire fleets. For this analysis, the TCO metric is based on individual vehicles (Section 2.1), but a U.S. fleet analysis could be completed in future work. The following sections discuss general assumptions used in T3CO for the TCO analysis in this report, as well as the scenarios analyzed.

\subsubsection{General Total Cost of Ownership Modeling Assumptions}

TCO modeling requires a number of assumptions about vehicle attributes, travel, lifetime, fuel prices, and other factors, all of which can have large impacts on the results. For this analysis, TCO is based on the full vehicle lifetime, rather than a specific ownership period (as described in Section 2.3.5). The vehicle lifetime is defined by the combination of annual VMT (mi/yr) and the engine (or alternative powertrain) design mileage. We assume a Class 8 tractor engine will be designed for 1 million miles and a Class 4 truck engine will be designed for 300,000 miles before a major overhaul is needed. The VMT assumptions for the truck vary by scenario and are discussed in Section 2.4.2. The TCO is then computed for each powertrain, year (2018, 2025, Ultimate), U.S. Census region, and for two discount rates (3\% and 7\%). For this analysis, the future costs were discounted back to present value dollars and everything is represented in 2021 dollar values. In contrast to some levelized-cost-of-driving analyses, the future miles were not discounted at this same discount rate. This can be done to further emphasize the importance of miles traveled in the early years or to represent the value as if it is a revenue stream (i.e., charging the $\$ /$ mile rate) rather than a cost. The TCO modeling data flow in the T3CO model is summarized in Figure 10.

\subsubsection{Total Cost of Ownership Scenario Analysis}

To understand the truck TCO, all costs associated with the trucks need to be accounted for. Section 2.3 outlines the costs considered and computations used in this analysis. Four scenarios are evaluated to reflect different typical business operating scenarios: (1) Single-Shift, Volume-Limited operation, (2) Single-Shift, Weight-Limited operation, (3) Multi-Shift, Volume-Limited operation, and (4) Multi-Shift, Weight-Limited operation. These scenarios are defined according to how trucks may be operated by fleets. For example, in a single-shift, volume-limited operating scenario, the truck would only be utilized for one shift of operation and have ample time to refuel or recharge overnight. Additionally, it would cube-out before weighing-out, so a slightly heavier powertrain would not cannibalize cargo weight capacity. Conversely, a truck operating in a weight-limited, multi-shift operation would be moving very heavy cargo up to the total GVWR of $80,000 \mathrm{lbs}$. In this scenario, a heavier powertrain would cannibalize cargo 

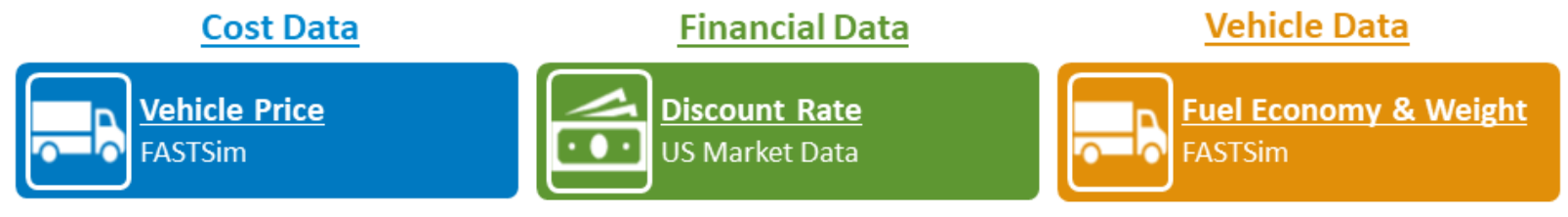
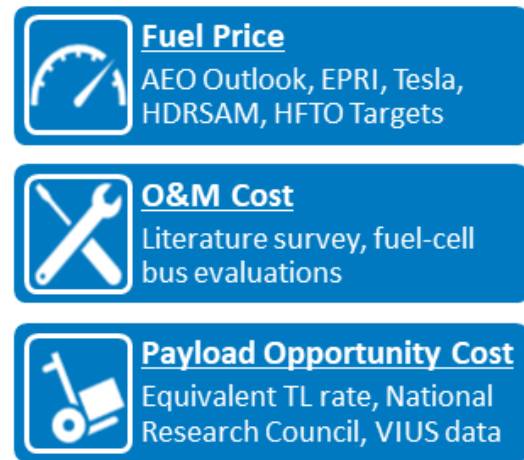

Payload Opportunity Cost Equivalent TL rate, National Research Council, VIUS data

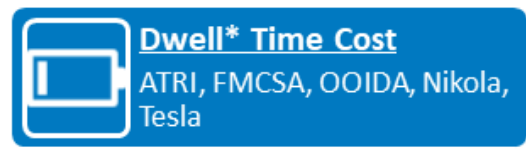

*Dwell time = down time for refueling/recharging
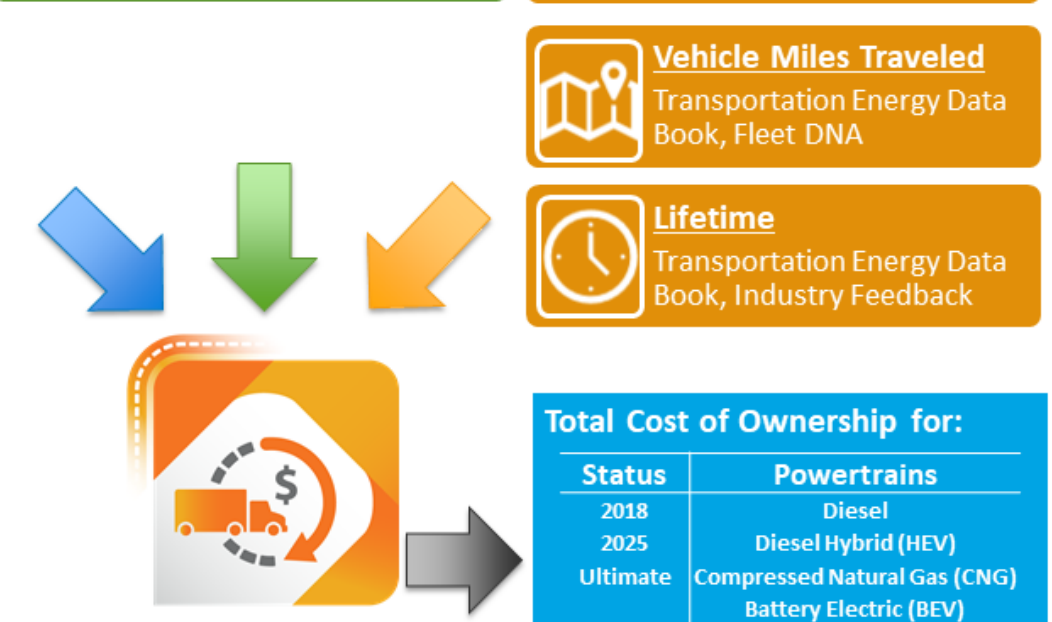

T3CO

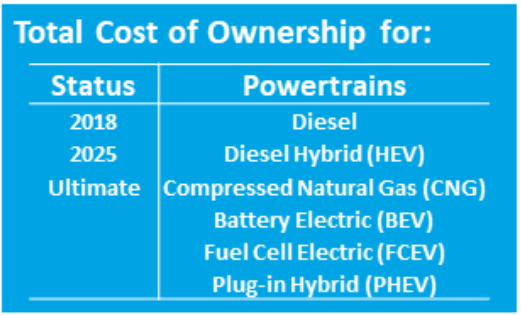

Figure 10. Summary of the T3CO M/HDT stock model data flow and output

weight capacity and have a cost associated with it. Similarly, if the truck has high daily utilization, downtime for refueling or recharging would have a cost associated with it. These scenarios are depicted in Figure 11, which outlines how dwell and payload costs are applied in each scenario. The other TCO cost components of fuel and O\&M are evaluated within each specific operating scenario.

For each scenario, the impact of R\&D progress on TCO is evaluated by estimating the TCO for the three time periods (2018, 2025, and Ultimate). For the purposes of fuel prices, the Ultimate scenario assumptions are assumed to occur in 2050 but are otherwise temporally agnostic.

We assume that the weight-limited scenario occurs for Class 8 tractors with total weight greater than or equal to 80,000 pounds, corresponding to the Class 8 GVWR weight limit. We assume multi-shift operation for Class 8 longhaul trucks with annual VMT greater than 200,000 miles, Class 8 short-haul trucks with annual VMT greater than 100,000 miles, and Class 4 parcel delivery vehicles with annual VMT greater than 50,000 miles. Table 9 gives the precise annual VMT and daily miles modeled for each vehicle considered in this study. Note that Class 8 tractors are modeled to have a lifetime VMT of 1 million miles and Class 4 trucks have a lifetime of 300,000 miles; as a result, total calendar lifetime (years) will be different between single-shift and multi-shift scenarios.

The four scenarios selected for this analysis were designed to help quantify the relative importance of different costs potentially associated with advanced powertrain commercial vehicles (e.g., lost payload capacity, downtime for refueling/recharging). Just as important as the quantification of the costs for a particular scenario is an assessment of the total number of trucks, miles, or fuel usage that may fall into each scenario. A literature review was completed to help answer this question. Based on a combination of VIUS data updated with Department of Motor Vehicle registration data (Lustbader et al. 2021; U.S. Census Bureau 2002; R.L. Polk and Co. 2013), Figure 12 shows the estimated proportion of fuel consumption accounted for tractors operating in volume- and weight-limited scenarios, as well as by single- and multi-shift scenarios. This demonstrates that $33 \%$ of Class 8 fuel consumption may be used by tractors that weigh-out. A recent study by the North American Council for Freight Efficiency (Halonen, Swim, and Roeth 2015) estimates the weight-limited proportion of Class 8 tractors at 2\%-10\%, whereas a survey by Shoettle, Sivak, and Tunnell 2016 estimates this fraction at 55\%. The National Research Council (Transportation 


\section{Operating Shift}

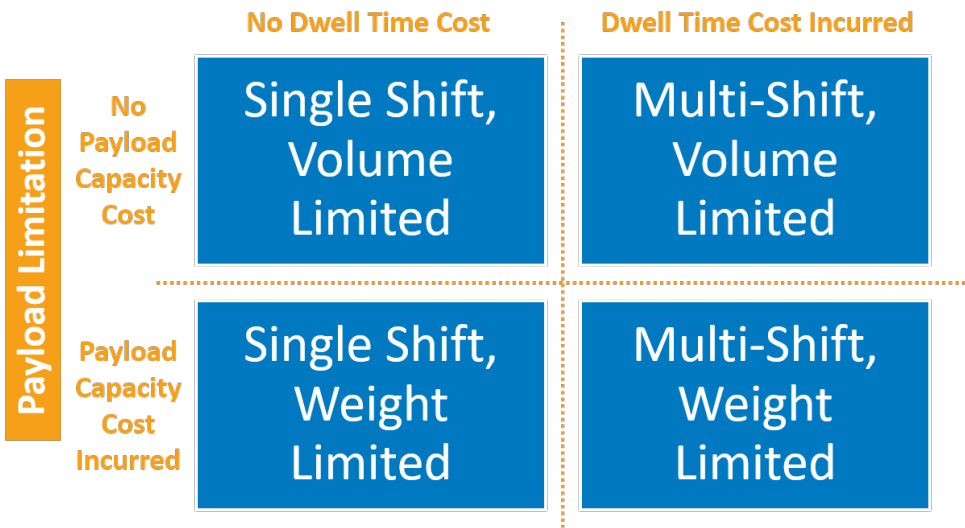

Figure 11. Summary of TCO scenarios evaluated

Table 9. Annual and Daily VMT for Each Vehicle Analyzed

\begin{tabular}{llcc}
\hline & & Single-shift & Multi-shift \\
\hline Class 8 long-haul & Annual VMT & 150,000 & 200,000 \\
(750-mile range) & Daily VMT & 580 & 770 \\
Class 8 long-haul & Annual VMT & 100,000 & 150,000 \\
(500-mile range) & Daily VMT $^{\mathrm{a}}$ & 380 & 580 \\
Class 8 short-haul & Annual VMT & 60,000 & 100,000 \\
(300-mile range) & Daily VMT $^{\mathrm{a}}$ & 230 & 380 \\
Class 4 Parcel & Annual VMT $^{\mathrm{a}}$ & 250,000 & 50,000 \\
(120-mile range) & Daily VMT & 80 & 170 \\
\hline \multicolumn{2}{c}{ a: Based on 260 workdays (Class 8) or 300 workdays (Class 4) }
\end{tabular}

Research Board and National Research Council 2010) evaluated truck and payload characteristics focusing on five-axle Class 8 combination trucks and found that approximately $30 \%$ of total five-axle VMT is expected to be weight-limited (Lowell and Balon 2009). Although these sources differ in their quantification approach (trucks vs. fuel usage), they collectively indicate that a significant amount of Class 8 tractors may weigh-out, and it is important to quantify potential payload costs and prioritize $R \& D$ to help reduce such potential impacts.

\subsection{Vehicle Design and Volume Considerations}

This report focuses on TCO and does not directly evaluate the design aspects of these advanced powertrain vehicles. Design aspects including volumetric considerations are very important to M/HDT adoption. Fuel cell truck powertrains have been evaluated in detail and been shown to be feasible from a spatial design perspective (Kast et al. 2017a; Kast et al. 2017b; Gangloff et al. 2017).

Electric truck powertrain sizing is more straightforward to assess based on the average fuel economy, required vehicle range, and battery energy density. For example, a 500-mile-range electric Class 8 tractor with a fuel economy of 15 miles/gge requires a 1,120-kWh battery. At an energy density of $530 \mathrm{Wh} / \mathrm{L}$ (Verbrugge and Wampler 2018), the battery size would be $2.1 \mathrm{~m}^{3}$, which is within the feasible range of $0.3-5 \mathrm{~m}^{3}$ (Gangloff et al. 2017). However, for longer range requirements (e.g., 1,200 miles), the size of the battery may exceed available onboard volume unless the battery energy density improves to offset the increase in energy requirements. Detailed system design and location specification are outside the scope of this work but should be considered in future studies to understand the optimal battery size based on volume, weight, and consumer preference trade-offs. 


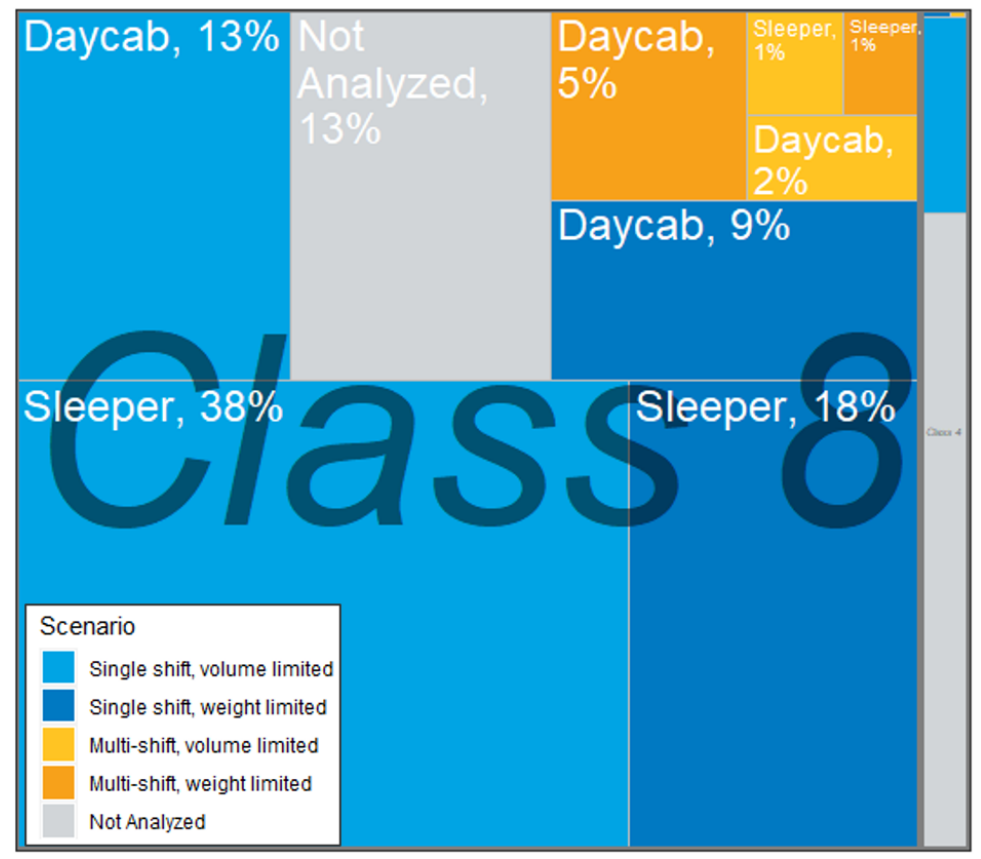

Figure 12. Estimation of percentage of Class 8 and Class 4 trucks associated with each scenario considered in this study based on VIUS data updated with Department of Motor Vehicle registration data (Lustbader et al. 2021; U.S. Census Bureau 2002; R.L. Polk and Co. 2013)

\subsection{Infrastructure Considerations}

Due to the battery electric and fuel cell electric powertrains being a nascent M/HDT industry, the current refueling/recharging infrastructure is insufficient to support widespread vehicle adoption by fleets. Clearly, without sufficient refueling and/or recharging infrastructure, fleets would not be able to operate. For this analysis, it is assumed that the cost of building and operating the required infrastructure to support M/HDT applications is encompassed in the fuel price charged to the M/HDT owner and/or operator. This would apply to both public and private refueling and/or recharging stations, as both will have costs amortized over the life of the equipment. Different equipment utilization will affect the amortized cost of the equipment, but that impact is captured by the various fuel prices studied in this analysis.

Incentives for refueling/recharging infrastructure were not directly included but may exist (e.g., Low Carbon Fuel Standard in California). Additionally, the potential convenience cost of a limited public refueling network and challenges associated with building a network were not evaluated directly in this analysis and could be studied in the future. In summary, detailed infrastructure analysis around the placement, sizing, rollout strategy, cost, and renewable energy and grid integration optimization of widespread electric charging or hydrogen refueling stations is beyond the scope of this work but should be considered in future work. 


\section{Results}

This section first outlines the vehicle modeling results for vehicle fuel economy, weight, and price. It then describes the TCO results.

\subsection{Vehicle Modeling}

Vehicle fuel economy, weight, and MSRP for each vehicle class, vocation, and powertrain were determined using FASTSim. In this analysis, components were sized to yield vehicle performance suitable for each vocation. Component masses were sized based on the following itemization of masses:

- Glider

- Electric motor and power electronics

- Battery

- Transmission

- Fuel converter (combustion engines, fuel cells)

- Fuel storage system

- Cargo.

Vehicle MSRP was also accounted for in FASTSim by applying technology scenario assumptions to individual powertrain components in the following categories:

- Glider

- Fuel converter (combustion engines, fuel cells)

- Fuel storage (liquid fuels, hydrogen)

- Plug cost (PHEV, BEV)

- Electric motor and power electronics

- Batteries.

Vehicle weights and costs were evaluated for Class 8 long-haul and short-haul tractors in addition to Class 4 delivery trucks.

\subsubsection{Vehicle Weight Breakdown: Class 8 Long-Haul and Short-Haul Trucks}

The powertrain weight was estimated in FASTSim based on the powertrain sizing methodology described in Section 2.2. Figure 13 shows the weight distribution of Class 8 long-haul trucks powered with a fuel cell. The hydrogen storage system is the most influential component on vehicle weight, and the hydrogen storage weight increases slightly with range. The contribution of hydrogen storage weight reduces noticeably if the Ultimate scenario assumptions are met due to improvements in fuel cell efficiency and storage system gravimetric energy density.

Figure 14 shows the battery electric powertrain Class 8 long-haul truck weight breakdown. The available cargo weight reduces dramatically as the required range of the vehicle increases because of the required increase in battery energy and weight. With the 2025 technology metrics, a 500-mile-range battery electric truck will have a maximum cargo capacity of approximately 43,000 lbs. These values are reasonably consistent with Tesla's claims of a maximum payload of approximately 45,000 lbs for its 500-mile Semi (Ritter 2018) after significant lightweighting. If the Ultimate scenario assumptions are achieved, approximately 52,000 lbs of cargo capacity would be available for a 500-mile-range tractor. Battery weight reduces substantially through the three analysis scenario assumption time frames, due primarily to improvements in battery energy density, an expanded state-of-charge operating window, and reductions in vehicle drag and rolling resistance. Note that currently, alternative powertrains are allowed a 2,000-pound exemption (U.S. Department of Transportation 2015; California Legislative Information 2018). If this 

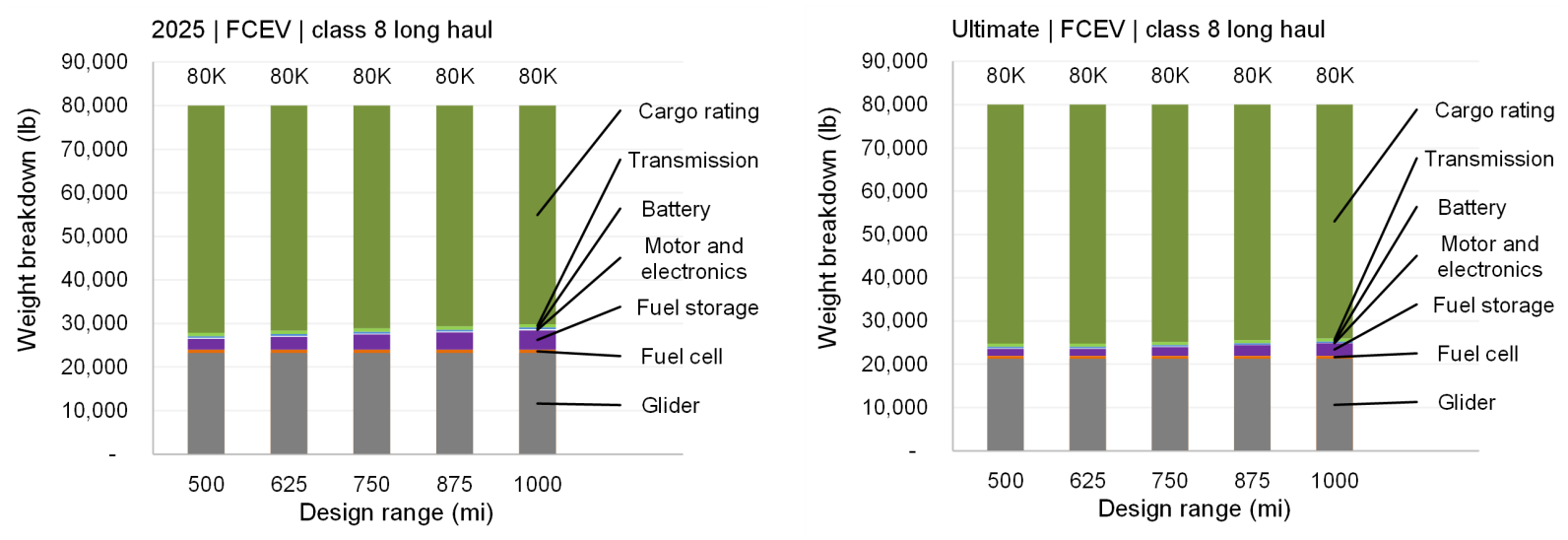

Figure 13. Class 8 FCEV long-haul truck (750-mile range) mass distribution relative to vehicle range using (left) 2025 scenario assumptions and (right) Ultimate scenario assumptions

exemption remains in effect, we estimate that Class 8 long-haul truck BEVs with 500-mile range will have nearly identical cargo capacity to diesel powertrains if the Ultimate scenario assumptions are achieved.
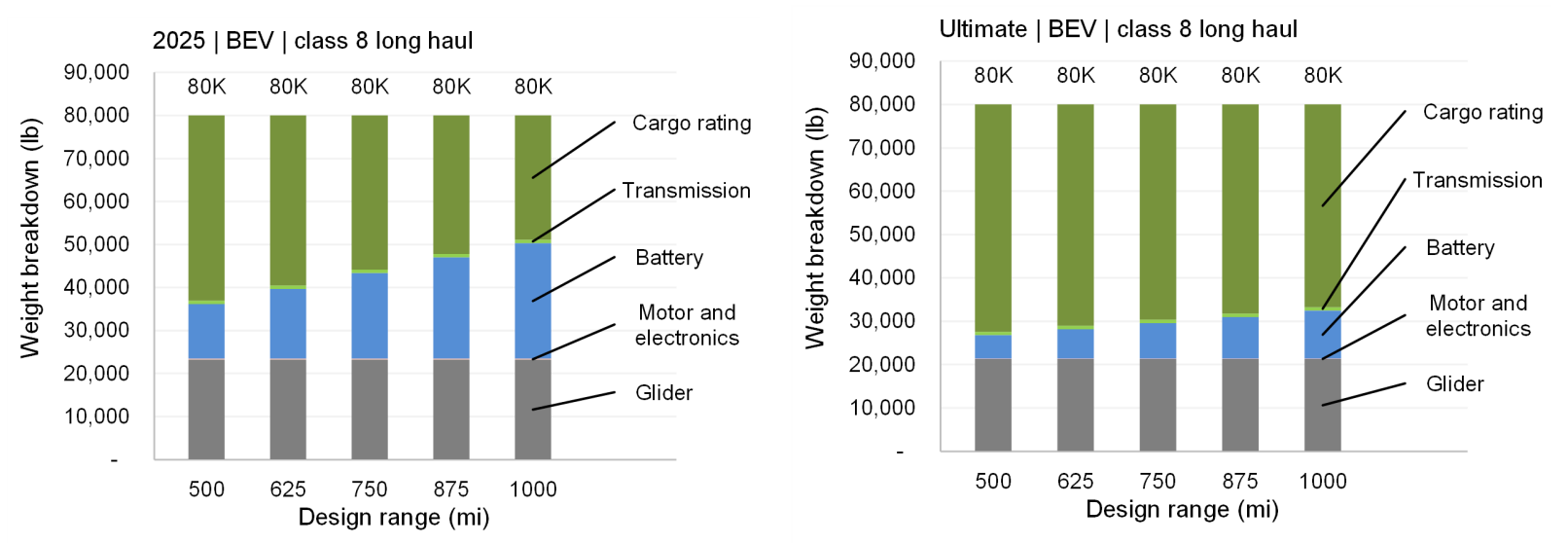

Figure 14. Class 8 BEV long-haul truck (750-mile range) mass distribution relative to vehicle range using (left) 2025 scenario assumptions and (right) Ultimate scenario assumptions

Figure 15 shows the relative weight of each alternative powertrain compared to the weight of a diesel powertrain capable of the same range and 0-60-mph acceleration time for (top) the Class 8 long-haul (750-mile) vehicle and (bottom) the Class 8 long-haul (500-mile) vehicle. For both vehicle ranges, CNG, PHEV, and FCEV powertrains all incur a few thousand extra pounds in the 2018 time frame, though this extra weight reduces by the Ultimate technology status time frame. HEV powertrains achieve a small net weight savings because of lower electric motor mass relative to conventional engines and a relatively small electric battery requirement. BEV powertrains, however, incur substantial extra weight in the current time frame of almost 25,000 pounds for the 750-mile-range vehicle and over 14,000 pounds for the 500-mile-range vehicle. This weight penalty reduces dramatically with 2025 and Ultimate technology status achievement, but the BEV powertrain still exceeds a conventional powertrain weight by approximately 5,000 pounds for the 750-mile-range vehicle even if Ultimate scenario assumptions are achieved. For the 500-mile-range vehicle, the 2,000-pound weight exemption would bring the BEV powertrain within weight parity of the diesel powertrain if Ultimate technology scenario assumptions are achieved.

These results suggest that battery electric powertrains may be suitable for lower-density goods transport with lower total weight or for applications with shorter range requirements. Fuel cell vehicles complement BEVs and may be 

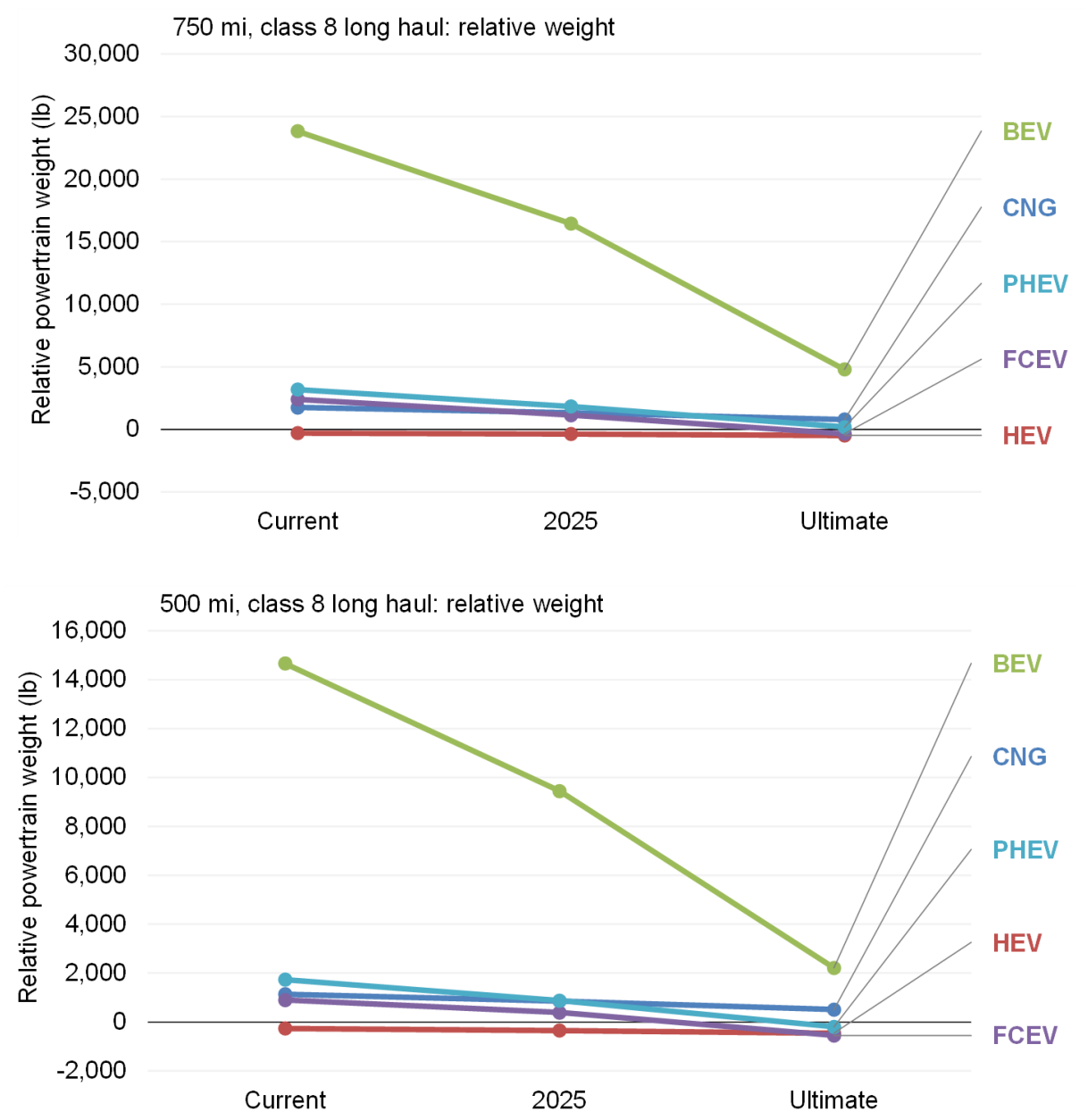

Figure 15. Class 8 long-haul 750-mile-range (top) and 500-mile-range (bottom) relative powertrain weight compared to a diesel powertrain that can achieve equivalent range and $0-60-\mathrm{mph}$ acceleration time

able to help decarbonize movements of heavier payloads or longer range requirements. The maximum allowable cargo capacity for all powertrains for both 2025 and the Ultimate (2050) time frame are shown in Figure 16. The BEV is the most weight-limited powertrain due to the large battery required; however, if Ultimate scenario assumptions are achieved, the cargo capacity penalty for BEVs is relatively minor at 500 miles of range. Fuel cell powertrains also have lower cargo allowances, but these limitations are comparable to CNG powertrains and generally less severe than those seen for fully battery electric powertrains.

Figure 17 shows the weight distribution of Class 8 short-haul trucks powered with a fuel cell. The overall impact of FCEV powertrain weight on the weight breakdown is relatively minimal. Hydrogen storage weight has a noticeable impact at ranges exceeding 300 miles in the 2025 time frame. In the Ultimate time frame, this impact is almost negligible.

Figure 18 shows the weight distribution of Class 8 short-haul BEVs. Battery weight contributes significantly to powertrain weight in the 2025 time frame, contributing to 6,000-12,000 pounds of vehicle weight, depending on range. If Ultimate scenario assumptions are met, the contribution of battery weight reduces substantially, but does not disappear entirely.

Figure 19 shows the relative weight of each alternative powertrain compared to the weight of a diesel powertrain 

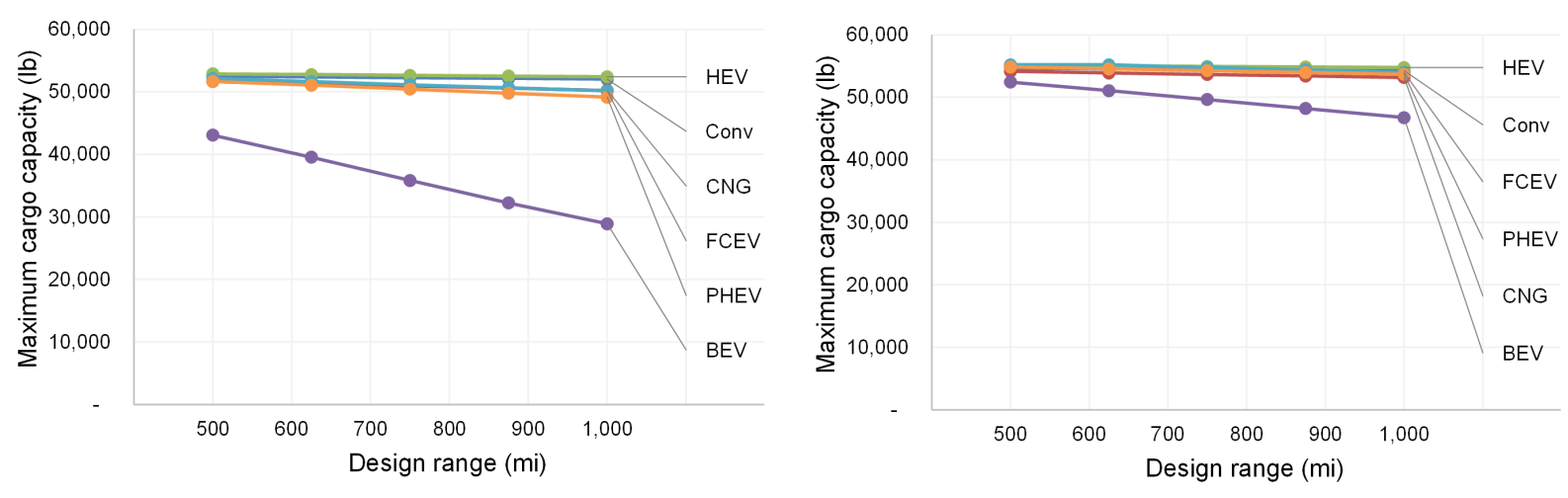

Figure 16. Class 8 long-haul maximum cargo capacity, limited by $80,000-$

Ib limit, for (left) 2025 and (right) Ultimate (2050) scenario assumptions
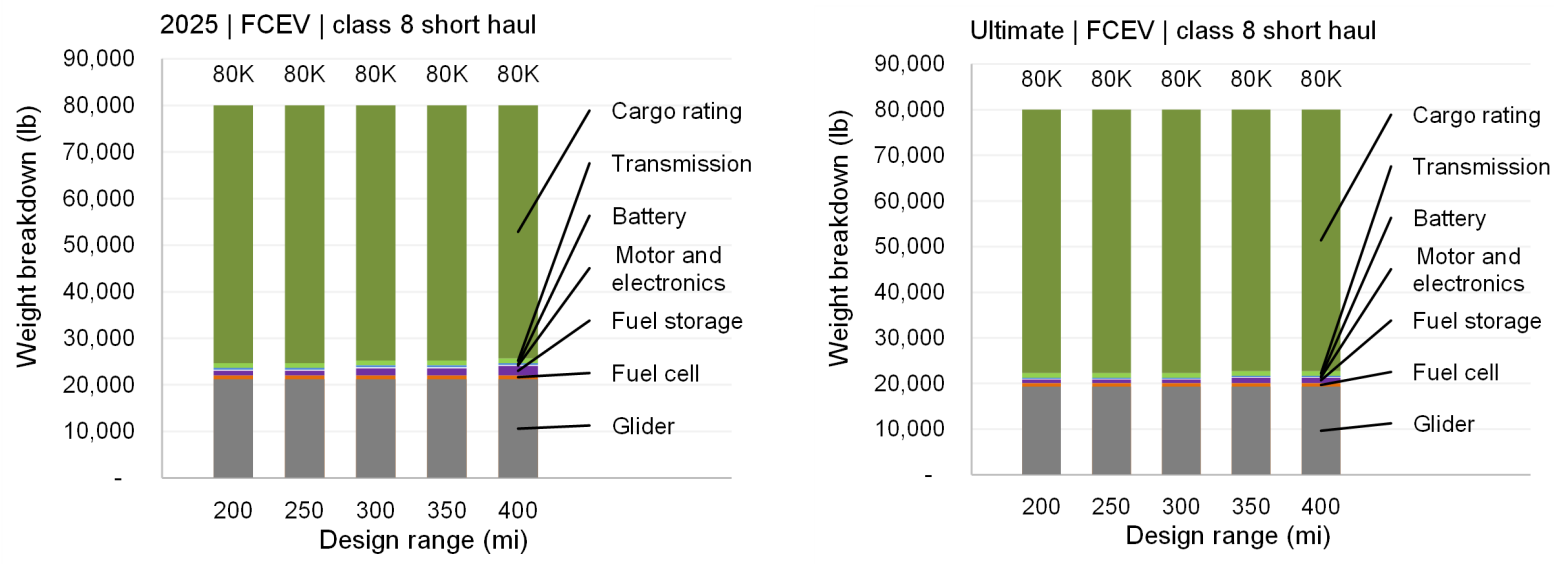

Figure 17. Class 8 FCEV short-haul truck (300-mile range) mass distribution relative to vehicle range for (left) 2025 and (right) Ultimate (2050) scenario assumptions

capable of the same range and 0-60-mph acceleration time for the Class 8 short-haul truck. CNG and PHEV powertrains weigh slightly more than diesel, whereas FCEV and HEV powertrains weigh slightly less. BEV powertrains weigh approximately 7,000 pounds more than diesel under the current technology status, but would reach weight parity with diesel powertrains if the Ultimate scenario assumptions are achieved.

Figure 20 shows the maximum allowable cargo capacity for all powertrains for both the 2025 and the Ultimate time frames. HEV, FCEV, PHEV, and CNG powertrain maximum cargo capacity is not significantly impacted under either the 2025 or Ultimate technology status scenarios. BEV powertrain maximum cargo is close to that of diesel for 200mile-range vehicles, but becomes about 8,000 pounds less at 400 miles of range in the 2025 scenario assumptions. If Ultimate scenario assumptions are met, BEVs join the other alternative powertrains in being capable of hauling an equivalent cargo capacity to diesel. 

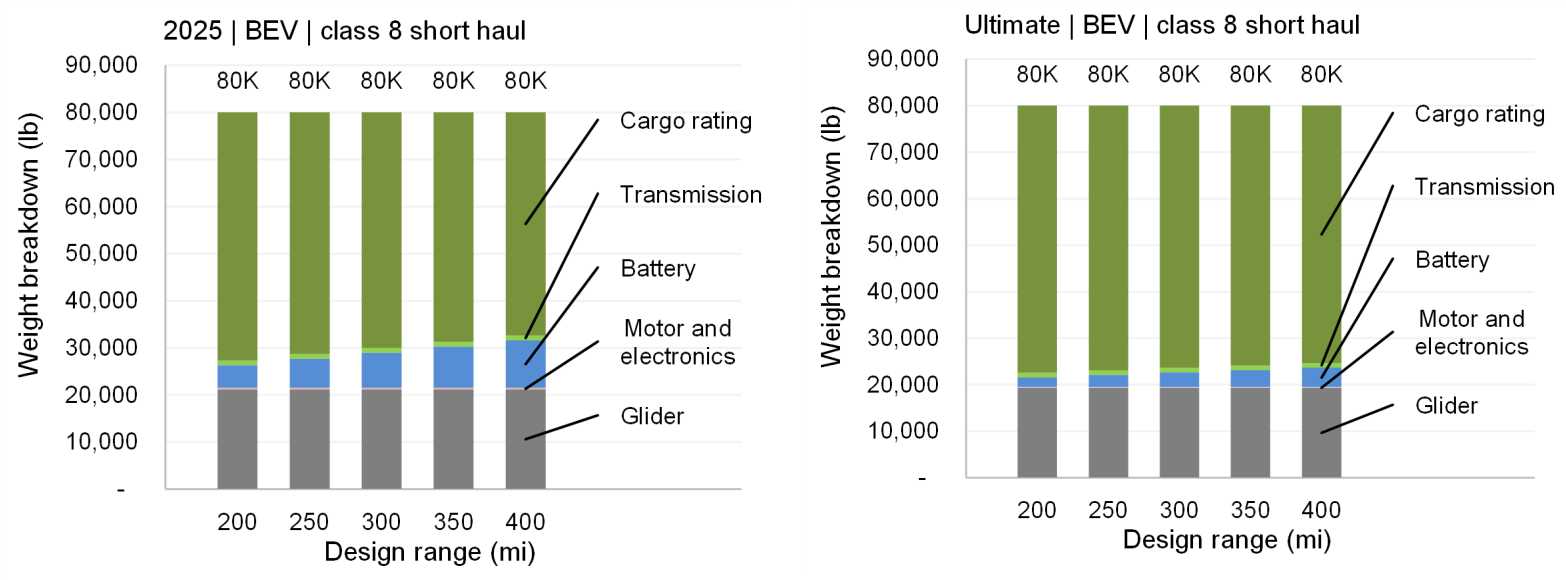

Figure 18. Class 8 BEV short-haul truck (300-mile range) mass distribution relative to vehicle range for (left) 2025 and (right) Ultimate (2050) scenario assumptions

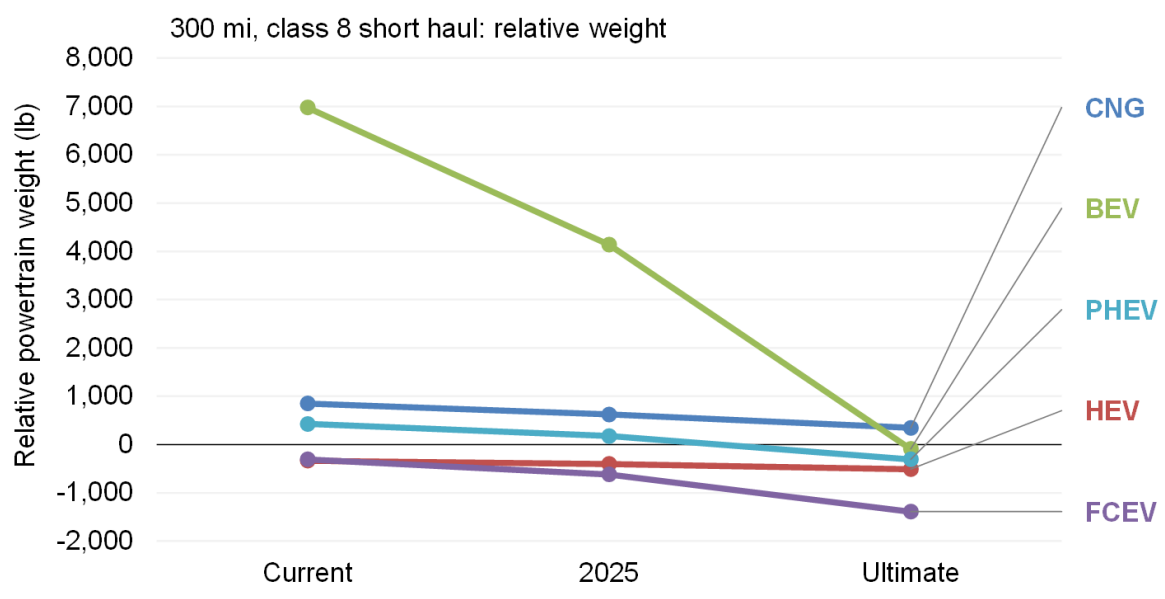

Figure 19. Class 8 short-haul relative powertrain weight compared to a diesel powertrain that can achieve equivalent range and $0-60-\mathrm{mph}$ acceleration time

\subsubsection{Vehicle Weight Breakdown: Class 4 Parcel Delivery Trucks}

As with Class 8 tractors, the Class 4 parcel delivery truck powertrain weight was estimated in FASTSim based on the powertrain sizing methodology described in Section 2.2. Potential future reductions in rolling resistance and potential improvements in aerodynamics were incorporated into the analysis and result in smaller powertrain and energy storage capacity requirements with time (see Appendix 6).

Figure 21 summarizes the estimated weight distribution of the Class 4 parcel delivery truck with the fuel cell electric powertrain. Total weight is generally independent of range across the spread of ranges considered here for Class 4 vehicles. Nonetheless, total powertrain contribution to weight breakdown does reduce by a few hundred pounds if Ultimate scenario assumptions are achieved, due to improvements in gravimetric energy density of fuel cells, hydrogen storage, and batteries.

Figure 22 shows the breakdown of Class 4 parcel delivery BEVs. In the 2025 technology status scenario, the impact of battery weight contributes between a few hundred pounds and up to approximately 2,000 pounds, depending on 

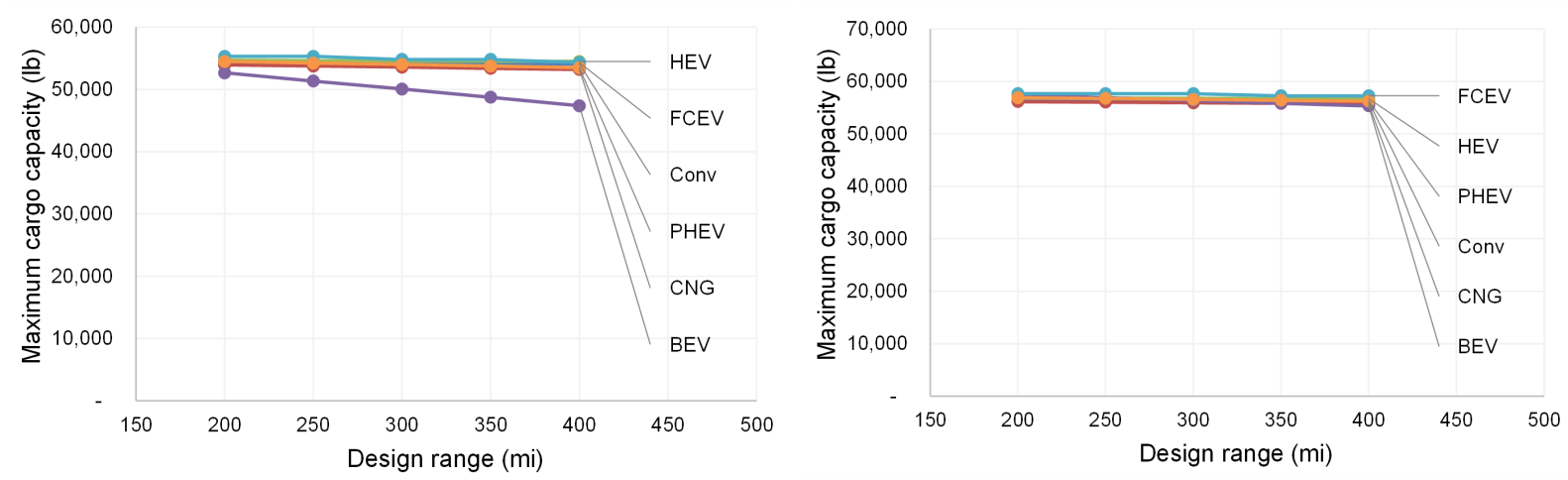

Figure 20. Class 8 short-haul truck maximum cargo capacity, limited by 80,000 Ib limit, for (left) 2025 and (right) Ultimate (2050) scenario assumptions
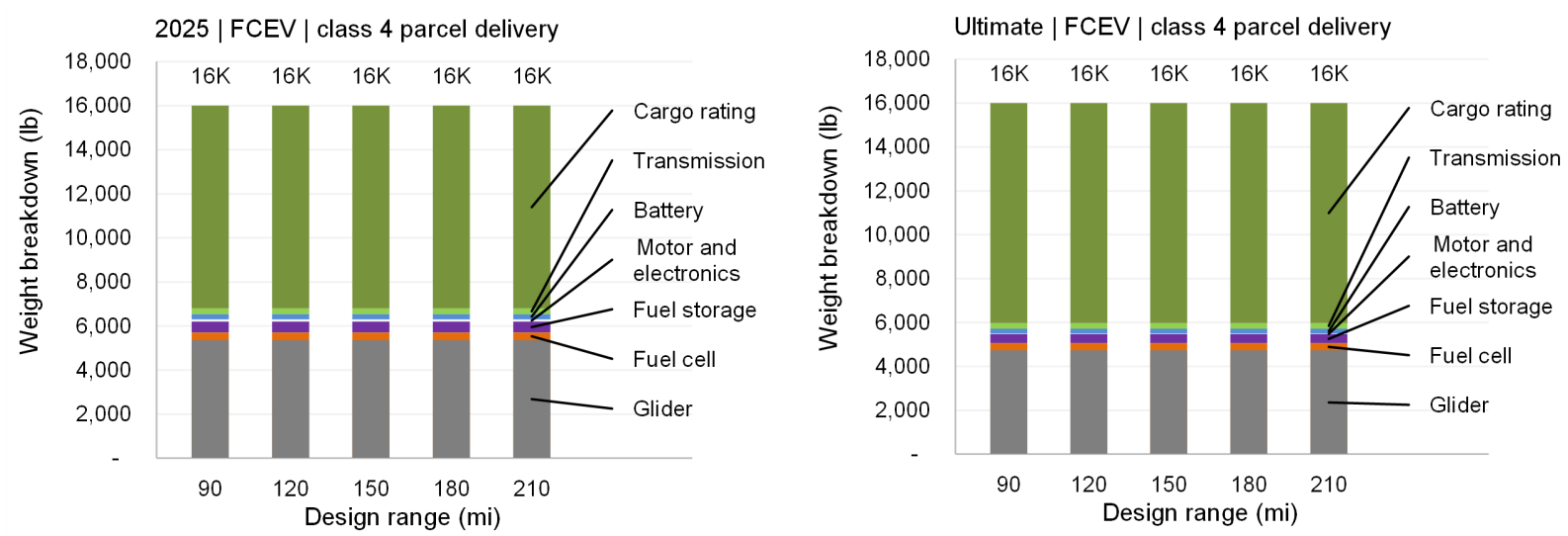

Figure 21. FCEV Class 4 parcel delivery truck mass distribution relative to vehicle range for (left) 2025 and (right) Ultimate (2050) scenario assumptions

range. This impact reduces substantially if Ultimate scenario assumptions are achieved.

Figure 23 shows the relative powertrain weight of each Class 4 parcel delivery truck alternative powertrain compared to a diesel powertrain capable of achieving the same range and 0-60-mph acceleration time. CNG, HEV, and PHEV powertrains start out very close to the same weight as diesel powertrains in the current technology time frame, but HEV and PHEV powertrains dip below the diesel weight if 2025 or Ultimate technology scenario assumptions are achieved. The FCEV powertrain starts about 200 pounds less than diesel in the 2018 technology status time frame and reduces slightly as 2025 and Ultimate technology status are achieved. The BEV powertrain starts out about 1,000 pounds above the diesel in the 2018 technology status time frame, but achieves weight parity with the diesel powertrain if 2025 scenario assumptions are achieved. In the Ultimate technology status scenario, BEVs become the lightest powertrain analyzed in this study due primarily to battery density improvements and improved fuel economy and could be 600 pounds lighter than its diesel counterpart. 

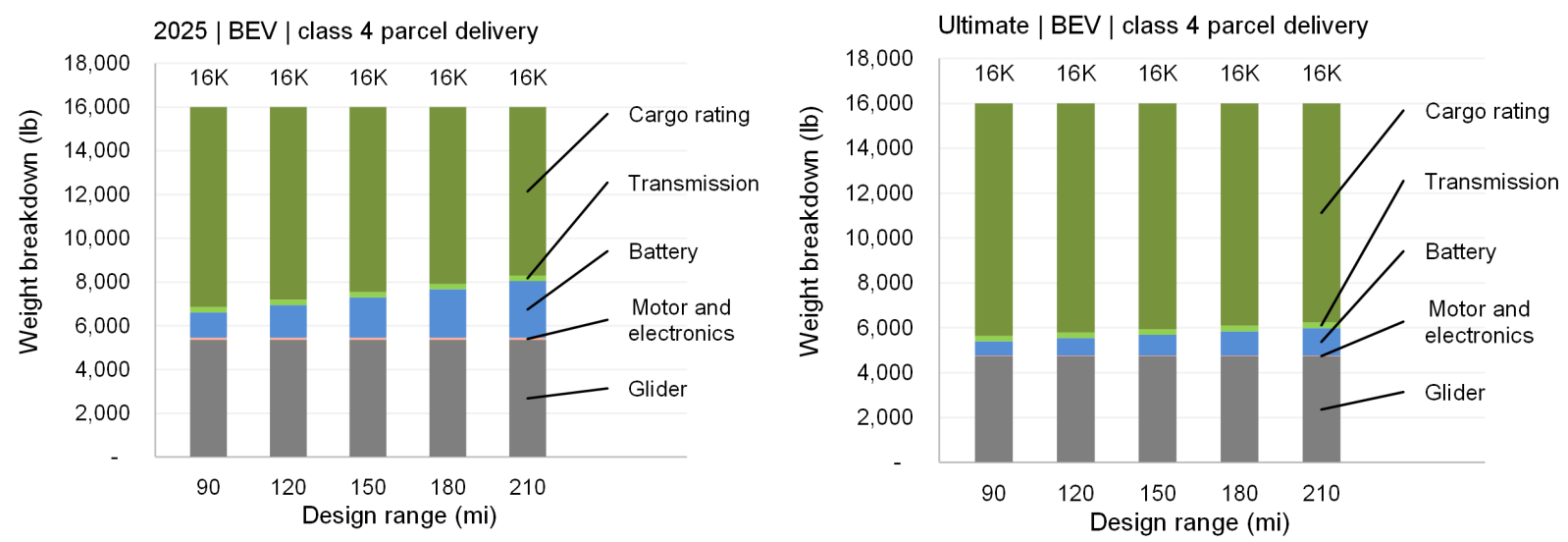

Figure 22. BEV Class 4 parcel delivery mass distribution relative to vehicle range for (left) 2025 and (right) Ultimate (2050) scenario assumptions

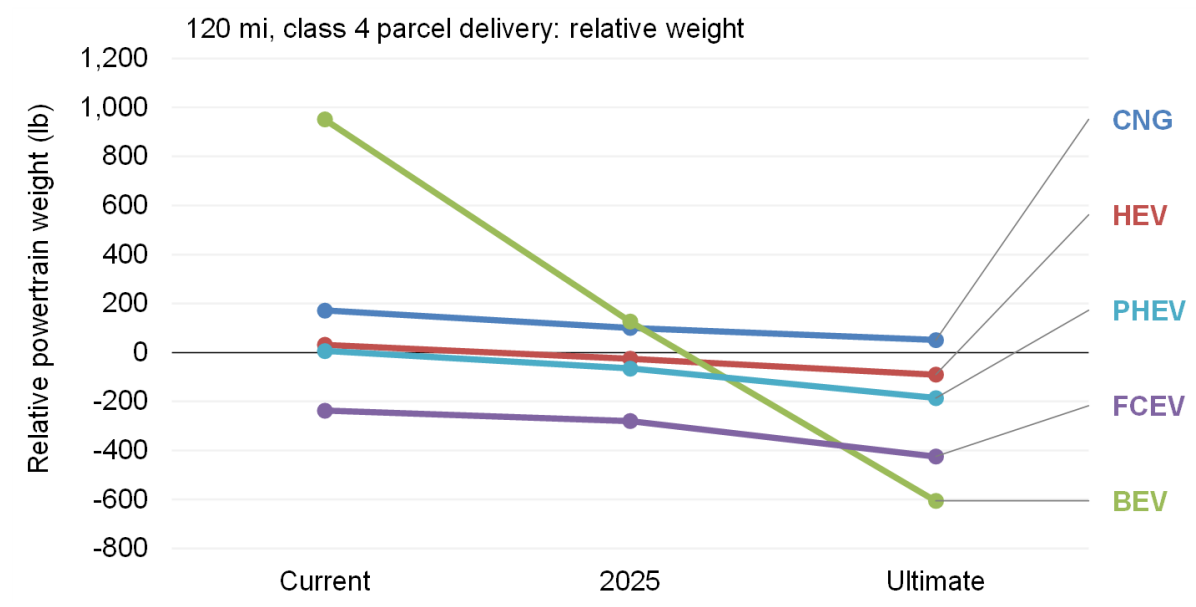

Figure 23. Class 4 parcel delivery truck relative powertrain weight compared to a diesel powertrain that can achieve equivalent range and 0-60-mph acceleration time

It is notable that the overall range requirement of this vehicle (typically approximately 120 miles), as well as its stop-and-go operation and ability to leverage its hybrid battery, yields a proportionately smaller need for a fuel tank as compared to Class 8 trucks. Thus, the fuel storage at the desired driving range accounts for a smaller fraction of the total vehicle weight than seen in Class 8 trucks. As such, the cargo capacity impact from the fuel cell powertrain configuration is minimal. In Figure 24, cargo capacity up to the GVWR of 16,000 lbs for each powertrain in this vocation is displayed.

Note that in Figure 24, cargo capacity for fuel cell powertrains is slightly higher than that of diesel powertrains. This is largely due to a higher power density of fuel cells, relatively low vehicle range, and high fuel economy, which result in a smaller fuel converter and hydrogen tank weight contribution to the overall vehicle weight. Battery electric powertrains also have cargo advantages for range requirements less than approximately 100 miles relative to diesel. However, BEVs have reduced cargo weights in the near term (until the 2025 technology performance is achieved) if the required range is greater than approximately 100 miles, due to the high specific mass of batteries. The mass breakdown of battery electric powertrains is shown in Figure 22. 

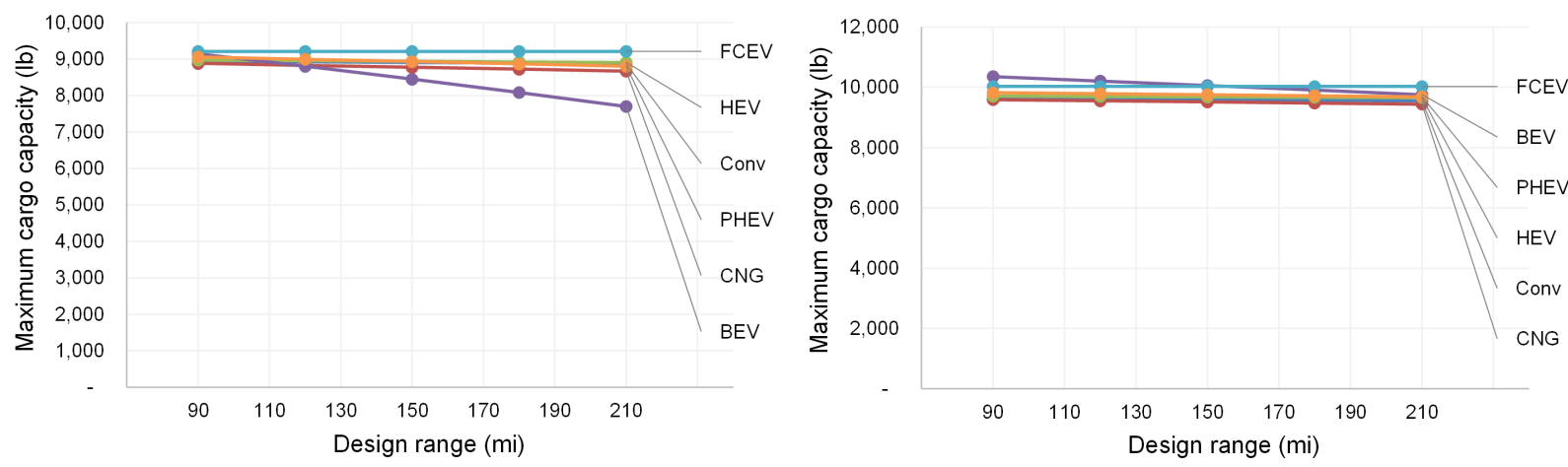

Figure 24. Vehicle maximum cargo capacity, limited to $16,000 \mathrm{lb}$, for (left) 2025 and (right) Ultimate (2050) scenario assumptions

\subsubsection{Vehicle Fuel Economy}

FASTSim models each vehicle's fuel economy based on the input drive cycle along with the vehicle specifications input (e.g., drag coefficient, frontal area), which improve between the current (2018), 2025, and Ultimate (2050) time frames. Figure 25 shows the FASTSim-estimated fuel economies for a Class 8 long-haul tractor with 750-mile and 500-mile ranges and a payload of approximately 36,500 lbs (or the maximum hauling capacity in the case of the battery electric powertrain). It also displays the fuel economy of a Class 8 short-haul tractor with 300-mile range and payload of 36,000 lbs, and lastly a Class 4 parcel delivery truck with a 120-mile range fully weighed out $(16,000$ lbs). As seen in Figure 25, the fuel economies of the BEVs and FCEVs are higher than those of the conventional diesel and CNG vehicles due to the higher powertrain efficiencies. The fuel economies improve marginally over time for Class 8 tractors as the tractor weight decreases. These fuel economies were used to represent the typical fuel consumption and resulting fuel expenses in the TCO analysis. Fuel economy estimates for the EPA Regulatory Cycles are included in Appendix $\mathrm{H}$ for comparison with other studies. 

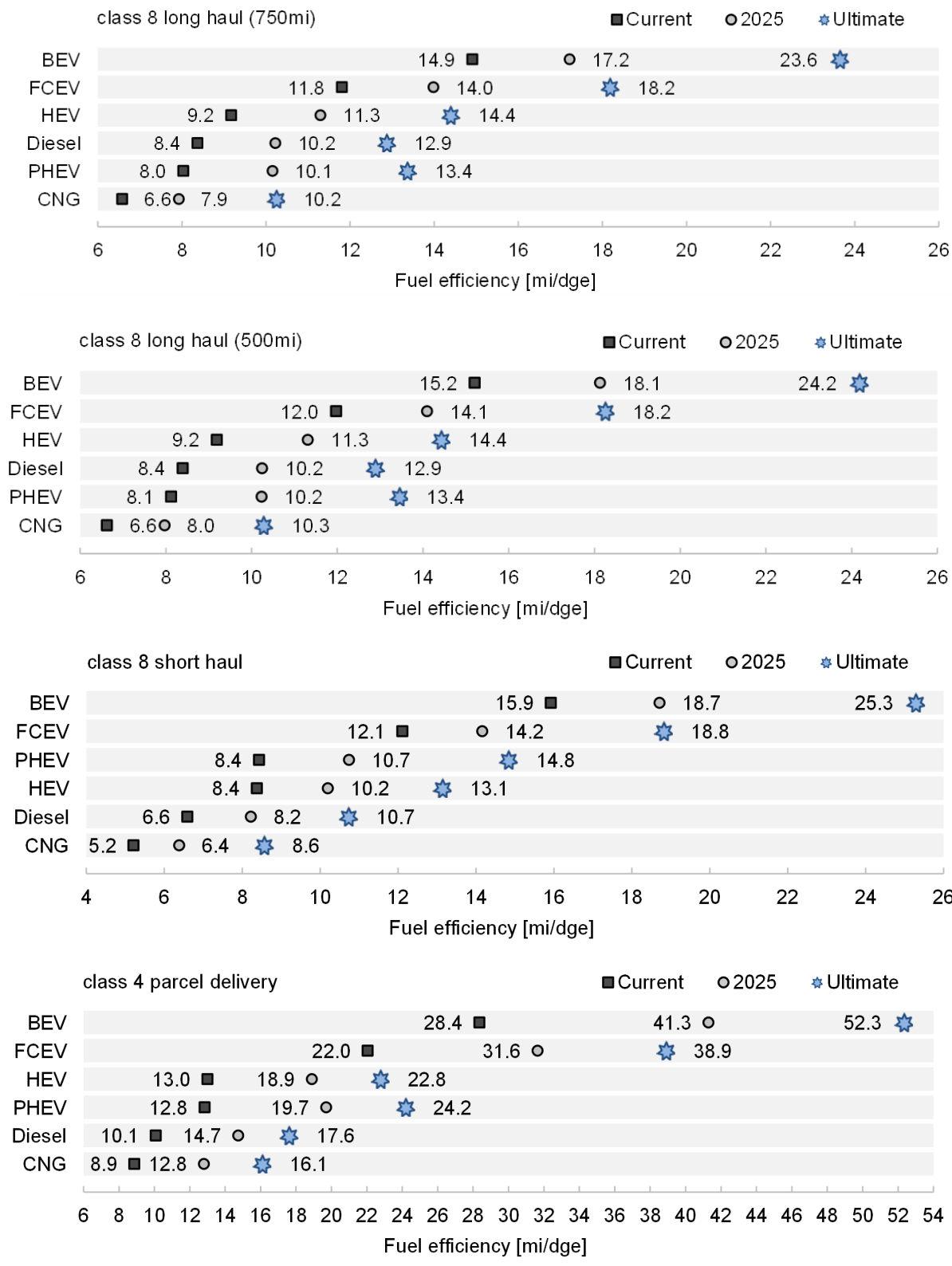

Figure 25. FASTSim-predicted fuel economy for a (top) Class 8 long-haul 750-mile-range truck, (top middle) Class 8 long-haul 500-mile-range truck, (bottom middle) Class 8 shorthaul truck (300-mile range), and (bottom) Class 4 parcel delivery truck (120-mile range)

\subsubsection{Vehicle MSRP}

FASTSim combines the powertrain component requirements with the costs reported in Table 2 to determine the base cost of the vehicle. FASTSim then multiplies this cost by 1.5 to convert it to an estimated vehicle MSRP (National Renewable Energy Laboratory, 2018a). The MSRP is broken down by the cost components that compose it, including the glider, fuel storage (e.g., diesel tank, hydrogen tank), fuel converter (e.g., engine, fuel cell stack), battery, motor and power electronics, charging plug, and purchase tax.

Figure 26 shows the estimated MSRP for the Class 8 long-haul tractors with 750-mile range. The 2018 Class 8 long-haul (750-mile-range) fuel cell powertrain shows a significant cost from the hydrogen storage and fuel cell 
stack, resulting in an FCEV MSRP 2.3 times greater than that of a diesel truck MSRP. Achieving the 2025 technical performance and cost assumptions greatly reduces the fuel cell vehicle MSRP to 50\% higher than the MSRP of the diesel powertrain. If Ultimate scenario assumptions are achieved, the FCEV MSRP would be approximately 13\% higher than the diesel vehicle MSRP. The Class 8 long-haul battery electric powertrain is very costly due to the large battery capacity required to achieve that range; the total BEV MSRP is approximately 5 times greater than the 2018 diesel MSRP. In the Ultimate scenario, the BEV price is still more than $80 \%$ higher than the diesel technology. CNG powertrains also see significant cost reductions as the Ultimate scenario assumptions are achieved. Figure 26 shows that this is primarily driven by cost reductions in natural gas storage, which occur due to both reducing storage costs and reducing the amount of CNG stored onboard as the CNG engine efficiency improves over time. Note that the MSRP of the diesel and HEV powertrains increases in 2025 from 2018 due to costs for waste-heat recovery and light-weighting that are needed to achieve the fuel economy improvements.

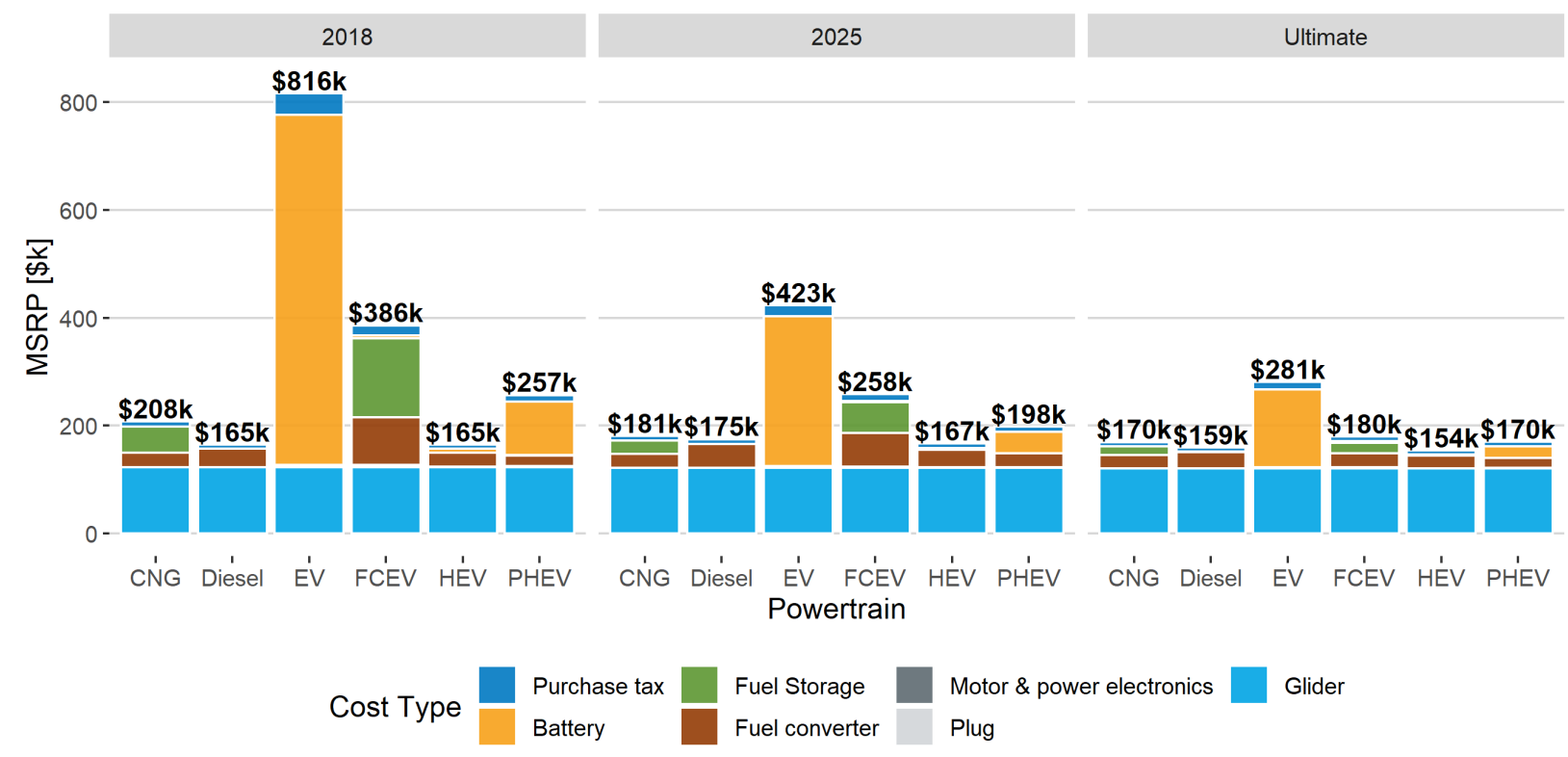

Figure 26. Class 8 long-haul (750-mile-range) FASTSim-estimated MSRP

Figure 27 shows the estimated MSRP for Class 8 long-haul tractors with 500 miles of range. Note that the MSRP for diesel and HEV powertrains is roughly identical to that of the 750-mile-range long-haul tractor because these powertrains have very low fuel storage costs. Due to the shorter range and lower energy storage requirements, FCEV and BEV powertrain MSRPs are slightly lower than for the 750-mile vehicle, but are still significantly higher than diesel for the 2018 technology status time frame. For example, FCEV MSRP is approximately 2 times that of the diesel powertrain in 2018, whereas the BEV MSRP is 3.5 times. In 2025, the FCEV MSRP premium reduces to just $37 \%$ above diesel, whereas the BEV MSRP is $80 \%$ above that of diesel. If the Ultimate scenario assumptions are achieved, FCEV and BEV MSRPs would be $10 \%$ and $43 \%$, respectively, above diesel MSRP.

Figure 28 shows the estimated MSRP for Class 8 short-haul tractors. For this vocation, the MSRP premium for alternative powertrains such as FCEVs, BEVs, and PHEVs is lower than for Class 8 long-haul trucks due to the lower battery and/or fuel storage capacity requirements. For the 2018 technology status time frame, FCEV and BEV MSRP values are approximately 1.84 and 2.44 times that of diesel, respectively. If the 2025 scenario assumptions are achieved, FCEV and BEV MSRP come close to matching each other at approximately 33\% higher than diesel MSRP. If the Ultimate scenario assumptions is achieved for each powertrain, FCEV MSRP would be only $5 \%$ higher than diesel MSRP, and BEV MSRP would be only 17\% higher than diesel MSRP.

Figure 29 shows the estimated MSRP for the Class 4 parcel delivery truck. At today's costs, the fuel cell powertrain is the most expensive, at approximately twice that of the cost of a diesel equivalent. If the 2025 scenario assumptions 


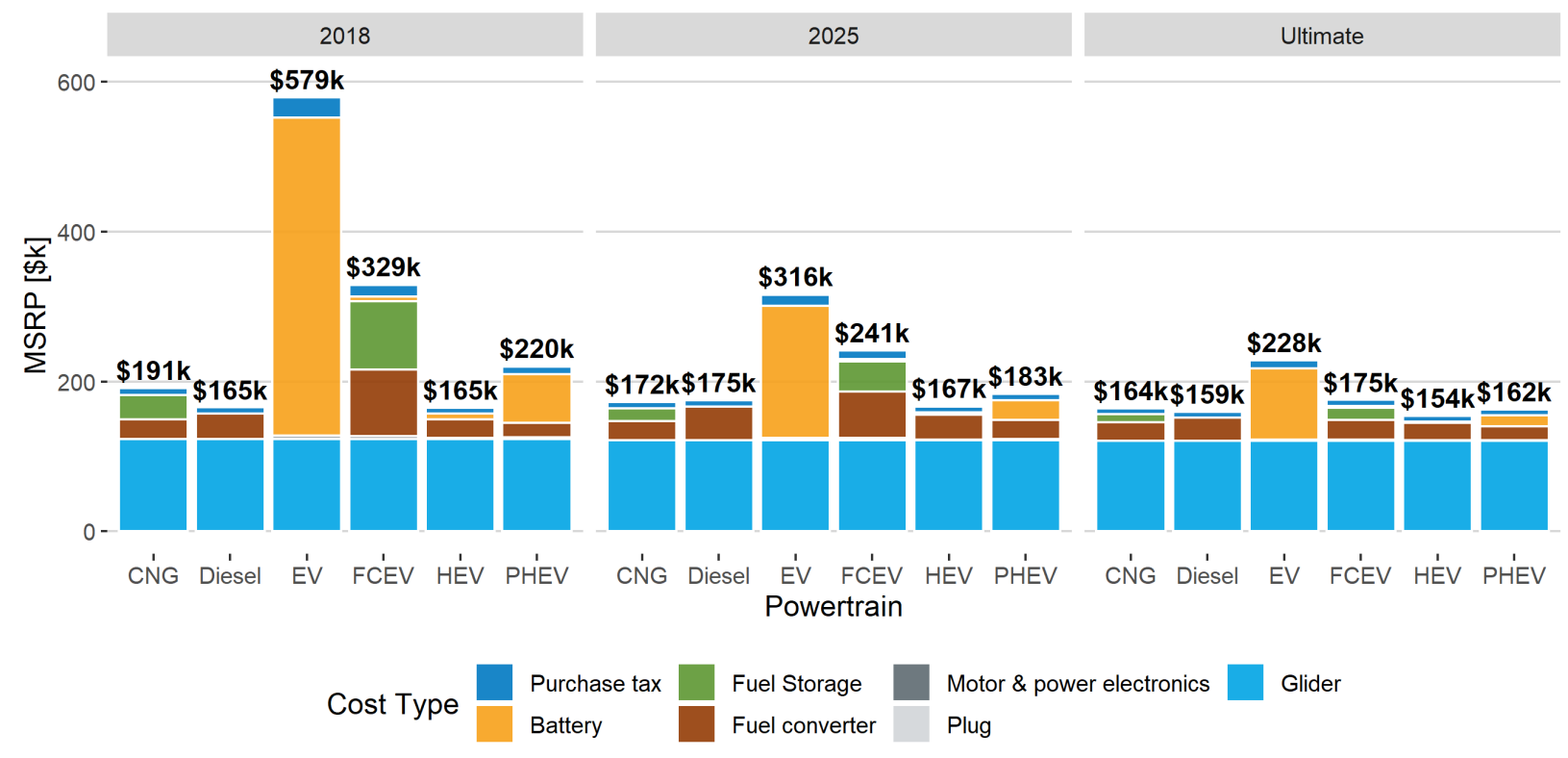

Figure 27. Class 8 long-haul (500-mile-range) FASTSim-estimated MSRP

are met, the fuel cell powertrain becomes economically competitive with conventional technologies and reaches cost parity with diesel if the Ultimate scenario assumptions are achieved. BEVs are much more economical for the Class 4 parcel delivery vocation, as the battery size is significantly reduced. At current costs, the battery electric powertrain MSRP is approximately $84 \%$ higher than a diesel powertrain, but if the price of batteries achieves the 2025 or Ultimate scenario assumptions, then the battery electric powertrain will reach cost parity or be less expensive than a diesel powertrain. As with the Class 8 tractors, CNG MSRP decrease due to the natural gas storage costs decreasing. Plug-in hybrid technology follows the trend in battery prices, so by the time the Ultimate scenario assumptions are achieved, PHEV costs would reach parity with the diesel powertrain. 


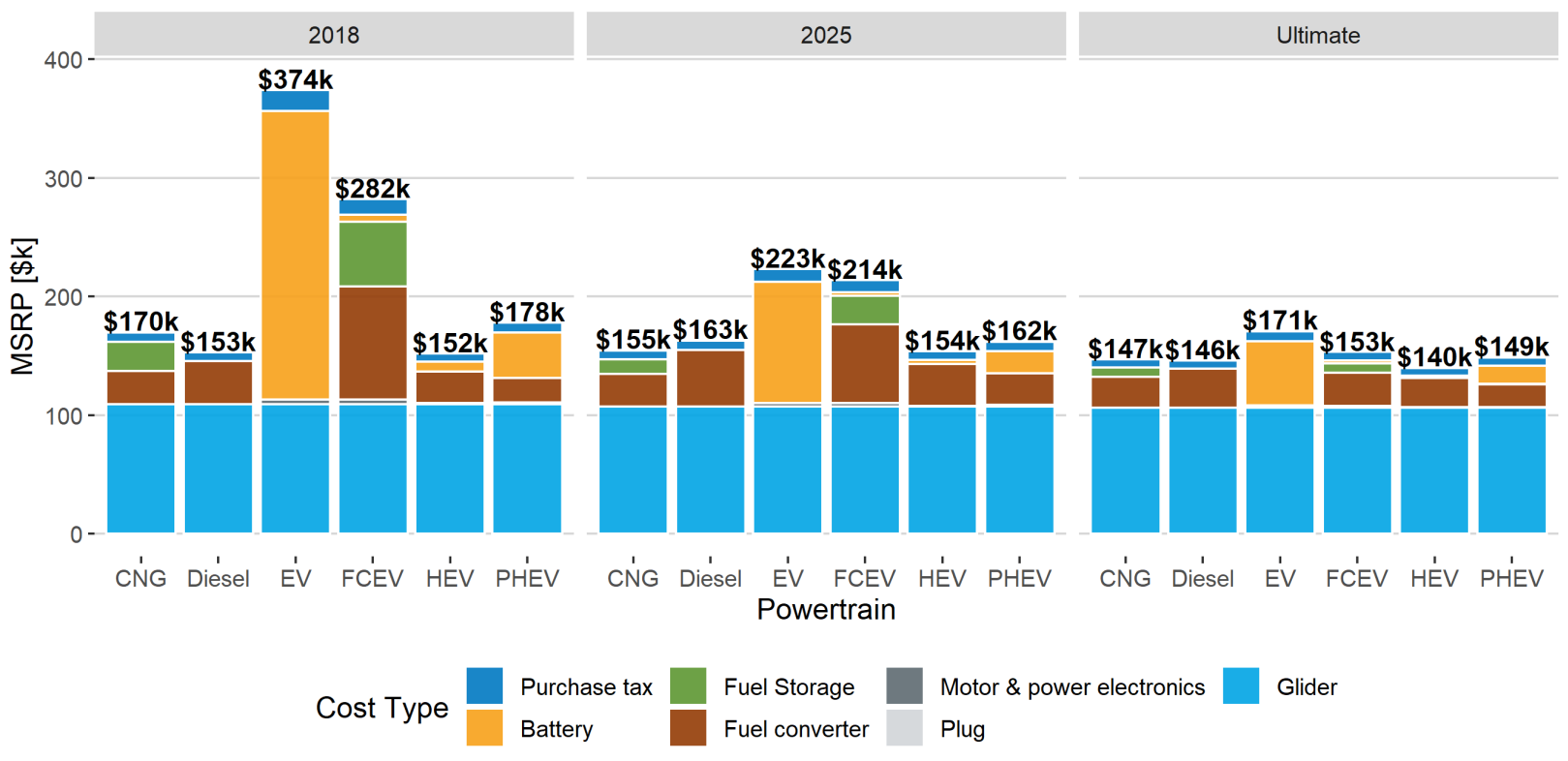

Figure 28. Class 8 short-haul (300-mile-range) FASTSim-estimated MSRP

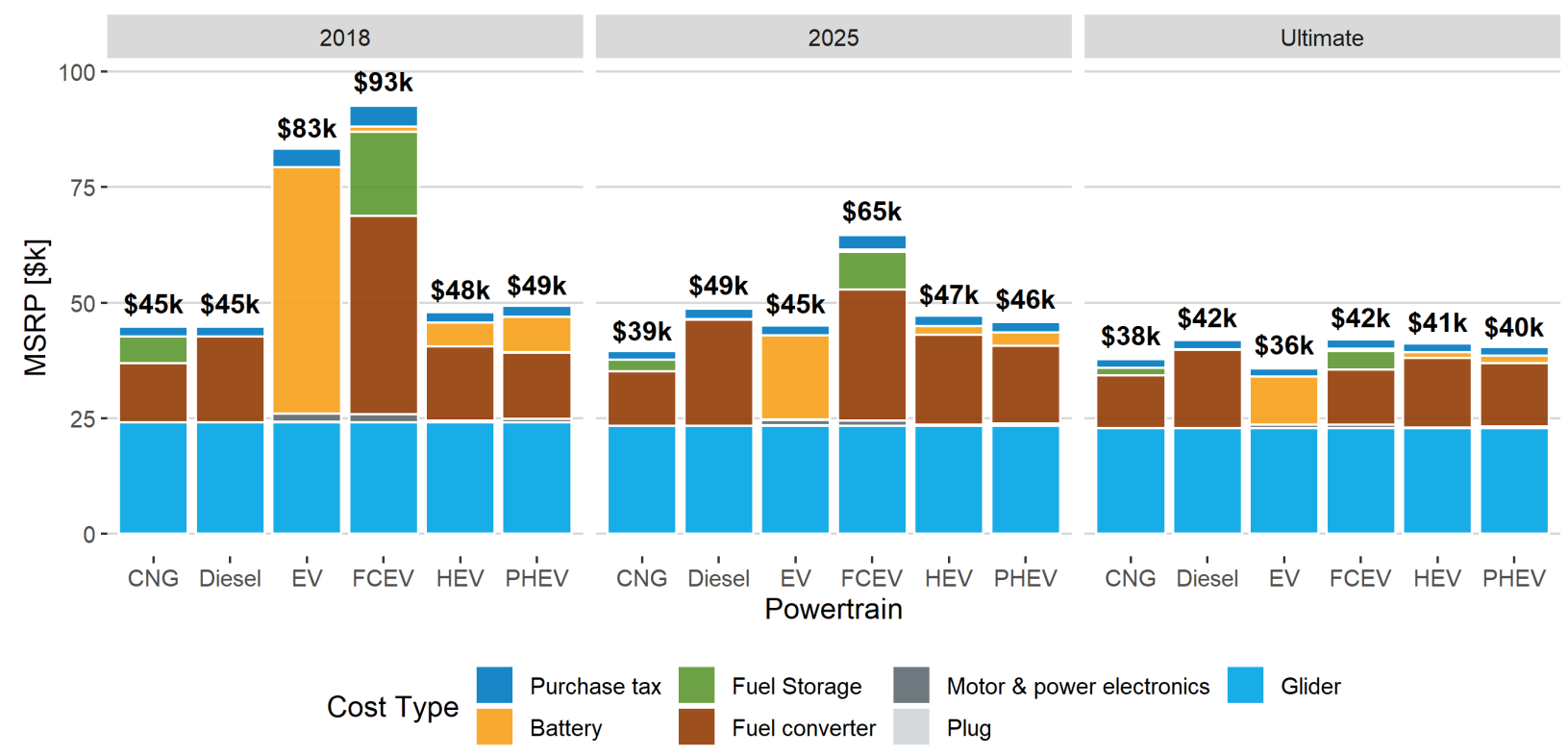

Figure 29. Class 4 parcel delivery (120-mile-range) FASTSim-estimated MSRP

\subsection{Total Cost of Ownership Modeling}

This section presents the TCO of each vehicle for two of the four operating scenarios: (1) Single-Shift, VolumeLimited operation and (2) Multi-Shift, Weight-Limited operation. These two scenarios represent the edge cases of the scenario design, and the Single-Shift, Weight-Limited operation and Multi-Shift, Volume-Limited operation are included in the Appendix I. For each vehicle, we present TCO bar charts, along with plots of the fuel price that enables each powertrain to achieve cost parity with the diesel-powered truck under three different diesel prices. 
Additionally, we present plots of how costs vary across U.S. Census divisions based on regional fuel prices to show the impact of regional fuel prices on TCO.

\subsubsection{Class 8 Long-Haul Tractor (750-Mile Range)}

Figure 30 shows the Single-Shift, Volume-Limited scenario TCO breakdown of a Class 8 long-haul tractor with a design range of 750 miles operating in the Middle Atlantic region. The TCO is based on mid costs for fuel and O\&M, a discount rate of 7\%, and a total life VMT of 1 million miles. We assume 150,000 miles driven per year (580 miles per day assuming 260 workdays per year) for the Class 8 long-haul 750-mile truck operating in the SingleShift scenarios so that the total life is expected at around 6.67 years. The error bars represent the high and low costs for fuel prices and O\&M costs. The diesel, HEV, CNG, and PHEV powertrains achieve the lowest TCO for the 2018 time frame, with BEVs and FCEVs having notably higher TCOs due to high capital costs and fuel prices. BEVs and FCEVs would see significant reductions in both TCO if the 2025 scenario assumptions are achieved, driven by reductions in upfront purchase price (battery cost reductions for BEVs, fuel cell stack and hydrogen storage cost reductions for FCEVs), and fuel costs. For FCEVs in particular, achieving Ultimate fuel costs is very important for reaching cost parity with conventional and electric powertrains. All powertrain technologies would be within the margin of uncertainty in fuel and O\&M costs if the Ultimate scenario assumptions are achieved.

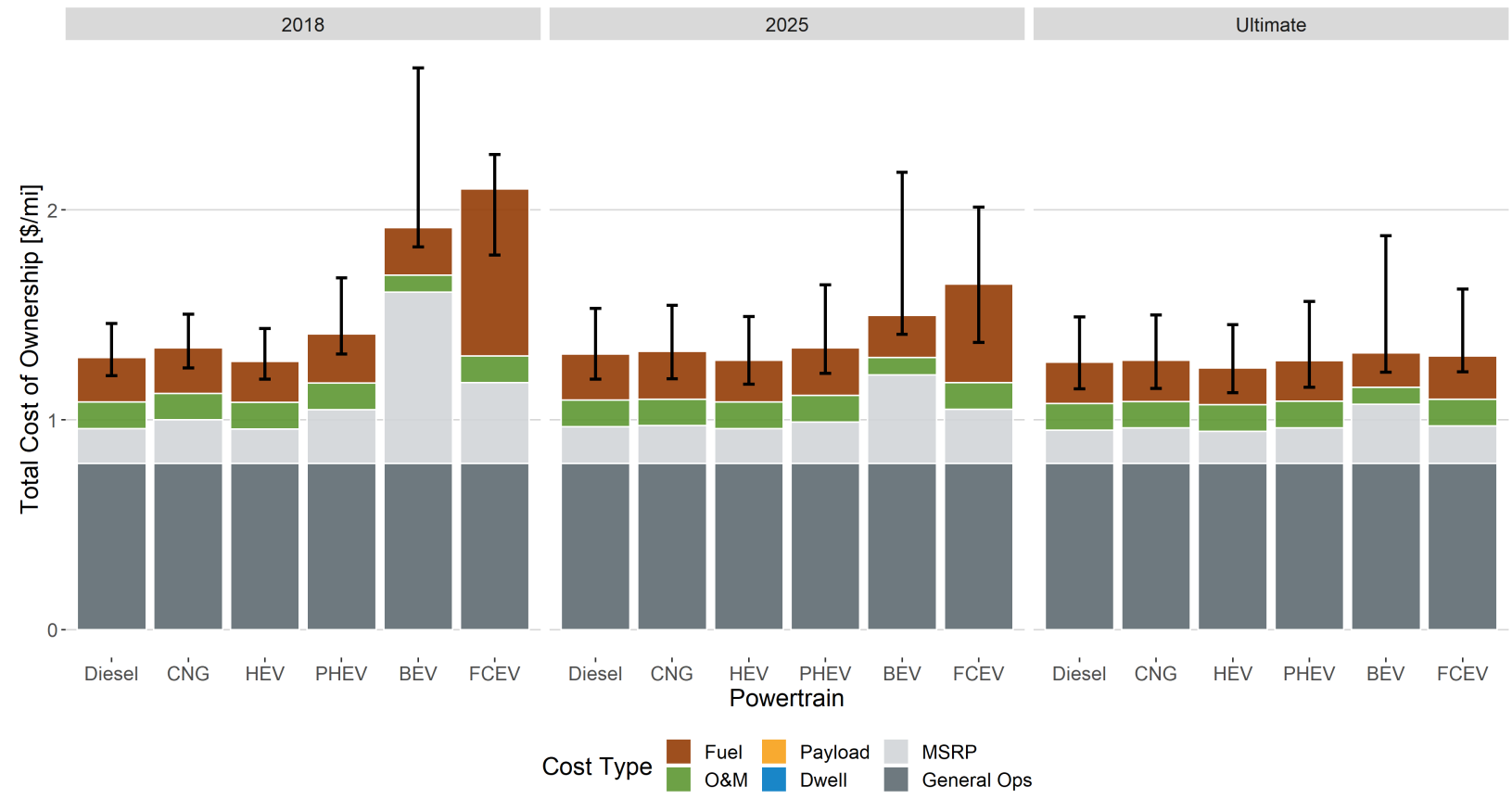

Figure 30. Single-Shift, Volume-Limited scenario TCO for Class 8 long-haul tractors (750-mile range) in the Middle Atlantic region

Figure 31 shows the Multi-Shift, Weight-Limited scenario TCO of a Class 8 long-haul tractor with a design range of 750 miles operating in the Middle Atlantic region. BEV powertrains are the only technology to experience a noticeable TCO increase associated with lost payload weight capacity. This penalty reduces significantly if the 2025 scenario assumptions are achieved, and effectively disappears if the Ultimate scenario assumptions are achieved. Note that for all three technology status time frames, all alternative powertrains are allowed a 2,000-pound exemption per current federal law.

All powertrains experience a slight increase in TCO due to the increase in annual VMT from 150,000 miles to 200,000 miles associated with the Multi-Shift scenario, as outlined in Table 9. Higher VMT increases TCO because future expenses for fuel and maintenance are incurred in a shorter period of time, and are thus discounted to a lower degree. Only the BEV powertrain experiences a noticeable increase in TCO associated with dwell time. This penalty would be reduced slightly if 2025 and Ultimate scenario assumptions are achieved, as the battery size decreases and 
reduces the dwell time associated with recharging the truck. Note that even with this cost, BEVs could still have lower TCO than diesel with Ultimate scenario assumptions, depending on fuel and O\&M costs.

Although BEVs must achieve Ultimate scenario assumptions to come within the margin of uncertainty of other powertrains for the Multi-Shift, Weight-Limited scenario, they have a chance of achieving cost parity with 2025 scenario assumptions for the Single-Shift, Weight-Limited scenario, shown in Appendix I, Figure I1. BEVs must achieve Ultimate scenario assumptions to come within the margin of uncertainty of conventional vehicles in the Multi-Shift, Volume-Limited scenario, as shown in Figure I2. These results illustrate that FCEVs and BEVs may be complementary in decarbonizing heavy-duty transport: The Multi-Shift scenarios that require fueling during shifts are economically viable for FCEVs, whereas BEVs may be more advantageous for Single-Shift scenarios.

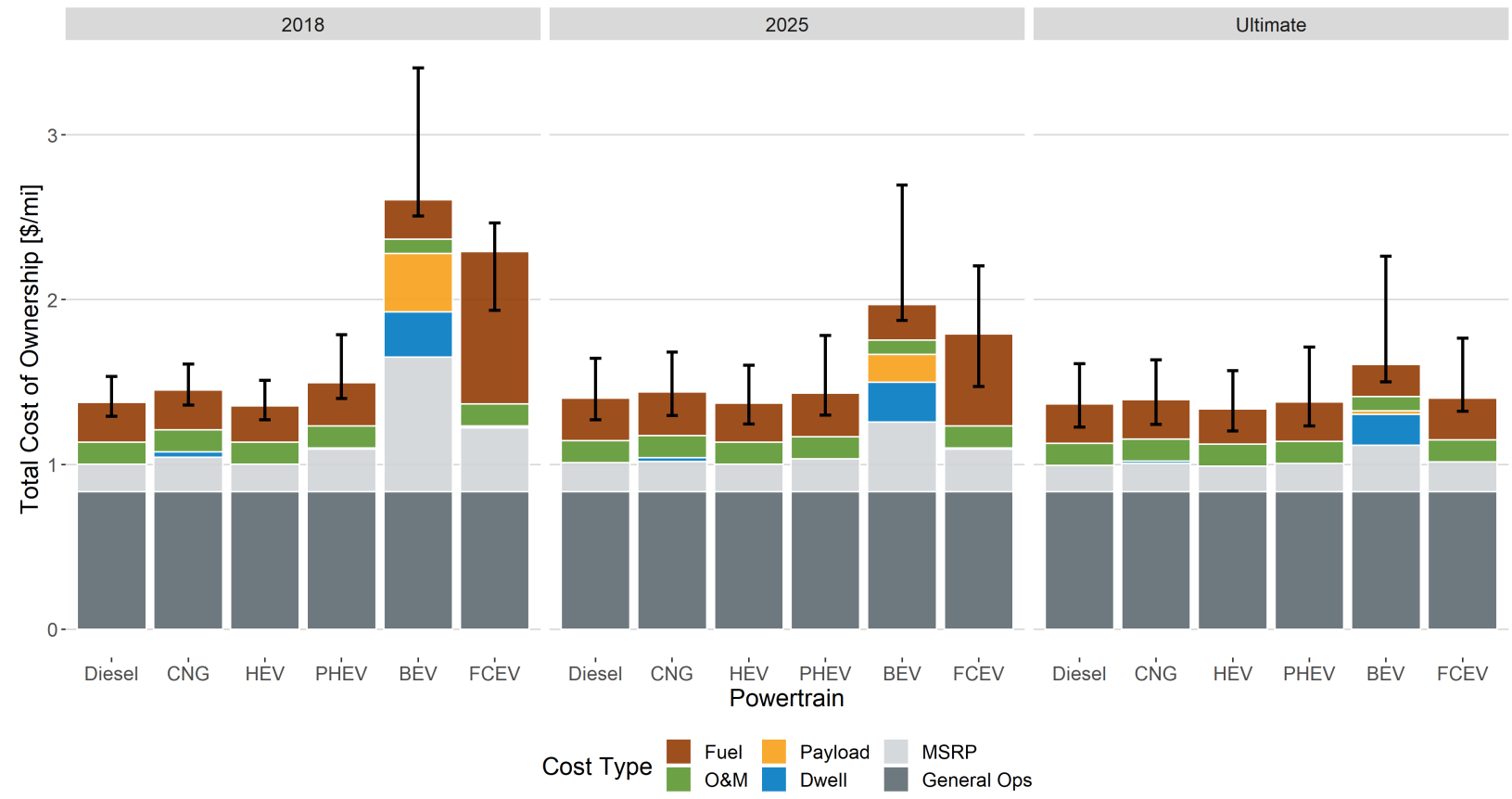

Figure 31. Multi-Shift, Weight-Limited scenario TCO for Class 8 long-haul tractors (750-mile range) in the Middle Atlantic region

Figure 32 shows the regional TCO distribution for the Single-Shift, Volume-Limited scenario of a Class 8 long-haul tractor with a design range of 750 miles. The BEV powertrain shows the largest spread (up to approximately 10\%) in TCO due to large differences in electricity price forecasts for each U.S. Census region. Regional differences in fuel prices can also be significant and affect the relative economic competitiveness of different powertrains. The trends in regional fuel prices for CNG and diesel are very similar due to our CNG fuel price approach described in Section 2.3.1. Hydrogen price is not currently regionally explicit, so the plot shows no spread in FCEV TCO across regions.

Figure 33 shows the regional TCO distribution for the Multi-Shift, Weight-Limited scenario of a Class 8 long-haul tractor with a design range of 750 miles. Once again, the TCO spread associated with regional differences in fuel price is consistent across diesel and CNG, whereas BEVs have larger spread in TCO due to greater regional variance in electricity prices, and FCEVs have no spread in TCO due to a lack of regional hydrogen price data. Note that all powertrains experience a slight increase in TCO due to the higher annual VMT of 200,000 miles for the Multi-Shift scenario. The regional TCO spread for the Single-Shift, Weight-Limited and Multi-Shift, Volume-Limited scenarios are given in Figures I3 and I4, respectively. Overall, the regional fuel price differences can result in regional TCO differences of up to approximately $10 \%$ as seen in the figures. 


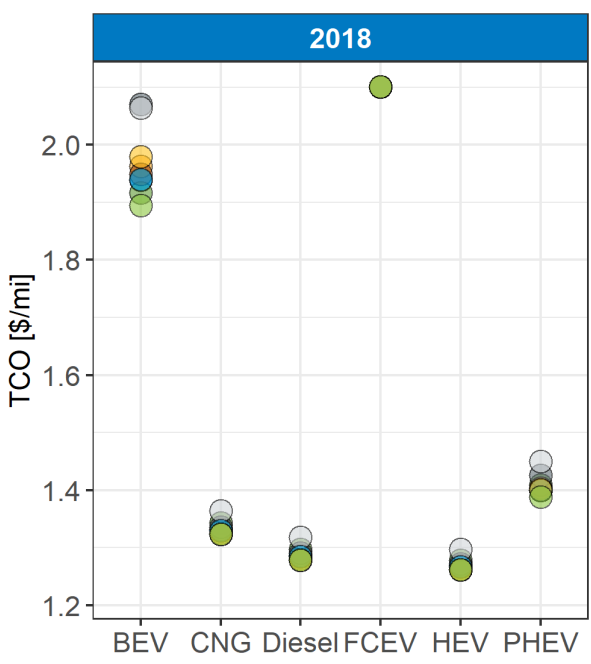

Region
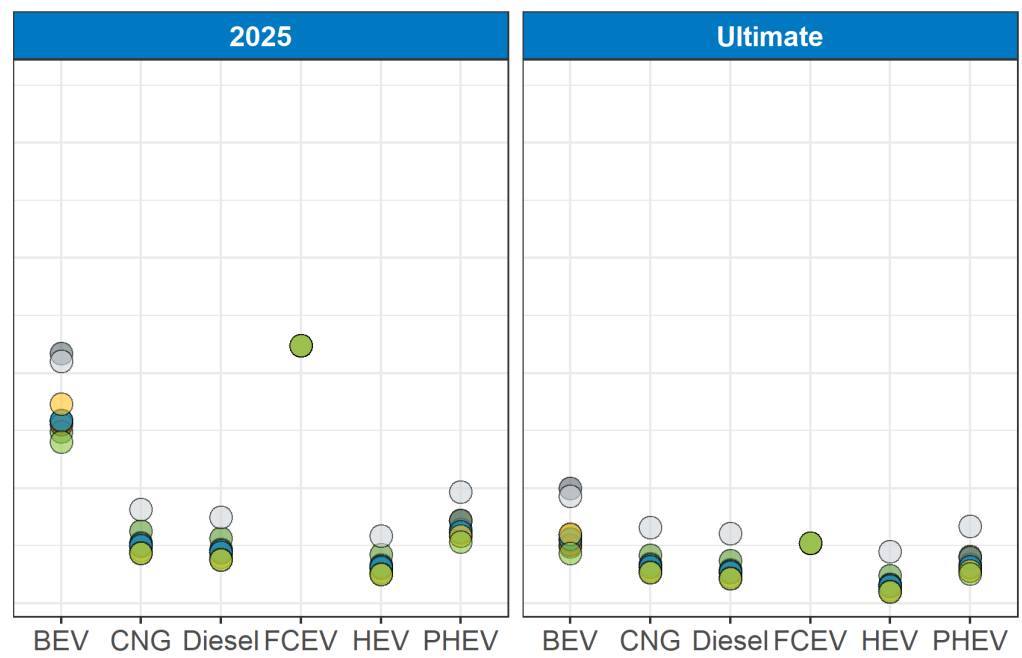

Figure 32. Regional TCO distribution for the Single-Shift, Volume-Limited scenario of a Class 8 long-haul tractor (750-mile range)

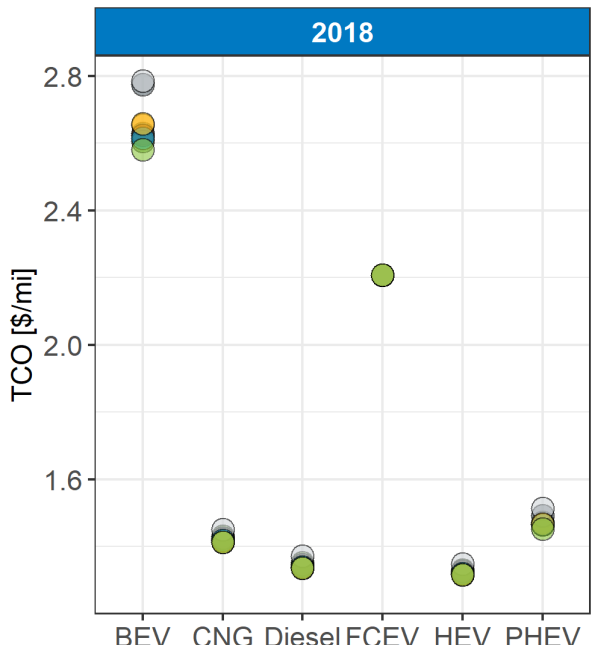

Region

.

East North Central

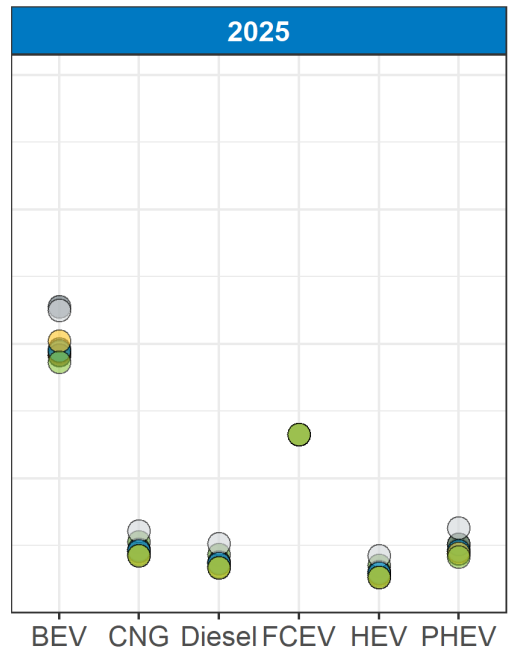

BEV CNG DieselFCEV HEV PHEV

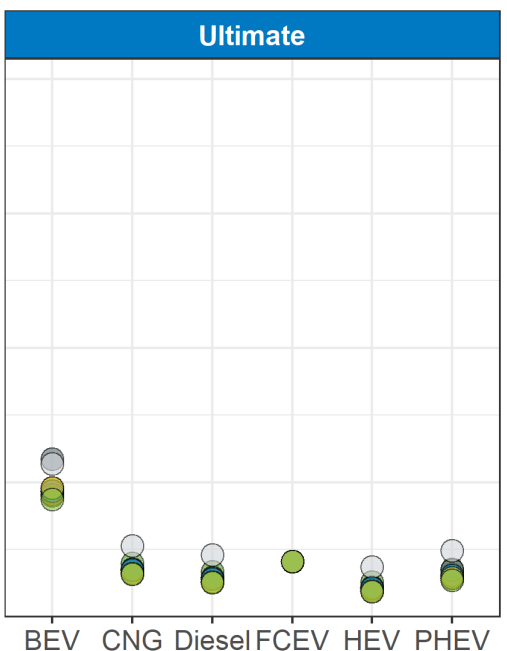

BEV CNG DieselFCEV HEV PHEV

East South Central

Middle Atlantic

Mountain

New England

South Atlantic

West North Central

Figure 33. Regional TCO distribution for the Multi-Shift, Weight-Limited scenario of a Class 8 long-haul tractor (750-mile range)

To better illustrate each powertrain's economic competitiveness with the diesel powertrain, a break-even analysis was completed. Figures 34 and 35 show the break-even fuel price analysis for the Single-Shift, Volume-Limited scenario and the Multi-Shift, Weight-Limited scenario, respectively, of a Class 8 long-haul tractor with a design range of 750 miles operating in the Middle Atlantic region, for three different diesel prices ( $\$ 2 / \mathrm{gal}$, \$3/gal, and \$4/gal). Breakeven fuel price plots for the Single-Shift, Weight-Limited and Multi-Shift, Volume-Limited scenarios can be found in Appendix I, Figures I5 and I6, respectively. The break-even price of each alternative fuel is highly dependent on 
the price of diesel itself, as higher diesel prices would increase the TCO of the diesel powertrain and allow for higher alternative fuel prices to still achieve TCO parity. High break-even prices for a given powertrain indicate that it does not require aggressively low fuel prices to compete with diesel, whereas a break-even price of zero indicates that a powertrain cannot reach cost parity with diesel at the given diesel price. The HEV powertrain is an exception to this in that a break-even fuel price less than the given diesel price indicates that cost parity cannot be achieved.

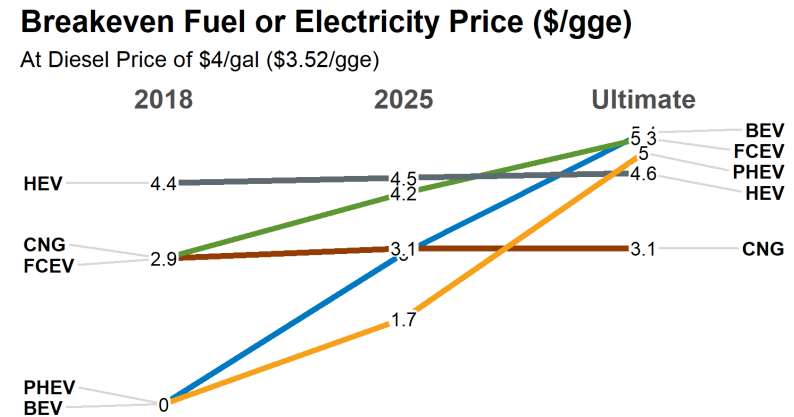

Breakeven Fuel or Electricity Price (\$/gge)

At Diesel Price of \$3/gal (\$2.64/gge)

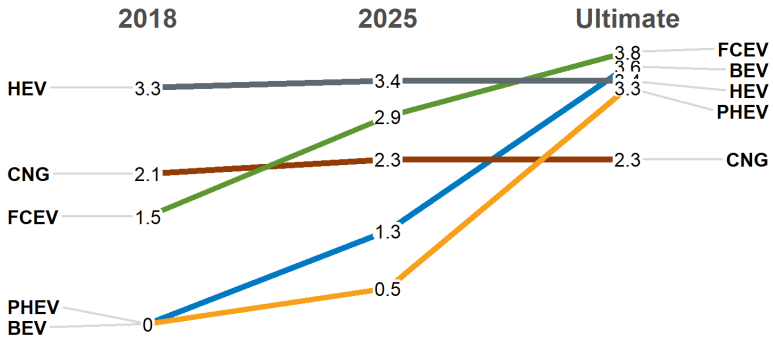

Breakeven Fuel or Electricity Price (\$/gge)

At Diesel Price of $\$ 2 / g a l$ ( $\$ 1.76 / g g e)$

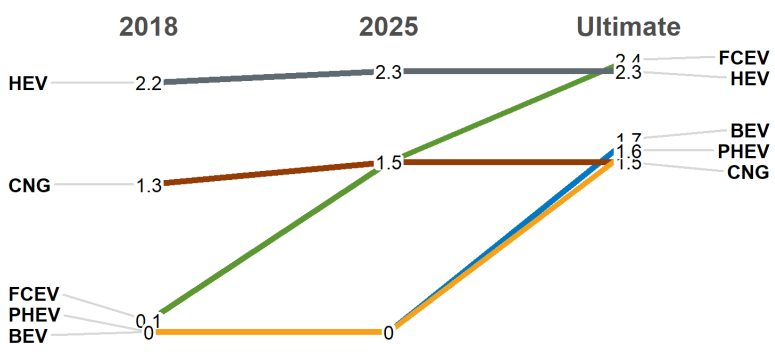

Figure 34. Single-Shift, Volume-Limited break-even fuel price analysis for Class 8 long-haul trucks (750-mile range) in the Middle Atlantic Region

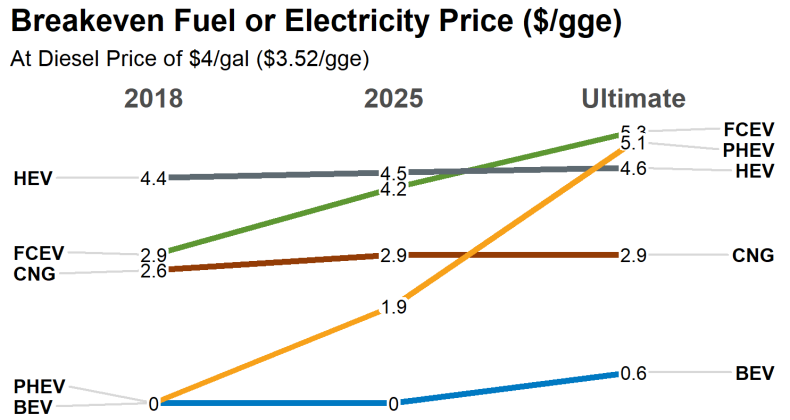

Breakeven Fuel or Electricity Price (\$/gge)

At Diesel Price of \$3/gal (\$2.64/gge)

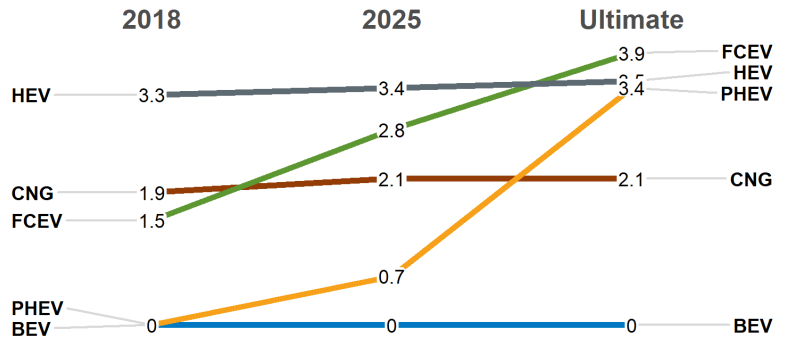

Breakeven Fuel or Electricity Price (\$/gge)

At Diesel Price of \$2/gal (\$1.76/gge)

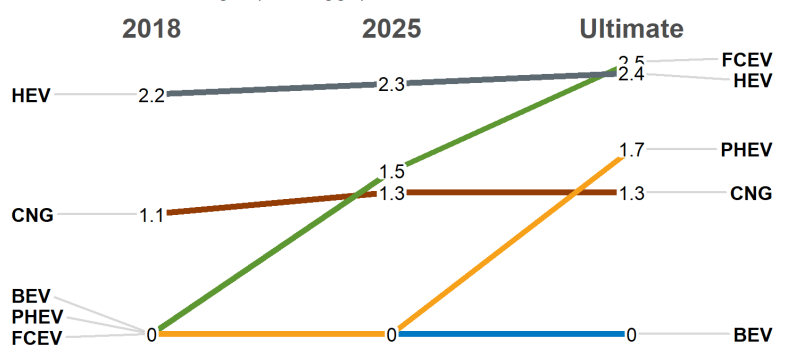

Figure 35. Multi-Shift, Weight-Limited break-even fuel price analysis for Class 8 long-haul trucks (750-mile range) in the Middle Atlantic Region

Figure 34 shows that BEVs and PHEVs cannot reach cost parity with diesel powertrains unless 2025 scenario assumptions are met and the diesel price is at least \$3/gal. HEVs consistently have a higher break-even price than the given diesel price, which is consistent with Figure 30, illustrating that the HEV powertrain is generally lower-cost than the diesel powertrain. The CNG powertrain break-even price does not change significantly with future scenario assumptions achievement, but increases from approximately \$1.5/gge (\$12/million British Thermal Unit [MMBTU]) at the $\$ 2 /$ gal diesel price to $\$ 3.1 / \mathrm{gge}$ (\$25/MMBTU) at the $\$ 4 / \mathrm{gal}$ diesel price. At $\$ 2 / \mathrm{gal}$ or $\$ 3 / \mathrm{gal}$ diesel prices, FCEVs must achieve 2025 scenario assumptions to achieve cost parity with an aggressive hydrogen price $(\$ 2.9 / \mathrm{kg})$. 
When competing against diesel powertrains at a diesel price of $\$ 4 /$ gal with 2025 or Ultimate scenario assumptions achieved, FCEVs are quite competitive, with a break-even price of $\$ 4.2-\$ 5.3 / \mathrm{kg}$. BEVs can reach cost parity with $\$ 2 /$ gal diesel prices only if Ultimate scenario assumptions are achieved. They can reach cost parity with $\$ 3 /$ gal or $\$ 4 /$ gal diesel prices if 2025 scenario assumptions are met, but are most competitive if Ultimate scenario assumptions are met, with break-even prices with $\$ 3 / \mathrm{gal}$ and $\$ 4 / \mathrm{gal}$ diesel prices being $\$ 3.6 / \mathrm{gge}(\$ 0.11 / \mathrm{kWh})$ and $\$ 5.4 / \mathrm{gge}$ $(\$ 0.16 / \mathrm{kWh})$, respectively. Note that these fuel prices are all on an unsubsidized basis. Assuming a $\$ 200 /$ tonne price for carbon as in California's Low Carbon Fuel Standard market (CARB 2021) and a diesel carbon intensity of $100 \mathrm{~g}$ $\mathrm{CO} 2 \mathrm{e} / \mathrm{MJ}$, a nearly $\$ 2.5 /$ dge cost would be incurred against a zero-carbon fuel. Thus, in regions where incentives do exist, these break-even fuel prices for alternative powertrain trucks are potentially feasible with in the 2018 scenario.

Figure I6 illustrates an ever-so-slight reduction in the break-even fuel price for PHEV, CNG, and FCEV associated with dwell costs. Note that the dwell costs for PHEV and FCEV are so small that they are not visible in the TCO breakdown plot in Figure 31. Small changes in break-even price may also be due to the increase in VMT associated with the Multi-Shift operating scenario. BEVs see a substantial reduction in break-even fuel price, only managing to reach cost parity with diesel if Ultimate scenario assumptions are met, the diesel price is $\$ 4 / \mathrm{gal}$, and the electricity cost is $\$ 0.6 / \mathrm{gge}$ or $\$ 0.018 / \mathrm{kWh}$. This plot once again illustrates the potential economic challenges faced by BEVs if they incur dwell time costs and signals FCEVs may be complementary to BEVs in helping decarbonize this commercial vehicle use-case.

\subsubsection{Class 8 Long-Haul Tractor (500-Mile Range)}

Figure 36 shows the Single-Shift, Volume-Limited scenario TCO of a Class 8 long-haul tractor with a design range of 500 miles operating in the Middle Atlantic region. Like the 750-mile-range long-haul truck, the TCO is based on mid costs for fuel and O\&M, a discount rate of 7\%, and a total life VMT of 1 million miles. We assume 100,000 miles per year (380 miles/day based on 260 workdays) for the Class 8 long-haul 500-mile truck operating in the Single-Shift scenarios, so total life for this scenario is expected at around 10 years. The error bars represent the high and low costs for fuel prices and O\&M costs. Similar to the results for the 750-mile-range long-haul truck, BEVs and FCEVs have much higher TCOs in the 2018 time frame than diesel, CNG, HEV, and PHEV. BEVs become cost-competitive if 2025 scenario assumptions are achieved, and FCEVs become cost-competitive once Ultimate fuel costs are achieved. FCEVs could be cost-competitive with diesel trucks in if the 2025 technology scenario assumptions are achieved and hydrogen fuel prices are $\$ 4 / \mathrm{kg}$.

Figure 37 shows the Multi-Shift, Weight-Limited scenario TCO of a Class 8 long-haul tractor with a design range of 500 miles operating in the Middle Atlantic region. BEV is the only powertrain to experience a noticeable increase in TCO associated with payload opportunity cost. With the 2,000-pound exemption, however, this increase is small and all but disappears if 2025 scenario assumptions are achieved. If Ultimate scenario assumptions are achieved, BEVs do not incur a payload opportunity cost. All powertrains experience a small increase in TCO due to the increase in annual VMT from 100,000 miles to 150,000 miles associated with the Multi-Shift operating scenario (580 miles per day resulting in at least one recharging/refueling event during the shift), according to Table 9. BEVs are the only powertrain to see an impact to TCO due to dwell time costs, and this impact is more significant than the cost associated with lost payload capacity due to the 2,000-lb exemption. With dwell time costs incurred, BEVs must achieve Ultimate scenario assumptions to come within the margin of uncertainty of diesel powertrain TCO. Figures I7 and I8 provide TCO breakdowns for the Class 8 500-mile long-haul truck under the Single-Shift, Weight-Limited and Multi-Shift, Volume-Limited scenarios, respectively. 


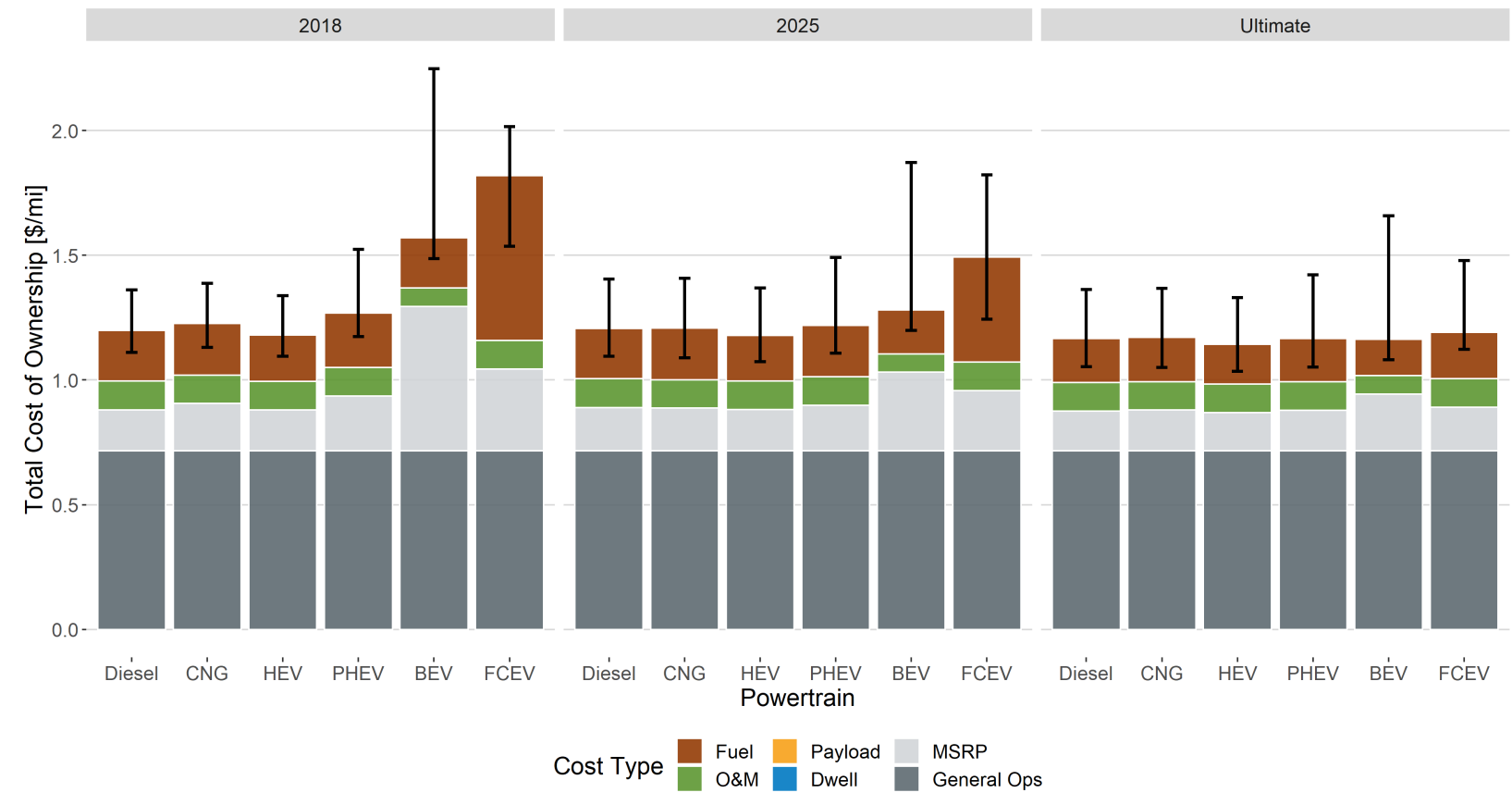

Figure 36. Single-Shift, Volume-Limited scenario TCO for Class 8 long-haul tractors (500-mile range) in the Middle Atlantic region

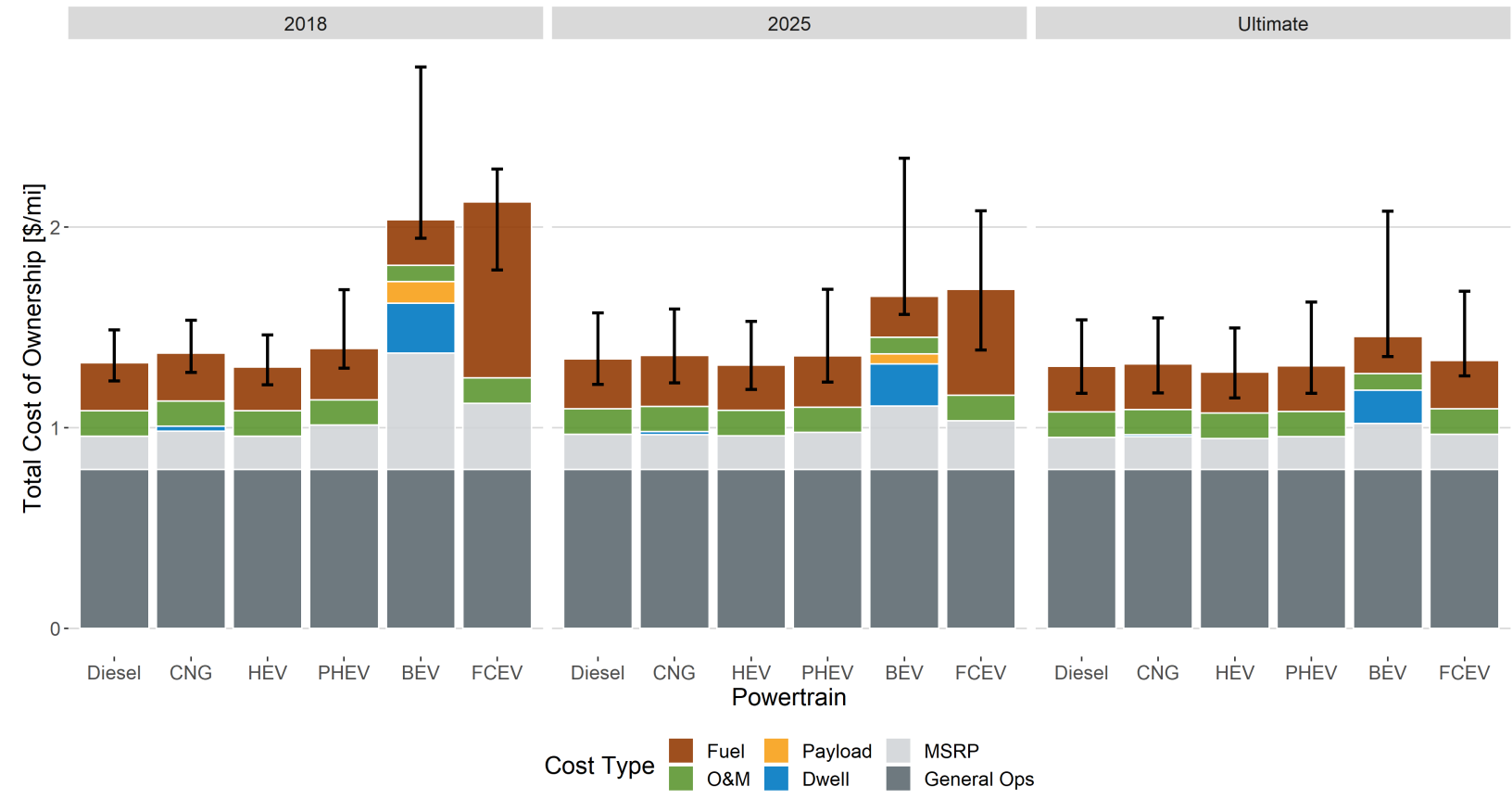

Figure 37. Multi-Shift, Weight-Limited scenario TCO for Class 8 long-haul tractors (500-mile range) in the Middle Atlantic region

Figure 38 shows the regional TCO distribution for the Single-Shift, Volume-Limited scenario of a Class 8 longhaul tractor with a design range of 500 miles. As with the 750-mile-range Class 8 long-haul tractor, the BEV and PHEV experience the largest degree of regional variation in TCO for the 2018 time frame due to larger variations in 
regional electricity prices. Future projections for regional fuel and electricity prices, however, are more consistent across technologies, so the spread in regional TCO seen for BEVs is only slightly larger than that of diesel and CNG for the Ultimate time frame. Note that hydrogen prices are not regionally specific, and thus FCEVs do not show any regional spread in TCO.

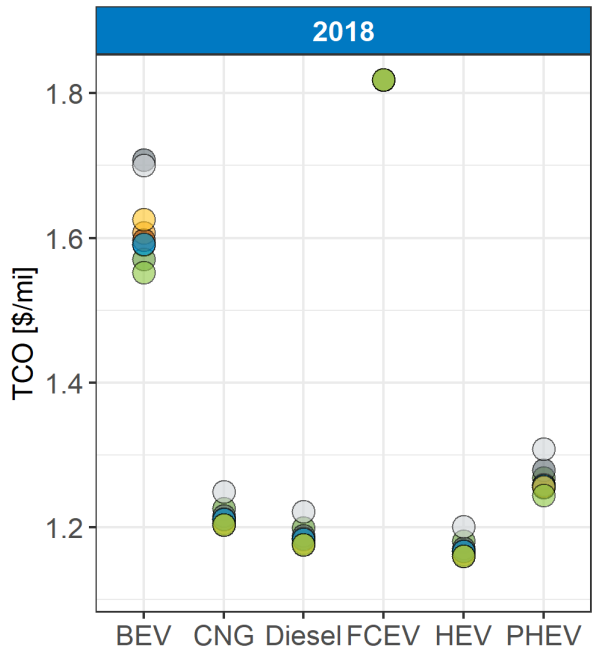

Region

East North Central
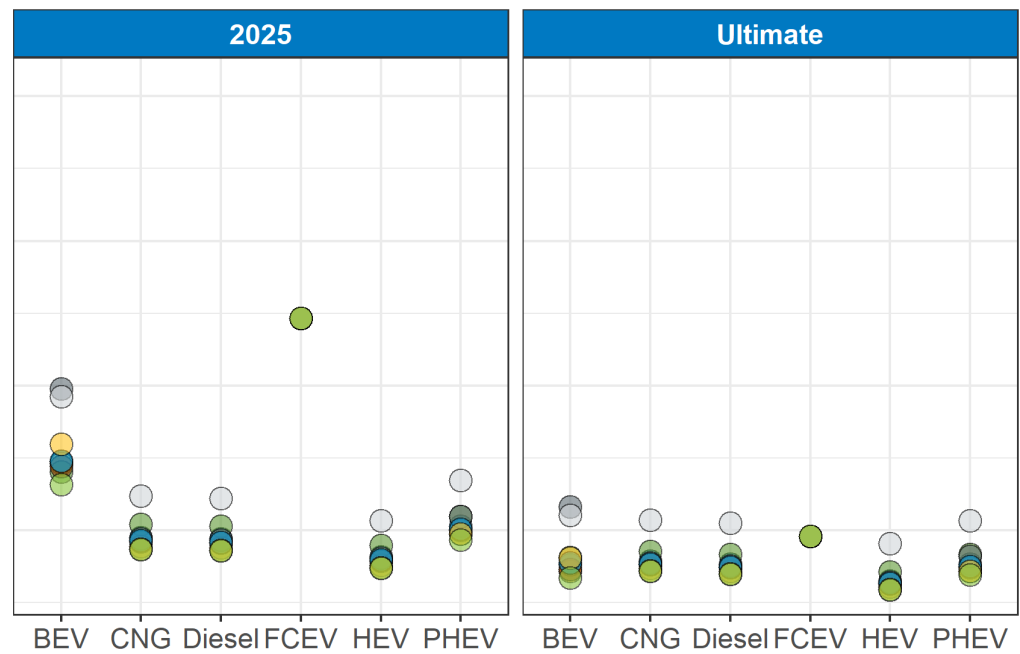

East South Central

Middle Atlantic

Mountain

New England

Pacific

South Atlantic

West North Central

Figure 38. Regional TCO distribution for the Single-Shift, Volume-Limited scenario of a Class 8 long-haul tractor (500-mile range)

Figure 39 shows the regional TCO distribution for the Multi-Shift, Weight-Limited scenario of a Class 8 longhaul tractor with a design range of 500 miles. Once again, the TCO spread associated with regional differences in fuel price is consistent across diesel and CNG, whereas BEVs have larger spread in TCO due to greater regional variance in electricity price, and FCEVs have no spread in TCO due to the lack of regional hydrogen price data. All powertrains experience a slight increase in TCO due to the higher annual VMT of 200,000 miles for the Multi-Shift scenario. The regional TCO spread for the Single-Shift, Weight-Limited and Multi-Shift, Volume-Limited scenarios are given in Figures I9 and I10, respectively. Across all scenarios, the regional fuel price variation can result in up to an approximately $10 \%$ difference in TCO, indicating regional price variations are important when comparing vehicle technologies.

Figure 40 shows the break-even fuel price analysis for the Single-Shift, Volume-Limited scenario of a Class 8 longhaul tractor with a design range of 500 miles operating in the Middle Atlantic region. Compared to the 750-milerange Class 8 long-haul tractor, the break-even prices are all higher as the onboard energy storage is lower, resulting in lower MSRP, which particularly helps the advanced powertrains. In particular, HEV and CNG powertrains are generally cost-competitive with diesel powertrains, with break-even fuel prices ranging from \$2.2-\$4.4/gge and \$1.4-\$3.1/gge (\$11.2-\$24.8/MMBTU), respectively, for diesel prices from \$2-\$4/gal. PHEV and BEV powertrains generally cannot reach cost parity in the 2018 time frame, but can achieve cost parity with electricity prices of around $\$ 1.2-\$ 4.9 / \mathrm{gge}(\$ 0.035-\$ 0.15 / \mathrm{kWh})$ for diesel prices of $\$ 2-\$ 4 / \mathrm{gal}$ if 2025 scenario assumptions are achieved. Both electrified powertrains, however, are most competitive if Ultimate scenario assumptions are met. BEV electricity break-even prices range from approximately $\$ 3 / \mathrm{gge}(\$ 0.09 / \mathrm{kWh})$ with a diesel price of $\$ 2 /$ gal to approximately $\$ 6.5 / \mathrm{gge}(\$ 0.19 / \mathrm{kWh})$ with a diesel price of $\$ 4 / \mathrm{gal}$. The FCEV powertrain can achieve cost parity with diesel in 2018 if the diesel price is high (\$4/gal) and hydrogen price is $\$ 3.4 / \mathrm{kg}$. If the Ultimate scenario assumptions are achieved, FCEVs can reach cost parity with $\$ 3.9 / \mathrm{kg}$ or $\$ 5.3 / \mathrm{kg}$ if the diesel prices are $\$ 3 / \mathrm{gal}$ or $\$ 4 / \mathrm{gal}$, respectively. These prices are in line with the HFTO dispensed hydrogen cost targets, indicating a strong potential for FCEVs to be economically competitive for Class 8 long-haul tractors with a 500-mile range. 


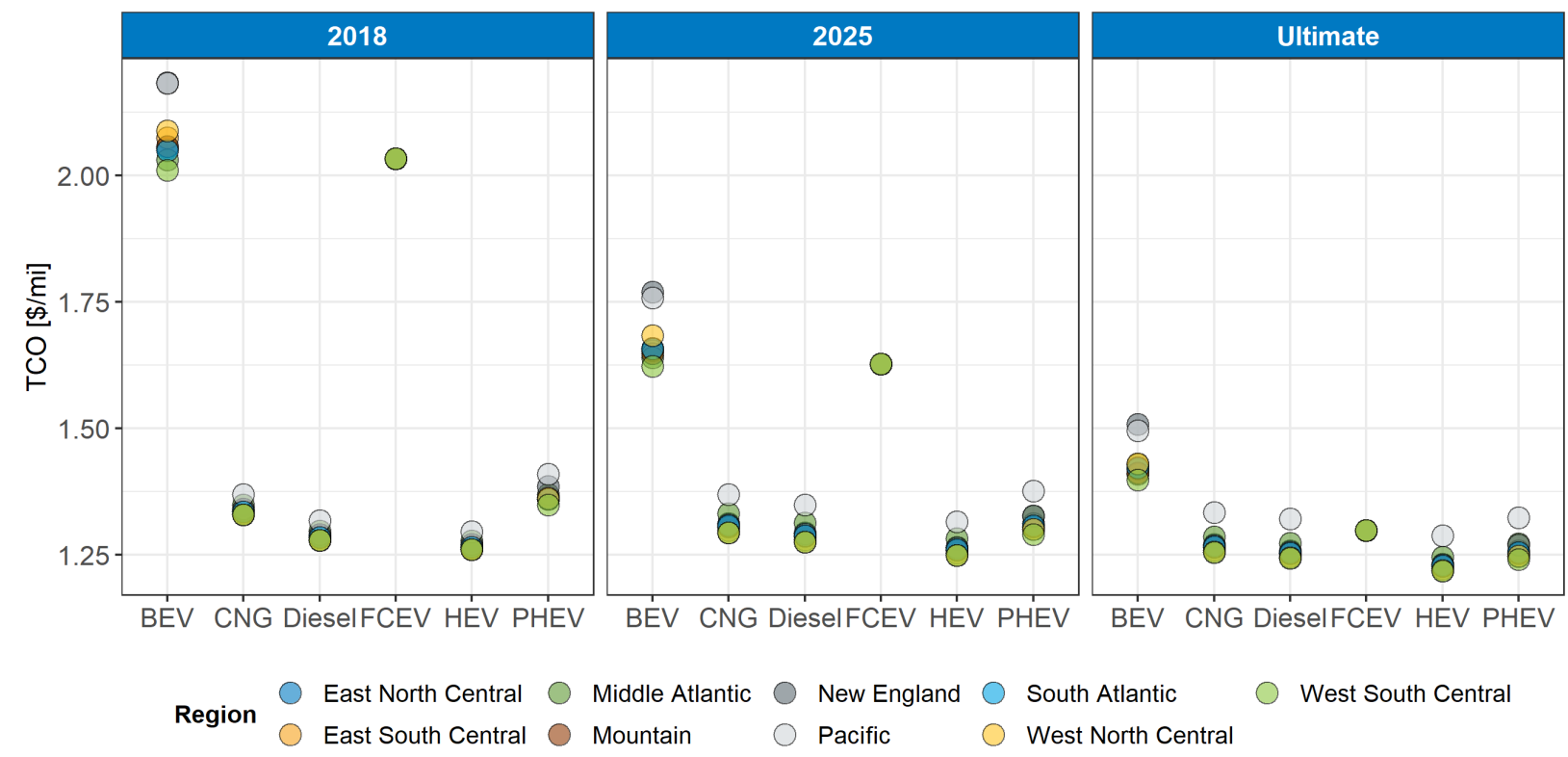

Figure 39. Regional TCO distribution for the Multi-Shift, Weight-Limited scenario of a Class 8 long-haul tractor (500-mile range)

Figure 41 shows the break-even fuel price analysis for the Multi-Shift, Weight-Limited scenario of a Class 8 longhaul tractor with a design range of 500 miles operating in the Middle Atlantic region. As with the 750-mile sleeper truck, most powertrains do not see significant changes in break-even price as they do not incur significant dwell time or lost payload capacity costs. Small changes in break-even price may be associated with the increase in VMT associated with the Multi-Shift scenario. BEVs see a substantial reduction in break-even fuel price, requiring Ultimate scenario assumptions and a $\$ 3 /$ gal diesel price to have any chance of being cost-competitive due to the combination of dwell and payload capacity costs incurred. However, BEVs could be competitive with an electricity price of $\$ 2.6 / \mathrm{gge}$ ( $\$ 0.08 / \mathrm{kWh}$ ) if Ultimate scenario assumptions are met and the diesel price is $\$ 4 / \mathrm{gal}$. This suggests that BEVs have a chance of becoming competitive with diesel long-haul trucks with a 500-mile range if diesel is expensive and electricity is relatively low-cost.

Break-even fuel price plots for the Single-Shift, Weight-Limited and Multi-Shift, Volume-Limited scenarios can be found in Appendix I, Figures I11 and I12, respectively. 
Breakeven Fuel or Electricity Price (\$/gge)

At Diesel Price of \$4/gal (\$3.52/gge)

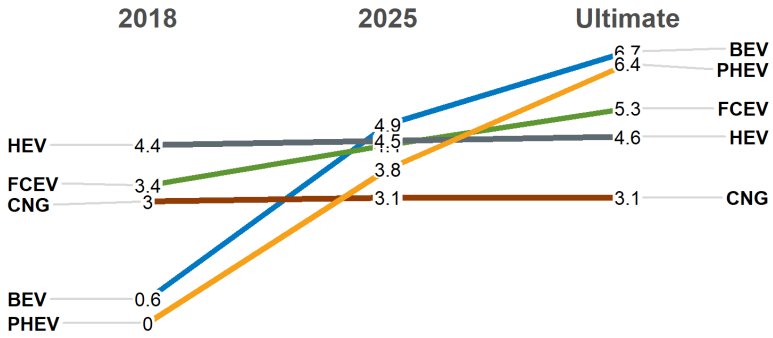

Breakeven Fuel or Electricity Price (\$/gge)

At Diesel Price of $\$ 3 / g a l$ (\$2.64/gge)

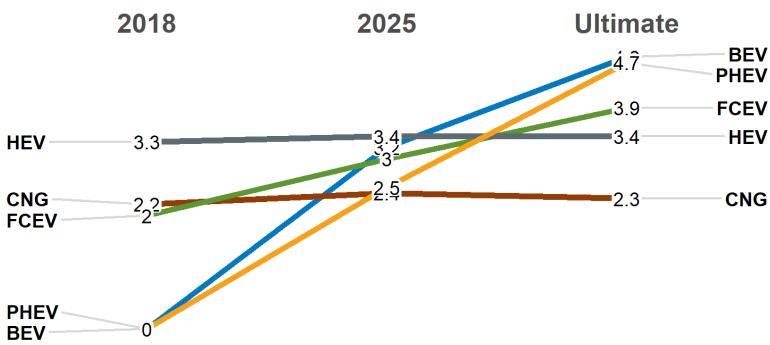

Breakeven Fuel or Electricity Price (\$/gge)

At Diesel Price of \$2/gal (\$1.76/gge)

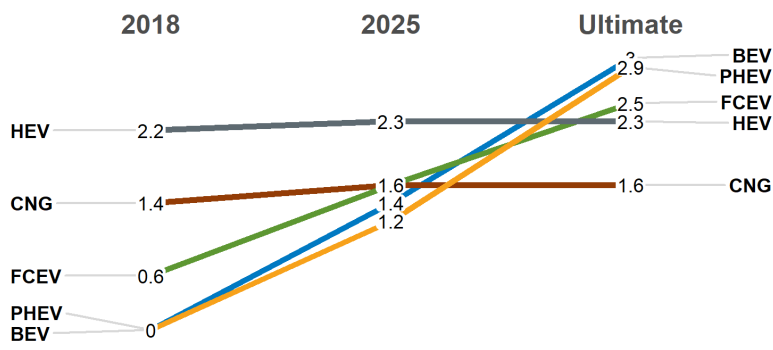

Figure 40. Single-Shift, Volume-Limited break-even fuel price analysis for Class 8 long-haul trucks (500-mile range) in the Middle Atlantic Region
Breakeven Fuel or Electricity Price (\$/gge)

At Diesel Price of \$4/gal (\$3.52/gge)

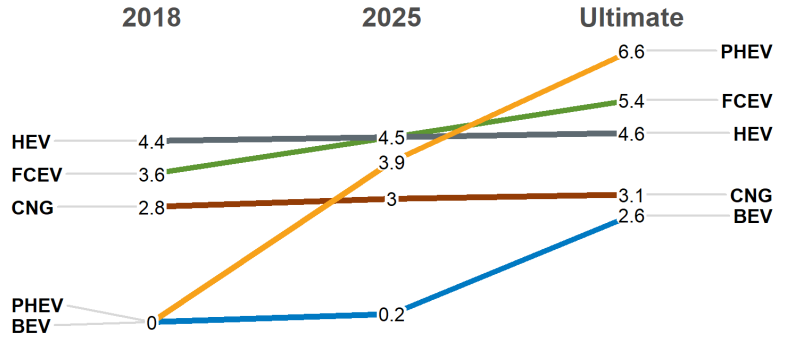

Breakeven Fuel or Electricity Price (\$/gge)

At Diesel Price of $\$ 3 / \mathrm{gal}$ ( $\$ 2.64 / \mathrm{gge}$ )

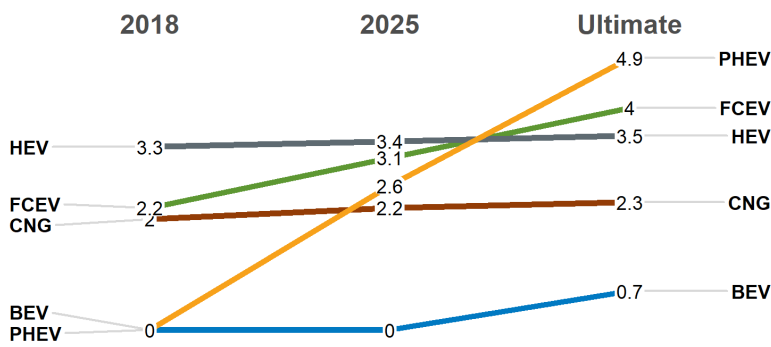

Breakeven Fuel or Electricity Price (\$/gge)

At Diesel Price of \$2/gal (\$1.76/gge)

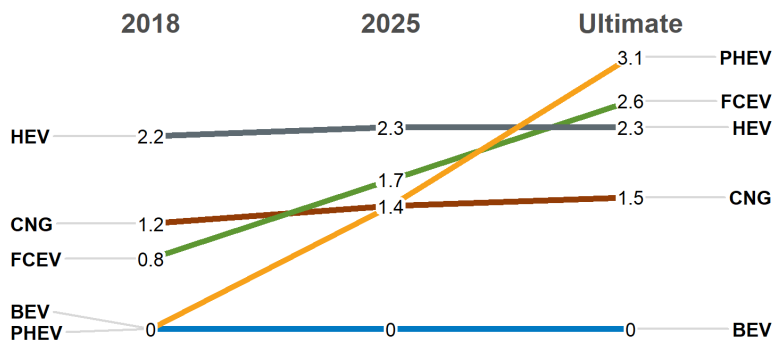

Figure 41. Multi-Shift, Weight-Limited break-even fuel price analysis for Class 8 long-haul trucks (500-mile range) in the Middle Atlantic Region

\subsubsection{Class 8 Short-Haul Tractor (300-Mile Range)}

Figure 42 shows the Single-Shift, Volume-Limited scenario TCO of a Class 8 short-haul tractor with a design range of 300 miles operating in the Middle Atlantic region. HEV and PHEV have the lowest TCO in the current time frame, with the diesel and CNG powertrains close behind. The analysis calculates lower PHEV TCO than diesel because the drive cycle for short-haul vehicles is more dynamic and benefits from the ability to use regenerative breaking. Furthermore, the MSRP for PHEV is more competitive at this range due to the smaller battery required. BEV has slightly higher TCO than diesel and CNG in the 2018 time frame due to higher MSRP driven by the battery cost. FCEVs have the highest TCO due to higher-than-conventional MSRP and high hydrogen fuel costs. BEVs will reach cost parity with conventional and hybrid powertrains if 2025 scenario assumptions are met and charging electricity costs are not excessive. FCEV TCO is within the margin of uncertainty of diesel in the 2025 time frame, dependent largely on fuel costs. All powertrains are expected to be cost-competitive if the Ultimate scenario assumptions are achieved, with BEVs potentially having the lowest TCO if low electricity prices can be achieved due to the high energy efficiency of the powertrain and low potential O\&M costs. 


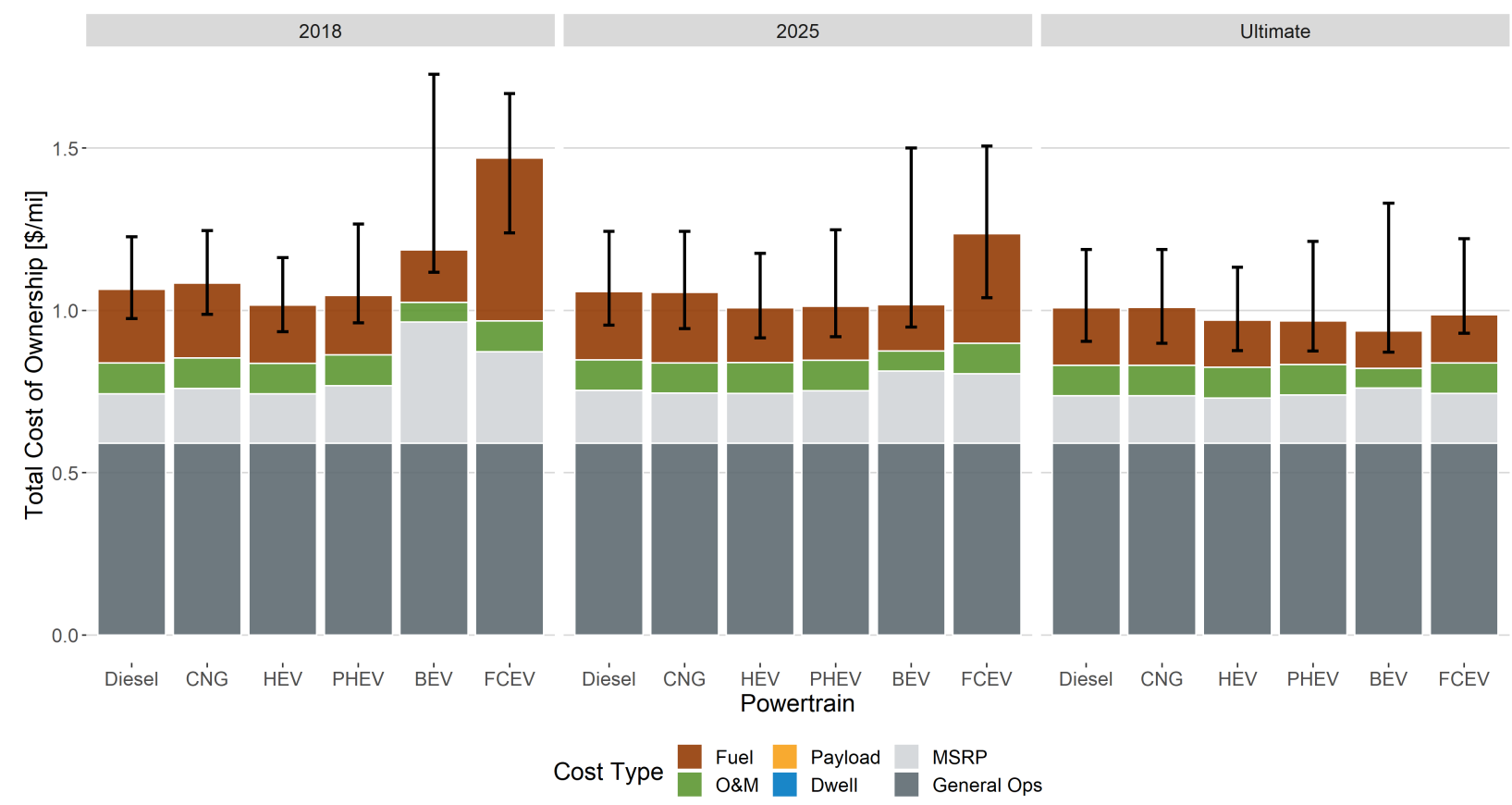

Figure 42. Single-Shift, Volume-Limited scenario TCO for Class 8 short-haul tractors (300-mile range) in the Middle Atlantic region

Figure 43 shows the Multi-Shift, Weight-Limited scenario TCO of a Class 8 short-haul tractor with a design range of 300 miles operating in the Middle Atlantic region. BEVs incur a very small payload opportunity cost in the 2018 time frame, but this does not significantly impact TCO. BEVs are the only powertrain to experience a TCO increase associated with dwell time costs. Although this cost puts BEV TCO outside the range of uncertainty for diesel powertrains in the current time frame, BEVs that incur dwell time costs may still be competitive with conventional powertrains if 2025 or Ultimate scenario assumptions are met, depending on fuel and O\&M costs. Lastly, in this operating scenario, FCEVs may complement BEVs to help decarbonize this segment as the FCEV is the lowest-cost ZEV if the Ultimate scenario assumptions are achieved, because there are effectively no dwell time costs incurred. Figures I13 and I14 show the TCO breakdown for the Single-Shift, Weight-Limited and Multi-Shift, Volume-Limited scenarios, respectively. 


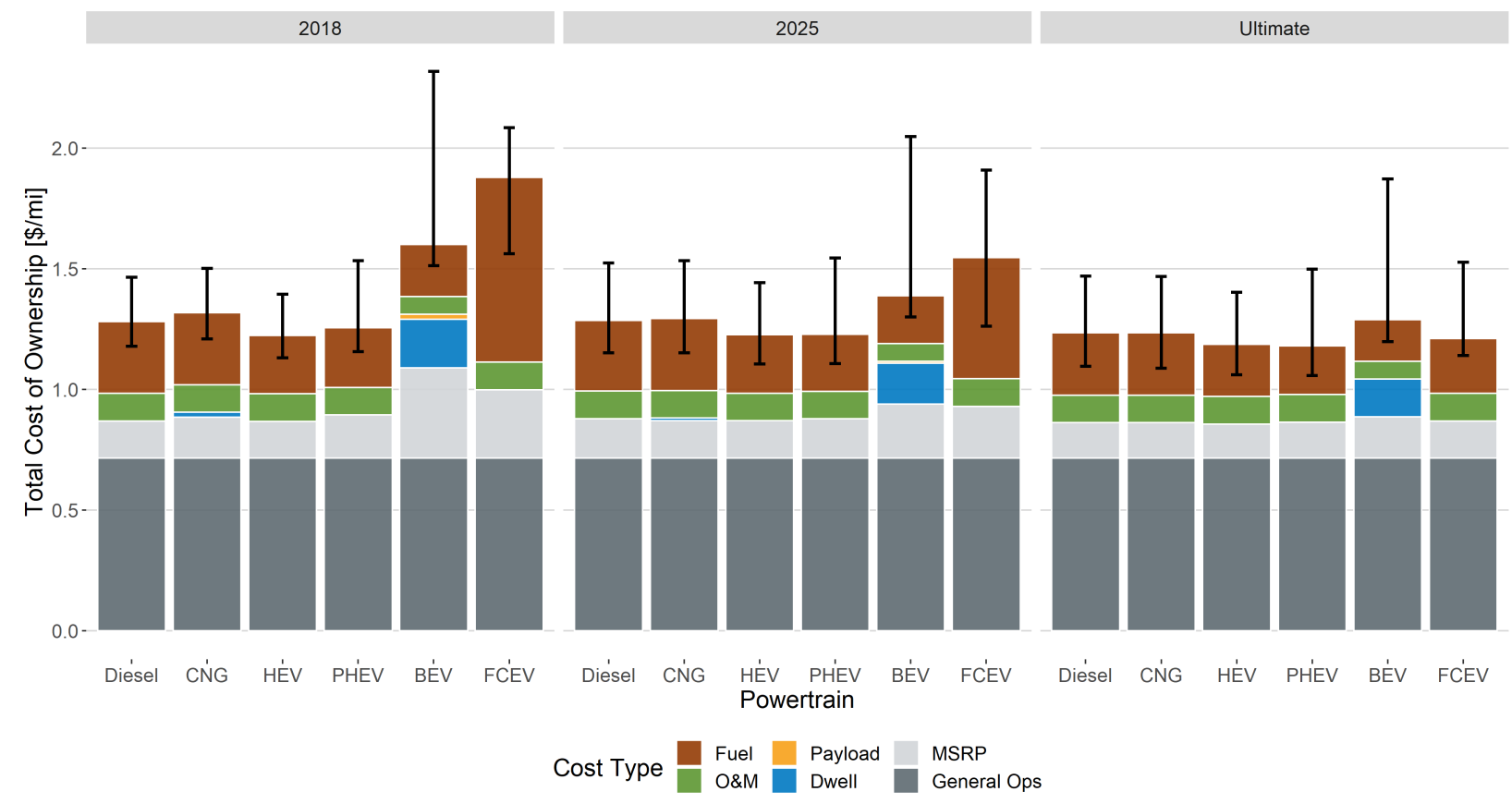

Figure 43. Multi-Shift, Weight-Limited scenario TCO for Class 8 short-haul tractors (300-mile range) in the Middle Atlantic region

Figure 44 shows the regional TCO distribution for the Single-Shift, Volume-Limited scenario of a Class 8 short-haul tractor with a design range of 300 miles. As with Class 8 long-haul trucks, BEVs show the greatest regional variance in TCO, due to greater regional spread in electricity prices than in diesel or natural gas prices. Once again, FCEVs see no regional variance in TCO because hydrogen prices used in this study do not have regional specificity. Overall, there is up to a $10 \%$ variation in TCO based on regional fuel prices across powertrains.

Figure 45 shows the regional TCO distribution for the Multi-Shift, Weight-Limited scenario of a Class 8 shorthaul tractor with a design range of 300 miles. BEV TCO increases slightly due to the incurred dwell time cost, and all powertrains experience a slight increase in TCO due to the increase in annual VMT from 60,000 miles for the Single-Shift scenario to 100,000 miles for the Multi-Shift scenario. The regional spread, however, shows the same trends as in the Single-Shift, Volume-Limited case. Figures I15 and I16 show the regional TCO distribution for the Single-Shift, Weight-Limited and Multi-Shift, Volume-Limited scenarios, respectively.

Figure 46 shows the break-even fuel price analysis for the Single-Shift, Volume-Limited scenario of a Class 8 shorthaul tractor with a design range of 300 miles operating in the Middle Atlantic region. HEV and CNG powertrains are generally cost-competitive regardless of scenario assumptions achievement, whereas BEVs and FCEVs are most cost-competitive when Ultimate scenario assumptions are met or if diesel prices are high. BEVs require a very low electricity price to be cost-competitive with $\$ 2 /$ gal diesel prices under the 2018 technology time frame, but otherwise have break-even electricity prices ranging from $\$ 3.3 / \mathrm{gge}(\$ 0.1 / \mathrm{kWh})$ to $\$ 9.8 / \mathrm{gge}(\$ 0.29 / \mathrm{kWh})$. Similarly, FCEV competitiveness requires the most aggressive fuel price $(\$ 1.4 / \mathrm{kg})$ under the 2018 technology status with $\$ 2 /$ gal diesel fuel price. The FCEV break-even price ranges from $\$ 3.3 / \mathrm{kg}$ to $\$ 5.1 / \mathrm{kg}$ with a diesel price of $\$ 3 / \mathrm{gal}$, however, and this range increases to $\$ 5.1-\$ 6.8 / \mathrm{kg}$ with a diesel price of $\$ 4 / \mathrm{gal}$. The most notable feature of Figure 46 is the high break-even fuel price of the PHEV powertrain. This is largely due to the higher fuel economy of short-haul PHEVs in urban traffic conditions (regenerative braking plus the electric powertrain) compared to the highway-heavy driving conditions of their 500-mile long-haul counterpart. Second, compared to long-haul PHEVs, the MSRP contribution of batteries is significantly lower, which allows the PHEV to be close to the diesel MSRP. 

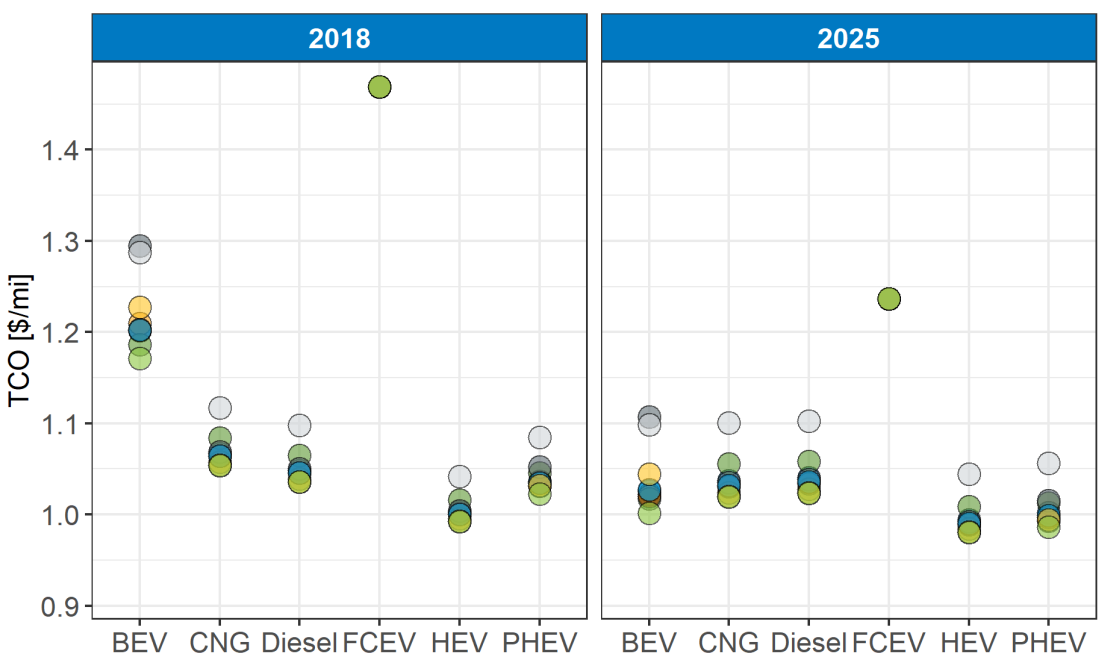

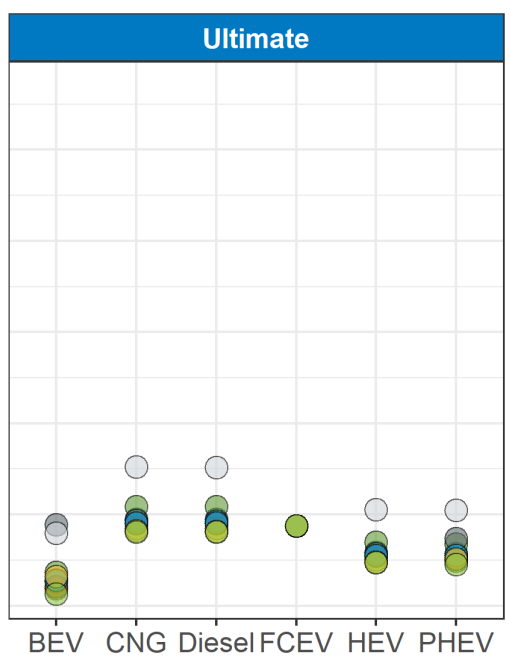

Region

Middle Atlantic

New England

South Atlantic

Mountain

Pacific

West North Central

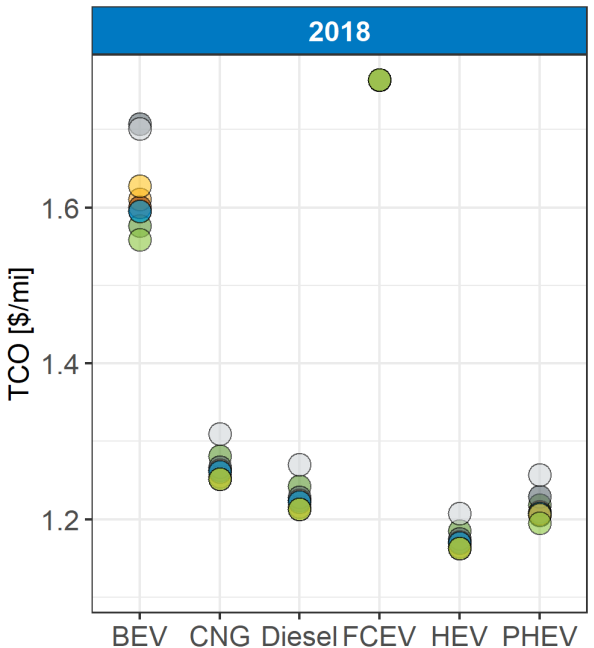

Region

\section{.}

East North Central

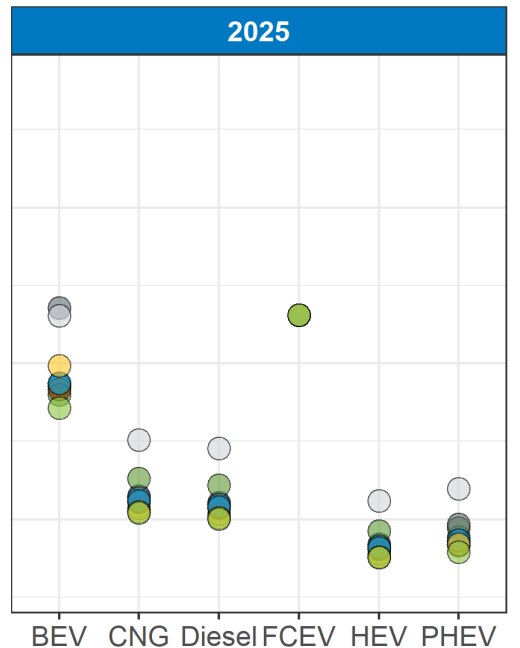

BEV CNG DieselFCEV HEV PHEV

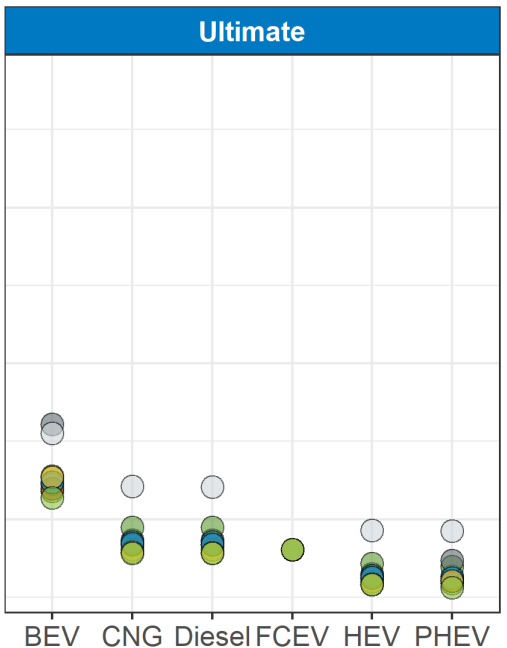

BEV CNG DieselFCEV HEV PHEV

East South Central

Middle Atlantic

Mountain

New England
Pacific

South Atlantic

West North Central

Figure 45. Regional TCO distribution for the Multi-Shift, Weight-Limited scenario of a Class 8 short-haul tractor (300-mile range)

Figure 47 shows the break-even fuel price analysis for the Multi-Shift, Weight-Limited scenario of a Class 8 shorthaul tractor with a design range of 300 miles operating in the Middle Atlantic region. Although all powertrains experience small changes associated with the increased VMT for the Multi-Shift scenario, BEVs experience the greatest change with a significant reduction in break-even price due to the high contribution of dwell time cost to their TCO. BEVs struggle to be competitive with diesel prices of $\$ 2 /$ gal for this scenario. BEVs can be competitive with diesel powertrains, however, if 2025 or Ultimate scenario assumptions are achieved and diesel prices are at least 
\$3/gal. BEVs are particularly competitive with $\$ 4 /$ gal diesel in the 2025 and Ultimate scenario assumptions cases, with break-even electricity prices of $\$ 4.9-\$ 5.3 / \mathrm{gge}(\$ 0.15-\$ 0.16 / \mathrm{kWh})$. FCEVs can be competitive with diesel tractors if the 2025 scenario assumptions are achieved, diesel prices are $\$ 3 / \mathrm{gal}$, and a hydrogen price of $\$ 3.8 / \mathrm{kg}$ is achieved. At higher diesel prices of $\$ 4 / \mathrm{kg}$, this break-even hydrogen price increases to $\$ 5.9 / \mathrm{kg}$, which overlaps to the low end of prices observed today $(\$ 5 / \mathrm{kg}$ ) in the fuel cell bus evaluations (Eudy 2019). As the Ultimate scenario assumptions are achieved, hydrogen prices can be $\$ 5.1 / \mathrm{kg}$ if diesel is $\$ 3 / \mathrm{gal}$ or nearly $\$ 7 / \mathrm{kg}$ if diesel is $\$ 4 / \mathrm{gal}$.

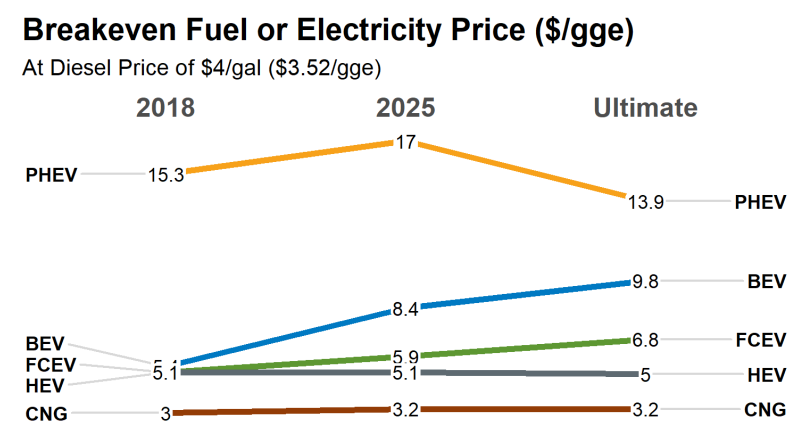

Breakeven Fuel or Electricity Price (\$/gge)

At Diesel Price of \$3/gal (\$2.64/gge)
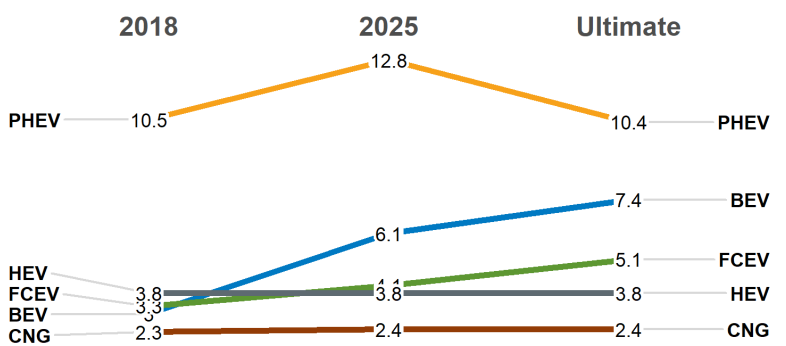

Breakeven Fuel or Electricity Price (\$/gge)

At Diesel Price of \$2/gal (\$1.76/gge)
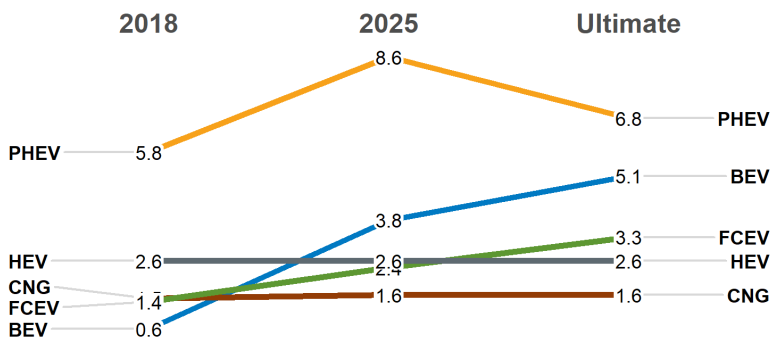

Figure 46. Single-Shift, Volume-Limited breakeven fuel price analysis for Class 8 short-haul trucks (300-mile range) in the Middle Atlantic region

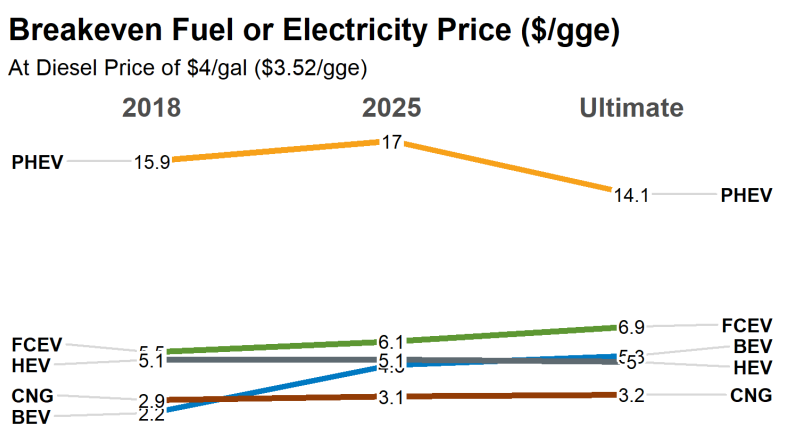

Breakeven Fuel or Electricity Price (\$/gge)

At Diesel Price of \$3/gal (\$2.64/gge)
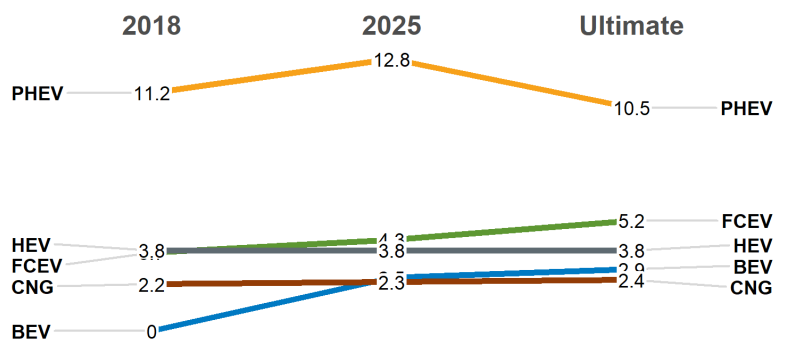

Breakeven Fuel or Electricity Price (\$/gge)

At Diesel Price of \$2/gal (\$1.76/gge)
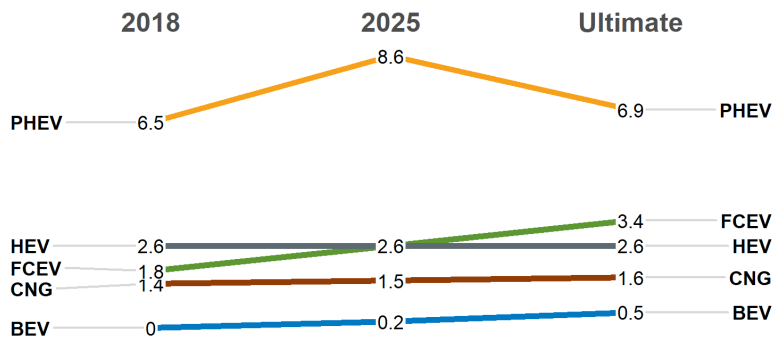

Figure 47. Multi-Shift, Weight-Limited break-even fuel price analysis for Class 8 short-haul trucks (300-mile range) in the Middle Atlantic region

\subsubsection{Class 4 Parcel Delivery (120-Mile Range)}

Figure 48 shows the Single-Shift scenario TCO of a Class 4 parcel delivery truck with a design range of 120 miles operating in the Middle Atlantic region. Although BEVs have slightly higher MSRPs, they are still potentially cost-competitive with diesel, CNG, and hybrid powertrains in the 2018 time frame depending on electricity and O\&M costs. FCEVs have higher TCO in the 2018 time frame due to high hydrogen fuel costs. All powertrains are predicted to be cost-competitive if 2025 or Ultimate scenario assumptions are achieved, with BEVs having the lowest 
potential TCO.

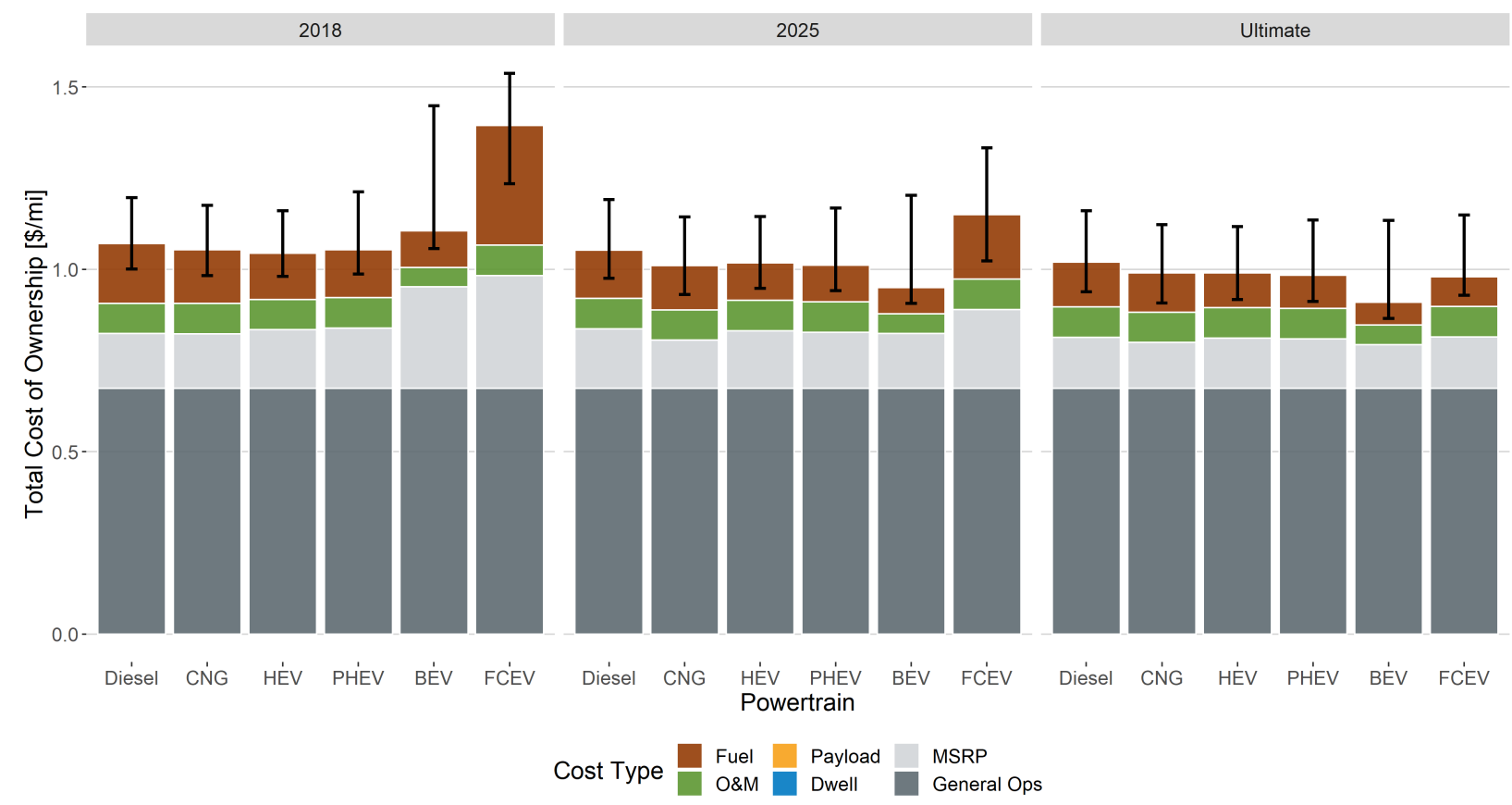

Figure 48. Single-Shift scenario TCO for Class 4 parcel delivery truck (120-mile range) in the Middle Atlantic region

Figure 49 shows the Multi-Shift scenario TCO of a Class 4 parcel delivery truck with a design range of 120 miles operating in the Middle Atlantic region. Only the BEV powertrain experiences a TCO increase associated with dwell time costs, and the increase is substantial for every technology scenario assumptions time frame. This impact is more pronounced for Class 4 parcel delivery trucks than for Class 8 vehicles due to the higher number of refueling events over the lifetime of the vehicle combined with the relatively lower MSRP and fuel expenses for the smaller, lower-fuel-consumption Class 4 parcel delivery truck. It should be noted here that the PHEV powertrain is assumed to utilize the fast-filling capability of diesel in this scenario, but that would result in potential challenges on the vehicle power output for hilly terrain as the diesel engine is downsized, as well as emissions implications that were not evaluated in this analysis. 


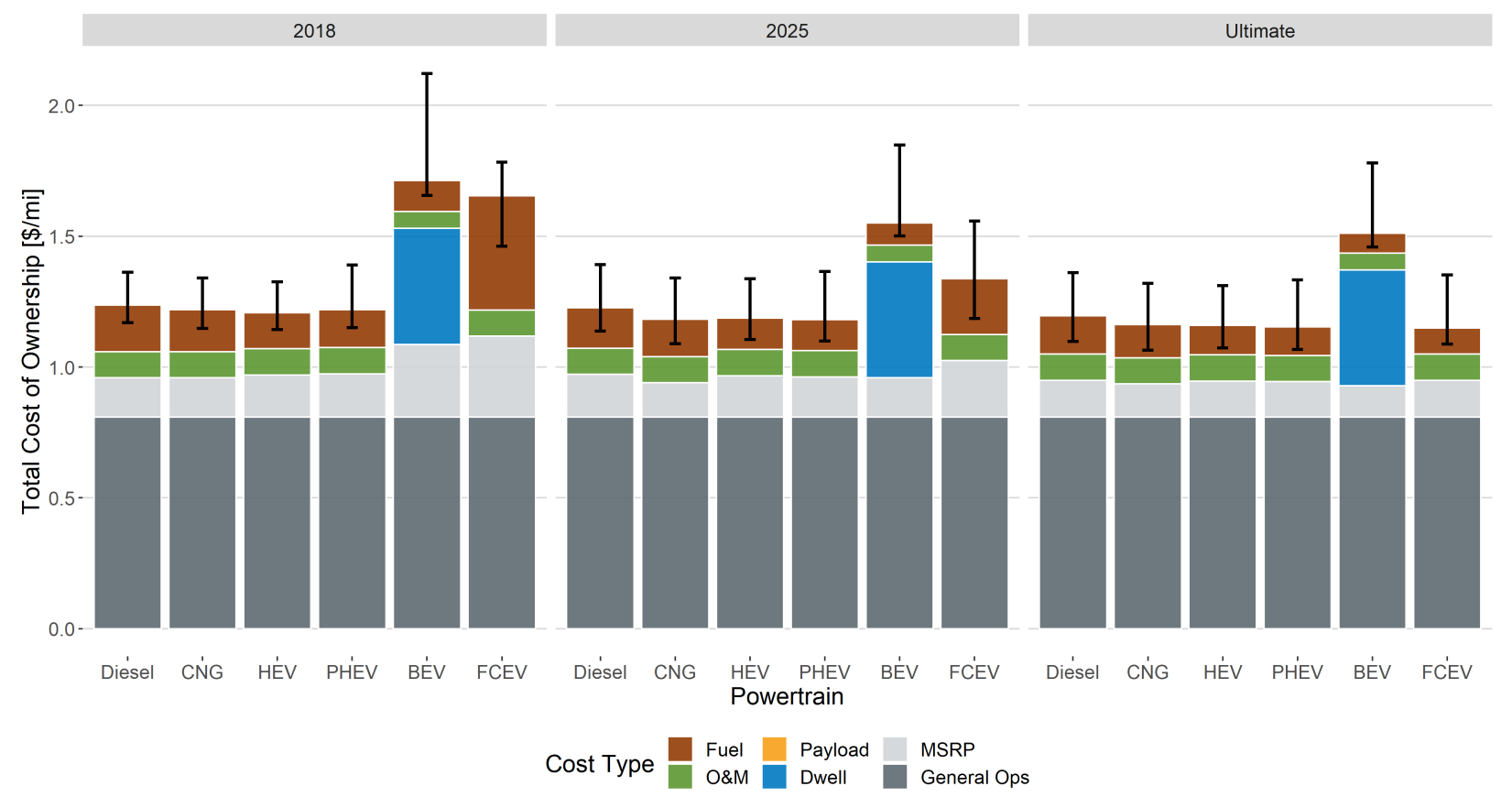

Figure 49. Multi-Shift scenario TCO for Class 4 parcel delivery truck (120-mile range) in the Middle Atlantic region

Figure 50 shows the regional TCO distribution for the Single-Shift, Volume-Limited scenario of a Class 4 parcel delivery truck with a design range of 300 miles. Like the Class 8 trucks, the BEV powertrain shows the greatest regional TCO spread for the Class 4 parcel delivery vehicle due to the wide variation in electricity price. This variation reduces as 2025 and Ultimate scenario assumptions are achieved. Diesel and CNG powertrains see a slight increase in spread in TCO associated with regional fuel costs as 2025 and Ultimate scenario assumptions are achieved. Note that regardless of region, $\mathrm{BEV}$ is predicted to have the lowest TCO if Ultimate scenario assumptions are achieved. Once again, FCEVs see no spread in TCO because the price of hydrogen is not regionally specified in this study. Figure 51 shows the regional TCO distribution for the Multi-Shift, Volume-Limited scenario of a Class 4 parcel delivery truck with a design range of 120 miles. All vehicles see a slight increase in TCO due to the higher VMT associated with the Multi-Shift scenario. Otherwise, the biggest difference relative to Figure 50 is that the BEV powertrain, TCO is much higher for all regions due to the significant dwell time cost incurred in the Multi-Shift scenario.

Figure 52 shows the break-even fuel price analysis for the Single-Shift, Volume-Limited scenario of a Class 4 parcel delivery truck with a design range of 120 miles operating in the Middle Atlantic region. HEV and CNG are both readily competitive with diesel, regardless of the technology status or diesel price. FCEVs are not competitive with diesel for the 2018 technology status unless diesel prices are at least \$3/gal. Under 2025 and Ultimate technology scenario assumptions, FCEVs can achieve cost parity with $\$ 2-\$ 3 /$ gal diesel with moderate to aggressive hydrogen prices. If the diesel price is $\$ 4 / \mathrm{gal}$, however, the FCEV break-even hydrogen prices are $\$ 6.5 / \mathrm{kg}$ and $\$ 8.8 / \mathrm{kg}$ for the 2025 and Ultimate technology scenario assumptions, respectively. BEVs show significant promise for the Class 4 parcel delivery truck, with the lowest break-even electricity price being $\$ 2.4 / \mathrm{gge}(\$ 0.07 / \mathrm{kWh})$ for the 2018 technology status and a diesel price of $\$ 2 /$ gal. For all other BEV cases, the break-even price is above $\$ 5 / \mathrm{gal}$ or $\$ 0.15 / \mathrm{kWh}$. The PHEV powertrain also looks promising, with break-even electricity prices above $\$ 7.6 / \mathrm{gge}(\$ 0.23 / \mathrm{kWh})$ across the board.

Figure 53 shows the break-even fuel price analysis for the Multi-Shift, Volume-Limited scenario of a Class 4 parcel delivery with a design range of 120 miles operating in the Middle Atlantic region. All powertrains experience minor shifts in break-even price associated with the increase in VMT for the Multi-Shift scenario. The most notable change relative to Figure 52 is that the BEV powertrain is unable to achieve TCO parity with diesel regardless of diesel or electricity price. This illustrates that FCEVs may complement BEVs and be the best powertrain to decarbonize the 
Class 4 parcel delivery trucks operating multiple shifts per day.
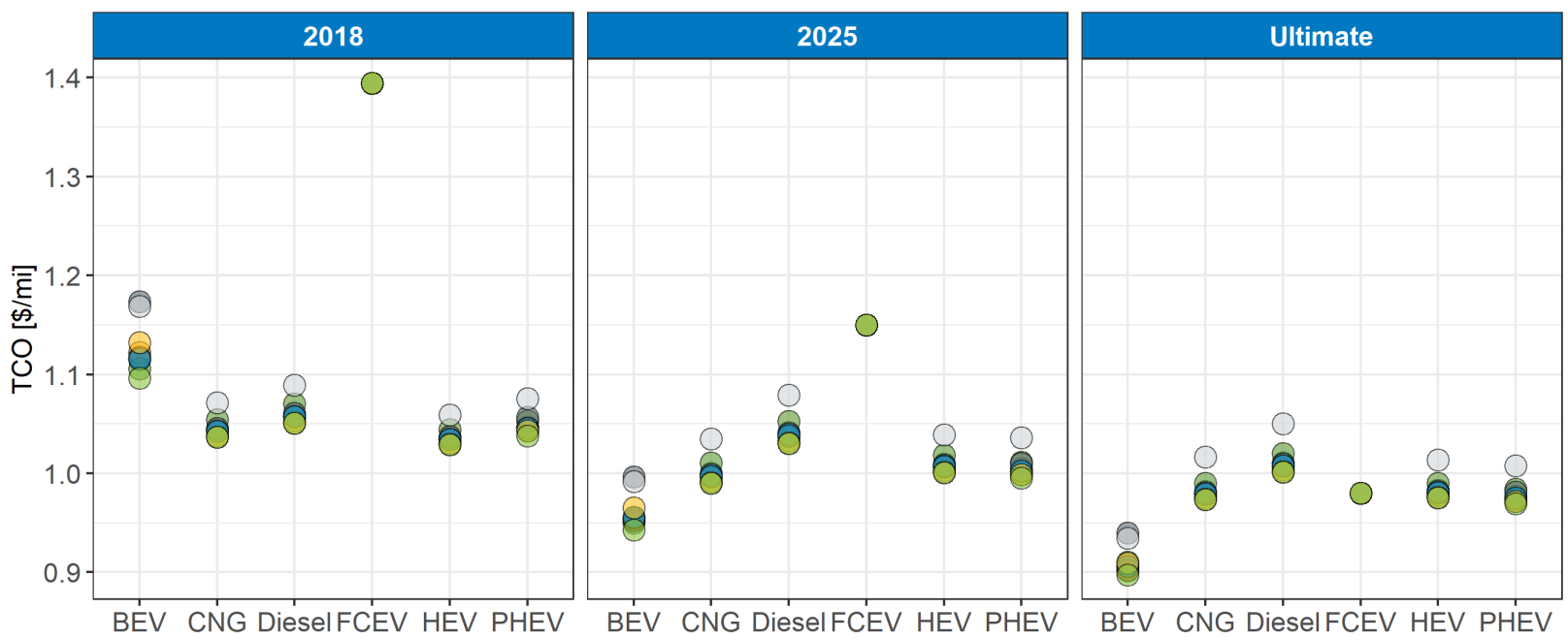

Region

East North Central

iddle Atlantic

New England
Pacific

South Atlantic

West North Central

Figure 50. Regional TCO distribution for the Single-Shift, Volume-Limited scenario of a Class 4 parcel delivery truck (120-mile range)

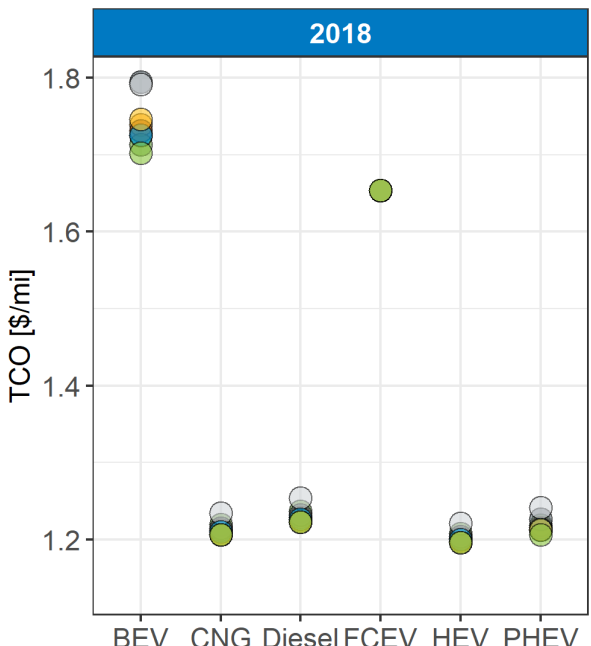

Region

.

East North Central

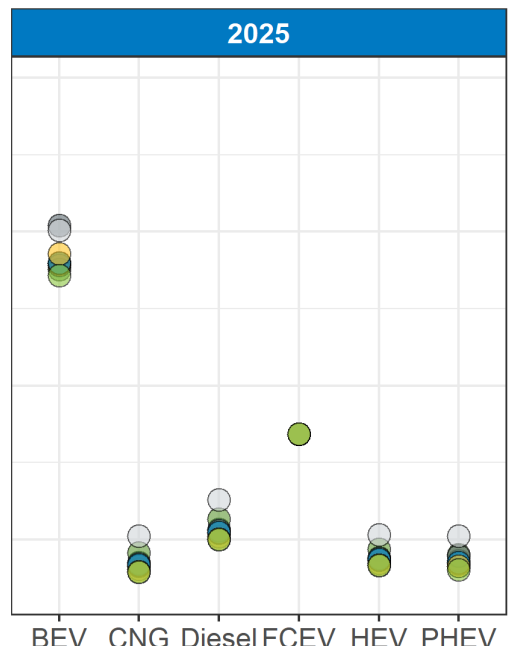

BEV CNG DieselFCEV HEV PHEV

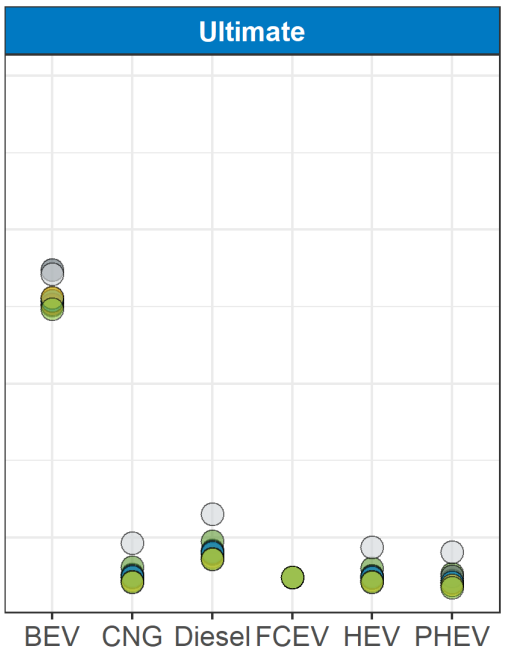

BEV CNG DieselFCEV HEV PHEV

East South Central

Middle Atlantic

Mountain

New England

South Atlantic

Pacific

West North Central

Figure 51. Regional TCO distribution for the Multi-Shift, Volume-Limited scenario of a Class 4 parcel delivery truck (120-mile range) 
Breakeven Fuel or Electricity Price (\$/gge)

At Diesel Price of $\$ 4 / \mathrm{gal}$ ( $\$ 3.52 / \mathrm{gge}$ )

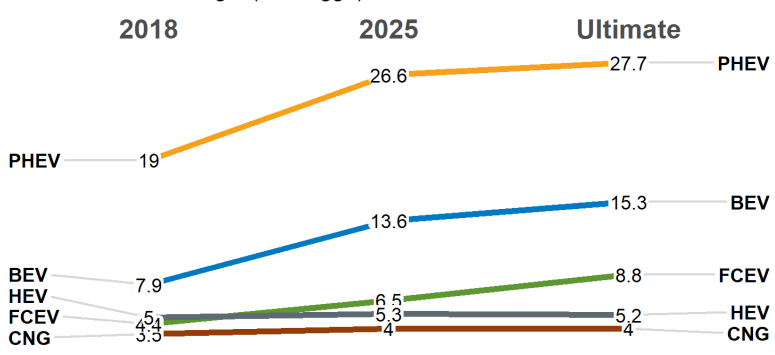

Breakeven Fuel or Electricity Price (\$/gge)

At Diesel Price of $\$ 3 / \mathrm{gal}(\$ 2.64 / \mathrm{gge})$

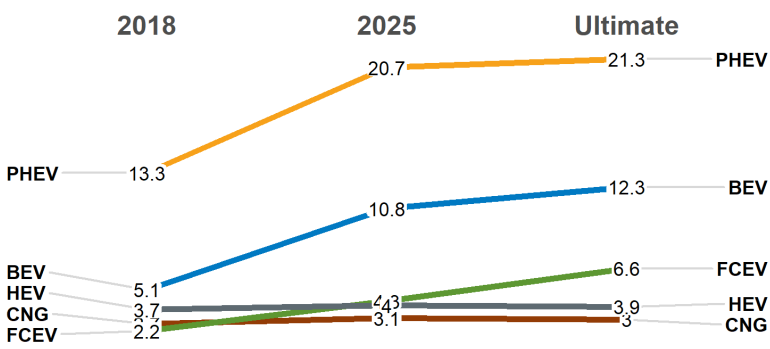

Breakeven Fuel or Electricity Price (\$/gge)

At Diesel Price of $\$ 2 / \mathrm{gal}$ (\$1.76/gge)

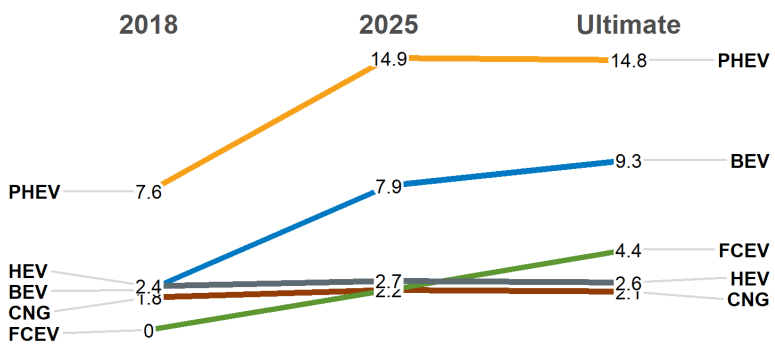

Figure 52. Single-Shift, Volume-Limited breakeven fuel price analysis for Class 4 parcel delivery trucks (120-mile range) in the Middle Atlantic region
Breakeven Fuel or Electricity Price (\$/gge)

At Diesel Price of $\$ 4 / \mathrm{gal}$ ( $\$ 3.52 / \mathrm{gge}$ )

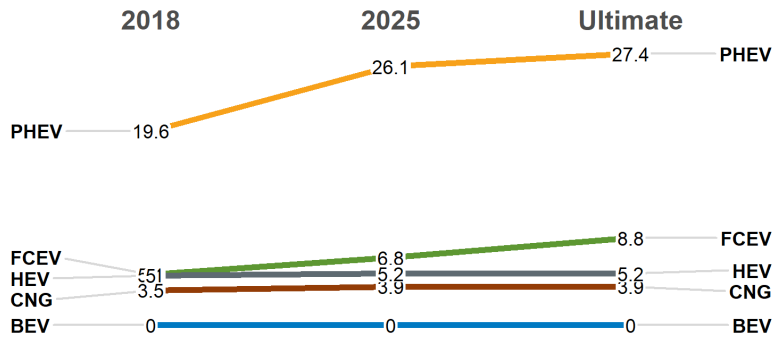

\section{Breakeven Fuel or Electricity Price (\$/gge)}

At Diesel Price of $\$ 3 / \mathrm{gal}(\$ 2.64 / \mathrm{gge})$
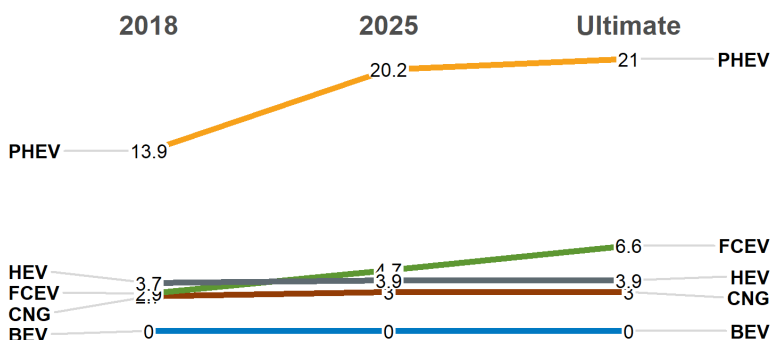

Breakeven Fuel or Electricity Price (\$/gge)

At Diesel Price of $\$ 2 / g a l$ (\$1.76/gge)

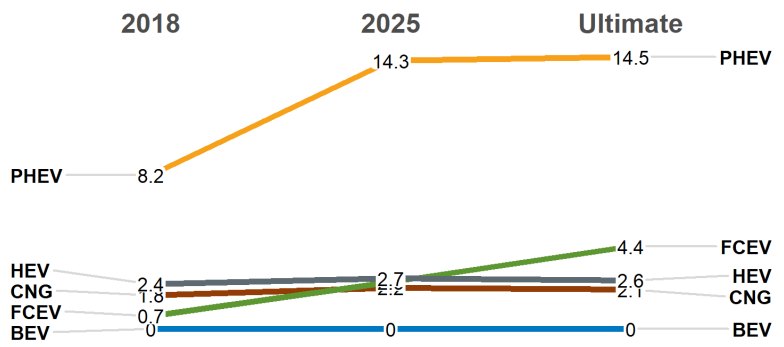

Figure 53. Multi-Shift, Volume-Limited break-even fuel price analysis for Class 4 parcel delivery trucks (120-mile range) in the Middle Atlantic region

\subsection{Sensitivity Analysis}

A TCO single-parameter sensitivity analysis was completed for each truck to understand and quantify the impact of uncertainty for each parameter on TCO. Vehicle use parameters (vehicle miles traveled, lifetime, and range), cost parameters (payload, dwell, fuel, O\&M), and financial parameters (discount rate) were all evaluated for the BEV and FCEV powertrains, as they are the most uncertain. The sensitivity analysis highlights results relative to their middle bounds defined in Section 2 (e.g., the impact of the "High" bound relative to the "Mid" bound) and is evaluated for vehicles operating in the Middle Atlantic region (regional fuel price). The following sections review the TCO sensitivity analysis for Class 8 long-haul, Class 8 short-haul, and Class 4 parcel delivery trucks in the form of single-parameter tornado charts. The sensitivity analysis is broken down by technology status, so it does not directly evaluate the impact of powertrain component costs (e.g., fuel cell stack cost, battery cost). Sensitivity analysis is also expressed using a waterfall analysis, which includes compounding of sensitivity parameters, shown after each tornado chart analysis. For these sensitivity analyses, the payload and dwell costs are either incurred or not, so the results to do not apply to a specific operating scenario defined in Section 2.4.2. However, VMT assumptions were 
needed for these sensitivity analyses and the Single-Shift VMT assumptions (see Table 9) as the baseline.

\subsubsection{Class 8 Long-Haul Tractor (750-Mile Range)}

This analysis has defined the Class 8 long-haul (750-mi) tractor as traveling 150,000 miles per year (for single-shift operation) and a range of 750 miles. Many tractors, however, may be designed with a slightly different range requirement or travel fewer or more miles per year. Other cost and financial parameters such as payload, dwell, O\&M, fuel, and discount rate also have uncertainty. The FCEV and BEV sensitivities to these parameters are presented here. Table 10 summarizes the Class 8 long-haul (750-mi) FCEV sensitivity analysis parameters and Figure 54 shows the results of the sensitivity analysis. All costs are shown relative to the mid TCO level for FCEVs for the 2018, 2025, and Ultimate technology statuses.

Table 10. Sensitivity Parameter Summary for a Class 8 Long-Haul (750-mi) Fuel Cell Truck

\begin{tabular}{lccc}
\hline Cost Parameter & Low & Mid & High \\
\hline Fuel (\$/gge) & 4 & 7 & 10 \\
O\&M (\$/mi) & 0.06 & 0.15 & 0.35 \\
Payload (\$/lb-mi) & 0 & 0 & 0 \\
Fueling rate (kg/min) & N/A & 10 & 5 \\
Range (mi) & 700 & 750 & 800 \\
VMT (mi/yr) & 130,000 & 150,000 & 170,000 \\
Discount rate $(\%)$ & 4 & 7 & 10 \\
\hline
\end{tabular}

As can be seen in Figure 54, fuel costs have the most significant potential impact on Class 8 long-haul FCEV TCO. O\&M costs and the discount rate have the next most influential impacts on TCO. VMT and range have relatively minor effects on TCO. The effect of VMT on TCO is low because each vehicle is still operated through its rated lifetime miles (1 million for Class 8 tractors) and VMT would only affect the timing of the future fuel and O\&M costs resulting in more or less discounting ${ }^{4}$ when converting back to a present value. Hydrogen fuel price is unidirectional in 2018 , as $\$ 10 / \mathrm{kg}$ is assumed to be achievable in today's markets based on the fuel cell electric bus evaluations (Eudy 2019), and an assumption that the price could achieve $\$ 7 / \mathrm{kg}$, resulting in the TCO reduction shown in Figure 54. Similarly, the hydrogen fuel price sensitivity is unidirectional in the Ultimate scenario because the hydrogen is assumed to be $\$ 4 / \mathrm{kg}$ with a higher bound of $\$ 7 / \mathrm{kg}$ and no lower bound below $\$ 4 / \mathrm{kg}$ (as that achieves the DOE target dispensed hydrogen cost). Range has a relatively minor effect on TCO because the capital cost of hydrogen storage is not a significant contributor to TCO. Additionally, there is no effect in the Ultimate scenario (and a unidirectional effect in the 2018 and 2025 scenarios) as the onboard hydrogen storage amount is cumulative of tanks being installed in $10-\mathrm{kg}$ increments. Dwell time and lost payload costs are negligible.

\footnotetext{
${ }^{4}$ At a fixed lifetime miles, a lower yearly VMT results in the truck operating for more years. Since future dollars are worth less today, this reduces the TCO in present value terms.
} 


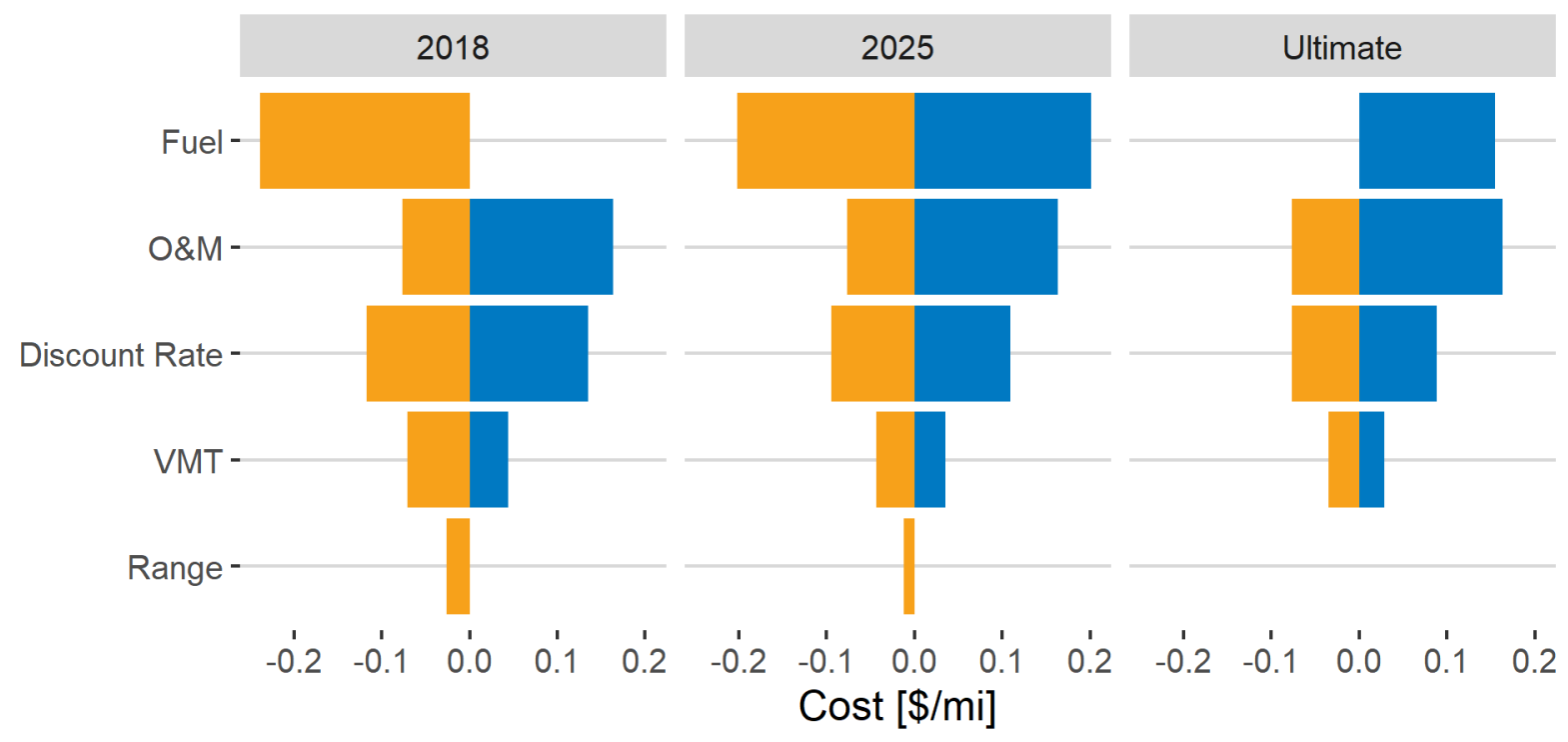

Figure 54. Sensitivity analysis on a fuel cell Class 8 long-haul truck (750-mi range, $150,000 \mathrm{mi} / \mathrm{yr}$ ) showing impact of low/high estimates $(\$ / \mathrm{mi})$ relative to the mid estimate

Figure 55 shows a double waterfall plot of the TCO for an FCEV Class 8 long-haul (750-mile) truck. The far-left bar of this plot shows the maximum FCEV TCO under the highest-cost conditions considered in this study. Each bar to the right shows the potential cost reduction with either moderate (achieving the mid-cost bound) or strong (achieving the low-cost bound) improvement in the given parameter. The bar to the far right shows the TCO (with uncertainty) of the equivalent diesel-fueled vehicle. As can be seen from Figure 55, fuel costs represent the greatest opportunity for cost reductions, followed by O\&M costs, hydrogen storage costs, and fuel cell stack cost. Dwell time cost and payload capacity cost do not have a substantial impact on TCO because the Class 8 long-haul FCEV tractor does not incur these costs, thanks to its quick refueling time and lightweight powertrain. With strong improvements in fuel cost, O\&M cost, and hydrogen storage cost, fuel cell-powered Class 8 long-haul (750-mile) trucks can achieve a TCO within the margin of uncertainty of diesel trucks.

Table 11 summarizes the Class 8 long-haul (750-mi) BEV sensitivity analysis parameters and Figure 56 shows the results of the sensitivity analysis. All costs are shown relative to the mid TCO level for the BEV 2018, 2025, and Ultimate technology statuses.

Table 11. Sensitivity Parameter Summary for a Class 8 Long-Haul (750-mi) Battery Electric Truck

\begin{tabular}{lccc}
\hline Cost Parameter & Low & Mid & High \\
\hline Fuel $(\$ / \mathrm{kWh})$ & 0.07 & 0.11 & 0.44 \\
O\&M $(\$ / \mathrm{mi})$ & 0.06 & 0.10 & 0.14 \\
Payload $(\$ / \mathrm{lb}-\mathrm{mi})$ & 0 & 0.255 & 0.282 \\
Max charging rate $(\mathrm{kW})$ & N/A & 1000 & 500 \\
Range $(\mathrm{mi})$ & 700 & 750 & 800 \\
VMT $(\mathrm{mi} / \mathrm{yr})$ & 130,000 & 150,000 & 170,000 \\
Discount rate $(\%)$ & 4 & 7 & 10 \\
\hline
\end{tabular}

As can be seen from Figure 56, the fuel (electricity) cost can have a significant impact on BEV TCO. This is largely because the upper bound on electricity cost considered in this study is $\$ 0.44 / \mathrm{kWh}$, whereas the midpoint value is $\$ 0.11 / \mathrm{kWh}$. This indicates that electricity price is very important to the TCO of the BEV, and today's prices observed for public DCFCs would not be economically attractive and would significantly increase TCO. Dwell time cost and discount rate are the most influential parameters after fuel cost. The dwell time cost is influential due to the long 


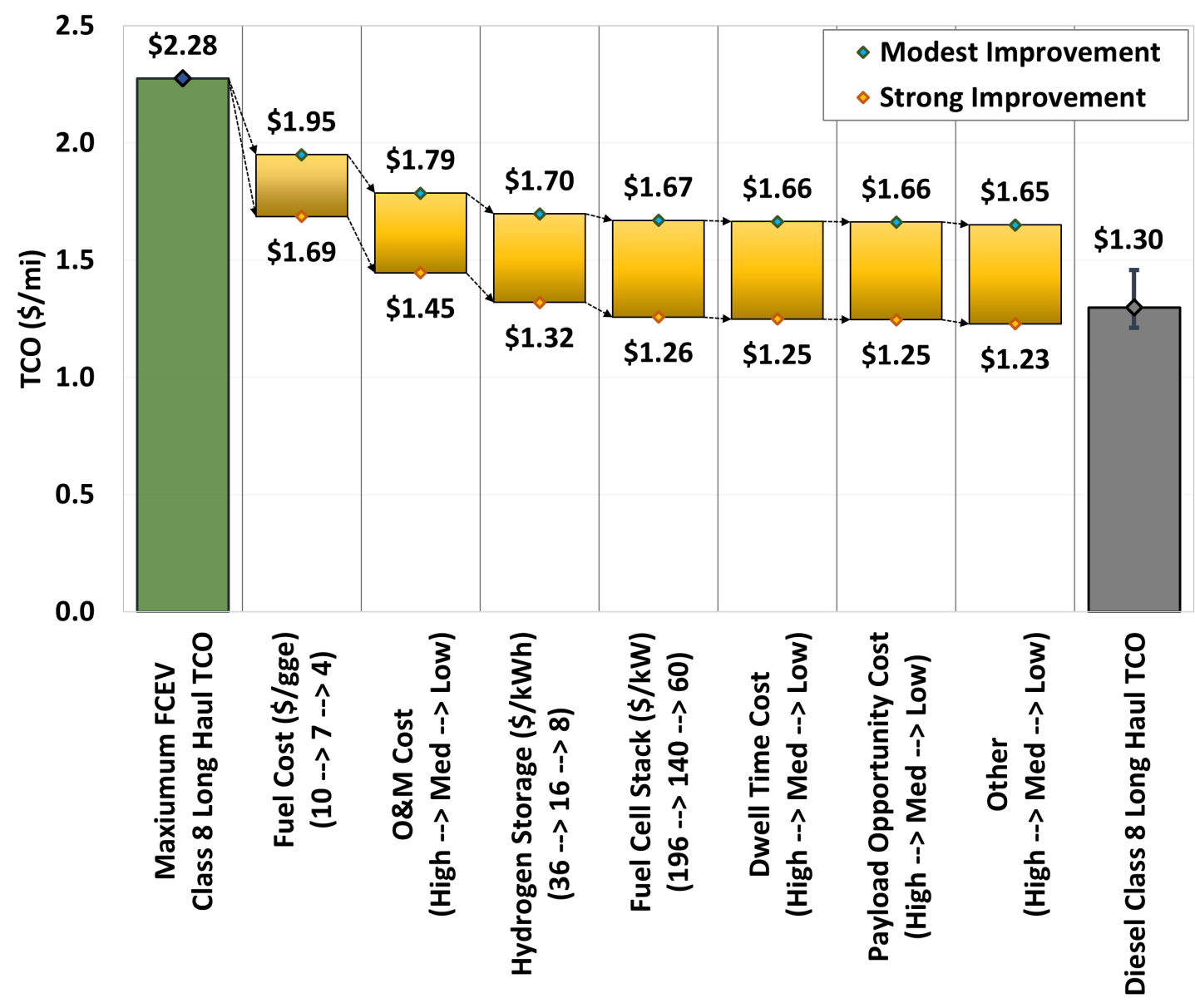

Figure 55. Double waterfall chart for a fuel cell electric Class 8 long-haul (750-mile) truck

charge times (500-kW charging) required, and the discount rate is influential due to the high future cash outflows (costs) associated with dwell costs. Lost payload cost, VMT, and range are also very influential in the 2018 time frame but become less influential as 2025 and Ultimate scenario assumptions are achieved. O\&M costs have a mild effect on TCO because the O\&M costs for BEVs are assumed to be much lower than the other powertrains due to the mechanically simple powertrain technology.

Figure 57 shows a double waterfall chart of the TCO for the Class 8 long-haul (750-mile) BEV truck. This plot demonstrates that fuel (electricity) costs and battery costs have the greatest TCO reduction potential, whereas dwell cost and payload cost improvements can also reduce TCO. Strong cost reductions in electricity price, battery cost, dwell time, and payload costs could bring the Class 8 long-haul (750-mile) BEV within the margin of uncertainty of a diesel-powered tractor. 


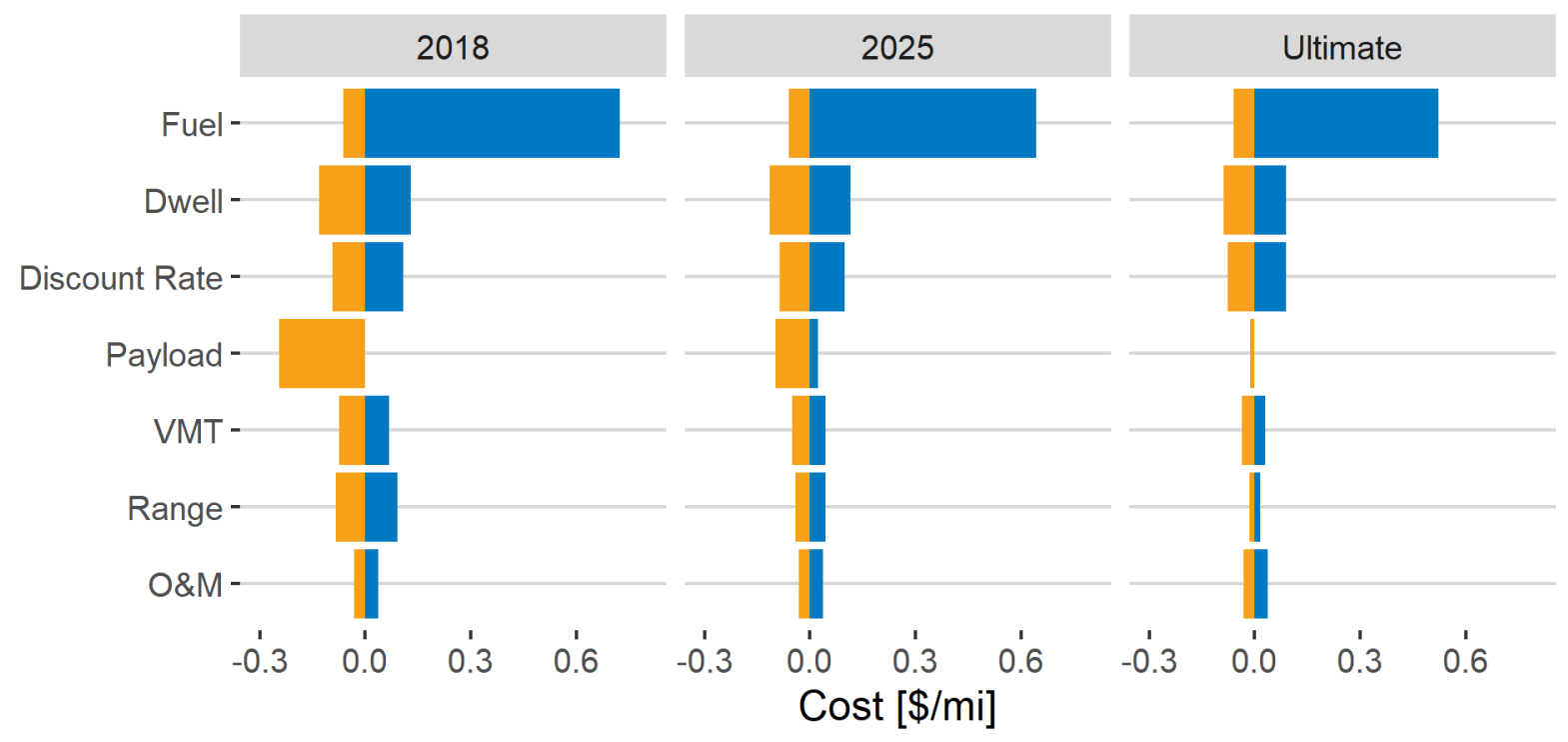

Figure 56. Sensitivity analysis on a battery electric Class 8 long-haul truck (750-mi range, $150,000 \mathrm{mi} / \mathrm{yr}$ ) showing impact of low/high estimates $(\$ / \mathrm{mi})$ relative to the mid estimate

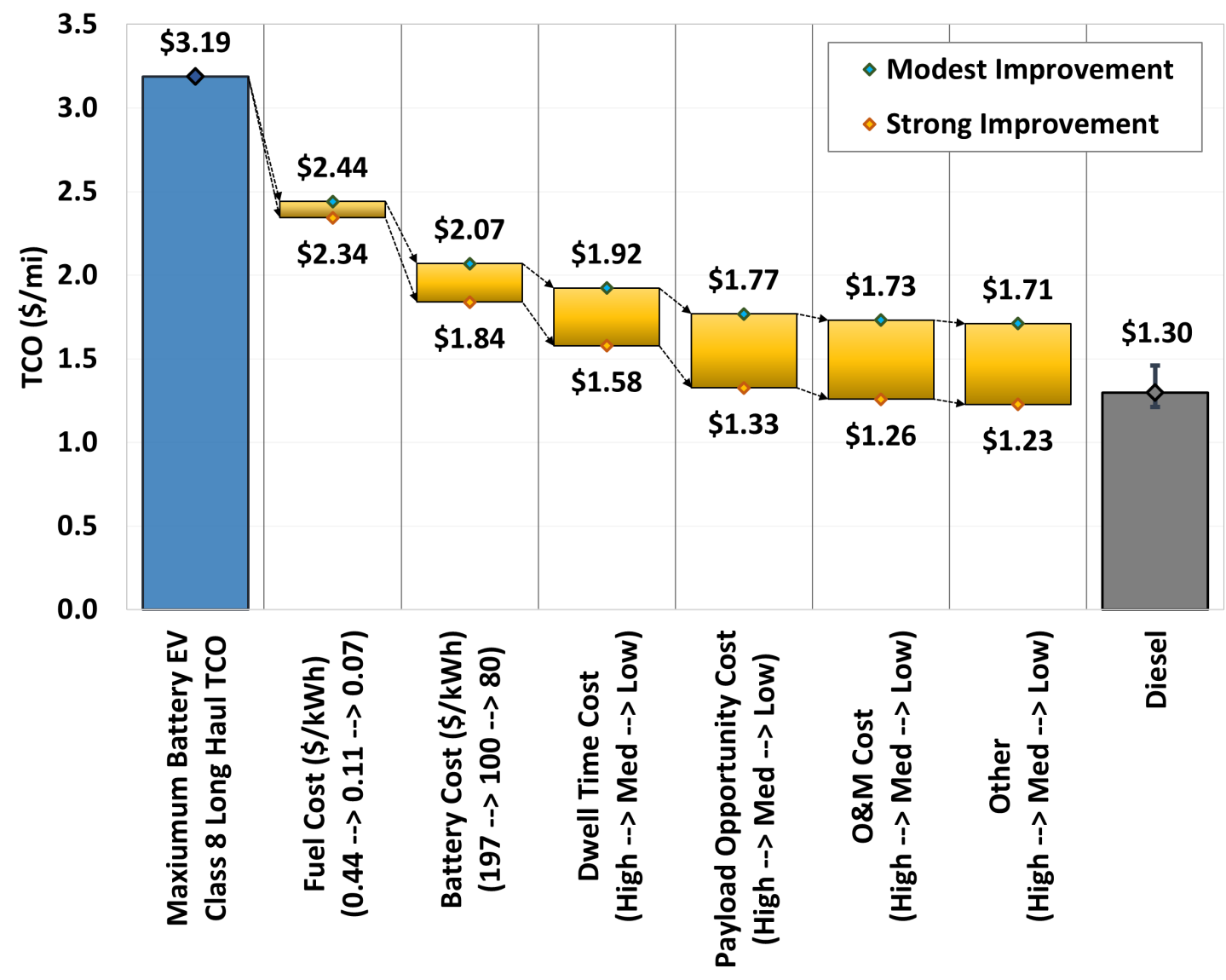

Figure 57. Double waterfall chart for a battery electric Class 8 long-haul (750-mile) truck 


\subsubsection{Class 8 Long-Haul Tractor (500-Mile Range)}

Table 12 summarizes the Class 8 long-haul (500-mi) FCEV sensitivity analysis parameters and Figure 58 shows the results of the sensitivity analysis. All costs are shown relative to the mid TCO level for FCEVS for 2018, 2025, and Ultimate technology statuses.

Table 12. Sensitivity Parameter Summary for a Class 8 Long-Haul (500-mi) Fuel Cell Truck

\begin{tabular}{lccc}
\hline Cost Parameter & Low & Mid & High \\
\hline Fuel $(\$ /$ gge $)$ & 4 & 7 & 10 \\
O\&M (\$/mi) & 0.06 & 0.15 & 0.35 \\
Payload (\$/lb-mi) & 0 & 0 & 0 \\
Fueling rate $(\mathrm{kg} / \mathrm{min})$ & N/A & 10 & 5 \\
Range (mi) & 450 & 500 & 550 \\
VMT (mi/yr) & 80,000 & 100,000 & 120,000 \\
Discount rate $(\%)$ & 4 & 7 & 10 \\
\hline
\end{tabular}

Figure 58 shows discount rate and fuel costs have the largest impacts on TCO, although O\&M costs and VMT are also influential. Fuel (hydrogen price) is less important in the 500-mile, 100,000-mi/yr FCEV than the 750-mile, 150,000-mi/yr FCEV due to the lower VMT. Range has a mild effect for the 2018 and 2025 technology status time frames, but is not influential for the Ultimate technology status scenario. Dwell time costs and lost payload capacity cost do not have a noticeable impact on TCO for any technology status time frame. As with the 750-mile-range truck, the hydrogen fuel price sensitivity is unidirectional in the Ultimate scenario because the hydrogen is assumed to be $\$ 4 / \mathrm{kg}$ with a higher bound of $\$ 7 / \mathrm{kg}$ and no lower bound below $\$ 4 / \mathrm{kg}$. Additionally, range has a relatively minor effect on TCO because the capital cost of hydrogen storage is not a significant contributor to TCO, and onboard hydrogen storage amount is cumulative of tanks being installed in 10-kg increments, so marginal range differences are within the same onboard hydrogen storage sizing.

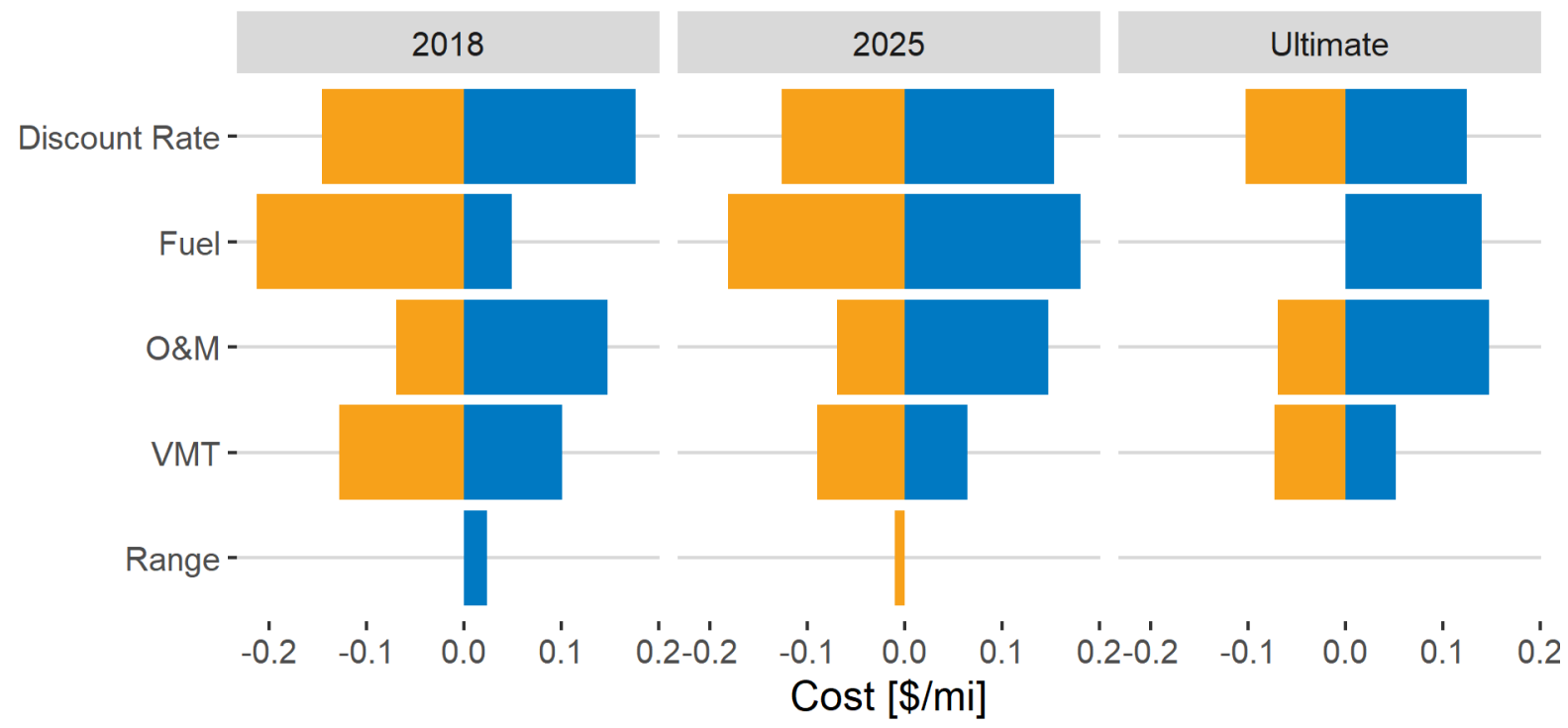

Figure 58. Sensitivity analysis on a fuel cell Class 8 long-haul truck (500-mi range, $100,000 \mathrm{mi} / \mathrm{yr})$ showing impact of low/high estimates $(\$ / \mathrm{mi})$ relative to the mid estimate

Figure 59 shows a double waterfall chart for the 500-mile-range Class 8 long-haul FCEV. Like the 750-mile-range FCEV long-haul tractor, the TCO for this vehicle is most affected by fuel costs, O\&M costs, hydrogen storage costs, and fuel cell costs. Moderate to strong improvements in these parameters can bring the TCO within the range of uncertainty for the diesel-powered equivalent vehicle. 


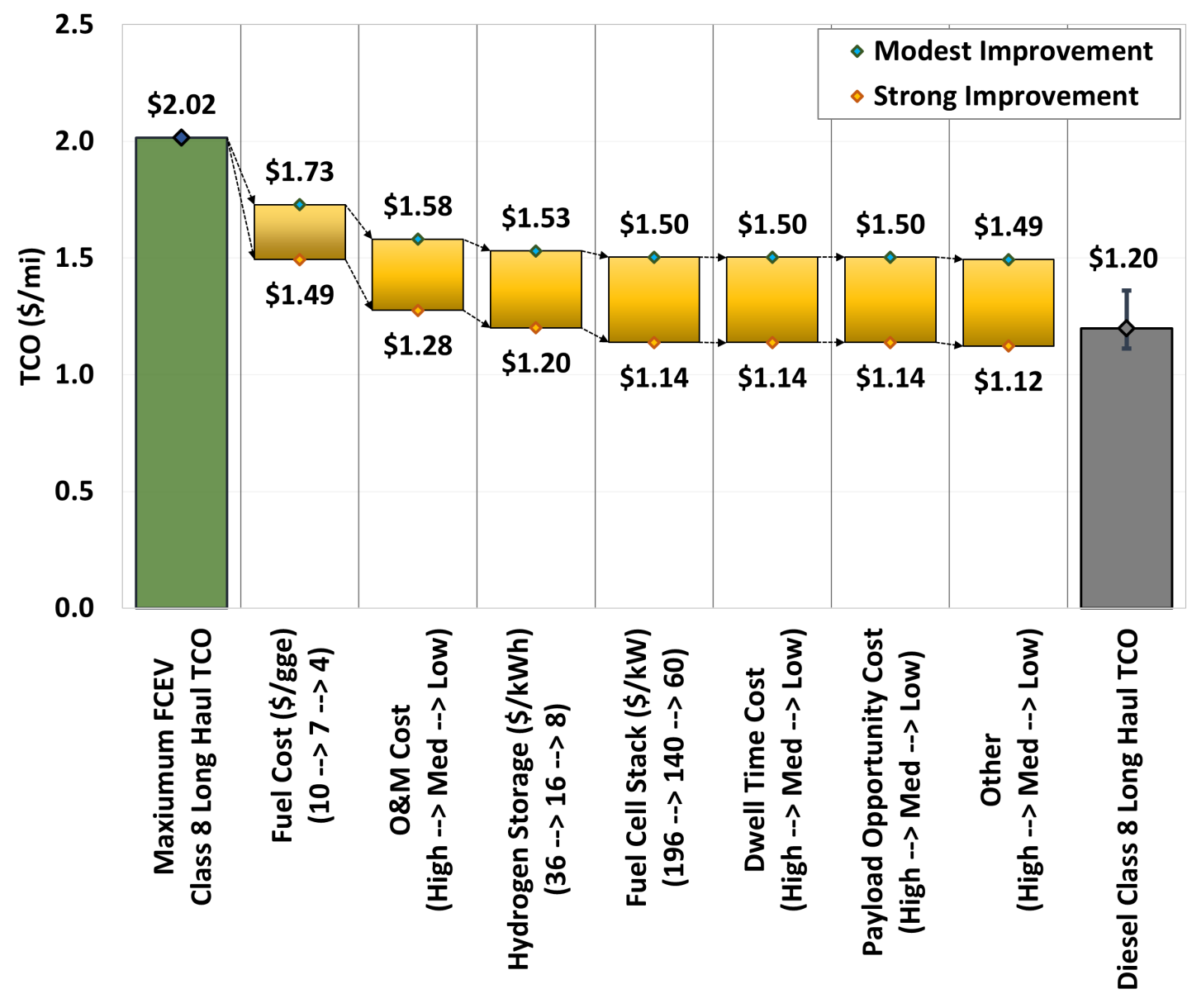

Figure 59. Double waterfall chart for a fuel cell electric Class 8 long-haul (500-mile) truck

Table 13 summarizes the Class 8 long-haul (500-mi) BEV sensitivity analysis parameters and Figure 60 shows the results of the sensitivity analysis. All costs are shown relative to the mid TCO level for BEVs for 2018, 2025, and Ultimate technology statuses.

Table 13. Sensitivity Parameter Summary for a Class 8 Long-Haul (500-mi) Battery Electric Truck

\begin{tabular}{lccc}
\hline Cost Parameter & Low & Mid & High \\
\hline Fuel $(\$ / \mathrm{kWh})$ & 0.07 & 0.11 & 0.44 \\
O\&M $(\$ / \mathrm{mi})$ & 0.06 & 0.10 & 0.14 \\
Payload $(\$ / \mathrm{lb}-\mathrm{mi})$ & 0 & 0.08 & 0.2 \\
Max charging rate $(\mathrm{kW})$ & N/A & 1,000 & 500 \\
Range $(\mathrm{mi})$ & 450 & 500 & 550 \\
VMT $(\mathrm{mi} / \mathrm{yr})$ & 80,000 & 100,000 & 120,000 \\
Discount rate $(\%)$ & 4 & 7 & 10 \\
\hline
\end{tabular}

Figure 60 illustrates that the fuel (electricity) price can have a significant impact on the 500-mile long-haul BEV TCO. Discount rate, dwell costs, and VMT can also have notable impacts on TCO. Range, O\&M costs, and lost payload capacity costs have lesser impacts on TCO. Importantly, in the 2018 and 2025 scenarios, the payload capacity cost is the least influential parameter. Additionally, there is not payload capacity cost for the 500-mile BEV 
in the Ultimate scenario as the tractor is within the 2,000-lb weight limit exemption of the diesel tractor. Thus, a 500-mile BEV is a potentially much more optimal design than a 750-mile BEV because the reduced range results in significantly more payload capacity.

Figure 61 shows a double waterfall chart of the 500-mile long-haul BEV tractor. Moderate to strong improvements in fuel cost, battery cost, and dwell time cost can bring the TCO of a 500-mile-range long-haul BEV tractor within the margin of uncertainty of an equivalent diesel-powered vehicle.

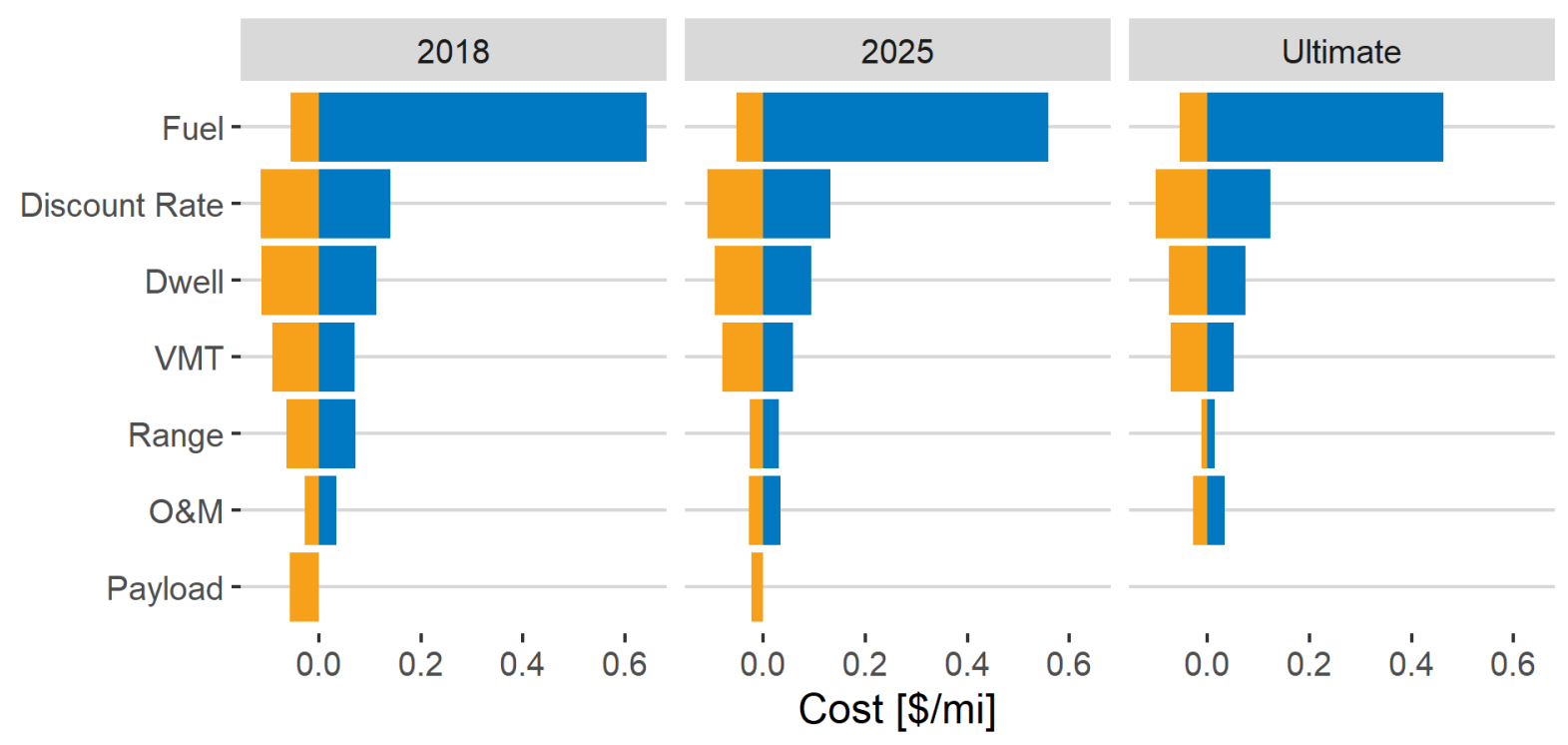

Figure 60. Sensitivity analysis on a battery electric Class 8 long-haul truck (500-mi range, $100,000 \mathrm{mi} / \mathrm{yr})$ showing impact of low/high estimates $(\$ / \mathrm{mi})$ relative to the mid estimate 


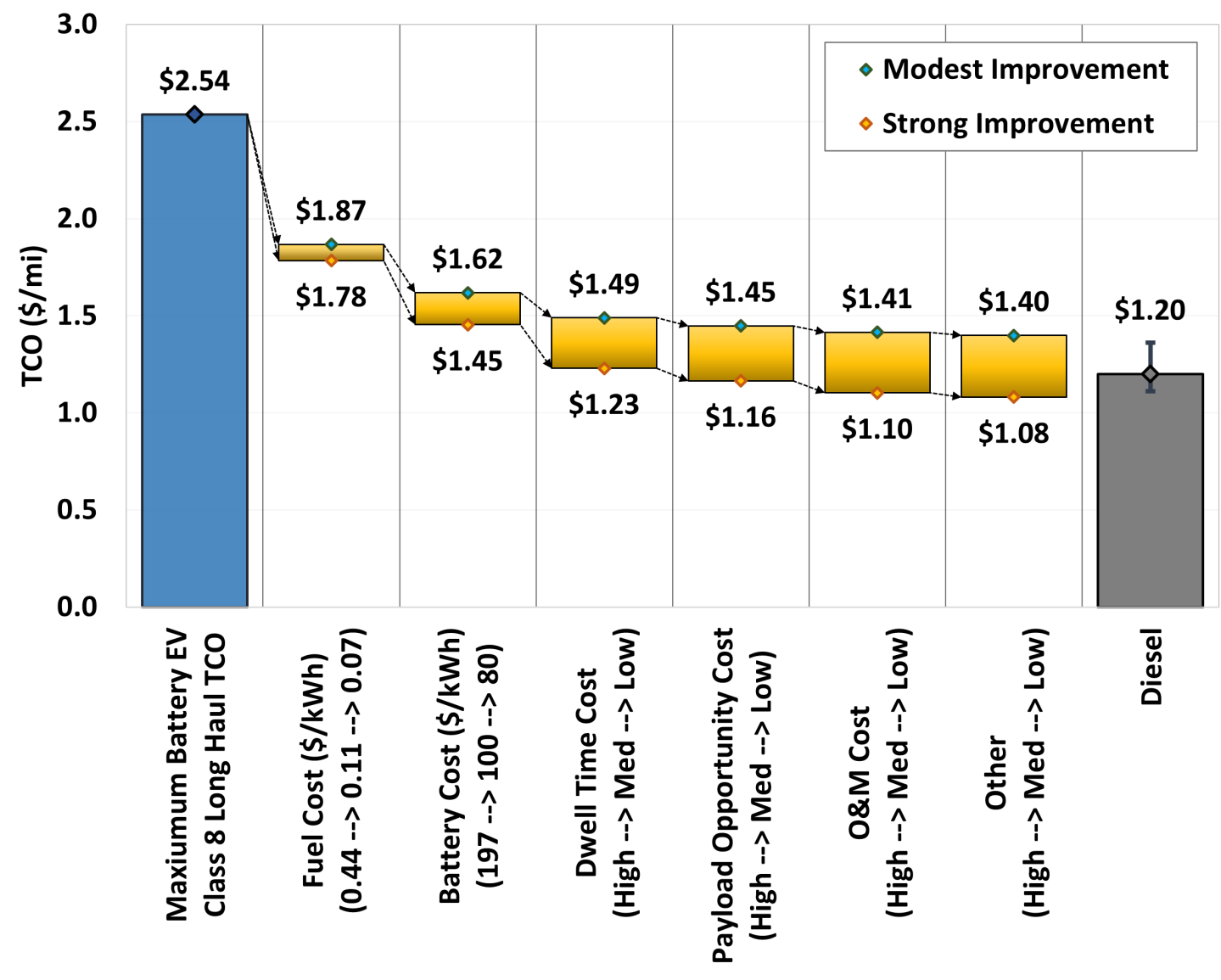

Figure 61. Double waterfall chart for a battery electric Class 8 long-haul (500-mile) truck

\subsubsection{Class 8 Short-Haul Tractor (300-Mile Range)}

Table 14 summarizes the Class 8 short-haul (300-mile-range) FCEV sensitivity analysis parameters and Figure 62 shows the results of the sensitivity analysis. All costs are shown relative to the mid TCO level for the FCEV for the 2018, 2025, and Ultimate technology statuses.

Table 14. Sensitivity Parameter Summary for a Class 8 Short-Haul Fuel Cell Truck

\begin{tabular}{lccc}
\hline Cost Parameter & Low & Mid & High \\
\hline Fuel $(\$ /$ gge $)$ & 4 & 7 & 10 \\
O\&M (\$/mi) & 0.06 & 0.15 & 0.35 \\
Payload (\$/lb-mi) & 0 & -0.004 & -0.001 \\
Fueling rate (kg/min) & N/A & 10 & 5 \\
Range (mi) & 250 & 300 & 350 \\
VMT (mi/yr) & 50,000 & 60,000 & 70,000 \\
Discount rate $(\%)$ & 4 & 7 & 10 \\
\hline
\end{tabular}

Figure 62 illustrates that discount rate and hydrogen costs are the most influential parameters to Class 8 short-haul FCEV TCO. O\&M costs and VMT also have a noticeable effect. Range, lost payload capacity costs, and dwell costs have negligible impacts on TCO for this vehicle. As with the other FCEVs analyzed, the Ultimate hydrogen fuel price sensitivity is unidirectional because the hydrogen is assumed to be $\$ 4 / \mathrm{kg}$, with a higher bound of $\$ 7 / \mathrm{kg}$ and no 
lower bound below $\$ 4 / \mathrm{kg}$. Similarly, range is not significant as the onboard hydrogen tanks are increments of $10 \mathrm{~kg}$, so slightly different range requirements do not impact the TCO (likely the same number of tanks installed).

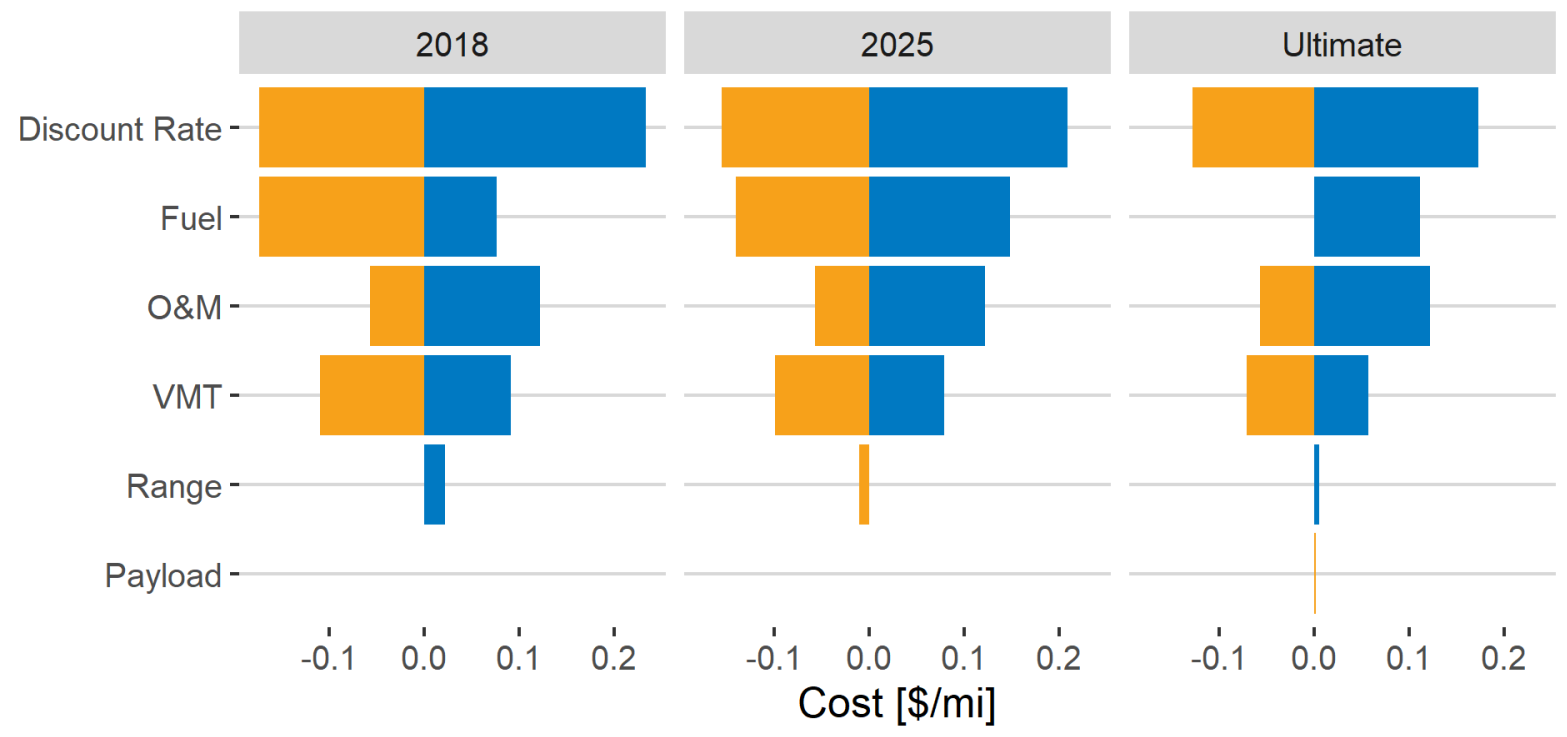

Figure 62. Sensitivity analysis on a fuel cell Class 8 short-haul truck (300-mi range, $60,000 \mathrm{mi} / \mathrm{yr}$ ) showing impact of low/high estimates $(\$ / \mathrm{mi})$ relative to the mid estimate

Figure 63 shows a double waterfall chart for the Class 8 short-haul FCEV. Interestingly, strong improvements in just hydrogen price and O\&M costs can bring the TCO within the margin of uncertainty of the TCO of an equivalent diesel vehicle. This potentially indicates that near-term market opportunities exist for shorter-range trucks, especially if a hydrogen price of $\$ 4 / \mathrm{kg}$ can be achieved.

Table 15 summarizes the Class 8 short-haul BEV sensitivity analysis parameters and Figure 64 shows the results of the sensitivity analysis. All costs are shown relative to the mid TCO level for BEVs for the 2018, 2025, and Ultimate technology statuses.

Table 15. Sensitivity Parameter Summary for a Class 8 Short-Haul Battery Electric Truck

\begin{tabular}{lccc}
\hline Cost Parameter & Low & Mid & High \\
\hline Fuel $(\$ / \mathrm{kWh})$ & 0.07 & 0.11 & 0.44 \\
O\&M $(\$ / \mathrm{mi})$ & 0.06 & 0.10 & 0.14 \\
Payload $(\$ / \mathrm{lb}-\mathrm{mi})$ & 0 & 0.013 & 0.05 \\
Max charging rate $(\mathrm{kW})$ & N/A & 1,000 & 500 \\
Range $(\mathrm{mi})$ & 250 & 300 & 350 \\
VMT $(\mathrm{mi} / \mathrm{yr})$ & 50,000 & 60,000 & 70,000 \\
Discount rate $(\%)$ & 4 & 7 & 10 \\
\hline
\end{tabular}

Figure 64 demonstrates that fuel (electricity) cost and discount rate are the most influential parameters on Class 8 short-haul BEV TCO. Dwell time costs, VMT costs, and range also have an impact on TCO, though the impact of range is expected to reduce as 2025 and Ultimate scenario assumptions are met. O\&M costs and lost payload capacity costs have perceptible but insignificant impacts on TCO for this vehicle as the battery is relatively small and the total truck weight is comparable to the diesel counterpart. Additionally, the range (battery size) of the BEV initially is a relatively meaningful contributor to TCO differences, but as the price of batteries decreases from the 2018 to the Ultimate scenarios, the truck range can be increased with little impact on TCO.

Figure 65 shows a double waterfall chart for the Class 8 short-haul BEV. Strong improvements in fuel (electricity) 


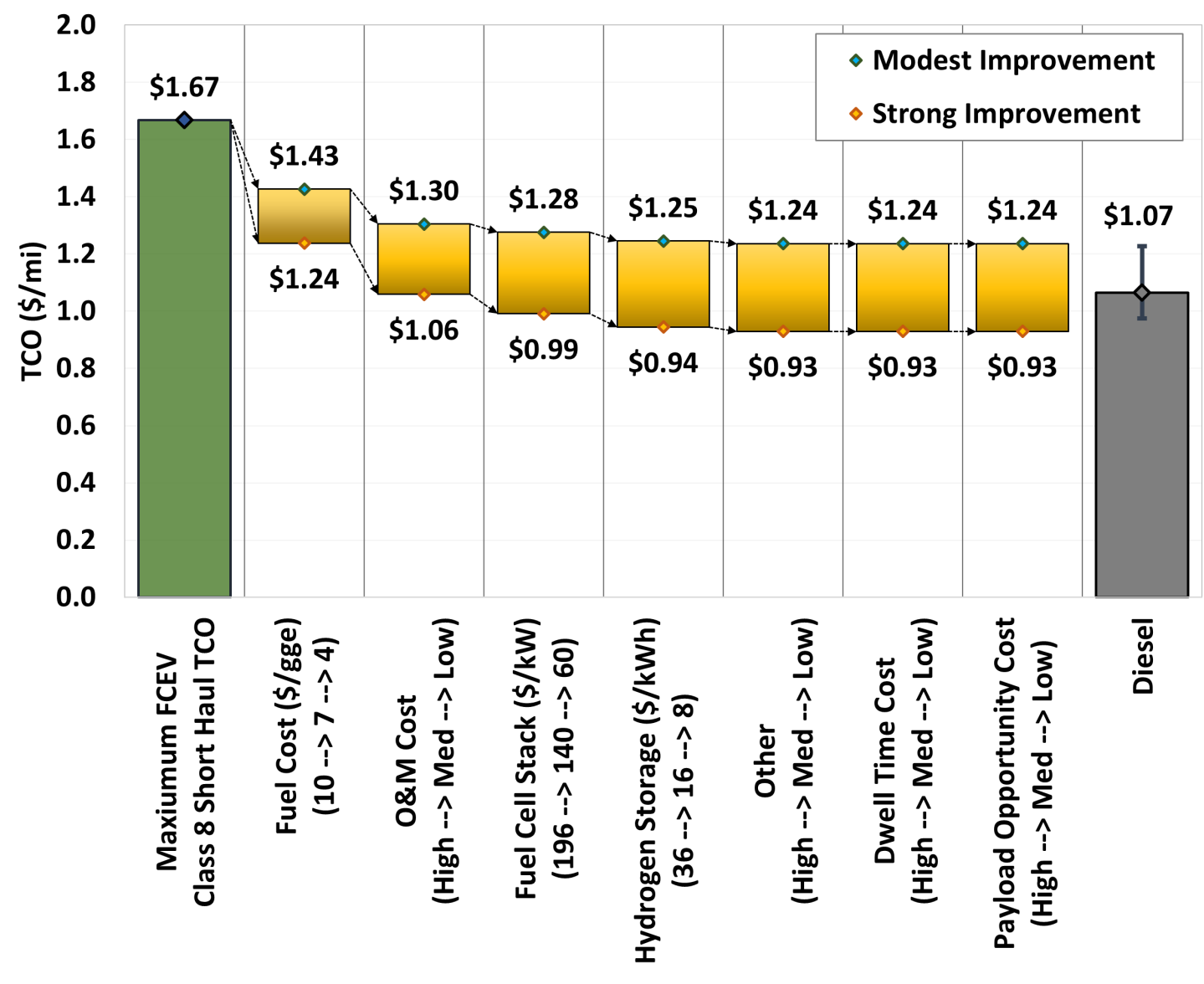

Figure 63. Double waterfall chart for a fuel cell electric Class 8 short-haul truck

and battery costs can bring the TCO within the margins of uncertainty of the TCO of an equivalent diesel vehicle. Further improvements in dwell time cost and O\&M cost can make the BEV powertrain very competitive relative to the diesel option. Thus, BEVs may be a very economically competitive option to decarbonize Class 8 short-haul tractor operation. 


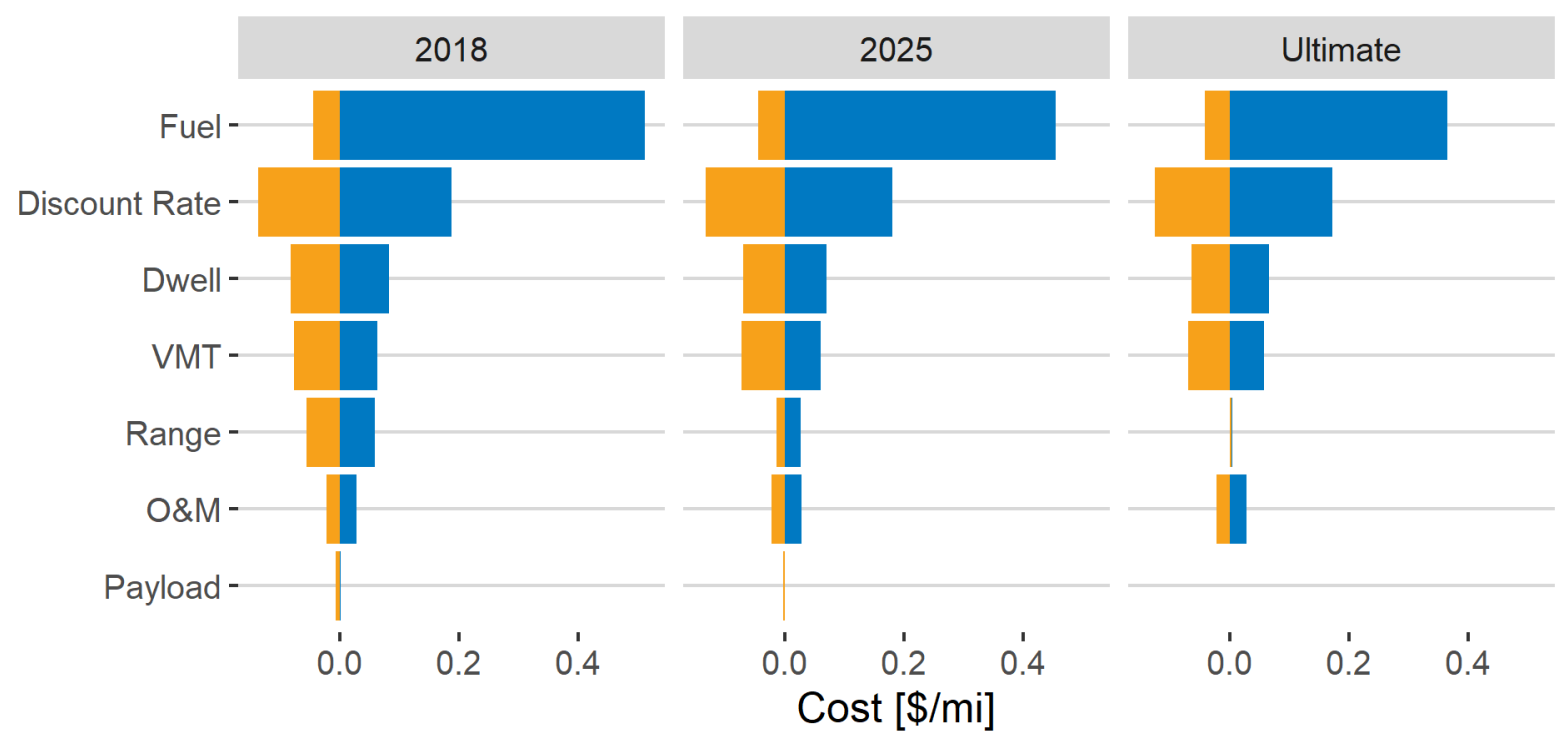

Figure 64. Sensitivity analysis on a battery electric Class 8 short-haul truck (300-mi range, $60,000 \mathrm{mi} / \mathrm{yr}$ ) showing impact of low/high estimates $(\$ / \mathrm{mi})$ relative to the mid estimate

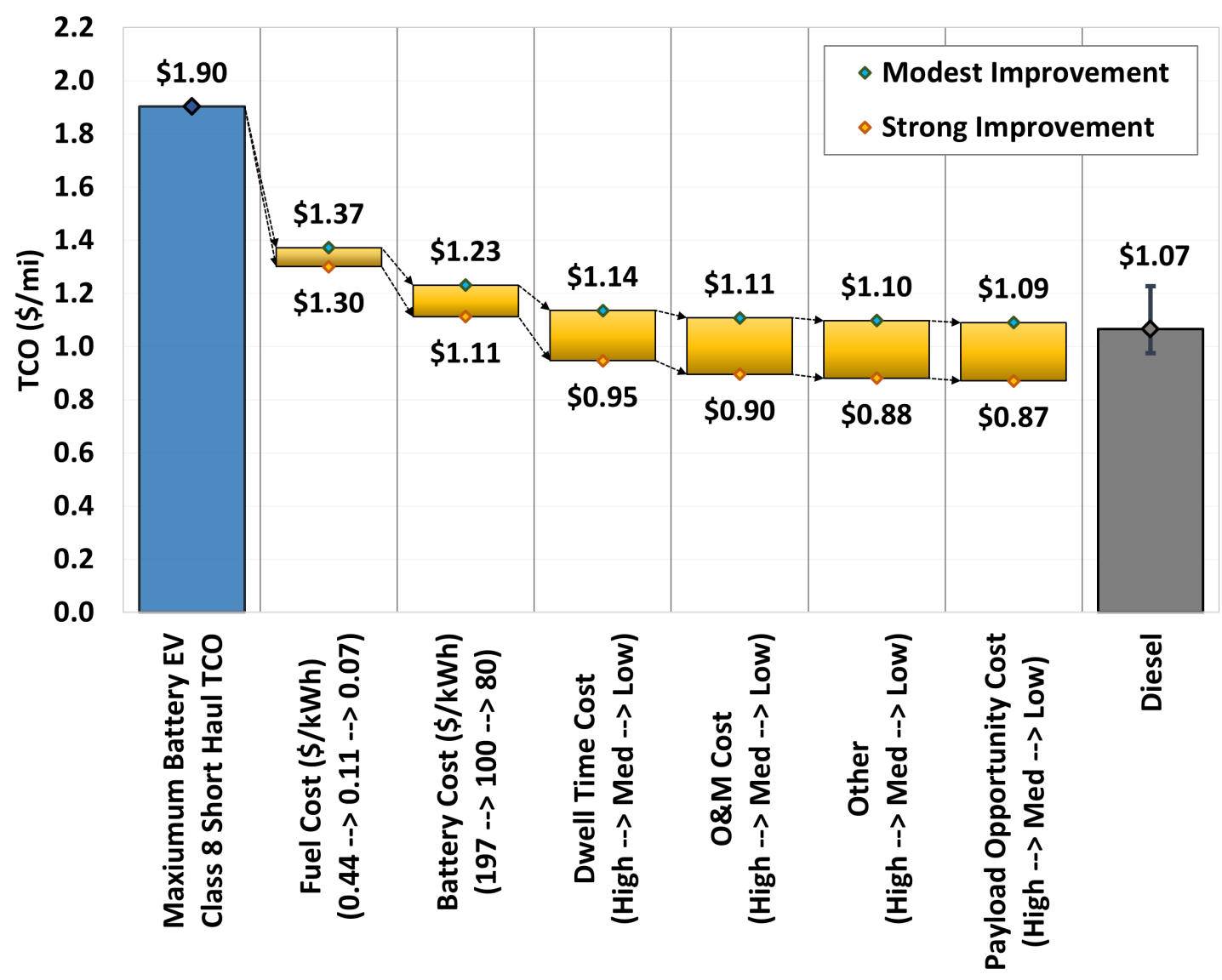

Figure 65. Double waterfall chart for a battery electric Class 8 short-haul (300-mile) truck 


\subsubsection{Class 4 Parcel Delivery (120-Mile Range)}

Table 16 summarizes the Class 4 parcel delivery FCEV sensitivity analysis parameters and Figure 66 shows the results of the sensitivity analysis. All costs are shown relative to the mid TCO level for the FCEV 2018, 2025, and Ultimate technology statuses.

Table 16. Sensitivity Parameter Summary for a Class 4 Parcel Delivery Fuel Cell Truck

\begin{tabular}{lccc}
\hline Cost Parameter & Low & Mid & High \\
\hline Fuel $(\$ /$ gge $)$ & 4 & 7 & 10 \\
O\&M (\$/mi) & 0.05 & 0.12 & 0.27 \\
Payload (\$/lb-mi) & 0 & 0 & 0 \\
Fueling rate (kg/min) & N/A & 10 & 5 \\
Range (mi) & 90 & 120 & 150 \\
VMT (mi/yr) & 20,000 & 25,000 & 30,000 \\
Discount rate (\%) & 4 & 7 & 10 \\
\hline
\end{tabular}

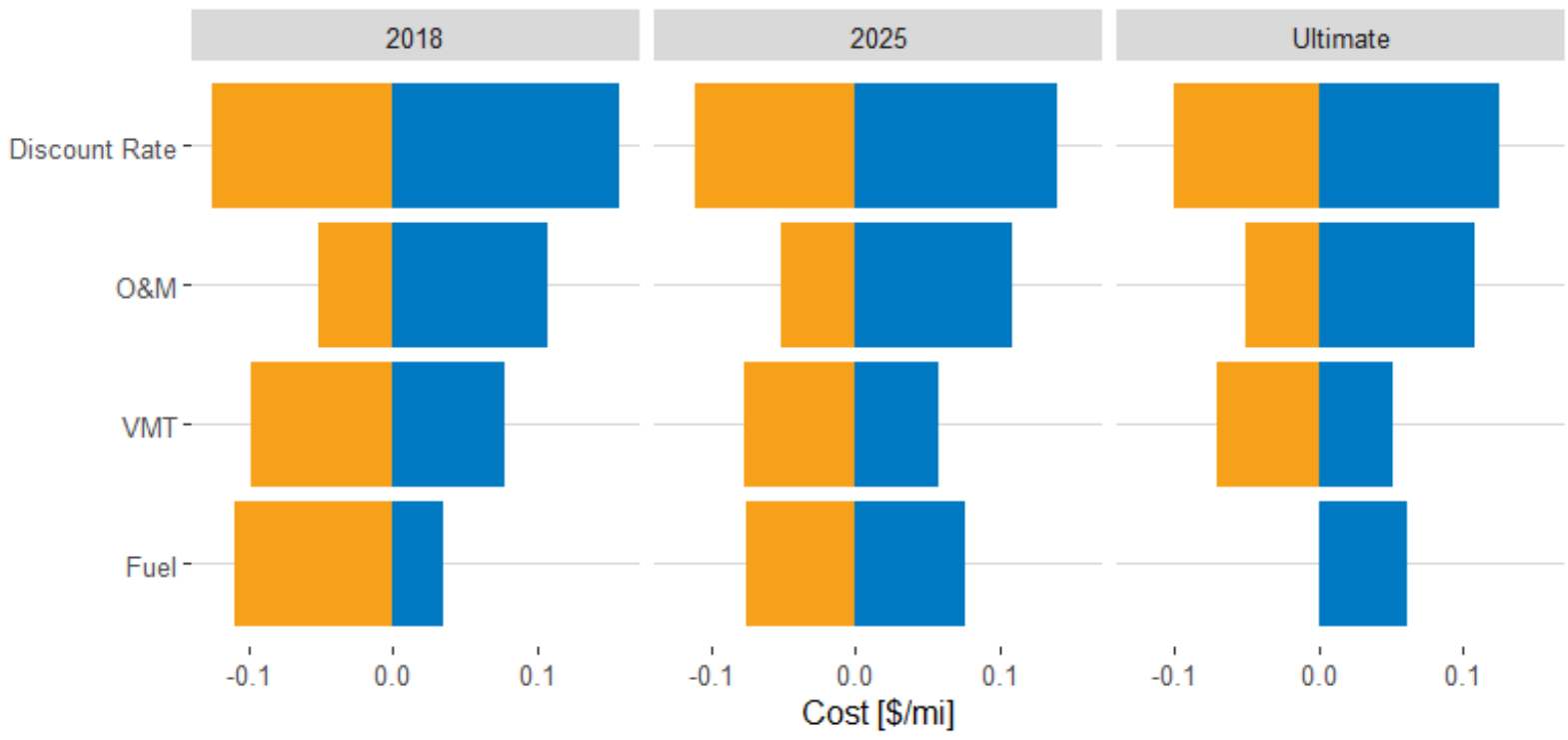

Figure 66. Sensitivity analysis on a fuel cell Class 4 parcel delivery truck (120-mi range, $25,000 \mathrm{mi} / \mathrm{yr}$ ) showing impact of low/high estimates $(\$ / \mathrm{mi})$ relative to the mid estimate

Figure 66 illustrates that discount rate, O\&M, VMT, and hydrogen (fuel) cost are all important to the TCO for the Class 4 parcel delivery FCEV. Because the O\&M costs are the same across vehicle classes but the overall expenses for this truck are much lower than in the Class 8 tractors due to lower fuel consumption and VMT, the O\&M costs become the most important parameters. Additionally, because this vehicle drives significantly less than the Class 8 tractors, the hydrogen fuel price is the least impactful.

Figure 67 shows a double waterfall chart for the Class 4 parcel delivery FCEV. Moderate to strong improvements in fuel cost and O\&M cost can bring the TCO of this vehicle within the margin of uncertainty of the TCO of an equivalent diesel vehicle. Improvements to parameters such as the fuel cell stack cost and hydrogen storage cost can make the FCEV powertrain even more competitive for this vocation. If the technological progress can be achieved, the TCO of the Class 4 parcel delivery FCEV can be considerably lower (13\%) than the diesel option.

Table 17 summarizes the Class 4 parcel delivery BEV sensitivity analysis parameters and Figure 68 shows the results of the sensitivity analysis. All costs are shown relative to the mid TCO level for BEVs for the 2018, 2025, and Ultimate technology statuses. 


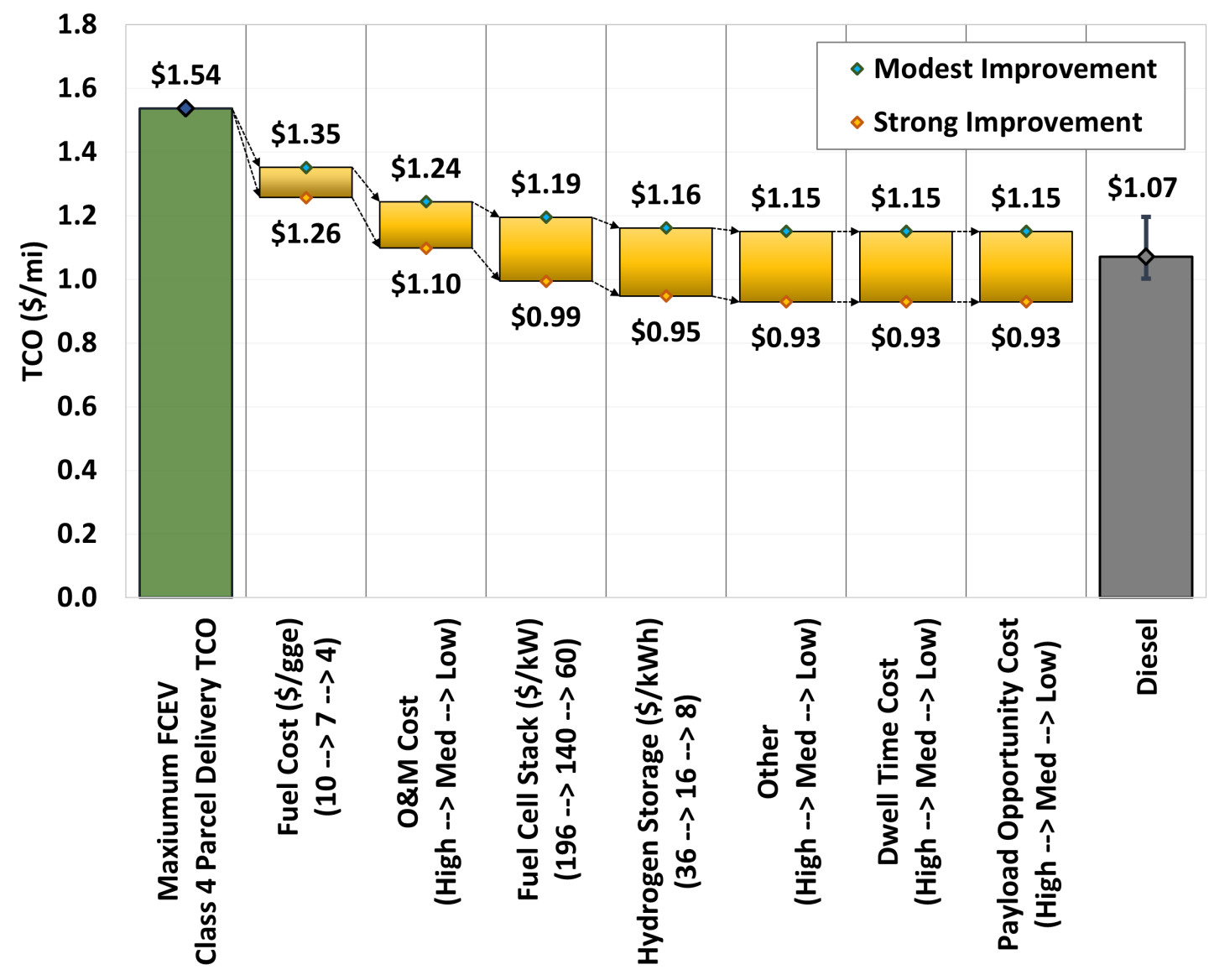

Figure 67. Double waterfall chart for a fuel cell electric Class 4 parcel delivery truck

Table 17. Sensitivity Parameter Summary for a Class 4 Parcel Delivery Battery Electric Truck

\begin{tabular}{lccc}
\hline Cost Parameter & Low & Mid & High \\
\hline Fuel $(\$ / \mathrm{kWh})$ & 0.07 & 0.11 & 0.44 \\
O\&M $(\$ / \mathrm{mi})$ & 0.05 & 0.08 & 0.11 \\
Payload $(\$ / \mathrm{lb}-\mathrm{mi})$ & 0 & 0 & 0 \\
Max charging rate $(\mathrm{kW})$ & N/A & 1,000 & 500 \\
Range $(\mathrm{mi})$ & 90 & 120 & 150 \\
VMT $(\mathrm{mi} / \mathrm{yr})$ & 20,000 & 25,000 & 30,000 \\
Discount rate $(\%)$ & 4 & 7 & 10 \\
\hline
\end{tabular}

Figure 68 demonstrates that dwell time cost is the most influential sensitivity parameter for the Class 4 parcel delivery truck. This indicates that if the truck requires a significant amount of multi-shift operation, this may be quite costly to the owner/operator and FCEV technology may complement the BEV and help decarbonize this operating scenario. Fuel (electricity) cost is also quite influential. Discount rate and VMT are moderately influential to the $\mathrm{TCO}$, whereas range and O\&M cost impacts are noticeable but not significant.

Figure 69 shows a double waterfall chart for the Class 4 parcel delivery BEV. Achieving low fuel (electricity), battery, and dwell time costs can bring the TCO of this powertrain within the uncertainty range of the TCO of an equivalent diesel-powered vehicle. Improvements to O\&M costs can also help to make the BEV powertrain even more 


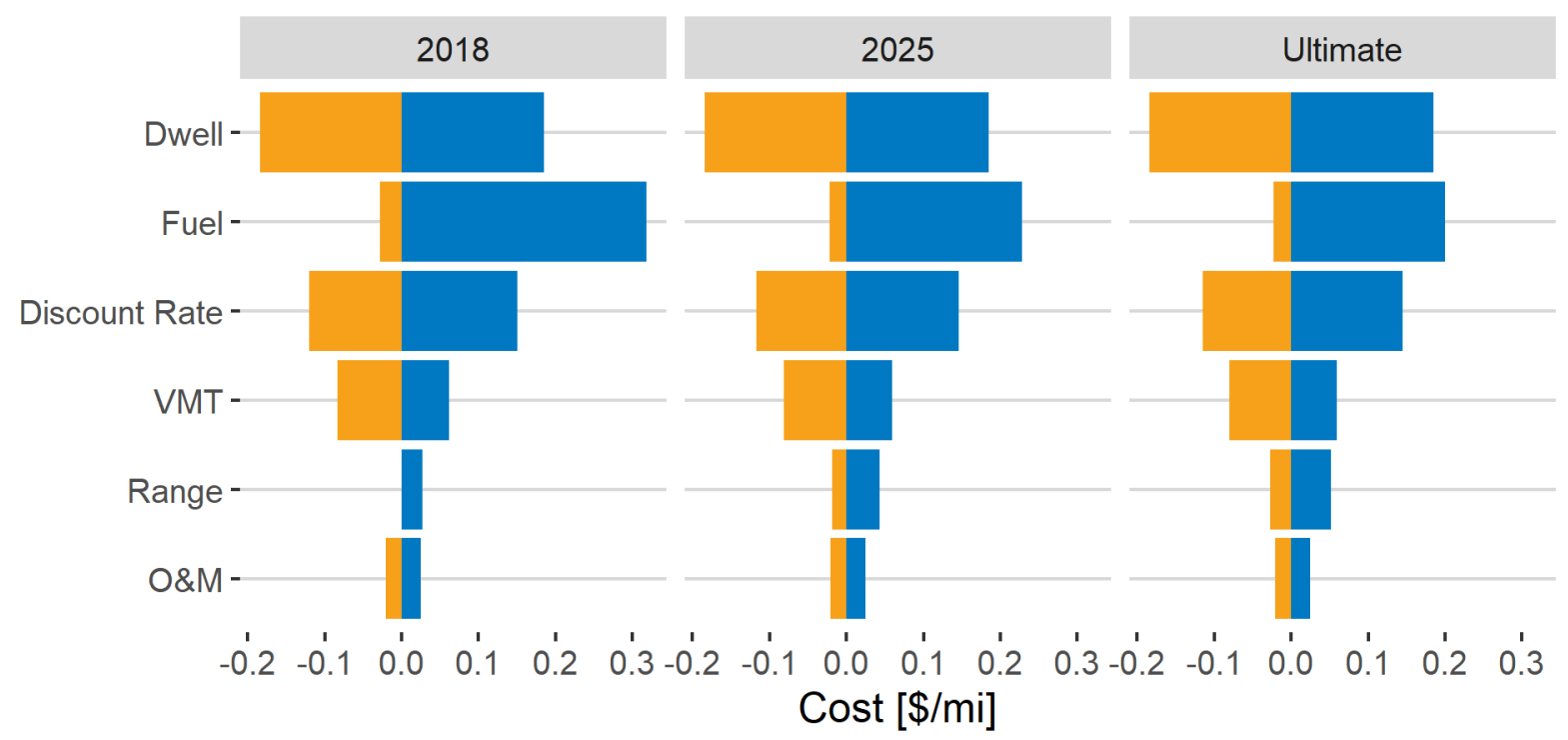

Figure 68. Sensitivity analysis on a battery electric Class 4 parcel delivery truck (120-mi range, $25,000 \mathrm{mi} / \mathrm{yr}$ ) showing impact of low/high estimates $(\$ / \mathrm{mi})$ relative to the mid estimate

competitive with the diesel powertrain. Thus, the BEV may represent a very economically competitive powertrain choice for this vehicle segment. 


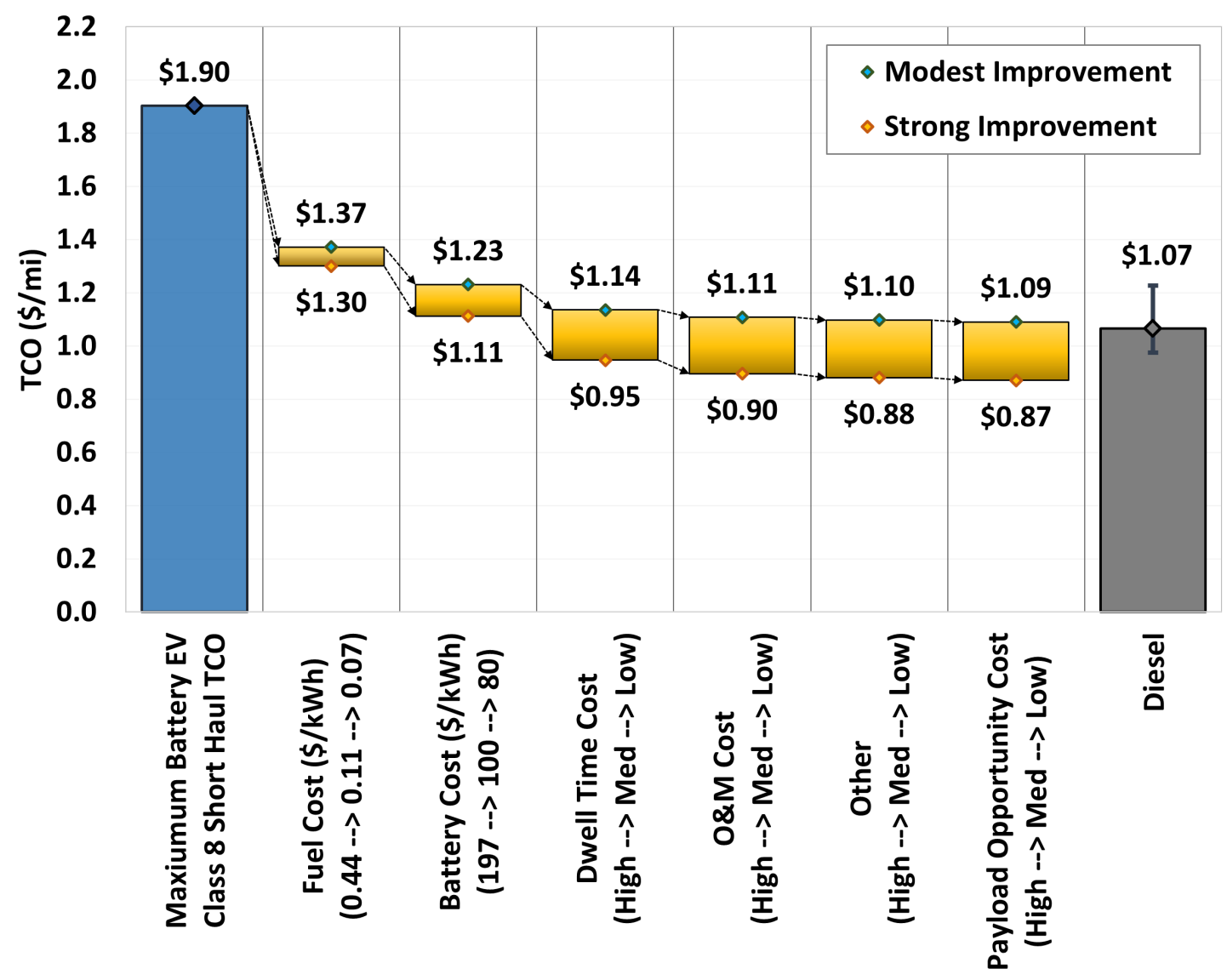

Figure 69. Double waterfall chart for a battery electric Class 4 parcel delivery (120-mile) truck 


\section{Discussion}

In this report, we have completed a rigorous scenario analysis of the TCO of Class 8 long-haul, Class 8 short-haul, and Class 4 parcel delivery trucks. This work complements and was coordinated with Burnham et al. (2021), which focuses on outlining a data framework for levelized cost of driving analyses, and Brooker et al. (2021), which focuses on technology evolution pathways and commercial vehicle adoption modeling. This work aims to use a bottom-up analytical approach to identify advanced vehicle powertrain opportunities and challenges to decarbonize commercial vehicle market segments. Key findings of this work are summarized as follows.

\section{Vehicle Modeling}

Key findings of vehicle powertrain modeling are related to the vehicle design, upfront purchase price, truck weight, and truck fuel economy. It should be noted that purchase price modeled here may not reflect the pricing strategy of original equipment manufacturers nor the expected influence of vehicle sales mandates, but nonetheless provides insights into the costs associated with each powertrain that would need to be recovered.

- BEV MSRP: The Class 8 long-haul 750-mile-range BEV is estimated to have an MSRP approximately 400\% more expensive than the diesel truck in the 2018 time frame but drops to an approximately $80 \%$ premium in the Ultimate time frame. For the 500-mile Class 8 long-haul, the BEV price premium is approximately $250 \%$ in the 2018 time frame and decreases to approximately $40 \%$ if the Ultimate technology targets are achieved. The Class 8 short-haul BEV price premium is lower than the long-haul and begins with approximately $140 \%$ in the 2018 time frame but decreases to $17 \%$ in the Ultimate time frame. Although the Class 4 parcel delivery BEV is estimated to be approximately $80 \%$ more expensive in the 2018 time frame, it becomes $8 \%$ cheaper and $14 \%$ cheaper in the 2025 and Ultimate time frames, respectively. In general, the price premium for the $\mathrm{BEV}$ is dominated by the battery pack size and cost, therefore efforts to reduce pack cost are very influential to the estimated MSRP.

- FCEV MSRP: The Class 8 long-haul 750-mile-range FCEV begins with an estimated approximately 130\% price premium over the diesel truck in the 2018 time frame, but reduces to only approximately $13 \%$ in the Ultimate time frame. The Class 8 long-haul 500-mile range has a similar trend, but with approximately $100 \%$ and $10 \%$ price premiums for the 2018 and Ultimate time frames, respectively. For the Class 8 short-haul, the FCEV price premiums are approximately $80 \%$ and 5\% for the 2018 and Ultimate time frames, respectively. Finally, the Class 4 parcel delivery FCEV is estimated to be approximately $100 \%$ more expensive in the 2018 time frame due to high fuel cell stack and hydrogen storage costs but achieves cost parity if the Ultimate scenario assumptions are achieved.

- BEV Weight: The Class 8 long-haul 750-mile-range BEV is approximately 24,000 lbs heavier than the diesel truck in the 2018 time frame but that spread reduces to 5,000 lbs in the Ultimate time frame. The 500-mile Class 8 long-haul is over 14,000 lbs heavier than the diesel equivalent in the 2018 time frame but can be within 2,000 lbs of the diesel truck in the Ultimate time frame. Thus, for Class 8 long-haul applications, tractor lightweighting may be very important for the BEV if the owner/operator requires heavy cargo loads, and R\&D to improve lightweighting or increase battery energy density could be very valuable. For the Class 8300 -mile short-haul, the tractor is 7,000 lbs heavier in the 2018 time frame but achieves weight parity with diesel in the Ultimate time frame.

- FCEV Weight: The Class 8 long-haul 750-mile-range FCEV is within 2,000 lbs of the equivalent diesel tractor in the 2018 time frame and becomes lighter as the fuel cell stack efficiency and hydrogen storage specific mass increase over time. This indicates that for trucks with heavy payload requirements, fuel cell powertrains may allow them to switch to a ZEV option without cannibalizing payload capacity.

- Fuel Economy: In general, BEVs are the most fuel-efficient powertrains and are approximately $70 \%-140 \%$ more energy-efficient than their diesel counterpart depending on truck type and duty cycle. FCEVs are the next most fuel-efficient powertrains and can be approximately $40 \%-80 \%$ more fuel-efficient than diesel trucks. 


\section{Total Cost of Ownership}

Key findings of the commercial vehicle TCO modeling include:

- Medium- and heavy-duty trucks with battery and fuel cell electric powertrains could be economically competitive with diesel powertrains under several operating scenarios and potentially by 2025 for shorter-range applications (<500-mile Class 8 tractors, 120-mile Class 4 delivery) if high diesel prices ( $>\$ 3 / g a l)$ and low hydrogen/electricity prices are realized.

- Battery electric powertrains may be best for shorter-range applications or when dwell time is not a concern and are complemented by fuel cell powertrains that may be better for longer ranges or operating scenarios that require higher uptime.

- Battery price reduction for BEVs and hydrogen fuel price reduction for FCEVs are key to accelerating medium- and heavy-duty vehicle electrification.

- Electricity price and hydrogen fuel price are key factors to the TCO of all trucks, and medium- and heavy-duty refueling/recharging cost reduction/management should be a key focus area for R\&D.

- Lost payload capacity cost for Class 8 long-haul (>500-mile) FCEVs or Class 8 short-haul (300-mile) BEVs is small due to the 2,000-lb exemption for alternative powertrain trucks.

- In the Class 8 short-haul (300-mile-range) and Class 4 parcel delivery (120-mile-range) vocations, BEVs are the lowest-cost ZEVs if dwell time costs are not incurred and Ultimate scenario assumptions are achieved.

- If dwell time costs are incurred, FCEVs are the lowest-cost ZEV for Class 4 parcel delivery, Class 8 short-haul (300-mile), and Class 8 long-haul (500-mile) vocations.

- In the Class 8 long-haul (500-mile-range) vocation, FCEVs and BEVs are very competitive with diesel if Ultimate scenario assumptions are met regardless of dwell and payload costs.

- In the Class 8 long-haul (750-mile-range) vocation, FCEVs are the lowest-cost ZEV if scenario assumptions are met regardless of dwell and payload costs.

\section{Real-World Considerations}

This modeling framework does not account for all aspects of the commercial vehicle sector. As discussed previously, the upfront purchase price estimated here is based on a bottom-up calculation, which may not reflect the pricing strategy of advanced truck manufacturers. Additionally, the TCO scenarios defined in this analysis represent edge-cases in which the truck operation is either never constrained by dwell time or payload (e.g., all single-shift operation) or always constrained by dwell time or payload (e.g., always multi-shift operation). In reality, these trucks may operate differently across the year and the owner may decide to adjust operating styles based on the powertrain, or select the powertrain technology that allows them the most operating flexibility. Also, the purchase and resale of battery electric and fuel cell electric trucks is also dependent on the availability of refueling and recharging infrastructure which was not evaluated in this analysis. Lastly, commercial vehicle transportation logistics are continually changing, and automated vehicles will likely further disrupt commercial vehicle travel patterns. This analysis focused on demonstrated, real-world duty cycles under different operating scenarios, but the TCO of future trucks will depend highly on their use-case and duty cycle in their respective time frames. 


\section{Conclusion}

The TCO framework presented here accounts for both direct and indirect costs for commercial vehicle applications. The direct costs include upfront vehicle purchase cost, fuel costs, and maintenance costs. The indirect costs include the payload opportunity cost and the dwell time cost incurred when a vehicle is refueling or charging. These indirect costs are often excluded in techno-economic analysis due to the complexity of modeling them and uncertainty in quantifying them.

The scenarios defined in this work aim to represent actual business operating models and provide insights into each specific one. Our results indicate that both the upfront purchase price and TCO of advanced powertrains in commercial vehicles can decrease rapidly and significantly if the 2025 and Ultimate time frame component costs and performance are achieved. Across all three vehicles studied in this analysis (Class 8 long-haul, Class 8 shorthaul, and Class 4 parcel delivery), there is a pathway for ZEVs to achieve cost parity with the diesel incumbent. The BEV and the FCEV powertrains complement each other in their vehicle attributes and help decarbonize the vehicles studied in this report. Specifically, BEVs may be best for shorter-range applications or when dwell time is not a concern, and are complemented by FCEVs that may be better for longer ranges or operating scenarios that require higher uptime.

Future work could focus on filling data gaps, enhancing powertrain modeling, completing detailed infrastructure analysis, and evaluating metrics outside of the TCO, including environmental emissions and resource consumption. 


\section{Future Work}

This report focuses on the TCO of Class 8 long-and short-haul tractors in addition to Class 4 parcel delivery trucks. However, there are many facets that were important yet beyond the scope of this work, including:

- Additional Commercial Vehicles/Vocations: Additional vehicles in the Class 4-8 segments or those with different use-cases (e.g., hauling) should be considered in future analyses.

- Detailed Infrastructure Modeling: Detailed spatial and temporal analysis of refueling and charging infrastructure is needed to improve the fuel price assumptions used in TCO modeling. Specifically, the placement, sizing, rollout strategy, cost, and renewable energy and grid integration optimization of widespread electric charging or hydrogen refueling stations should be considered in future work. Additional integrated electricity grid, refueling infrastructure, and vehicle-to-grid investment and operations modeling should also be conducted.

- Regional Impacts of Climate/Weather: The energy demand and resulting fuel economy of trucks is impacted by the local climate. These impacts should be further investigated and analyzed to better understand the impact on truck powertrain design (e.g., onboard energy storage) and TCO across regions.

- Regional Impacts of Road Grade: The average grade of the road impacts the fuel economy of the truck and could be further investigated to improve the regional resolution of the estimated TCO.

- Regional Emissions Modeling: This analysis did not evaluate the emissions associated with operating each of these truck powertrains over its lifetime. Additionally, regional variations and dynamics associated with a decarbonizng electricity grid should be studied.

- Component Durability and Degradation: This analysis assumed that technology performance characteristics were representative of the average component operation. However, component performance (e.g., engines, fuel cells, batteries) may degrade over time and costs above and beyond the assumed O\&M costs may be incurred to replace these components. Future work should evaluate the impact of component degradation (e.g., fuel cell degradation as a function of operating hours) or component replacements on powertrain design (e.g., power electronics may be sized based on end-of-life voltage) and commercial vehicle TCO.

- TCO-Based Powertrain Design Optimization: The TCO modeling framework developed in T3CO used in this analysis did not have the capability to complete TCO-based powertrain design optimizations. The ability to trade-off vehicle design attributes (e.g., smaller onboard energy storage at the expense of increased dwell time) should be evaluated in future work and is currently being added to NREL's T3CO model.

- Scenario Assumption Alignment: TCO assumptions could be aligned more directly with technology assumptions if the data are available. For example, detailed infrastructure analysis results could be used to pair the observed fuel price (e.g., electricity price) with the type of infrastructure used in a particular operating scenario (e.g., multi-shift operation). Additionally, a 1-MWh+ battery that requires a fast charge may be more costly than a comparable battery designed for slower charges and longer lifetimes.

- Medium- and Heavy-Duty Vehicle Adoption Criteria Analysis: Additional analysis similar to Brooker et al. (2021) is needed to better understand and quantify how fleets and business owners make fleet purchasing decisions. The combination of economics, risk, regulatory impacts, and public/driver perception are all important factors that should be evaluated to identify how commercial vehicles are adopted and what barriers may exist for alternative powertrain technology.

- Dwell Time and Payload Data: This analysis aimed to quantify the potential impact of dwell time and payload costs using a first-order estimation method. Future work could be focused on improving the representation of nonlinear refueling rates for advanced powertrain vehicles or using probability payload distributions.

- Resource Consumption: This report focuses on the economics of advanced powertrains in the commercial vehicle space. Additional work could be completed to assess the resource consumption associated with build- 
ing and operating these vehicles over their lifetime such as hydrogen production resources (e.g., water for electrolyzers) or rare earth metals for battery production.

- Policy Levers: This analysis did not assume any financial incentives for alternative powertrain technologies or zero emission vehicle mandates. Additionally, carbon markets such as the Low Carbon Fuel Standard were not explicitly studied in this work. These policy levers could be studied in future analyses.

- Resale/Salvage Value: This analysis evaluated trucks over their lifetime and assumed that the alternative powertrains would be produced to meet the durability requirements equal to that of conventional technology. Further analysis could be completed on the resale and salvage value as would impact the TCO for each powertrain. 


\section{References}

ACPS. 2015. School Bus Per-Mile Operating Cost Analysis. Alleghany County Public Schools. Low Moor, Virginia. Accessed July 2018: http://cms. alleghany.k12.va.us/UserFiles/Servers/Server_8986/File/School\%20Board/ Agendas/2015-2016/10-19-2015/16-112\%202015\%20Per-mile\%20Bus\%20Operating\%20Cost.pdf.

Adams, J., C. Houchins, and R. Ahluwalia. 2019. Onboard Type IV Compressed Hydrogen Storage System - Cost and Performance Status. U.S. Department of Energy Hydrogen and Fuel Cells Program Record. https://www. hydrogen.energy.gov/pdfs/19008_onboard_storage_cost_performance_status.pdf.

Alternative Fuels Data Center. 2018. Station Locator. Alternative Fuels Data Center. Accessed July 2018. https: //www.afdc.energy.gov/fuels/prices.html.

- . 2021. Compressed Natural Gas Fueling Stations. Alternative Fuels Data Center. Accessed January 2021. https: //afdc.energy.gov/fuels/natural_gas_cng_stations.html.

Argonne National Laboratory. 2021. Heavy Duty Refueling Station Analysis Model (HDRSAM). Argonne National Laboratory. https://hdsam.es.anl.gov/index.php?content=hdrsam.

ATRI. 2017. An Analysis of the Operational Costs of Trucking: 2017 Update. American Transportation Research Institute. http://atri- online.org/wp- content/uploads/2017/10/ATRI-Operational-Costs- of-Trucking-2017-102017.pdf.

- .2020. An Analysis of the Operational Costs of Trucking: 2020 Update. American Transportation Research Institute. https://truckingresearch.org/wp-content/uploads/2020/11/ATRI-Operational-Costs-of-Trucking-2020.pdf.

Automotive Fleet. 2006. Maintenance Statistics Medium Duty Truck. https ://www. automotive - fleet. com/fc_ resources/stats/affb06-48-49.pdf.

Barnitt, R. 2011. FedEx Express Gasoline Hybrid Electric Delivery Truck Evaluation: 12-Month Report. Tech. rep. NREL/TP-5400-48896. Golden, Colorado: National Renewable Energy Laboratory.

Barradas, S. 2012a. The Real Cost of Trucking - Per Mile Operating Cost of a Commercial Truck. Truckers Report. https://www.thetruckersreport.com/infographics/cost-of-trucking/.

- . 2012b. The Real Cost of Trucking - Per Mile Operating Cost of a Commercial Truck. Truckers Report. https: //www.thetruckersreport.com/infographics/cost-of-trucking/.

Bloomberg NEF. 2020. Battery Pack Prices Cited Blow \$100/kWh for the First Time in 2020, While Market Average Sits at \$137/kWh. https://about.bnef.com/blog/battery-pack-prices-cited-below-100-kwh-for-the-first-time-in2020-while-market-average-sits-at-137-kwh/\#: :text=By\%202023\%2C\%20average\%20prices\%20will,in\%20e\% 2Dbuses $\% 20$ in $\%$ 20China.\&text $=$ At $\% 20$ the $\% 20$ cell $\% 20$ level $\% 2$ C $\% 20$ average, prices $\% 20$ were $\% 20$ ust $\% 20 \%$ $24100 \% 2 \mathrm{FkWh}$.

Borlaug, B., S. Salisbury, M. Gerdes, and M. Muratori. 2020. "Levelized Cost of Charging Electric Vehicles in the United States". Joule 4:1470-1485.

Boyd, S. 2018. Batteries and Electrification R\&D Overview: U.S. Department of Energy Office of Energy Efficiency \& Renewable Energy. https://www.energy.gov/sites/prod/files/2018/06/f53/bat918_boyd_2018.pdf.

Brooker, A., et al. 2021. Vehicle Technologies and Hydrogen and Fuel Cells Technologies Research and Development Programs Benefits Assessment Report for 2020. Tech. rep. National Renewable Energy Laboratory, Golden, CO. NREL/TP-5400-79617.

Burnham, A., et al. 2021. Comprehensive Total Cost of Ownership Quantification for Vehicles with Different Size Classes and Powertrains. Tech. rep. Argonne National Laboratory, ANL/ESD-21/4.

Bush, B., M. Melaina, A. Nag, M. Penev, and J. Zuboy. 2021. Scenario Evaluation and Regionalization Analysis (SERA): Technical Manual. Tech. rep. Golden, Colorado: National Renewable Energy Laboratory. NREL/TP6A20-65182.

Bush, B., M. Muratori, C. Hunter, J. Zuboy, and M. Melaina. 2019. Scenario Evaluation and Regionalization Analysis (SERA) Model: Demand Side and Refueling Infrastructure Build-Out. Tech. rep. Golden, Colorado: National Renewable Energy Laboratory. NREL/TP-5400-70090.

California Legislative Information. 2018. Assembly Bill No. 2061. Near-zero emission and zero-emission vehicles. https://leginfo.legislature.ca.gov/faces/billTextClient.xhtml?bill_id=201720180AB2061.

CARB. 2015. Technology Assessment: Medium- and Heavy-Duty Battery Electric Trucks and Buses (Draft Report). Sacramento, CA: California Air Resources Board. 
- . 2016. Advanced Clean Transit Program: Literature Review on Transit Bus Maintenance Cost (Discussion Draft). Sacramento, CA: California Air Resources Board. https://www.arb.ca.gov/msprog/bus/maintenance_cost.pdf.

- . 2020. 2020 Annual Evaluation of Fuel Cell Electric Vehicle Deployment \& Hydrogen Fuel Station Network Development. Sacramento, CA: California Air Resources Board. https://ww2.arb.ca.gov/sites/default/files/202009/ab8_report_2020.pdf.

- .2021. Low Carbon Fuel Standard Data Dashboard. Sacramento, CA: California Air Resources Board. https: //ww3.arb.ca.gov/fuels/lcfs/dashboard/dashboard.htm.

Deloitte. 2020. Fueling the Future of Mobility: Hydrogen and fuel cell solutions for transportation. https://www2. deloitte.com/content/dam/Deloitte/cn/Documents/finance/deloitte- $\mathrm{cn}$ - fueling- the-future- of - mobility-en200101.pdf.

Dunckley, J., and C. Valluri. 2017. National Charging Costs. EPRI Fall Advisory 2017, Product ID 3002011098. Palo Alto, California: Electric Power Research Institute https://www.epri.com/\#/pages/product/3002011098/ ?lang=en.

Ernst and Young. 2003. Ernst \& Young Total Cost of Ownership. St. Paul, Minnesota: Minnesota Department of Transportation. https://www.lrrb.org/pdf/200319.pdf.

Eudy, L. 2019. “Technology Acceleration: Fuel Cell Bus Evaluations”. In DOE Fuel Cell Technology Annual Merit Review, May 1, 2019.

Eudy, L., and M. Jeffers. 2019. Foothill Transit Agency Battery Electric Bus Progress Report. Tech. rep. National Renewable Energy Laboratory, Golden, Co. NREL/PR-5400-73516.

Eudy, L., and M. Post. 2017. Fuel Cell Buses in U.S. Transit Fleets: Current Status 2017. Tech. rep. NREL/TP-540070075. Golden, Colorado: National Renewable Energy Laboratory.

- . 2018. Fuel Cell Buses in U.S. Transit Fleets: Current Status 2018. Tech. rep. NREL/TP-5400-70075. Golden, Colorado: National Renewable Energy Laboratory.

- . 2020. Fuel Cell Buses in U.S. Transit Fleets: Current Status 2020. Tech. rep. NREL/TP-5400-75583. Golden, Colorado: National Renewable Energy Laboratory.

Eudy, L. E., and M. Post. 2019. Zero-Emission Bus Evaluation Results: Stark Area Regional Transit Authority Fuel Cell Electric Buses. Tech. rep. Federal Transit Administration.

Federal Motor Carrier Safety Administration. 2015. Interstate Truck Driver's Guide to Hours of Service. https: //www.fmcsa.dot.gov/sites/fmcsa.dot.gov/files/docs/Drivers\%20Guide\%20to\%20HOS\%202015_508.pdf.

- . 2017. Summary of Hours of Service Regulations. Federal Motor Carrier Safety Administration. Updated March 9, 2017. https://www.fmcsa.dot.gov/regulations/hours-service/summary-hours-service-regulations.

- . 2018. Estimates Show Commercial Driver Detention Increases Crash Risk and Costs, but Current Data Limit Further Analysis. Federal Motor Carrier Safety Administration. https://www.oig.dot.gov/sites/default/files/ FMCSA\%20Driver\%20Detention\%20Final\%20Report.pdf.

Financial, R. 2014. How to Calculate Cost per Mile for Your Trucking Company. RTS Financial. http : //www . rtsfinancial.com/guides/trucking-calculations-formulas.

Gangloff, J. J. J., J. Kast, G. Morrison, and J. Marcinkoski. 2017. "Design Space Assessment of Hydrogen Storage Onboard Medium and Heavy Duty Fuel Cell Electric Trucks". Journal of Electrochemical Energy Conversion and Storage 13 (2): 021001.

Halonen, A., R. Swim, and M. Roeth. 2015. Trucking Efficiency Confidence Report: Lightweighting. North American Council for Freight Efficiency. https://nacfe.org/report-library/confidence-reports/.

HART. 2017. Adapting New Fuel Technologies. Hillsborough Area Regional Transit. Presented to Legislative and Strategic Planning Committee, May 15, 2017. http://www.gohart.org/Style\%20Library/goHART/pdfs/board/ Presentation\%20CNG\%20Verses\%20Electric\%20Bus.pdf.

Heid, B., R. Hensley, S. Knupfer, and A. Tschiesner. 2017. What's sparking electric-vehicle adoption in the truck industry? https://www.mckinsey.com/industries/automotive-and-assembly/our-insights/whats-sparking-electricvehicle-adoption-in-the-truck-industry.

Hirsch, J. 2021. Navistar and GM Developing Heavy-Duty Hydrogen Fuel Cell Truck. https://www.trucks.com/2021/ 01/27/navistar-gm-heavy-duty-fuel-cell-truck/.

Hooper, A., and M. Dan. 2017. An Analysis of the Operational Costs of Trucking: 2017 Update. Arlington, Virginia: American Transportation Research Institute. http://atri-online.org/wp-content/uploads/2017/10/ATRI-OperationalCosts-of-Trucking-2017-10-2017.pdf. 
Hua, T., R. Ahluwalia, L. Eudy, G. Singer, B. Jermer, N. Asselin-Miller, S. Wessel, T. Patterson, and J. Marcinkoski. 2014. "Status of hydrogen fuel cell electric buses worldwide". Journal of Power Sources 269:3975-993. doi:https: //doi.org/10.1016/j.jpowsour.2014.06.055.

Hyundai. 2018. Hyundai and H2 Energy to launch world's first fleet of Fuel Cell Trucks. https://www.hyundai.news/ eu/technology/hyundai-motor-and-h2-energy-will-bring-the-worlds-first-fleet- of-fuel-cell-electric-truck-intocommercial-operation.

James, B., J. Huya-Kouadio, and C. Houchins. 2021. "2021 DOE Hydrogen and Fuel Cells Program Review Presentation Fuel Cell Systems Analysis". In DOE Fuel Cell Technology Annual Merit Review, June 9, 2021.

James, B., J. Huya-Kouadio, C. Houchins, and D. DeSantis. 2018. Mass Production Cost Estimation of Direct $\mathrm{H}_{2}$ PEM Fuel Cell Systems for Transportation Applications: 2018 Update. Strategic Analysis Inc. https://www. energy.gov/sites/prod/files/2019/12/f70/fcto-sa-2018-transportation-fuel-cell-cost-analysis.pdf.

Josephs, S. 2015. The per-mile Costs of Operating Compressed Natural Gas Trucks: Experience from 16 Million Miles with the Cummins ISX12G. Chicago, IL: ampCNG. https : / static1 . squarespace . com / static / 54df8befe4b0419b74c936c2/t/55f706f8e4b0c1c31ccc861d/1442252536965/ampCNG + White + Paper + on + $12 \mathrm{~L}+$ Operating+Costs+per+Mile.pdf.

Kast, J., G. Morrison, J. J. G. Jr., R. Vijayagopal, and J. Marcinkoski. 2017a. "Designing hydrogen fuel cell electric trucks in a diverse medium and heavy duty market". Research in Transportation Economics 70:139-147.

Kast, J., R. Vijayagopal, J. J. G. Jr., and J. Marcinkoski. 2017b. "Clean commercial transportation: Medium and heavy duty fuel cell electric trucks". Journal of Hydrogen Energy 42 (7):4508-4517.

Kenworth. 2020. T680E Electric Truck. https://kenworth.com/media/qrbigowa/2020-act-expo-single-page-flyer-0918-2020.pdf.

Kleiner, F., E. D. Ozdemir, S. A. Schmidt, M. Beerman, B. Catay, B. Moran, O. T. Lim, and H. E. Friedrich. 2015. "Electrification of transport logistic vehicles: A techno-economic assessment of battery and fuel cell electric transporter". In EVS28, KINTEX, Korea, May 3-6, 2015.

Lajunen, A., and T. Lipman. 2016. "Lifecycle cost assessment and carbon dioxide emissions of diesel, natural as, hybrid electric, fuel cell hybrid and electric transit buses". Energy 106:329-342. doi:https://doi.org/10.1016/j. energy.2016.03.075.

Lammert, M. 2009. Twelve-Month Evaluation of UPS Diesel Hybrid Electric Delivery Vans. Tech. rep. NREL/TP540-44134. Golden, Colorado: National Renewable Energy Laboratory.

Lee, D.-Y., V. M. Thomas, and M. A. Brown. 2013. "Electric Urban Delivery Trucks: Energy Use, Greenhouse Gas Emissions, and Cost-Effectiveness". Environmental Science and Technology 47 (14): 8022-8030. doi:https: //doi.org/10.1021/es400179w.

Load Delivered. 2017. The Cost of Dwell Time Under the ELD Mandate. https://www.loaddelivered.com/blog/thecost-of-dwell-time-under-the-eld-mandate/.

Logistics, F. M. 2021. Freight classes. https://www.fmlfreight.com/freight-101/freight-classes/.

Lowell, D., and T. Balon. 2009. Setting the Stage for Regulation of Heavy-Duty Vehicle Fuel Economy \& GHG Emissions: Issues and Opportunities. M.J. Bradley and Associates LLC. https://mjbradley.com/sites/default/files/ HDV\%20Fuel\%20Economy\%20Scoping\%20Paper_0.pdf.

Lustbader, J., A. Birky, C. Zhang, C. Baker, and C. Hunter. 2021. Transportation Technology Total Cost of Ownership (T3CO) Methodology and Application to Class 8 Commercial Vehicle Electrification. Tech. rep. NREL/TP5400-79737. National Renewable Energy Laboratory, Golden, Colorado.

Marcinkoski, J., R. Vijayagopal, J. Addams, B. James, J. Kopasz, and R. Ahluwalia. 2019. Hydrogen Class 8 long haul Truck Targets. Department of Energy Program Record. https://www.hydrogen.energy.gov/program_records. html.

Marcinkoski, J., R. Vijayagopal, and A. Duran. 2016. "Driving an Industry: Medium and Heavy Duty Fuel Cell Electric Truck Component Sizing". World Electric Vehicle Journal 8.

Meintz, A. 2020. "Charging Infrastructure Technologies: Development of a Multiport, >1 MW Charging System for Medium- and Heavy-Duty Electric Vehicles". In DOE Vehicle Technologies Program 2020 Annual Merit Review and Peer Evaluation Meeting.

Melaina, M., B. Bush, M. Muratori, J. Zuboy, and S. Ellis. 2017. National Hydrogen Scenarios: How Many Stations, Where, and When? Prepared by the National Renewable Energy Laboratory for the H2USA Locations Roadmap Working Group. https://www.nrel.gov/docs/fy18osti/71083.pdf. 
Mihelic, R., K. Otto, J. Lund, J. Wheeler, M. Roeth, D. Rondini, L. Gueveraa-Stone, and kim Ehrenhart. 2020.

Making Sense of Heavy-Duty Hydrogen Fuel Cell Tractors. https://nacfe.org/emerging-technology/electric-trucks2/making-sense-of-heavy-duty-hydrogen-fuel-cell-tractors/.

MNDOT. 2003. Figuring Cost per Mile. St. Paul, Minnesota: Minnesota Department of Transportation. https: //www.lrrb.org/pdf/200319.pdf.

Muratori, M., E. Kontou, and E. Eichman. 2019. "Electricity rates for electric vehicle direct current fast charging in the United States". Renewable and Sustainable Energy Reviews 113:109235.

National Center for Transit Research. 2011. Tracking Costs of Alternatively Fueled Buses in Florida: Final Report. BDK85 977-18. Tallahassee, Florida: State of Florida Department of Transportation. https://www.nctr.usf.edu/wpcontent/uploads/2012/02/77927-final-report.pdf.

National Motor Freight Traffic Association. 2018. National Motor Freight Classification Book. National Motor Freight Traffic Association. https://store.nmfta.org/category/nmfcbooks.

National Renewable Energy Laboratory. 2018a. FASTSim: Future Automotive Systems Technology Simulator. National Renewable Energy Laboratory. https://www.nrel.gov/transportation/fastsim.html.

- .2018b. Fleet DNA: Commercial Fleet Vehicle Operating Data. National Renewable Energy Laboratory. https: //www.nrel.gov/transportation/fleettest-fleet-dna.html.

Nikola. 2020. Nikola Two. urlhttps://nikolamotor.com/two.

O’Dell, J. 2018. Here's How Toyota Improved Project Portal, its Fuel Cell Truck. https://www.trucks.com/2018/07/ 30/toyota-fuel-cell-truck-improvements/.

OOIDA. 2011. Truckers say detention legislation would improve productivity, safety. Owner-Operated Independent Drivers Association. https://www.ooida.com/MediaCenter/PressReleases/pressrelease.asp?prid=188.

- . 2015. Figuring Cost per Mile. Owner-Operator Independent Drivers Association. https://www. ooida.com/ EducationTools/Tools/costpermile.asp.

Penske. 2021. Penske Heavy-Duty Semi Truck Rentals. https://www.pensketruckrental .com/commercial- truckrental/commercial-trucks/heavy-duty-trucks/.

Phadke, A., A. Khandekar, N. Abhyankar, D. Wooley, and D. Rajagopal. 2021. Why Regional and Long-Haul Trucks are Primed for Electrification Now. https://eta-publications.lbl.gov/sites/default/files/updated_5_final_ehdv_ report_033121.pdf.

Ramsden, T., and F. Joseck. 2018. Hydrogen R\&D Cost Target Calculation - 2018 Update. Department of Energy

Program Record. https://www.hydrogen.energy.gov/pdfs/18004_h2_cost_target_calculation_2018.pdf.

Ritter, K. 2018. The Tesla Semi Weighs In - Part 3. https://insideevs.com/tesla-semi-weighs-part-3/.

R.L. Polk and Co. 2013. U.S. Vehicle Registration Data for Class 4-8.

Robinson, C.H. 2021. LTL Freight Quotes. https://www.freightquote.com/freight-shipping/ltl-less-than-truckload/.

Rondini, D. L., K. Ehrenhaft, D. Schaller, M. Roeth, and R. Mihelic. 2020. Collected Works 2020. North American Council for Freight Efficiency. https://nacfe.org/nacfes-2020-collected-works/.

Shell and Deloitte. 2020. Decarbonizing Road Freight: Getting Into Gear. https://www2.deloitte.com/global/en/ pages/energy-and-resources/articles/decarbonizing-road-freight.html.

Shoettle, B., M. Sivak, and M. Tunnell. 2016. A Survey of Fuel Economy and Fuel Usage By Heavy-Duty Truck Fleets. University of Michigan and American Transportation Research Institute. http://umich.edu/ umtriswt/PDF/ SWT-2016-12.pdf.

Smith, D. 2021. Personal conversation with Dennis Smith, VTO.

Stella, D. 2015. "Own or lease: are you making the right choice for your truck fleet?" Performance 5 (1): 40-47.

Stork, Kevin. 2021. CNG cost assumptions for MD/HD TCO Analysis. Personal communication.

Stork, Kevin and Curran, Scott and Graves, Ronald and Pihl, Josh. 2021. Cummins note on NG engine efficiency. Personal communication.

TCRP. 2018. TCRP Annual Report of Progress 2018. Transit Cooperative Research Program. https://doi. org/10. $17226 / 25345$.

Tesla. 2021. Tesla Semi. https://www.tesla.com/semi.

Total Transportation Services, Inc. 2018. Benefits for Hydrogen for Trucks. Total Transportation Services, Inc. Presented at the DOE Fuel Cell Truck Workshop, July 31, 2018. https:/www.energy.gov/sites/prod/files/2018/08/f54/ fcto-truck-workshop-2018-1-williamson.pdf.

Trader, C. T. 2021. Find your truck here. https://www.commercialtrucktrader.com/. 
Transport \& Environment. 2020. Comparison of hydrogen and battery electric trucks: Methodology and underlying assumptions. https://www.transportenvironment.org/sites/te/files/publications/2020_06_TE_comparison_ hydrogen_battery_electric_trucks_methodology.pdf.

Transport Topics. 2021. Carriers Use Pre-Planning to Help Drivers Secure Truck Parking. https://www.ttnews.com/ articles/carriers-use-pre-planning-help-drivers-secure-truck-parking.

Transportation Research Board. 2018. Synthesis 130: Battery Electric Buses-State of the Practice. Transportation Research Board. https://www.nap.edu/catalog/25061/battery-electric-buses-state-of-the-practice.

Transportation Research Board and National Research Council. 2010. Technologies and Approaches to Reducing the Fuel Consumption of Medium- and Heavy-Duty Vehicles. Transportation Research Board and National Research Council. Washington, DC: The National Academies Press. https://doi.org/10.17226/12845.

Truck Drivers Salary. 2017. How Much Can Truck Drivers Make? Truck Drivers Salary. https://www.truckdriverssalary. com/how-much-can-you-earn-your-1st-year-as-a-trucker/..

ultimateSPECS. 2021. Toyota Prius Plug-in 1.8 Hybrid Specs. https://www.ultimatespecs.com/car-specs/Toyota/ 114810/Toyota-Prius-Plug-in-18-Hybrid.html.

U.S. Census Bureau. 2002. 2002 Vehicle Inventory and Use Survey. ECO2TV-US. Washington, D.C.: U.S. Census Bureau. https://www.census.gov/library/publications/2002/econ/census/vehicle-inventory-and-use-survey.html.

U.S. Department of Energy. 2021. Batteries. U.S. Department of Energy Vehicle Technologies Office, https://www. energy.gov/eere/vehicles/batteries.

U.S. Department of Transportation. 2015. The Fixing America's Surface Transportation Act or "FAST Act". https: //www.transportation.gov/fastact.

U.S. DRIVE. 2017. Electrical and Electronics Technical Team Roadmap. https://www.energy.gov/sites/prod/files/ 2017/11/f39/EETT\%20Roadmap\%2010-27-17.pdf.

U.S. Energy Information Administration. 2021. Annual Energy Outlook 2021. Washington, D.C.: U.S. Energy Information Administration. https://www.eia.gov/outlooks/aeo/.

U.S. Environmental Protection Agency. 2016. Greenhouse Gas Emissions and Fuel Efficiency Standards for Medium- and Heavy-Duty Engines and Vehicles - Phase 2. Final Rule Making. Tech. rep. U.S. Environmental Protection Agency. EPA-420-R-16-900. Washington, D.C.

U.S. Environmental Protection Agency and National Highway Traffic Safety Administration. 2011. Final Rulemaking to Establish Greenhouse Gas Emissions Standards and Fuel Efficiency Standards for Medium- and HeavyDuty Engines and Vehicles. Tech. rep. U.S. Environmental Protection Agency and National Highway Traffic Safety Administration. EPA-420-R-11-901. Washington, D.C.

Verbrugge, M. W., and C. W. Wampler. 2018. "On the optimal sizing of batteries for electric vehicles and the influence of fast charge". Journal of Power Sources 384:312-317.

Volvo. 2021. Volvo VNR Electric. https://www.volvotrucks.us/trucks/vnr-electric/. 


\section{Appendix A. Powertrain Sizing and FASTSim Vehicle Parameters}

This appendix provides powertrain sizing for each powertrain type, vocation, and model year analyzed. Each powertrain reduces in output size $(\mathrm{kW})$ by roughly $5 \%$ due to improvements in such areas as lightweighting, aerodynamics, and tire rolling resistance. These modeling parameters are provided in Tables A1 and A2. Fuel converter represents the engine (in the case of diesel, CNG, and HEV powertrains) or fuel cells (in the case of FCEV powertrains).

Table A1. Powertrain Sizing

\begin{tabular}{|c|c|c|c|}
\hline Powetrain and model year & C8 long haul & C8 short haul & C4 parcel delivery \\
\hline Conv current fuel converter (kW) & 317 & 340 & 155 \\
\hline Conv 2025 fuel converter (kW) & 309 & 331 & 143 \\
\hline Conv ultimate fuel converter (kW) & 300 & 320 & 140 \\
\hline CNG current fuel converter (kW) & 317 & 340 & 155 \\
\hline CNG 2025 fuel converter (kW) & 309 & 331 & 143 \\
\hline CNG ultimate fuel converter (kW) & 300 & 320 & 140 \\
\hline HEV current fuel converter (kW) & 235 & 253 & 115 \\
\hline HEV 2025 fuel converter (kW) & 229 & 245 & 106 \\
\hline HEV ultimate fuel converter (kW) & 223 & 238 & 103 \\
\hline HEV current motor (kW) & 78 & 84 & 38 \\
\hline HEV 2025 motor (kW) & 76 & 82 & 35 \\
\hline HEV ultimate motor (kW) & 74 & 79 & 34 \\
\hline BEV current motor $(\mathrm{kW})$ & 309 & 332 & 146 \\
\hline BEV 2025 motor (kW) & 302 & 323 & 135 \\
\hline BEV ultimate motor (kW) & 294 & 314 & 132 \\
\hline FCEV current fuel converter (kW) & 303 & 325 & 146 \\
\hline FCEV 2025 fuel converter (kW) & 295 & 316 & 135 \\
\hline FCEV ultimate fuel converter (kW) & 288 & 307 & 132 \\
\hline FCEV current motor (kW) & 303 & 325 & 146 \\
\hline FCEV 2025 motor (kW) & 295 & 316 & 135 \\
\hline FCEV ultimate motor $(\mathrm{kW})$ & 288 & 307 & 132 \\
\hline PHEV current fuel converter (kW) & 170 & 182 & 82 \\
\hline PHEV 2025 fuel converter (kW) & 166 & 177 & 76 \\
\hline PHEV ultimate fuel converter (kW) & 161 & 171 & 74 \\
\hline PHEV current motor (kW) & 140 & 150 & 68 \\
\hline PHEV 2025 motor (kW) & 136 & 146 & 62 \\
\hline PHEV ultimate motor (kW) & 133 & 142 & 61 \\
\hline
\end{tabular}


Table A2. Powertrain Sizing

\begin{tabular}{|c|c|c|c|c|}
\hline Parameter & Year/Status & C8long haul & C8 short haul & $\begin{array}{l}\text { C4 parcel } \\
\text { delivery }\end{array}$ \\
\hline \multirow{3}{*}{ Glider mass (kg) } & Current & 10,833 & 9,848 & 3,694 \\
\hline & 2025 & 10,529 & 9,631 & 2,430 \\
\hline & Ultimate & 9,647 & 8,770 & 2,145 \\
\hline \multirow{3}{*}{ Cargo (kg) } & Current & 16,329 & 16,329 & 2,722 \\
\hline & 2025 & 16,329 & 16,329 & 2,780 \\
\hline & Ultimate & 16,329 & 16,329 & 2,875 \\
\hline \multirow{3}{*}{$\begin{array}{l}\text { Lightweighting } \\
\& \text { transmission } \\
\text { cost }(\$)\end{array}$} & Current & 0 & 0 & 0 \\
\hline & 2025 & $-1,650$ & $-1,768$ & -765 \\
\hline & Ultimate & $-2,700$ & $-2,882$ & $-1,258$ \\
\hline \multirow{3}{*}{ Drag coefficient } & Current & 0.47 & 0.54 & 0.71 \\
\hline & 2025 & 0.41 & 0.46 & 0.44 \\
\hline & Ultimate & 0.35 & 0.38 & 0.38 \\
\hline \multirow{3}{*}{$\begin{array}{l}\text { Rolling } \\
\text { resistance }\end{array}$} & Current & 0.0054 & 0.0055 & 0.0071 \\
\hline & 2025 & 0.0048 & 0.0049 & 0.0070 \\
\hline & Ultimate & 0.0042 & 0.0042 & 0.0066 \\
\hline \multirow{3}{*}{$\begin{array}{l}\text { Frontal area } \\
\qquad\left(\mathrm{m}^{2}\right)\end{array}$} & Current & \multirow{3}{*}{10.2} & \multirow{3}{*}{10.2} & \multirow{3}{*}{6.0} \\
\hline & 2025 & & & \\
\hline & Ultimate & & & \\
\hline \multirow{3}{*}{$\begin{array}{l}\text { Auxiliary load } \\
\qquad(\mathrm{kW})\end{array}$} & Current & 3.40 & 3.38 & 2.00 \\
\hline & 2025 & 2.75 & 2.75 & 1.03 \\
\hline & Ultimate & 1.50 & 1.50 & 0.56 \\
\hline
\end{tabular}




\section{Appendix B. Benchmarking}

This section describes an analysis that benchmarked the T3CO model against Autonomie, an existing vehicle system model (Argonne National Laboratory 2021). We compared representative vehicle inputs and outputs for a Class 4 delivery truck described in a study by Marcinkoski, Vijayagopal, and Duran (2016) and analogous to the class 4 parcel delivery truck considered in the present study. Table B1 provides input and output parameters for each study. Although there are differences in model input scope, assumptions, and drive cycles, the models predict FCEV fuel efficiency within 5\% of each other. For Class 4 parcel delivery, the fuel efficiency estimate is $21.5 \mathrm{mpg}$ in the Autonomie analysis and $22.6 \mathrm{mpg}$ in the FASTSim analysis.

Table B1. Benchmark Against Autonomie

\begin{tabular}{|c|c|c|c|c|c|c|c|}
\hline Performance criteria & $\begin{array}{l}\text { Autonomie } \\
2016 \text { tech }\end{array}$ & $\begin{array}{l}\text { FASTSim } \\
\text { FCEV } 2015 \\
\text { tech target }\end{array}$ & $\begin{array}{l}\text { FASTSim } \\
\text { FCEV } 2020 \\
\text { tech target }\end{array}$ & $\begin{array}{l}\text { FASTSim } \\
\text { FCEV } 2050 \\
\text { tech target }\end{array}$ & $\begin{array}{l}\text { FASTSim } \\
\text { Conv. } 2015 \\
\text { tech target }\end{array}$ & $\begin{array}{l}\text { FASTSim } \\
\text { Conv. } 2020 \\
\text { tech target }\end{array}$ & $\begin{array}{l}\text { FASTSim } \\
\text { Conv. } 2050 \\
\text { tech target }\end{array}$ \\
\hline \multicolumn{8}{|l|}{ Class 4 delivery, conventional } \\
\hline \multirow{4}{*}{$\begin{array}{l}\text { Cargo mass (lb) } \\
0-30 \mathrm{mph} \text { acceleration time (s) } \\
0-60 \mathrm{mph} \text { acceleration time (s) } \\
\text { Auxiliaries, non-mechanical }(\mathrm{kW})\end{array}$} & 5,280 & 5,868 & 5,788 & 5,574 & 6,044 & 5,742 & 5,742 \\
\hline & 7.2 & & & & & & \\
\hline & 29.8 & 14 & 14 & 14 & 31 & 31 & 31 \\
\hline & & 3 & 3 & 3 & 3 & 3 & 3 \\
\hline \multirow{2}{*}{$\begin{array}{l}\text { Total vehicle mass }(\mathrm{kg}) \text {, conventional } \\
\text { Total vehicle mass }(\mathrm{kg}) \text {, FCEV }\end{array}$} & 6,809 & & & & 7,257 & 7,257 & 7,257 \\
\hline & 6,854 & 7,257 & 7,257 & 7,257 & & & \\
\hline Glider weight (kg), conv & 3,417 & & & & 3,694 & 3,694 & 3,694 \\
\hline Glider weight (kg), FCEV & 3,417 & 3,694 & 3,694 & 3,694 & & & \\
\hline Cargo mass (kg), conv & 2,400 & & & & 2,741 & 2,604 & 2,604 \\
\hline Cargo mass (kg), FCEV & 2,400 & 2,661 & 2,625 & 2,528 & & & \\
\hline $\begin{array}{l}\text { Fuel + tank mass }(\mathrm{kg}) \text { conventional } \\
\text { Fuel + tank mass }(\mathrm{kg}) \text { FCEV }\end{array}$ & 140 & & & & 44 & 44 & 44 \\
\hline \multirow{2}{*}{$\begin{array}{l}\text { Fuel + tank mass }(\mathrm{kg}) \text { FCEV } \\
\text { Conv. engine mass }(\mathrm{kg})\end{array}$} & 454 & 196 & 183 & 125 & & & \\
\hline & 305 & & & & 365 & 365 & 365 \\
\hline Fuel cell mass (kg) & 125 & 163 & 327 & 327 & & & \\
\hline Gearbox mass ( $\mathrm{kg}$ ) conv & 142 & & & & 95 & 95 & 95 \\
\hline Gearbox mass (kg) FCEV & 10.0 & 95 & 95 & 95 & & & \\
\hline Motor mass (kg) & 145 & 352 & 352 & 352 & & & \\
\hline \multirow{2}{*}{$\begin{array}{l}\text { Battery mass }(\mathrm{kg}) \text { conv } \\
\text { Batteries mass ( } \mathrm{kg} \text { ) FCEV }\end{array}$} & 83 & & & & - & - & - \\
\hline & 148 & 127 & 131 & 77 & & & \\
\hline \multicolumn{8}{|l|}{ FCEV component sizes } \\
\hline Motor power (kW) & 260 & 276 & 276 & 276 & & & \\
\hline Fuel cell power (kW) & 164 & 152 & 152 & 152 & & & \\
\hline \multirow{2}{*}{$\begin{array}{l}\text { Battery power (kW) } \\
\text { Battery energy (kWh) }\end{array}$} & 54 & 124 & 124 & 124 & & & \\
\hline & 1.4 & 22.0 & 22.0 & 22.0 & & & \\
\hline \multirow{2}{*}{$\begin{array}{l}\text { Fuel economy regional conventional (mpgge) } \\
\text { Fuel economy regional FCEV (mpgge) }\end{array}$} & 14.1 & & & & 10.2 & 10.2 & 10.2 \\
\hline & 21.5 & 22.6 & 22.6 & 22.6 & & & \\
\hline
\end{tabular}

For Class 8 line-haul trucks, we validated the FASTSim FCEV and conventional powertrain results against published values by Nikola Motor Company (Nikola 2020). Whereas Nikola states a driving fuel efficiency of 13.5 miles per kilogram of hydrogen, FASTSim estimates fuel cell vehicle fuel economies closer to 8.5 miles per kilogram. Because a variety of inputs impact the fuel efficiency and thus range of the vehicle, we performed a calibration of a FASTSim fuel cell line-haul vehicle to match the weight and efficiency characteristics disclosed by Nikola. Table B2 summarizes the characteristics and performance of FCEV line-haul sleeper cab vehicles for three tech target years in FASTSim, as well as a calibrated Nikola vehicle. The main points of calibration were:

- Adjusting FASTSim glider weight to match tractor weight of 19,000 lbs stated by Nikola. This calibration encompasses the weight of all drivetrain components.

- Fixing hydrogen storage to $100 \mathrm{~kg}$.

- Adjusting fuel converter (fuel cell system) efficiency from $61 \%$ to $70 \%$. 
When analyzing the vehicle in FASTSim with these parameters and the same drive cycle used for all line-haul vehicles in this study, the model predicts a fuel efficiency of 10.33 miles per kilogram and a range of 1,033 miles. The efficiency is significantly closer to the stated fuel efficiency by Nikola. Additional differences may exist in the methodology of Nikola's fuel economy estimation. For example, they do not specify cargo and trailer weight, and a lighter trailer and cargo load could yield higher fuel efficiency than what FASTSim predicts. Nikola also did not specify a drive cycle, and a lower cruising velocity drive cycle with fewer stops would yield higher fuel efficiency. Other design details such as vehicle aerodynamics, motor efficiency, lack of transmission, tire rolling resistance, and others could add up to additional fuel efficiency differences. Nikola also uses a significantly larger hybridization battery: $320 \mathrm{kWh}$, compared to the 22-kWh battery modeled in FASTSim. Although we have adjusted the total weight of the vehicle for this discrepancy, additional fuel efficiency gains could be achieved by a larger hybrid battery by reducing primary energy consumption associated with braking and acceleration. It is not clear why such a large battery was used in Nikola's design. One possibility could be that fuel cell system startup time may be lengthy and the system could require more battery power to span system startup. In general, we see higher fuel cell vehicle efficiency claims by Nikola than vehicle efficiency estimated by FASTSim line-haul vehicles. As such, analysis results of FCEVs in the report may be conservative relative to commercial experience.

Table B2. Benchmark Against Industry

\begin{tabular}{|l|r|r|r|r|r|r|}
\hline \multicolumn{1}{|c|}{ Vehicle } & $\begin{array}{r}\text { FASTSim } \\
\text { long haul (750) } \\
\text { FCEV 2018 }\end{array}$ & $\begin{array}{r}\text { FASTSim } \\
\text { long haul (750) } \\
\text { FCEV 2025 }\end{array}$ & $\begin{array}{r}\text { FASTSim } \\
\text { long haul (750) } \\
\text { FCEV 2050 }\end{array}$ & $\begin{array}{r}\text { NIKOLA ONE } \\
\text { line haul } \\
\text { sleeper cab }\end{array}$ & $\begin{array}{r}\text { Toyota drayage } \\
\text { Project Portal } \\
\text { FCEV }\end{array}$ & $\begin{array}{r}\text { Hyundai line } \\
\text { haul day calb } \\
\text { FCEV }\end{array}$ \\
\hline Fuel economy (mpgge) & 10.4 & 12.4 & 16.1 & 10.33 & 6.00 & 7.60 \\
\hline Fuel storage capacity (kWh) & 2,696 & 2,359 & 1,685 & 3,370 & 1,348 & 1,112 \\
\hline Storage capacity (kg H2) & 80 & 70 & 50 & 100 & 40 & 33 \\
\hline Range (miles) & 836 & 866 & 804 & 1,033 & 240 & 250 \\
\hline
\end{tabular}

\begin{tabular}{|l|r|r|r|r|r|r|}
\hline Fuel converter peak efficiency & $64 \%$ & $66 \%$ & $72 \%$ & $70 \%$ & & \\
\hline FC power (kW) & 303 & 295 & 288 & 240 & 228 & 190 \\
\hline Motor power (kW) & 303 & 295 & 288 & 746 & 500 & 350 \\
\hline Battery energy (kWh) & 20 & 20 & 20 & 320 & 12 & \\
\hline
\end{tabular}

\begin{tabular}{|l|r|r|r|r|r|r|}
\hline Vehicle without cargo weight (lb) & 31,043 & 28,858 & 25,202 & 32,500 & 36,700 \\
\hline Tractor weight (lb) & 17,543 & 15,358 & 11,702 & 19,000 & 21,970 & \\
\hline Trailer weight (lb) & 13,500 & 13,500 & 13,500 & 13,500 & 13,500 & \\
\hline
\end{tabular}

\begin{tabular}{|l|r|r|r|r|r|r|}
\hline Cargo weight (lb) & 36,000 & 36,000 & 36,000 & 28,804 & 36,000 & \\
\hline Glider weight (Ib) & 23,882 & 23,213 & 21,268 & 23,882 & & \\
\hline Transmission (Ib) & 794 & 794 & 794 & 794 & & \\
\hline Motor (lb) & 267 & 208 & 80 & 658 & & \\
\hline Fuel converter weight (Ib) & 834 & 765 & 704 & 661 & & \\
\hline Battery weight (Ib) & 4,819 & 412 & 331 & 4,177 & & \\
\hline Fuel storage weight & 6,467 & 2,026 & 6,024 & & \\
\hline Total vehicle weight (Ib) & 67,043 & 64,858 & 61,202 & 65,000 & 80,000 & 75,000 \\
\hline
\end{tabular}


Appendix C. Impact of Power Electronics Costs on MSRP

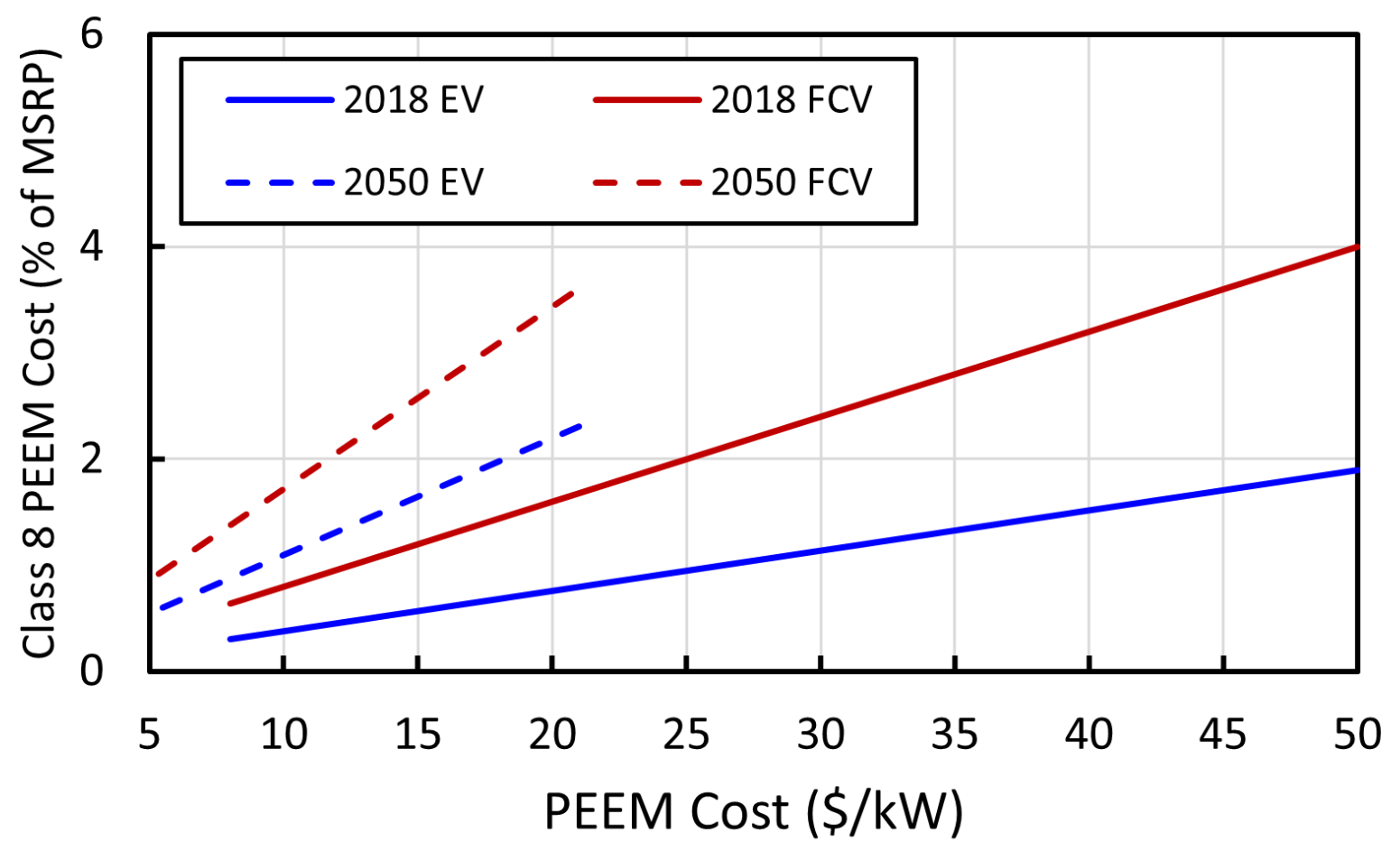

Figure C1. Impact of the cost of power electronics and electric motor (PEEM) on MSRP 


\section{Appendix D. BEV MSRP}

This appendix demonstrates how battery electric vehicle MSRP changes as a function of battery cost.

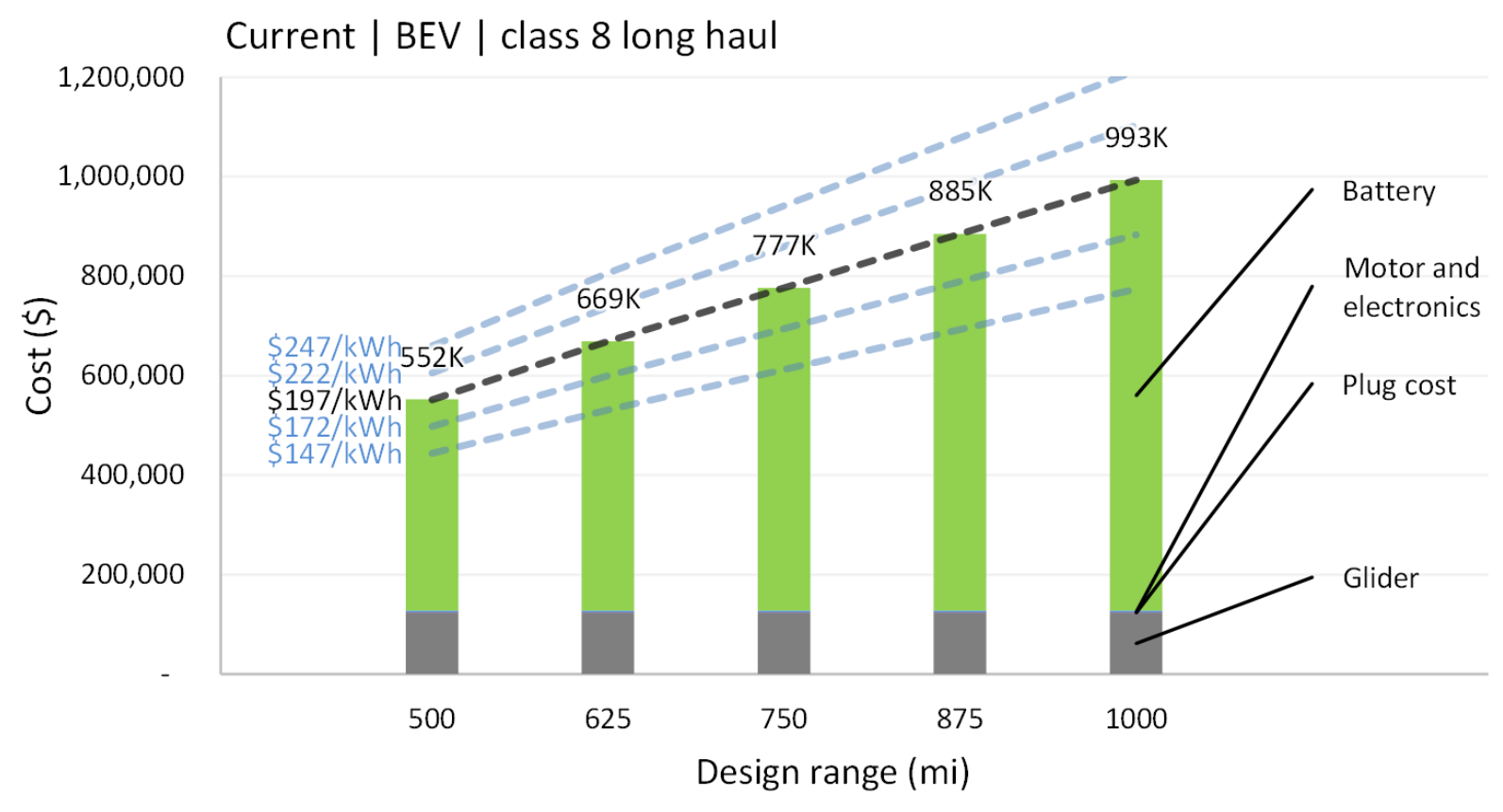

Figure D1. Impact of battery cost on BEV MSRP in current time frame 


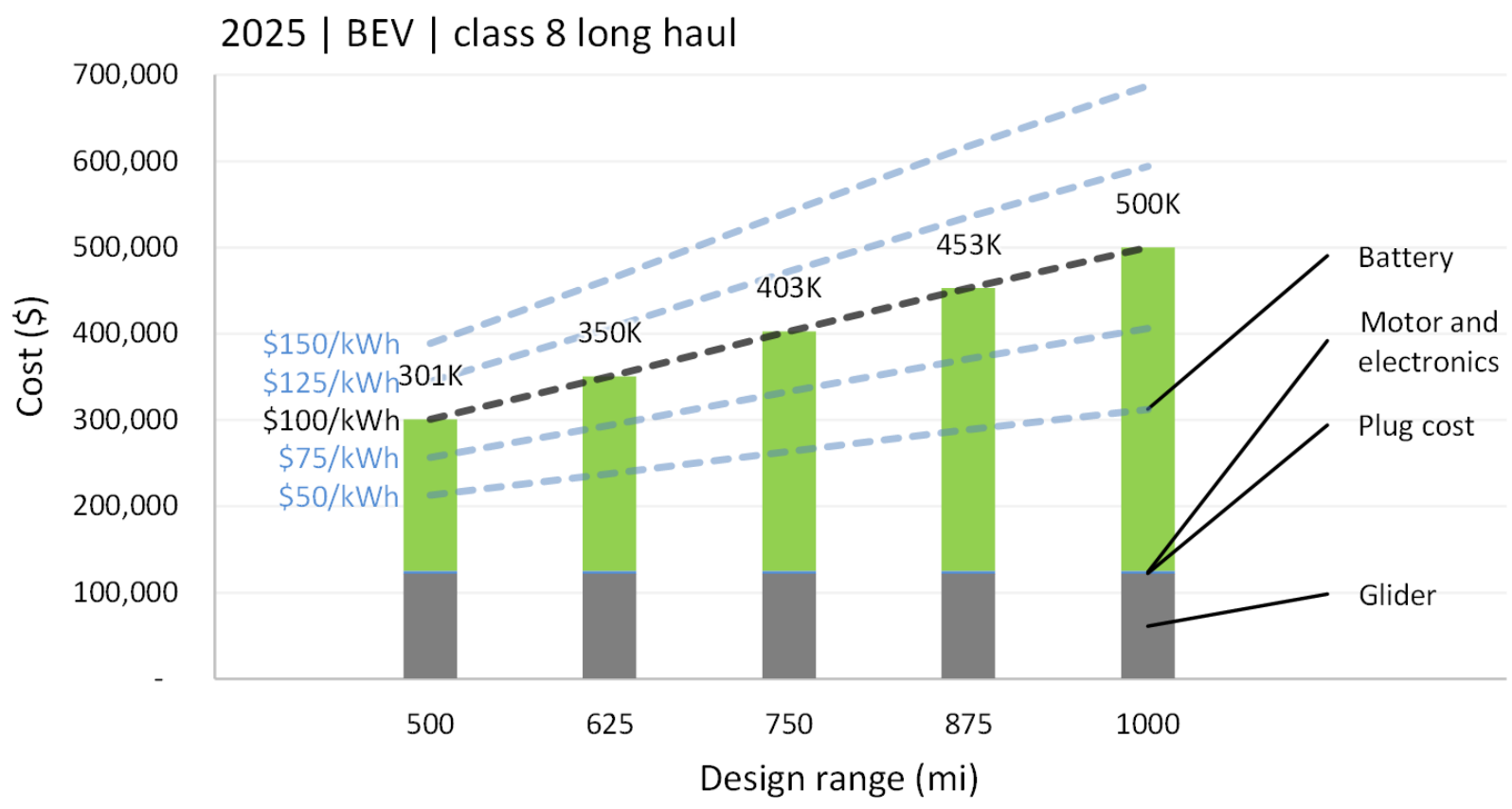

Figure D2. Impact of battery cost on BEV MSRP in 2025 time frame

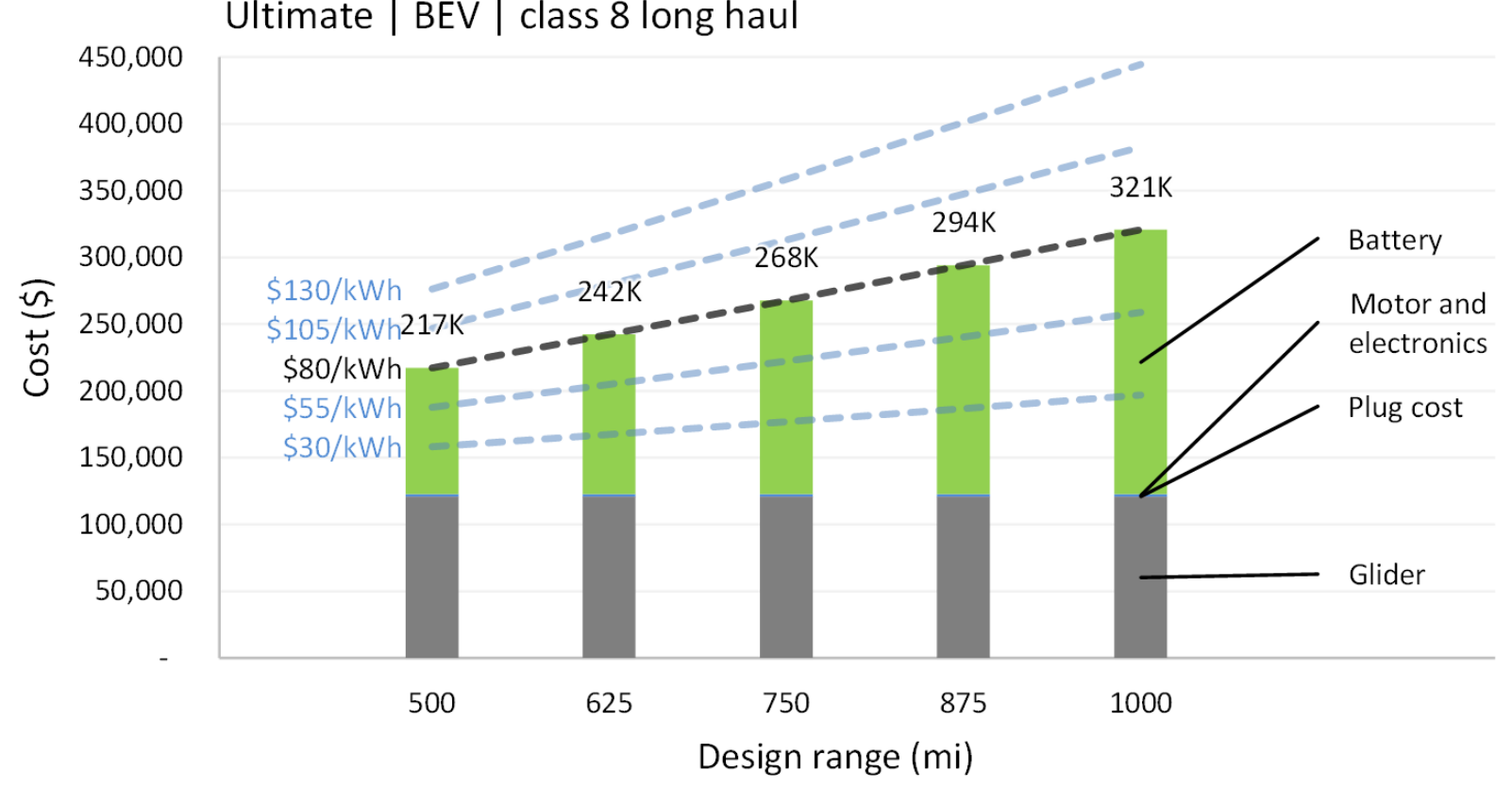

Figure D3. Impact of battery cost on BEV MSRP in Ultimate time frame 


\section{Appendix E. Regional Fuel Pricing}

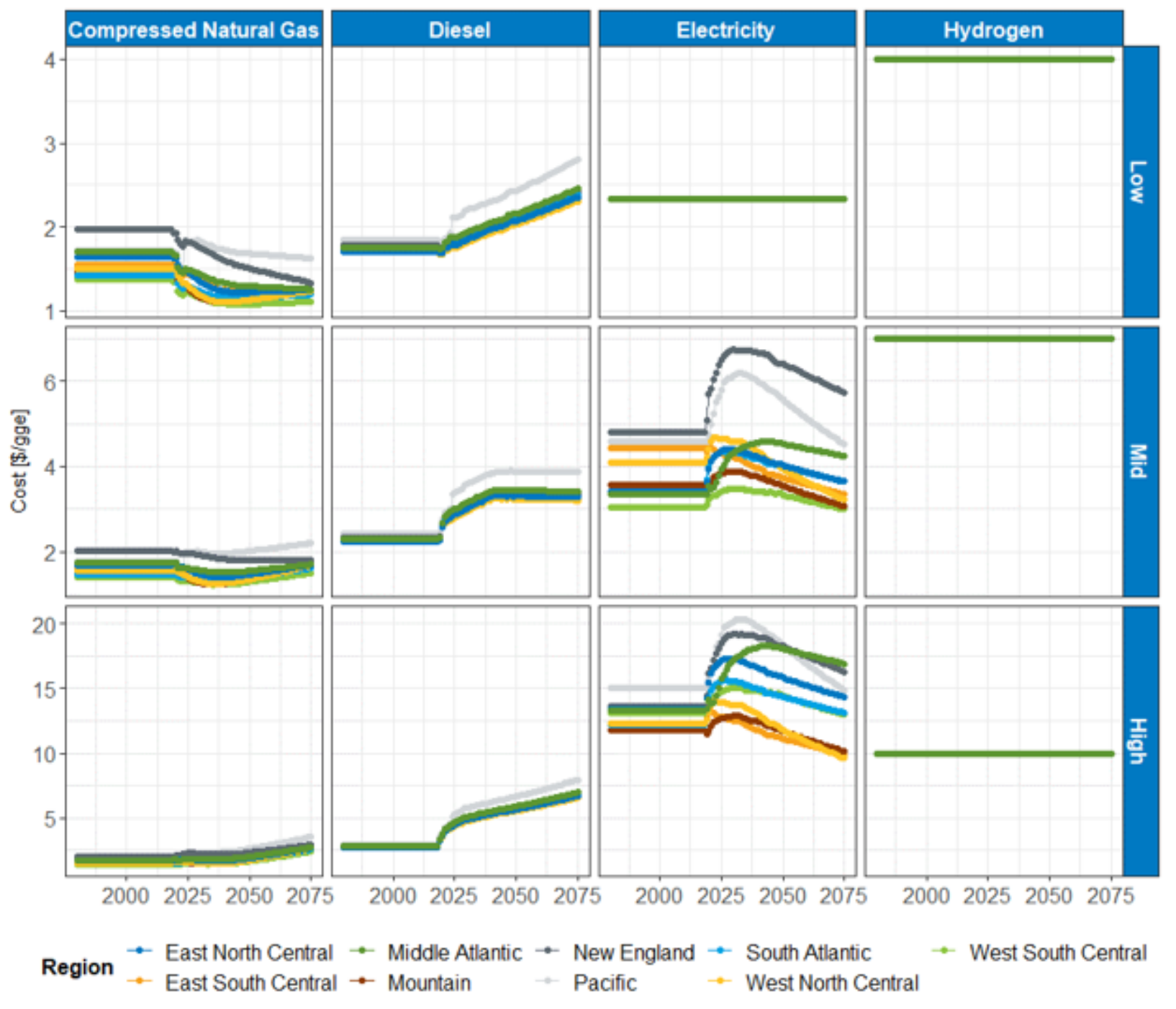

Figure E1. Regional fuel pricing 


\section{Appendix F. Lost Payload Capacity Costs}

Table F1. Payload Cost Range for Class 8 Long-Haul (750-Mile-Range) Truck

\begin{tabular}{llcccc}
\hline $\begin{array}{l}\text { Model } \\
\text { Year }\end{array}$ & Bound & $\begin{array}{c}\text { HEV } \\
(\$ / \mathrm{mi})\end{array}$ & $\begin{array}{c}\text { CNG } \\
(\$ / \mathrm{mi})\end{array}$ & $\begin{array}{c}\text { BEV } \\
(\$ / \mathrm{mi})\end{array}$ & $\begin{array}{c}\text { FCEV } \\
(\$ / \mathrm{mi})\end{array}$ \\
\hline \multirow{3}{*}{2018} & Low & 0 & 0 & 0 & 0 \\
& Mid & $-0.002^{\mathrm{a}}$ & 0 & 0.819 to $-0.844^{\mathrm{a}}$ & 0 \\
& High & $-0.001^{\mathrm{a}}$ & 0 & 0.286 to $-0.318^{\mathrm{a}}$ & 0 \\
\hline \multirow{3}{*}{2025} & Low & 0 & 0 & 0 & 0 \\
& Mid & $-0.003^{\mathrm{a}}$ & 0 & 0.255 to $-0.266^{\mathrm{a}}$ & 0 \\
& High & $-0.002^{\mathrm{a}}$ & 0 & 0.133 to $-0.149^{\mathrm{a}}$ & 0 \\
\hline \multirow{2}{*}{ Ultimate } & Low & 0 & 0 & 0 & 0 \\
& Mid & $-0.003^{\mathrm{a}}$ & 0 & 0.027 to $-0.028^{\mathrm{a}}$ & $-0.002^{\mathrm{a}}$ \\
& High & -0.002 & 0 & 0.016 to $-0.018^{\mathrm{a}}$ & $-0.002^{\mathrm{a}}$ \\
\hline
\end{tabular}

a: Negative values indicate lighter powertrains but no credit was applied in the TCO analysis

Table F2. Payload Cost Range for Class 8 Short-Haul (300-Mile-Range) Truck

\begin{tabular}{llcccc}
\hline $\begin{array}{l}\text { Model } \\
\text { Year }\end{array}$ & Bound & $\begin{array}{c}\text { HEV } \\
(\$ / \mathrm{mi})\end{array}$ & $\begin{array}{c}\mathrm{CNG} \\
(\$ / \mathrm{mi})\end{array}$ & $\begin{array}{c}\text { BEV } \\
(\$ / \mathrm{mi})\end{array}$ & $\begin{array}{c}\text { FCEV } \\
(\$ / \mathrm{mi})\end{array}$ \\
\hline \multirow{2}{*}{2018} & Low & 0 & 0 & 0 & 0 \\
& Mid & $-0.001^{\mathrm{a}}$ & 0 & 0.049 to $-0.05^{\mathrm{a}}$ & $-0.002^{\mathrm{a}}$ \\
& High & $-0.001^{\mathrm{a}}$ & 0 & 0.015 to $-0.016^{\mathrm{a}}$ & $-0.001^{\mathrm{a}}$ \\
\hline \multirow{2}{*}{2025} & Low & 0 & 0 & 0 & 0 \\
& Mid & $-0.002^{\mathrm{a}}$ & 0 & 0.013 to $-0.013^{\mathrm{a}}$ & $-0.004^{\mathrm{a}}$ \\
& High & $-0.001^{\mathrm{a}}$ & 0 & 0.005 to $-0.006^{\mathrm{a}}$ & $-0.001^{\mathrm{a}}$ \\
\hline \multirow{2}{*}{ Ultimate } & Low & 0 & 0 & 0 & 0 \\
& Mid & $-0.002^{\mathrm{a}}$ & 0 & 0 & $-0.006^{\mathrm{a}}$ \\
& High & $-0.001^{\mathrm{a}}$ & 0 & 0 & $-0.002^{\mathrm{a}}$ \\
\hline
\end{tabular}

a: Negative values indicate lighter powertrains but no credit was applied in the TCO analysis 


\section{Appendix G. O\&M Literature Survey}

Table G1. Operating and Maintenance Cost Literature Review

\begin{tabular}{|c|c|c|c|c|c|c|}
\hline Class & Vocation & Tech & $\begin{array}{l}\text { Assessment } \\
\text { Year Cost } \\
\text { (cents/mi) }\end{array}$ & $\begin{array}{c}\text { Assess. } \\
\text { Year }\end{array}$ & $\begin{array}{l}\text { Nom. Cost } \\
\text { in } 2017 \\
\text { (cents/mi) }\end{array}$ & Reference \\
\hline $4-6$ & Delivery Truck & Diesel & 3.4 & 2004 & 4.3 & Automotive Fleet 2006 \\
\hline $4-6$ & Delivery Truck & Diesel & 5.6 & 2004 & 7.1 & Automotive Fleet 2006 \\
\hline $4-6$ & Delivery Truck & Diesel & 8.7 & 2004 & 11.1 & Automotive Fleet 2006 \\
\hline $4-6$ & Delivery Truck & Diesel & 9.6 & 2004 & 12.2 & Automotive Fleet 2006 \\
\hline $4-6$ & Delivery Truck & Diesel & 10 & 2004 & 12.7 & Automotive Fleet 2006 \\
\hline $4-6$ & Delivery Truck & Diesel & 9.3 & 2004 & 11.8 & Automotive Fleet 2006 \\
\hline $4-6$ & Delivery Truck & Diesel & 10.5 & 2004 & 13.4 & Automotive Fleet 2006 \\
\hline $4-6$ & Delivery Truck & Diesel & 22.3 & 2011 & 24.5 & Barnitt 2011 \\
\hline $4-6$ & Delivery Truck & Diesel & 12.15 & 2015 & 13.5 & CARB 2015 \\
\hline $4-6$ & Delivery Truck & Diesel & 4.5 & 2013 & 4.8 & Kleiner et al. 2015 \\
\hline $4-6$ & Delivery Truck & Diesel & 8 & 2013 & 8.5 & Lee, Thomas, and Brown 2013 \\
\hline $4-6$ & Delivery Truck & Diesel & 22.3 & 2013 & 22.7 & Lee, Thomas, and Brown 2013 \\
\hline $4-6$ & Delivery Truck & Diesel & 8.3 & 2013 & 8.8 & Lee, Thomas, and Brown 2013 \\
\hline $4-6$ & Delivery Truck & Electric & & 2015 & 7 & CARB 2015 \\
\hline $4-6$ & Delivery Truck & Electric & 3.63 & 2013 & 3.8 & Kleiner et al. 2015 \\
\hline $4-6$ & Delivery Truck & Fuel Cell & 3.94 & 2013 & 4.2 & Kleiner et al. 2015 \\
\hline $4-6$ & Delivery Truck & Hybrid & 20.6 & 2011 & 22.7 & Barnitt 2011 \\
\hline $4-6$ & Service Truck & Diesel & 7.3 & 2004 & 9.3 & Automotive Fleet 2006 \\
\hline $4-6$ & Service Truck & Diesel & 8 & 2004 & 10.6 & Automotive Fleet 2006 \\
\hline $4-6$ & Service Truck & Diesel & 8.3 & 2004 & 9.3 & Automotive Fleet 2006 \\
\hline $4-6$ & Service Truck & Diesel & 8.5 & 2004 & 10.8 & Automotive Fleet 2006 \\
\hline $4-6$ & Service Truck & Diesel & 2 & 2004 & 2.5 & Automotive Fleet 2006 \\
\hline $4-6$ & Service Truck & Diesel & 8.4 & 2004 & 10.7 & Automotive Fleet 2006 \\
\hline $4-6$ & Service Truck & Diesel & 8.9 & 2004 & 11.3 & Automotive Fleet 2006 \\
\hline 6 & Bus & $\mathrm{CNG}$ & 28 & 2016 & 28.5 & CARB 2016 \\
\hline 6 & Bus & $\mathrm{CNG}$ & 232 & 2016 & 236.4 & CARB 2016 \\
\hline 6 & Bus & $\mathrm{CNG}$ & 84 & 2016 & 85.6 & CARB 2016 \\
\hline 6 & Bus & $\mathrm{CNG}$ & 27 & 2017 & 27 & Eudy and Post 2017 \\
\hline 6 & Bus & $\mathrm{CNG}$ & 50 & 2018 & 49.2 & Eudy and Post 2018 \\
\hline 6 & Bus & Diesel & 20 & 2015 & 20.6 & ACPS 2015 \\
\hline 6 & Bus & Diesel & 86 & 2016 & 87.6 & CARB 2016 \\
\hline 6 & Bus & Diesel & 110 & 2016 & 112.1 & CARB 2016 \\
\hline 6 & Bus & Diesel & 44 & 2016 & 44.8 & CARB 2016 \\
\hline 6 & Bus & Diesel & 277 & 2016 & 282.3 & CARB 2016 \\
\hline 6 & Bus & Diesel & 36 & 2017 & 36 & Eudy and Post 2018 \\
\hline 6 & Bus & Diesel & 24 & 2016 & 24.5 & HART 2017 \\
\hline 6 & Bus & Diesel & 10 & 2016 & 10.2 & HART 2017 \\
\hline
\end{tabular}


Table G2. Operating and Maintenance Cost Literature Review (continued)

\begin{tabular}{|c|c|c|c|c|c|c|}
\hline Class & Vocation & Tech & $\begin{array}{l}\text { Assessment } \\
\text { Year Cost } \\
\text { (cents/mi) }\end{array}$ & $\begin{array}{c}\text { Assess. } \\
\text { Year }\end{array}$ & $\begin{array}{l}\text { Nom. Cost } \\
\text { in } 2017 \\
\text { (cents/mi) }\end{array}$ & Reference \\
\hline 6 & Bus & Diesel & 30 & 2015 & 30.9 & Lajunen and Lipman 2016 \\
\hline 6 & Bus & Diesel & 40 & 2015 & 41.2 & Lajunen and Lipman 2016 \\
\hline 6 & Bus & Diesel & 53 & 2015 & 54.6 & Lajunen and Lipman 2016 \\
\hline 6 & Bus & Diesel & 60 & 2015 & 61.8 & Lajunen and Lipman 2016 \\
\hline 6 & Bus & Diesel & 75 & 2015 & 77.3 & Lajunen and Lipman 2016 \\
\hline 6 & Bus & Diesel & 80 & 2015 & 82.4 & Lajunen and Lipman 2016 \\
\hline 6 & Bus & Diesel & 90 & 2015 & 92.7 & Lajunen and Lipman 2016 \\
\hline 6 & Bus & Diesel & 23.5 & 2011 & 25.9 & Barradas 2012b \\
\hline 6 & Bus & Diesel & 88.8 & 2013 & 94.2 & TCRP 2018 \\
\hline 6 & Bus & Electric & 22 & 2016 & 22.4 & CARB 2016 \\
\hline 6 & Bus & Electric & 32 & 2017 & 32 & Eudy and Post 2017 \\
\hline 6 & Bus & Electric & 41 & 2017 & 41 & Eudy and Post 2017 \\
\hline 6 & Bus & Electric & 27 & 2017 & 27 & Eudy and Post 2018 \\
\hline 6 & Bus & Electric & 74 & 2013 & 78.5 & TCRP 2018 \\
\hline 6 & Bus & Fuel Cell & 95 & 2016 & 62.2 & CARB 2016 \\
\hline 6 & Bus & Fuel Cell & 108 & 2016 & 110.1 & CARB 2016 \\
\hline 6 & Bus & Fuel Cell & 53 & 2018 & 52.1 & Eudy and Post 2018 \\
\hline 6 & Bus & Hybrid & 76 & 2016 & 77.4 & CARB 2016 \\
\hline 6 & Bus & Hybrid & 81 & 2016 & 82.5 & CARB 2016 \\
\hline 6 & Bus & Hybrid & 230 & 2016 & 234.4 & CARB 2016 \\
\hline 6 & Bus & Hybrid & 139 & 2016 & 141.6 & CARB 2016 \\
\hline 6 & Bus & Hybrid & 14.9 & 2011 & 16.4 & Barradas 2012b \\
\hline 8 & Long-Haul Truck & $\mathrm{CNG}$ & 9.8 & 2015 & 10.1 & Josephs 2015 \\
\hline 8 & Long-Haul Truck & Diesel & 16.6 & 2017 & 16.6 & ATRI 2017 \\
\hline 8 & Long-Haul Truck & Diesel & 16.2 & 2015 & 16.7 & Ernst and Young 2003 \\
\hline 8 & Long-Haul Truck & Diesel & 12 & 1992 & 19.2 & MNDOT 2003 \\
\hline 8 & Long-Haul Truck & Diesel & 10.9 & 1988 & 19.9 & MNDOT 2003 \\
\hline 8 & Long-Haul Truck & Diesel & 10 & 1996 & 14.8 & MNDOT 2003 \\
\hline 8 & Long-Haul Truck & Diesel & 15.5 & 1995 & 23.3 & MNDOT 2003 \\
\hline 8 & Long-Haul Truck & Diesel & 10.5 & 2001 & 14.2 & MNDOT 2003 \\
\hline 8 & Long-Haul Truck & Diesel & 7.1 & 2003 & 9.3 & MNDOT 2003 \\
\hline 8 & Long-Haul Truck & Diesel & 12 & 2003 & 15.7 & MNDOT 2003 \\
\hline 8 & Long-Haul Truck & Diesel & 10.3 & 2017 & 10.3 & OOIDA 2015 \\
\hline 8 & Long-Haul Truck & Diesel & 10.5 & 2012 & 11.3 & Barradas 2012a \\
\hline
\end{tabular}




\section{Appendix H. EPA Regulatory Cycle Fuel Economy}

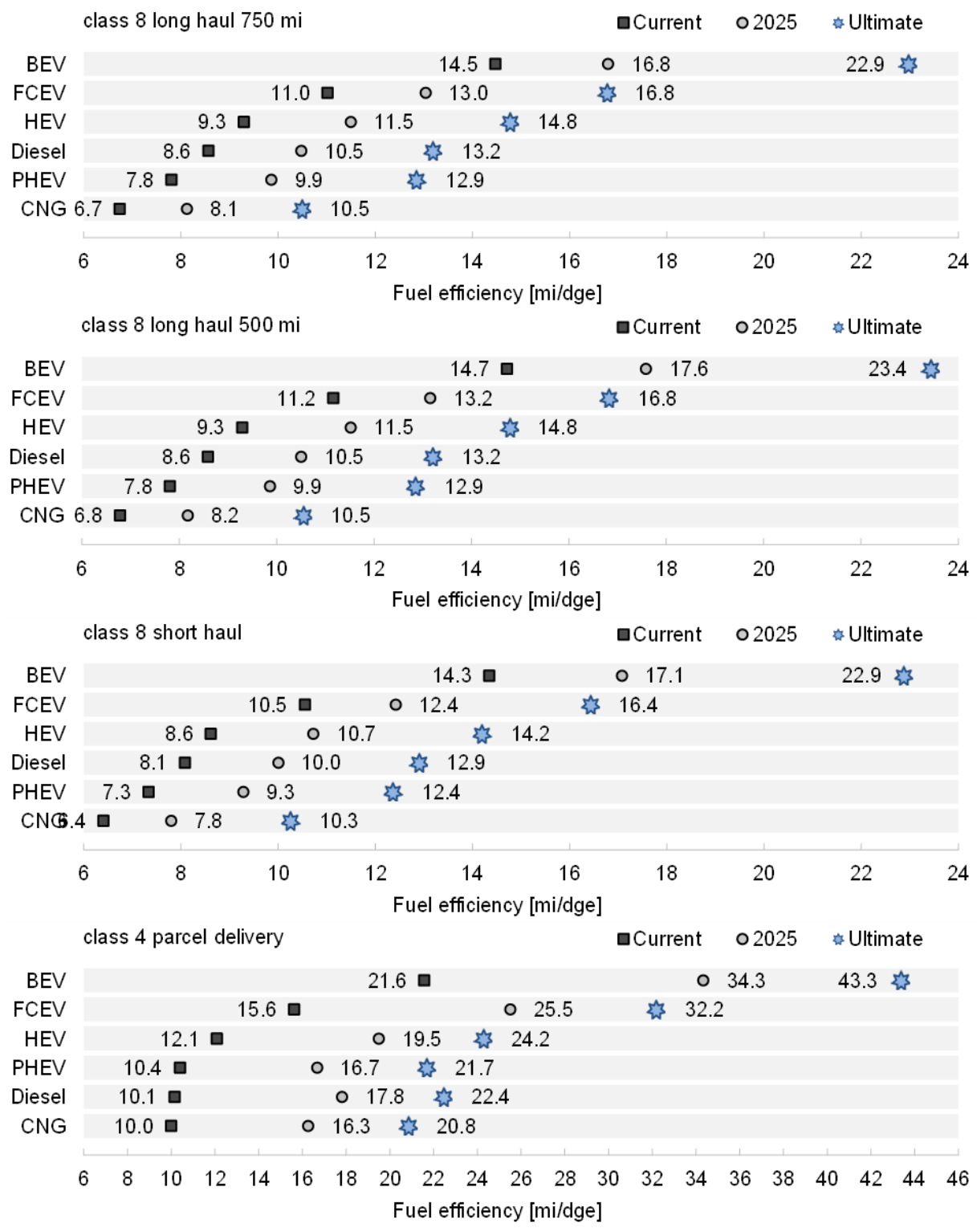

Figure H1. U.S. Environmental Protection Agency (EPA) 65-mph regulatory cycle fuel economy 


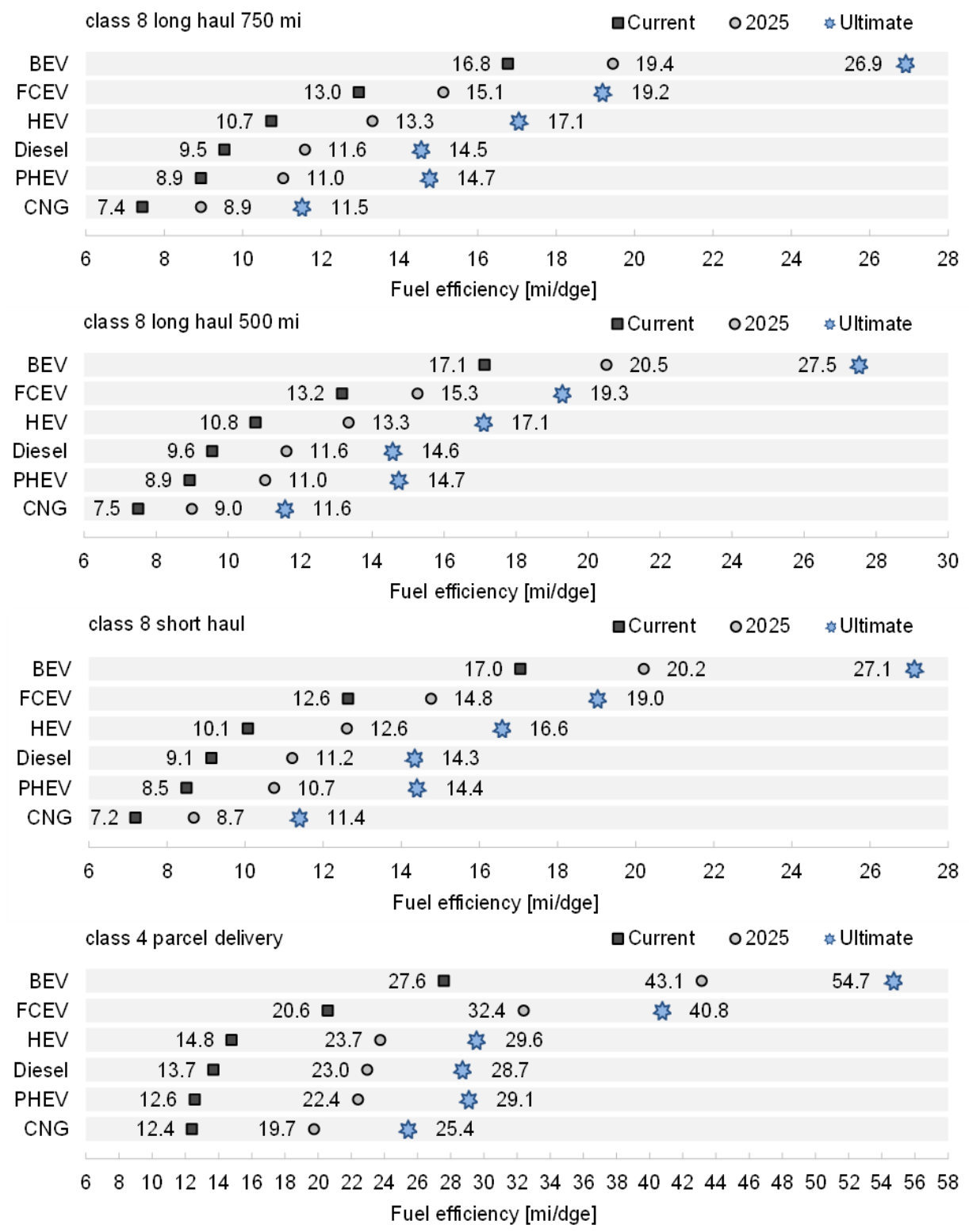

Figure H2. EPA 55-mph regulatory cycle fuel economy 


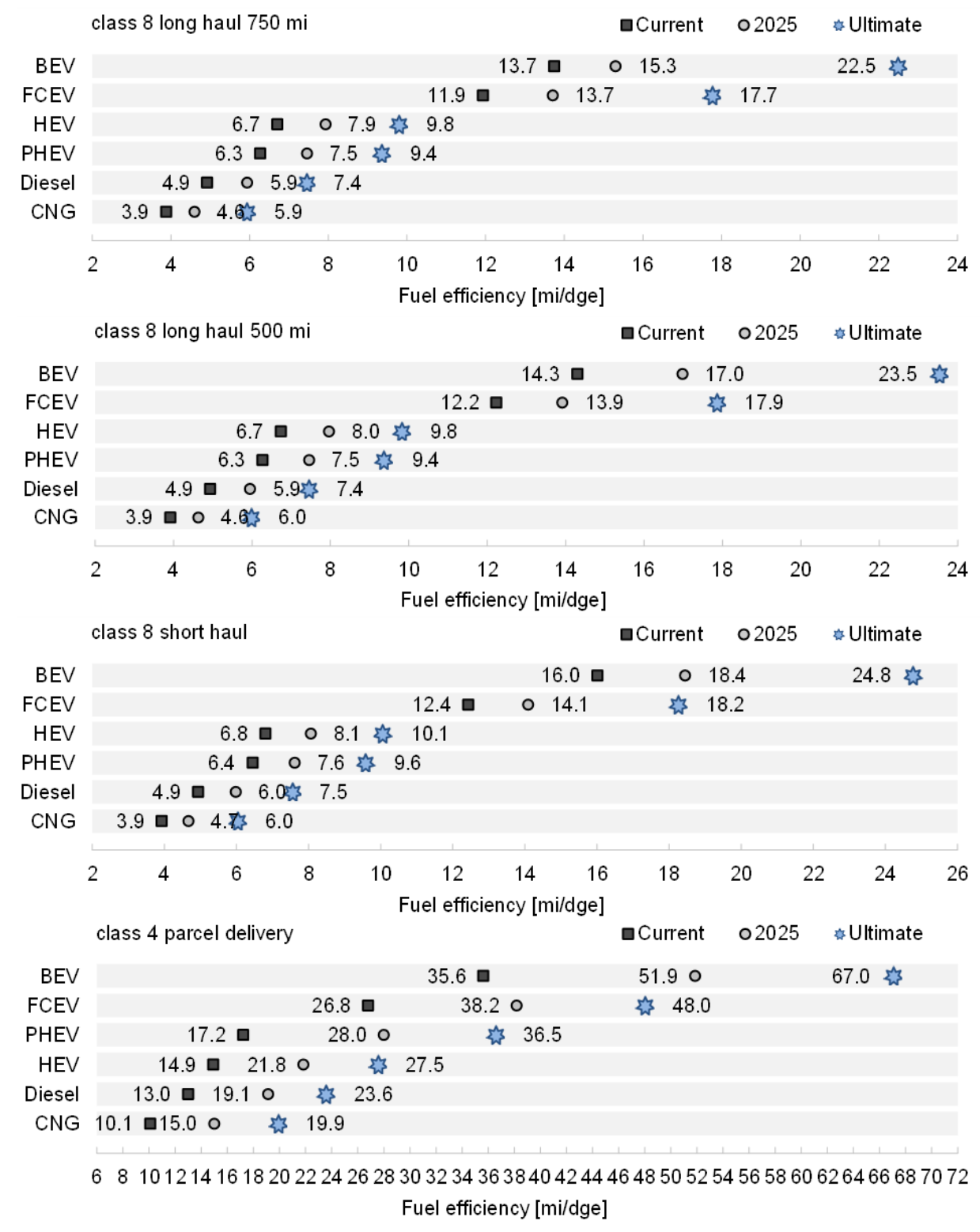

Figure H3. EPA city regulatory cycle fuel economy 
Appendix I. TCO Plots for Single-Shift, Weight-Limited and Multi-Shift, VolumeLimited Scenarios

I.1 Class 8 Long-Haul (750-Mile Range)

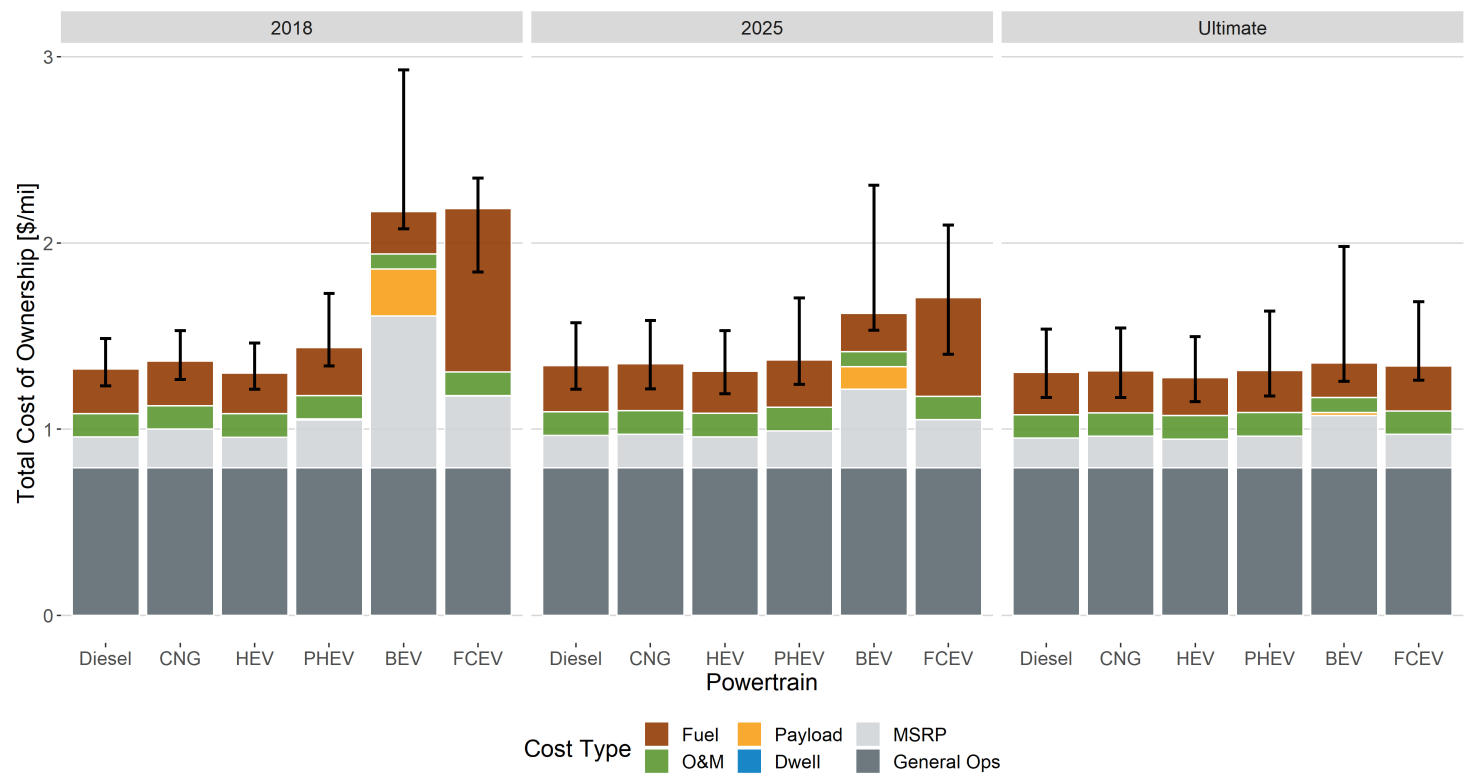

Figure I1. Single-Shift, Weight-Limited scenario TCO for Class 8 long-haul tractors (750-mile range) in the Middle Atlantic region

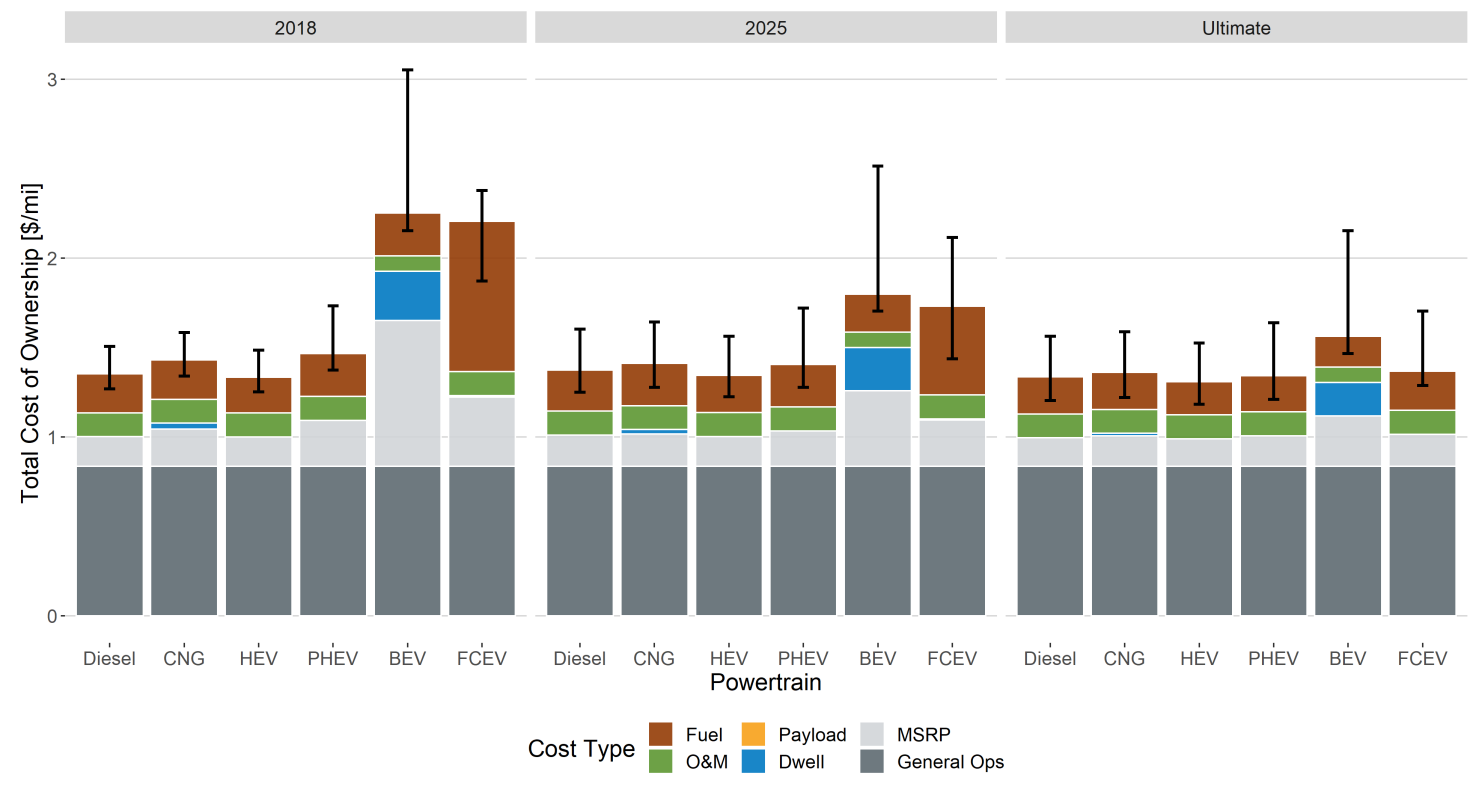

Figure 12. Multi-Shift, Volume-Limited scenario TCO for Class 8 long-haul tractors (750-mile range) in the Middle Atlantic region 

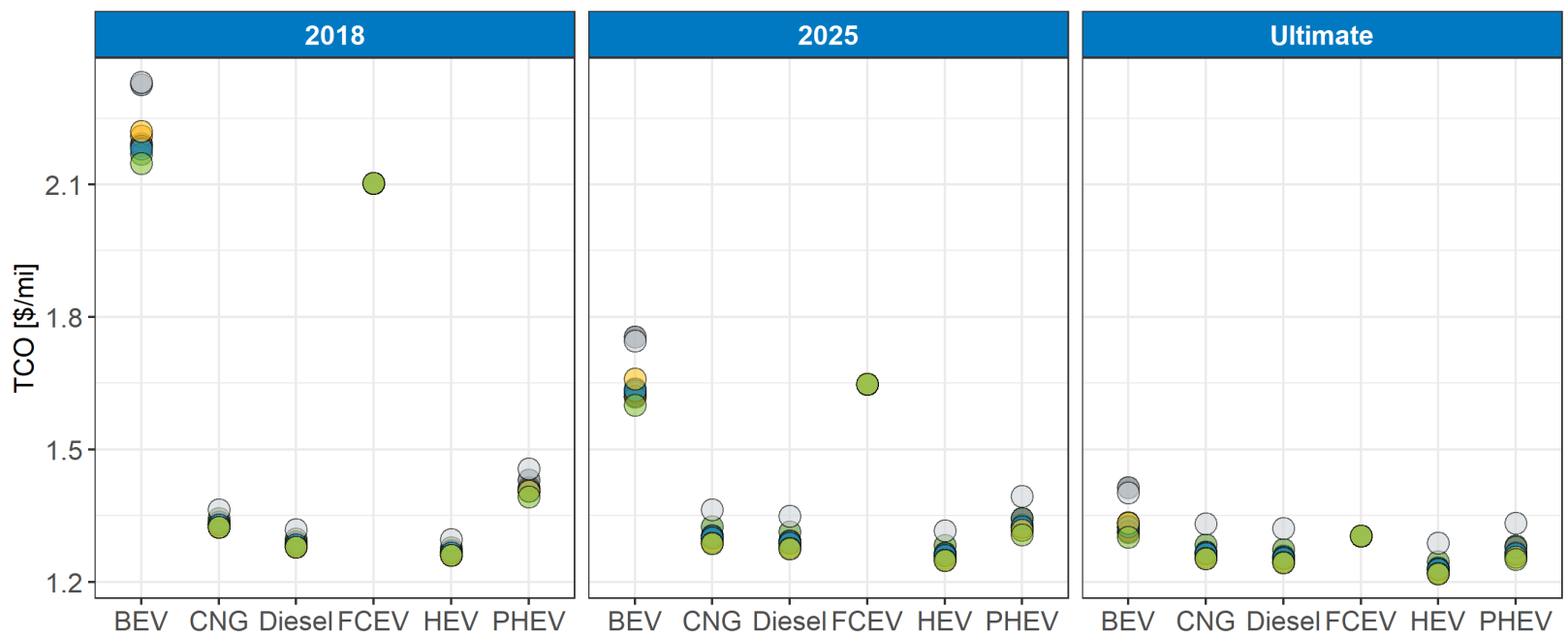
Region
East North Central
Middle Atlantic
New England
South Atlantic
East South Central $\bigcirc$ Mountain
Pacific
West North Central

West South Central

Figure 13. Regional TCO distribution for the Single-Shift, Weight-Limited scenario of a Class 8 long-haul tractor (750-mile range)
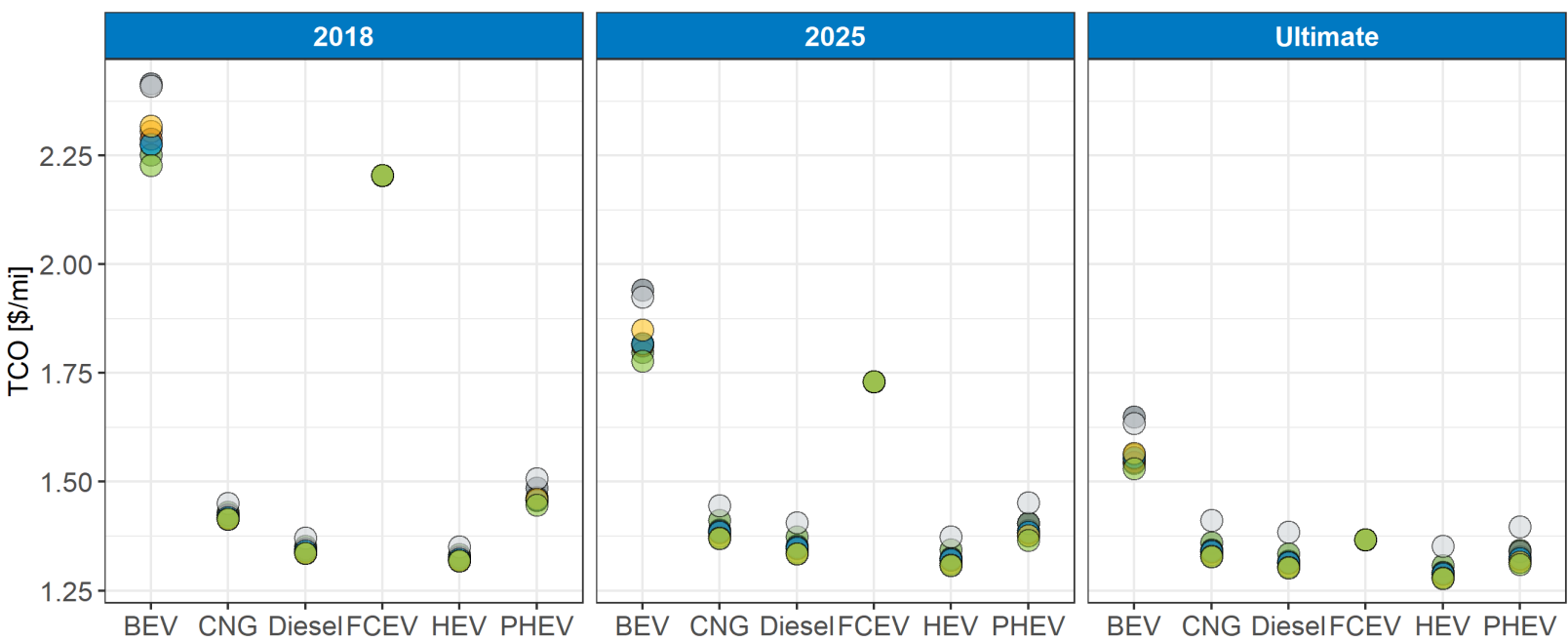

Region

East North Central Middle Atlantic

New England

South Atlantic

West South Central

East South Central

Mountain

Pacific

West North Central

Figure 14. Regional TCO distribution for the Multi-Shift, Volume-Limited scenario of a Class 8 long-haul tractor (750-mile range) 
Breakeven Fuel or Electricity Price (\$/gge)

At Diesel Price of $\$ 4 / g a l(\$ 3.52 / g g e)$

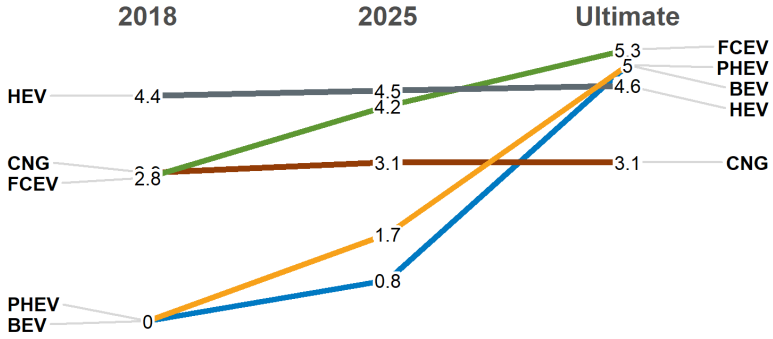

Breakeven Fuel or Electricity Price (\$/gge)

At Diesel Price of $\$ 3 / \mathrm{gal}$ (\$2.64/gge)

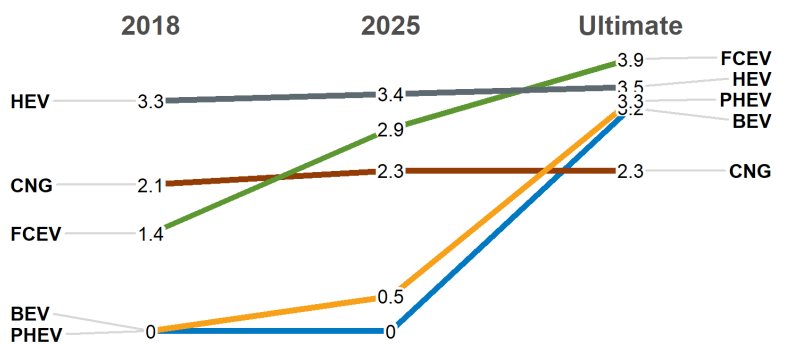

Breakeven Fuel or Electricity Price (\$/gge)

At Diesel Price of \$2/gal (\$1.76/gge)

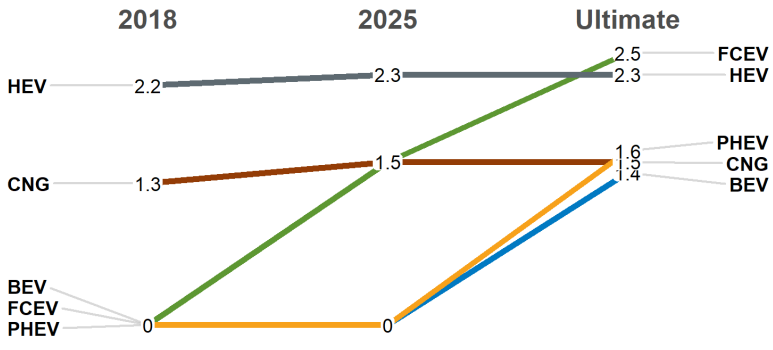

Figure 15. Single-Shift, Weight-Limited break-even fuel price analysis for Class 8 long-haul trucks

(750-mile range) in the Middle Atlantic region
Breakeven Fuel or Electricity Price (\$/gge)

At Diesel Price of $\$ 4 / \mathrm{gal}$ ( $\$ 3.52 / \mathrm{gge}$ )

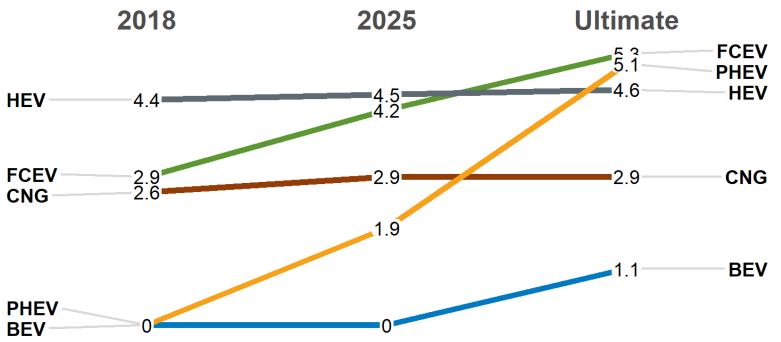

Breakeven Fuel or Electricity Price (\$/gge)

At Diesel Price of \$3/gal (\$2.64/gge)

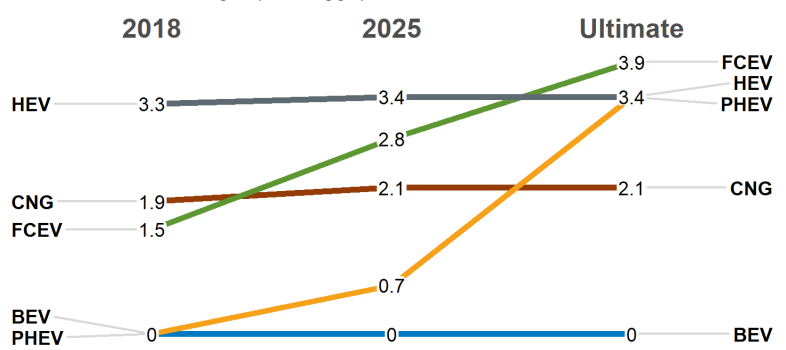

Breakeven Fuel or Electricity Price (\$/gge)

At Diesel Price of $\$ 2 /$ gal (\$1.76/gge)

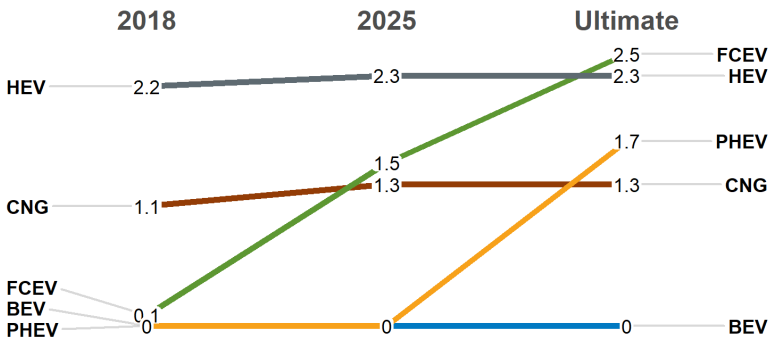

Figure 16. Multi-Shift, Volume-Limited break-even fuel price analysis for Class 8 long haul trucks (750-mile range) in the Middle Atlantic region 
I.2 Class 8 Long-Haul (500-Mile Range)

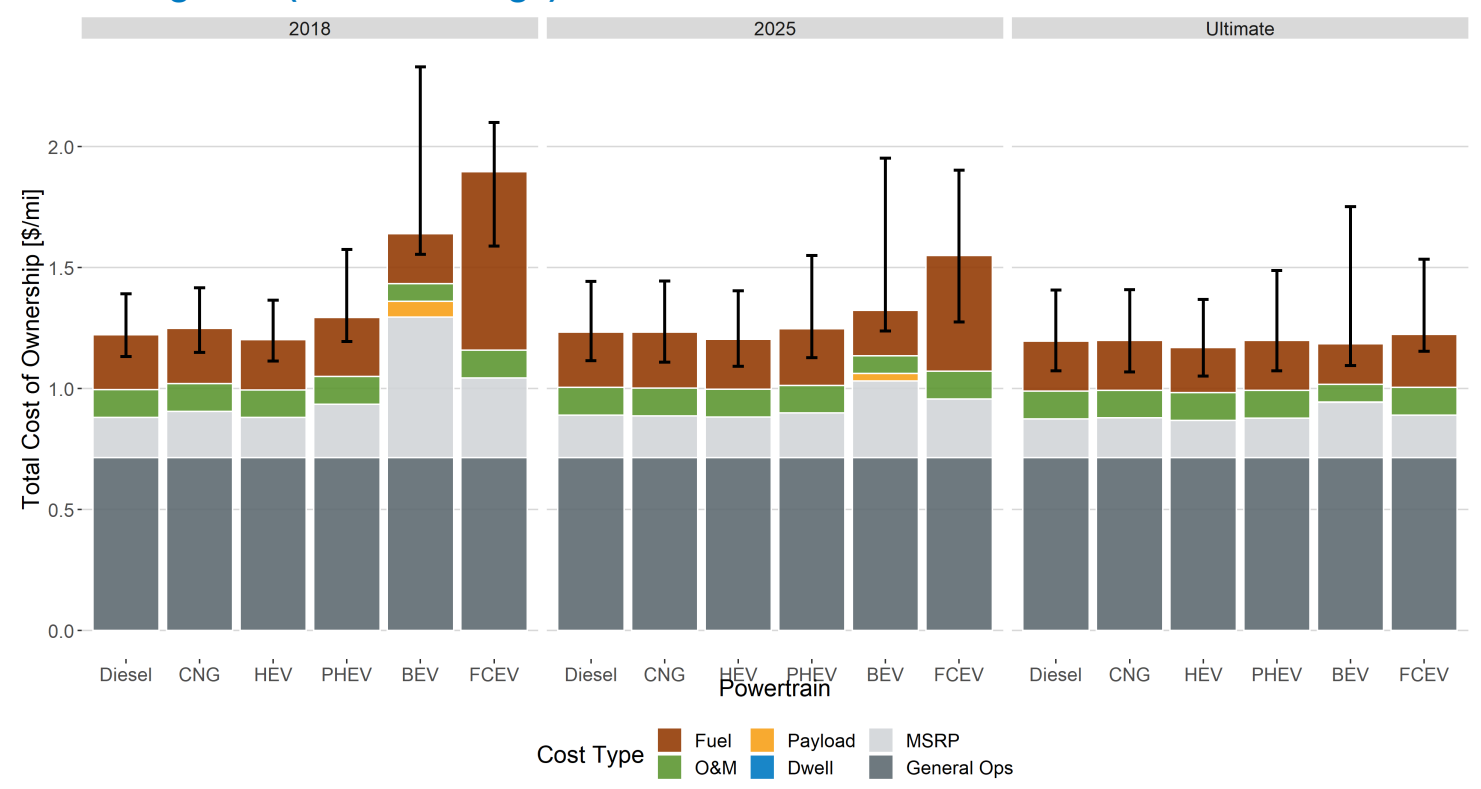

Figure 17. Single-Shift, Weight-Limited scenario TCO for Class 8 long-haul tractors (500-mile range) in the Middle Atlantic region

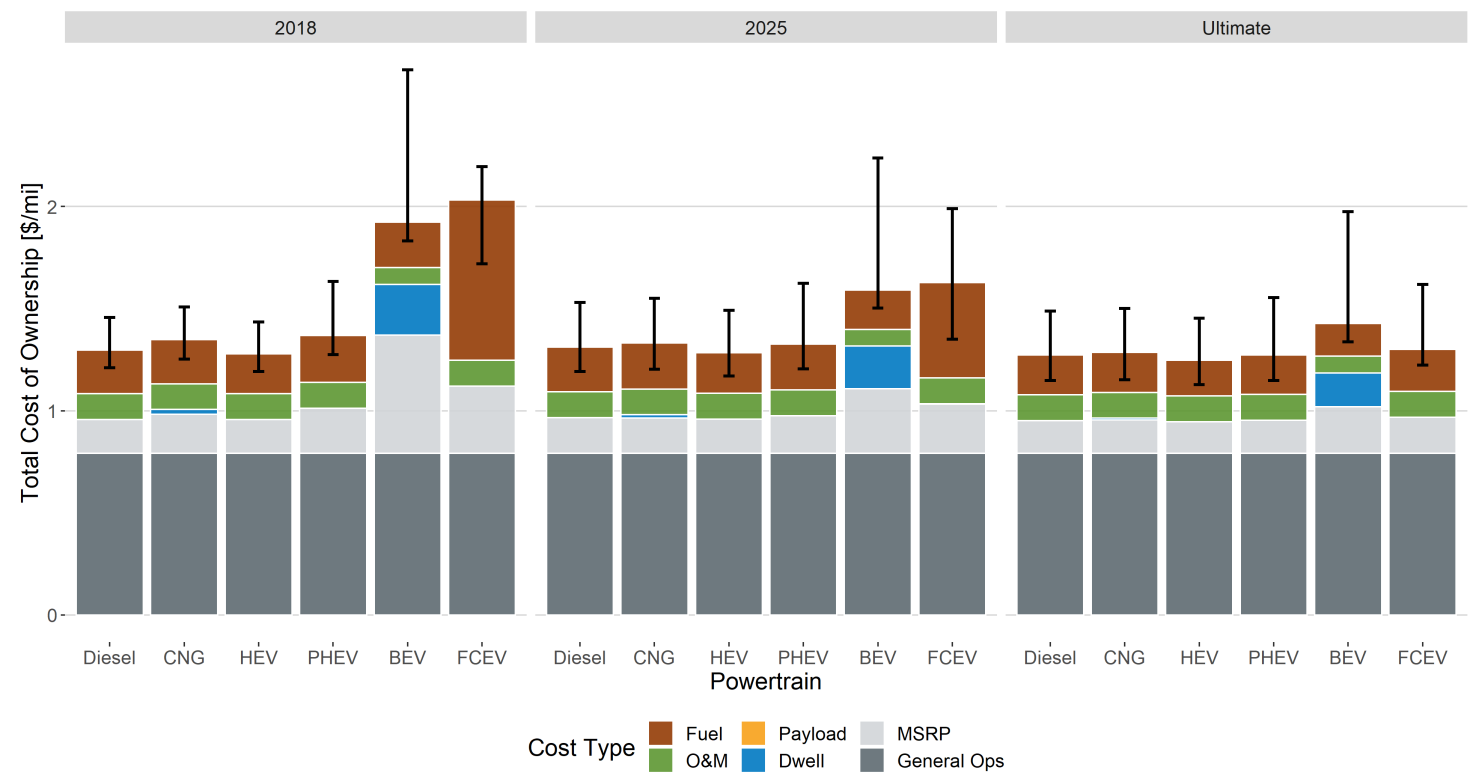

Figure 18. Multi-Shift, Volume-Limited scenario TCO for Class 8 long-haul tractors (500-mile range) in the Middle Atlantic region 


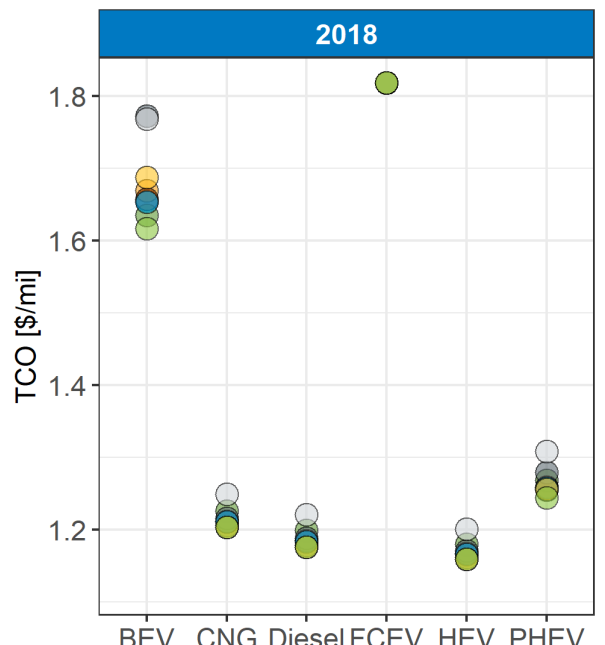

BEV CNG DieselFCEV HEV PHEV

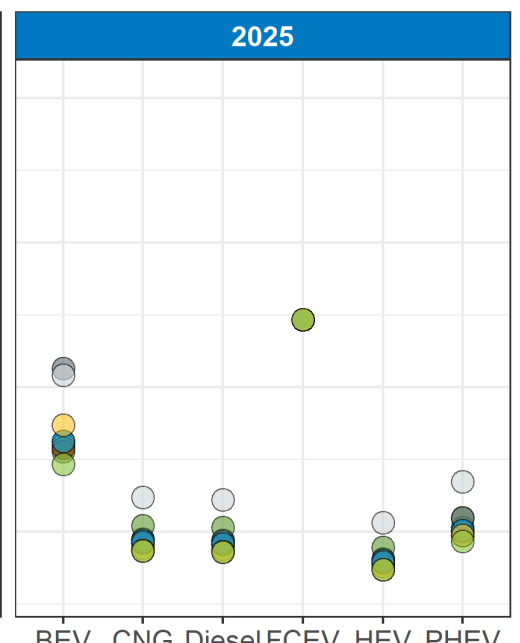

BEV CNG DieselFCEV HEV PHEV

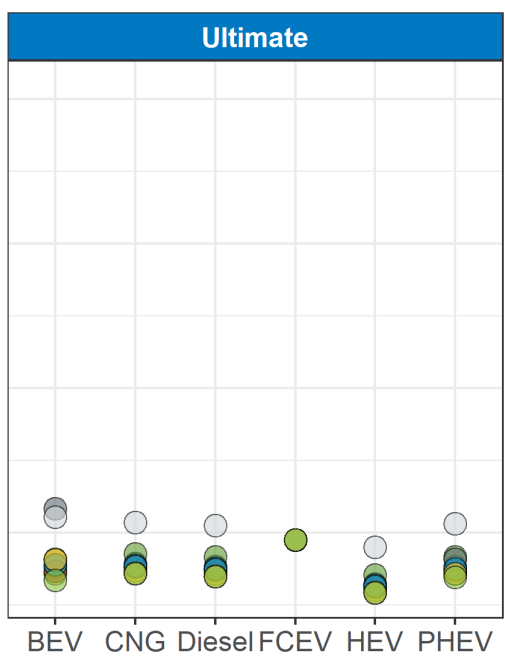

BEV CNG DieselFCEV HEV PHEV
Region
East North Central
Middle Atlantic
New England
South Atlantic
East South Central $\bigcirc$ Mountain
Pacific
West North Central

West South Central

Figure 19. Regional TCO distribution for the Single-Shift, Weight-Limited scenario of a Class 8 long-haul tractor (500-mile range)
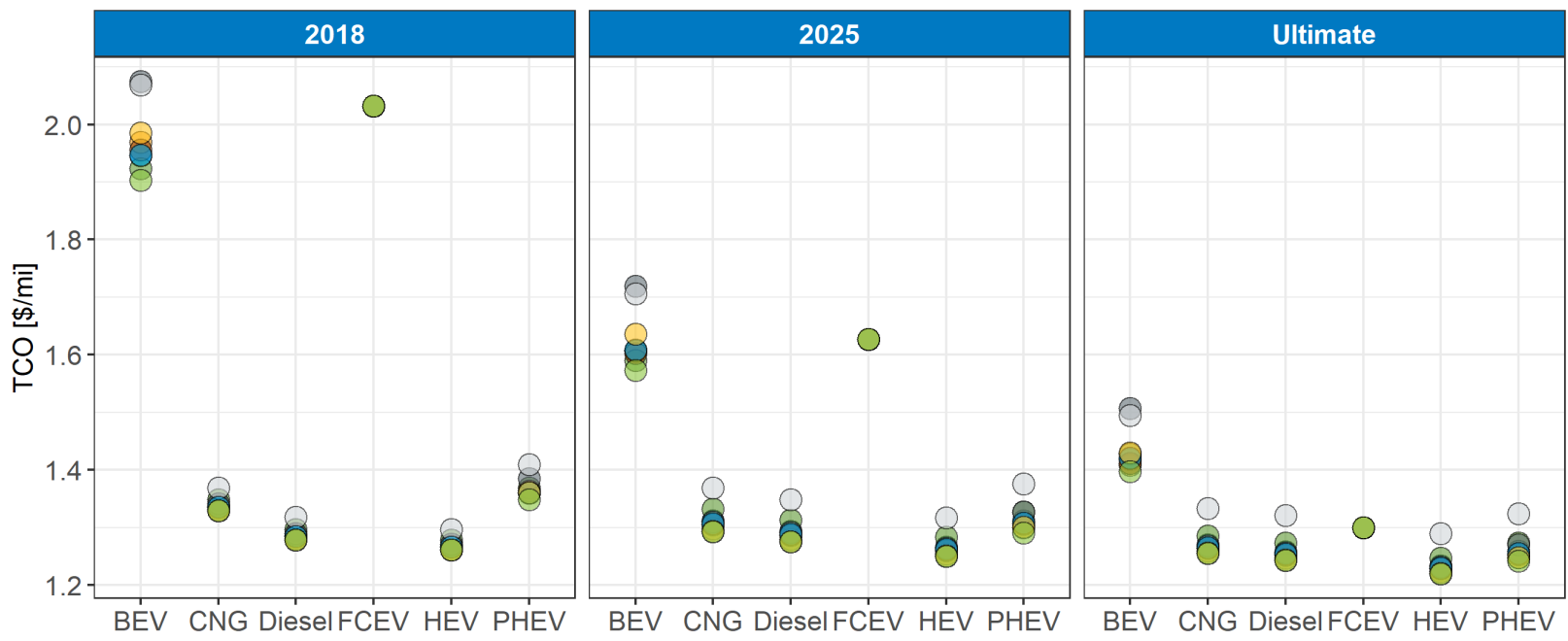

Region

East North Central $\bigcirc$ Middle Atlantic

New England

South Atlantic

West South Central

East South Central

Mountain

Pacific

West North Central

Figure 110. Regional TCO distribution for the Multi-Shift, Volume-Limited scenario of a Class 8 long-haul tractor (500-mile range) 
Breakeven Fuel or Electricity Price (\$/gge)

At Diesel Price of $\$ 4 / \mathrm{gal}$ ( $\$ 3.52 / \mathrm{gge}$ )

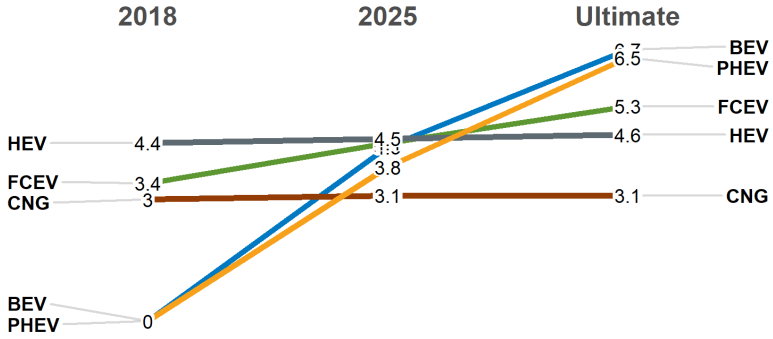

Breakeven Fuel or Electricity Price (\$/gge)

At Diesel Price of $\$ 3 / \mathrm{gal}$ (\$2.64/gge)

2018

2025

Ultimate

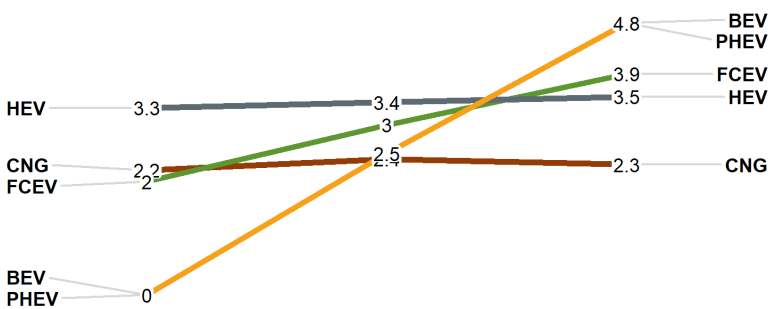

Breakeven Fuel or Electricity Price (\$/gge)

At Diesel Price of $\$ 2 /$ gal (\$1.76/gge)

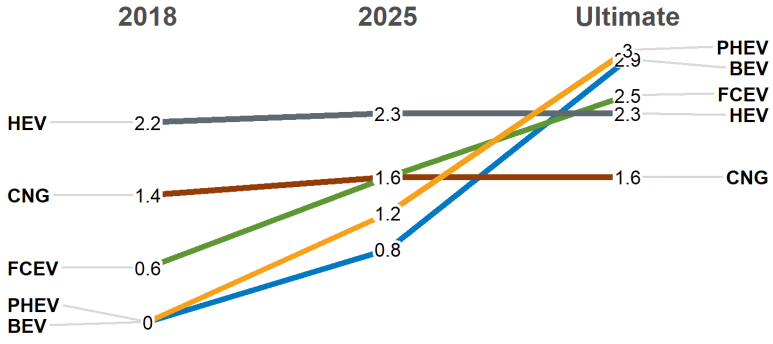

Figure I11. Single-Shift, Weight-Limited break-even fuel price analysis for Class 8 long-haul trucks (500-mile range) in the Middle Atlantic region
Breakeven Fuel or Electricity Price (\$/gge)

At Diesel Price of $\$ 4 / \mathrm{gal}$ ( $\$ 3.52 / \mathrm{gge}$ )

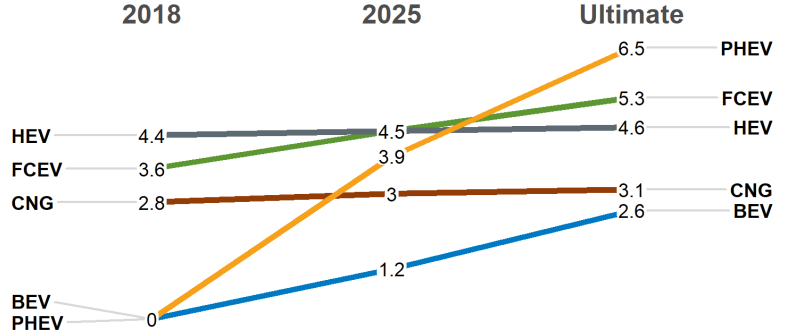

Breakeven Fuel or Electricity Price (\$/gge)

At Diesel Price of \$3/gal (\$2.64/gge)

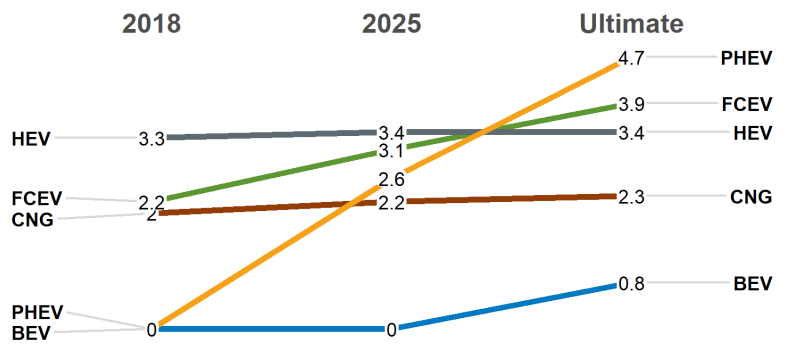

Breakeven Fuel or Electricity Price (\$/gge)

At Diesel Price of $\$ 2 /$ gal (\$1.76/gge)

2018

2025

Ultimate

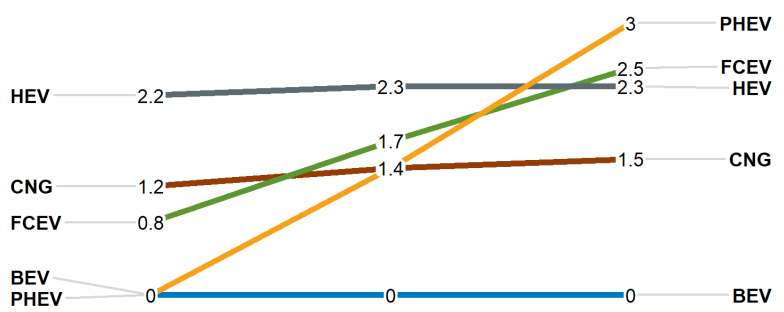

Figure I12. Multi-Shift, Volume-Limited breakeven fuel price analysis for Class 8 sleeper trucks (500-mile range) in the Middle Atlantic region 
I.3 Class 8 Short-Haul (300-Mile Range)

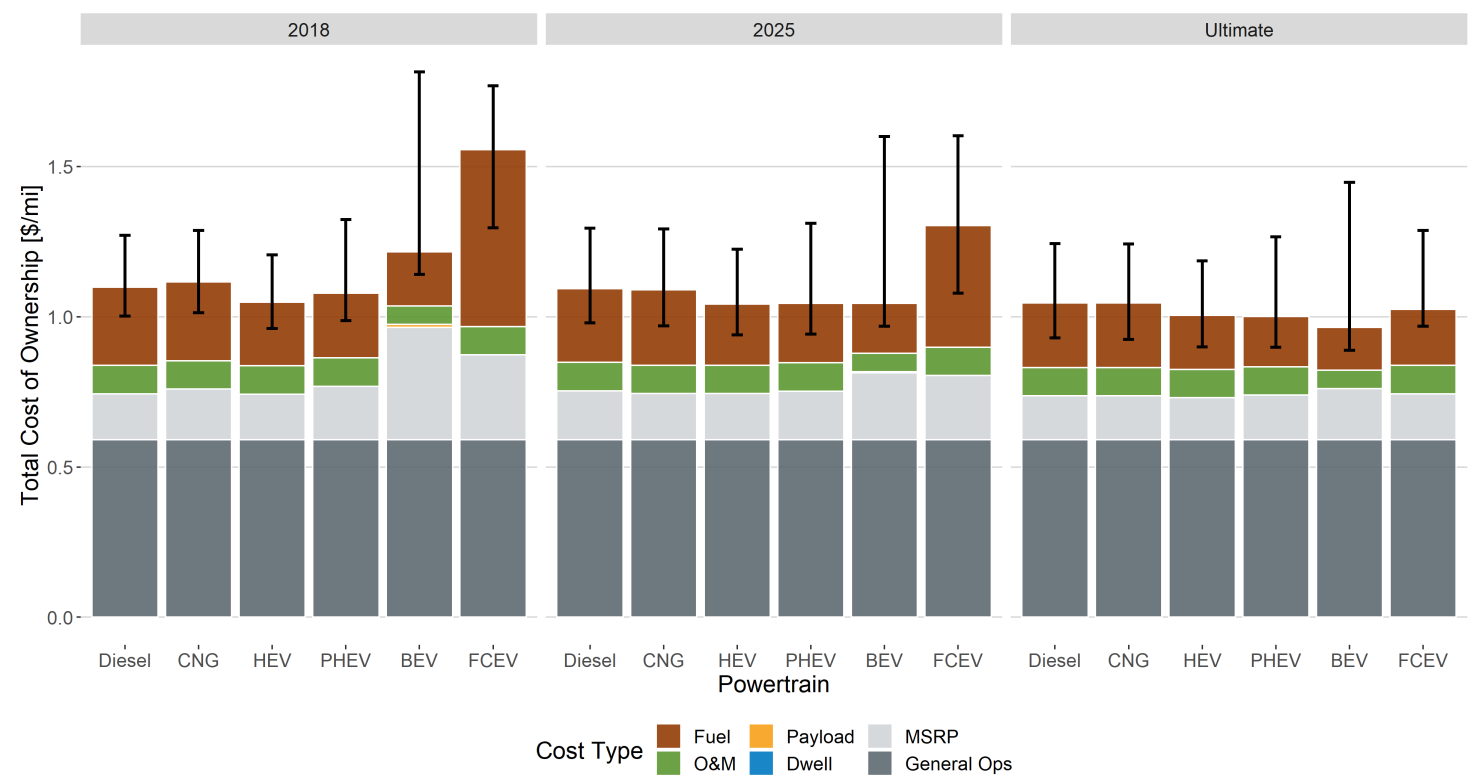

Figure 113. Single-Shift, Weight-Limited scenario TCO for Class 8 short-haul tractors (300-mile range) in the Middle Atlantic region

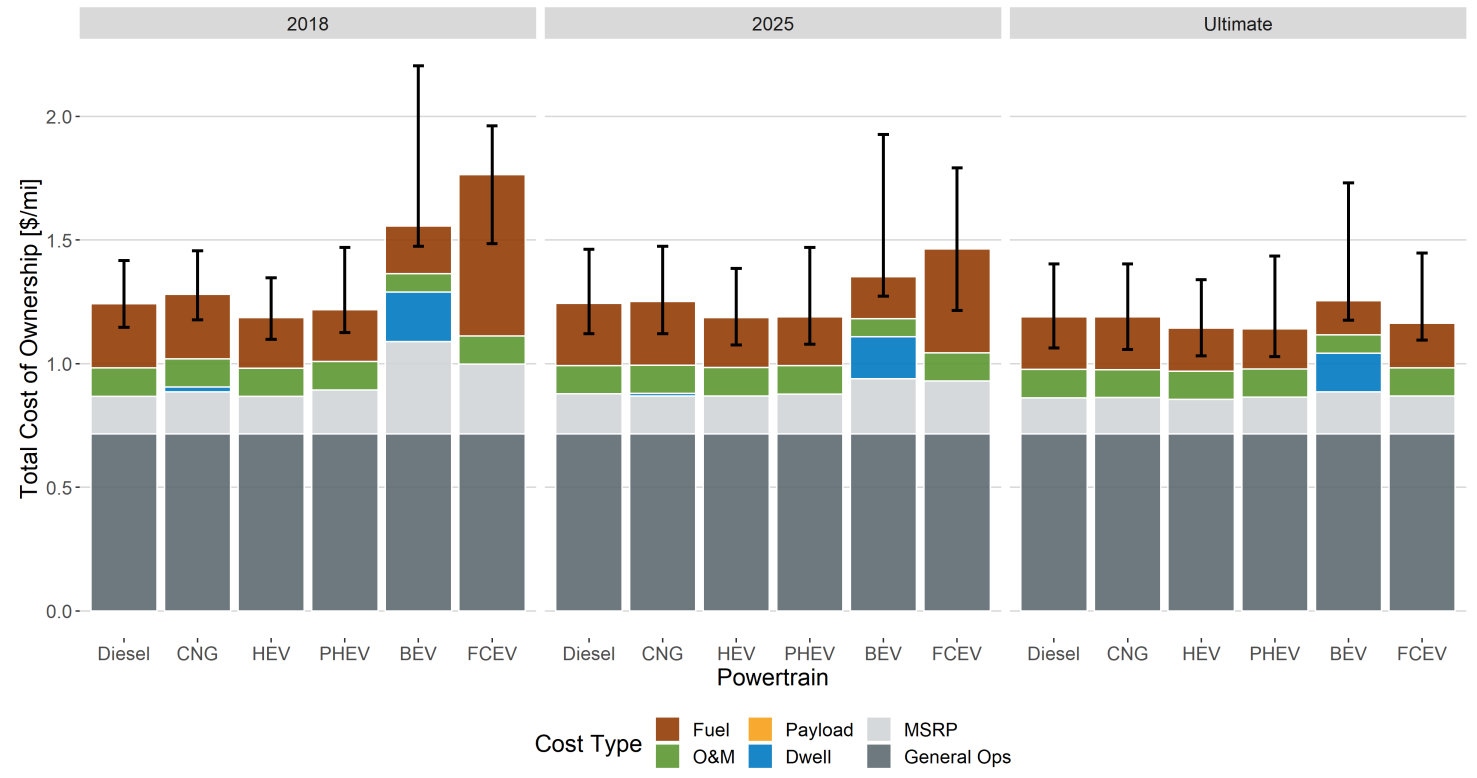

Figure 114. Multi-Shift, Volume-Limited Scenario TCO for Class 8 short-haul tractors (300-mile range) in the Middle Atlantic region 

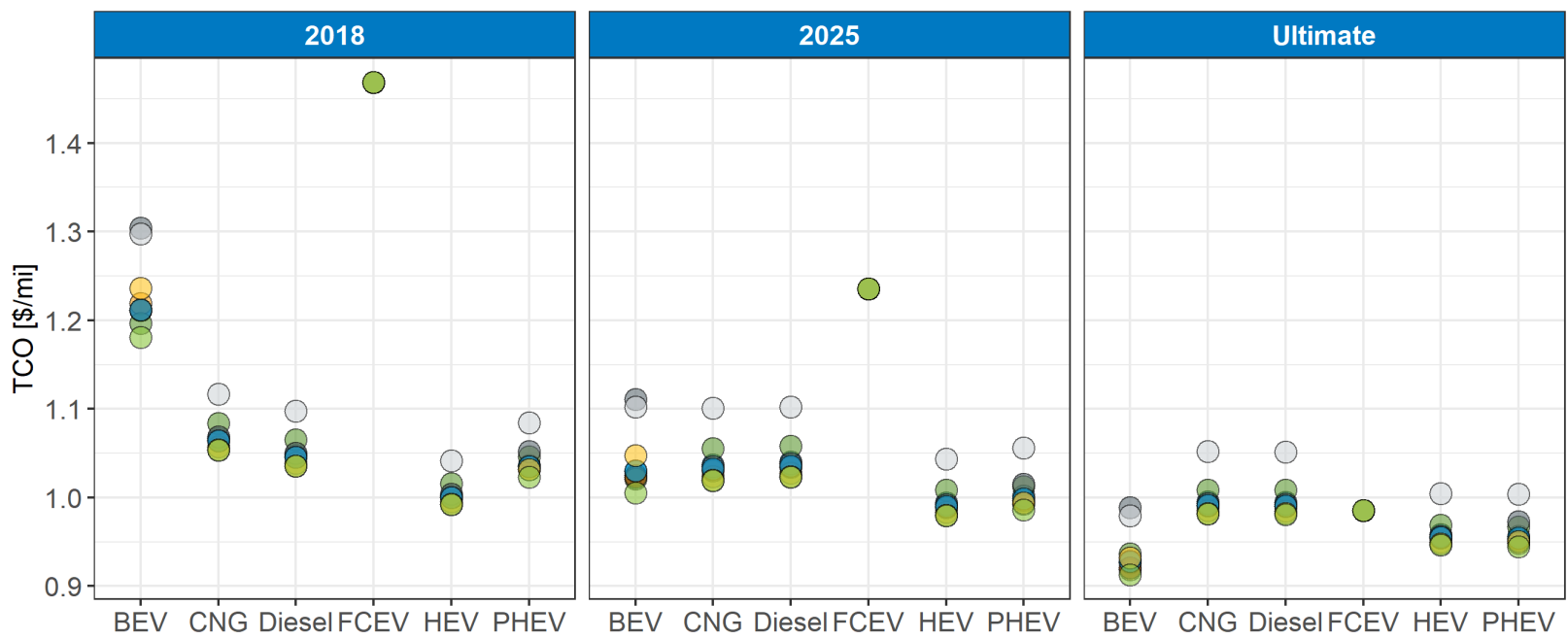
Region
East North Central
Middle Atlantic
New England
South Atlantic
East South Central $\bigcirc$ Mountain
Pacific
West North Central

West South Central

Figure 115. Regional TCO distribution for the Single-Shift, Weight-Limited scenario of a Class 8 short-haul tractor (300-mile range)

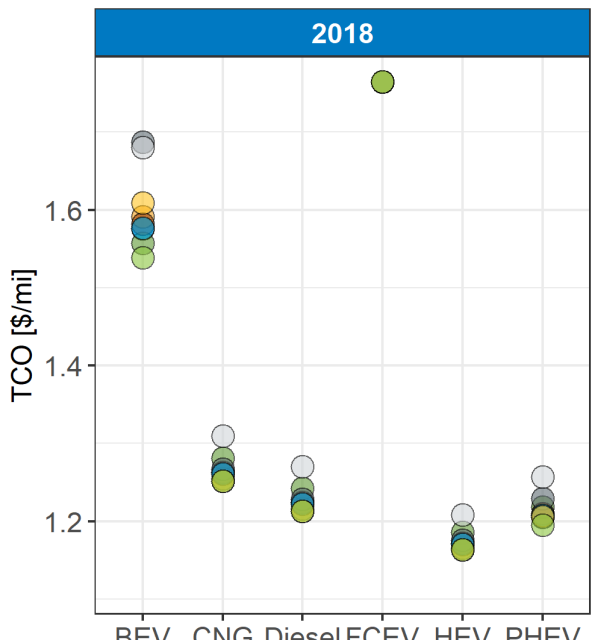

BEV CNG DieselFCEV HEV PHEV

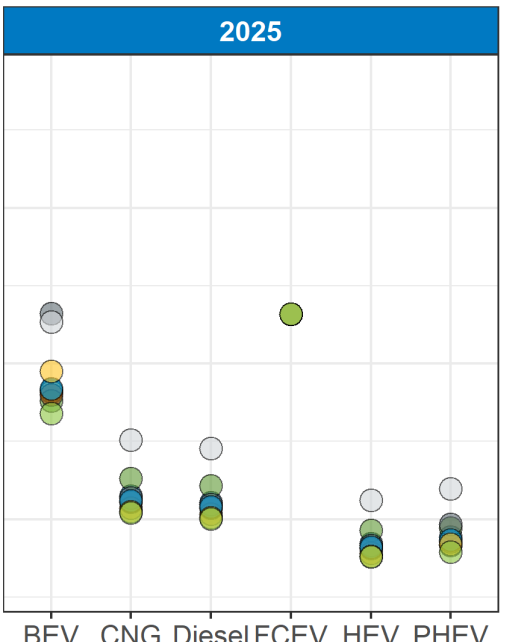

BEV CNG DieselFCEV HEV PHEV

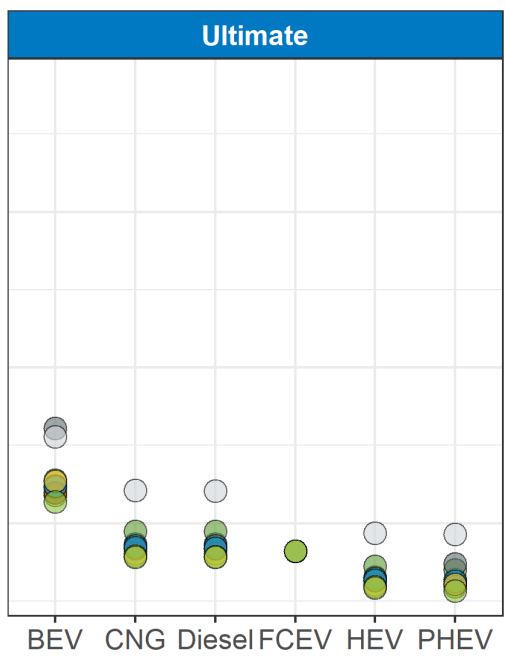

BEV CNG DieselFCEV HEV PHEV
Region
East North Central
Middle Atlantic
New England
South Atlantic
East South Central
Mountain
Pacific
West North Central

West South Central

Figure 116. Regional TCO distribution for the Multi-Shift, Volume-Limited scenario of a Class 8 short-haul tractor (300-mile range) 
Breakeven Fuel or Electricity Price (\$/gge)

At Diesel Price of $\$ 4 / \mathrm{gal}$ (\$3.52/gge)
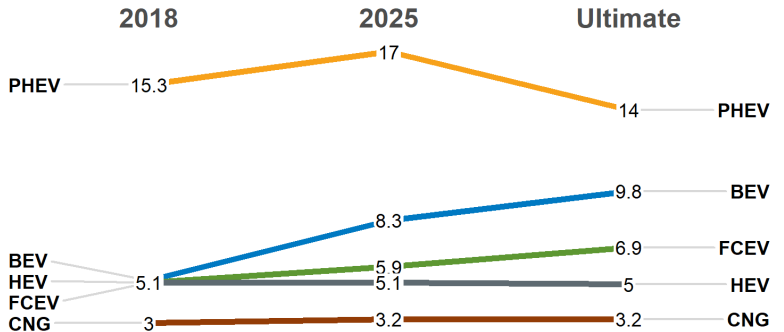

Breakeven Fuel or Electricity Price (\$/gge)

At Diesel Price of $\$ 3 / \mathrm{gal}$ (\$2.64/gge)
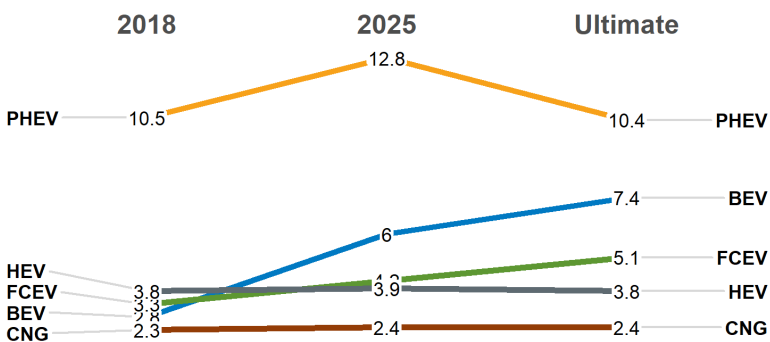

Breakeven Fuel or Electricity Price (\$/gge)

At Diesel Price of $\$ 2 /$ gal (\$1.76/gge)

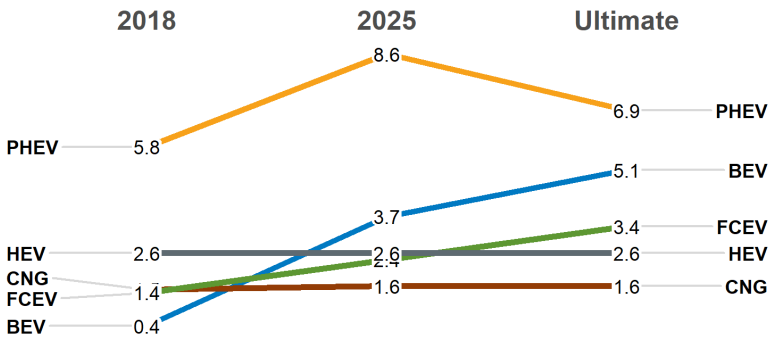

Figure 117. Single-Shift, Weight-Limited breakeven fuel price analysis for Class 8 short-haul trucks (300-mile range) in the Middle Atlantic region
Breakeven Fuel or Electricity Price (\$/gge)

At Diesel Price of $\$ 4 / \mathrm{gal}$ ( $\$ 3.52 / \mathrm{gge}$ )
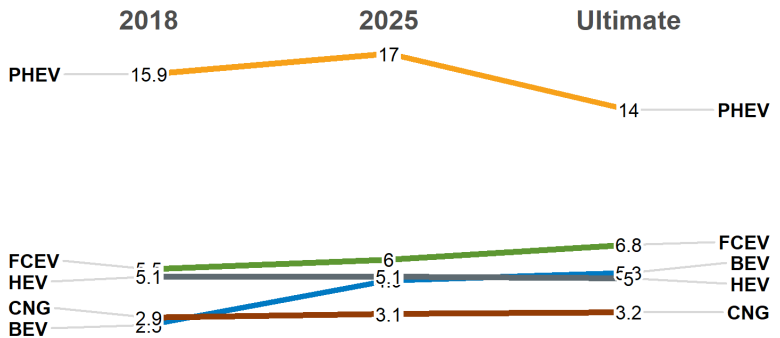

\section{Breakeven Fuel or Electricity Price (\$/gge)}

At Diesel Price of $\$ 3 / \mathrm{gal}$ ( $\$ 2.64 / \mathrm{gge}$ )
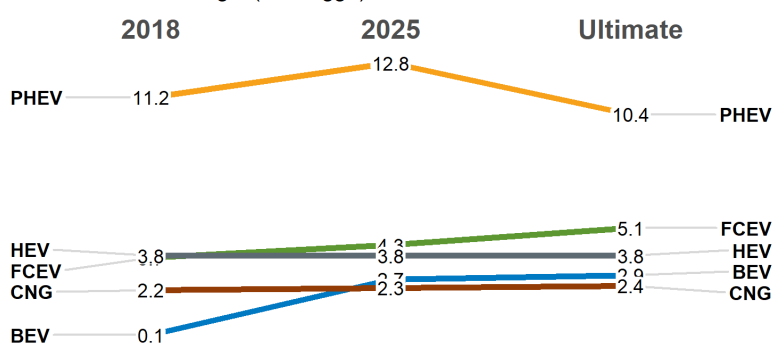

Breakeven Fuel or Electricity Price (\$/gge)

At Diesel Price of $\$ 2 / g a l$ (\$1.76/gge)

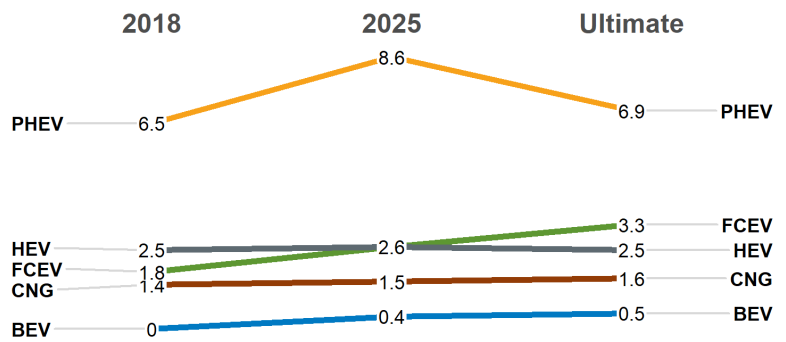

Figure I18. Multi-Shift, Volume-Limited break-even fuel price analysis for Class 8 short-haul trucks (300-mile range) in the Middle Atlantic region 